Aus der Abteilung Biochemie II

(Prof. Dr. rer. nat. P. Rehling)

im Zentrum Biochemie und Molekulare Zellbiologie

der Medizinischen Fakultät der Universität Göttingen

\title{
Molekulare Charakterisierung des murinen 66.3-kDa-Proteins
}

\author{
INAUGURAL-DISSERTATION \\ zur Erlangung des Doktorgrades \\ der Medizinischen Fakultät \\ der Georg-August-Universität zu Göttingen
}

vorgelegt von

Florian G. Deuschl

aus

Dachau

Göttingen 2008 
Dekan: Prof. Dr. med. C. Frömmel

I. Berichterstatter: JProf. Dr. rer. nat. T. Lübke

II. Berichterstatter/in:

III. Berichterstatter/in:

Tag der mündlichen Prüfung: 


\section{Inhaltsverzeichnis}

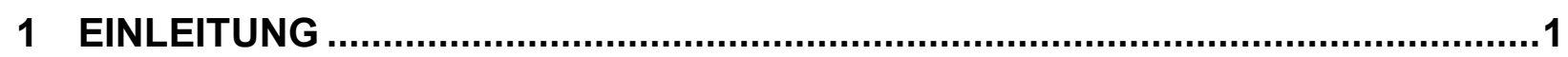

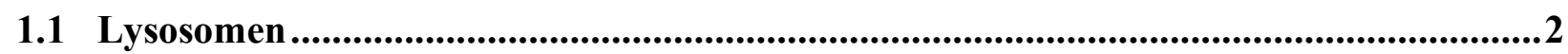

1.2 Lysosomale Proteine ...................................................................................................2

1.2.1 Synthese und Sortierung lysosomaler Matrixproteine............................................ 2

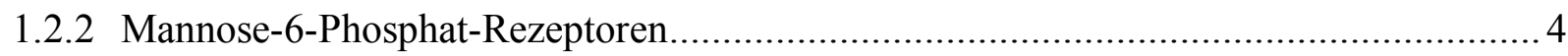

1.3 Lysosomale Speichererkrankungen ....................................................................4

1.4 Therapie von lysosomalen Speichererkrankungen..................................................5

1.5 Proteomanalyse des Lysosoms..............................................................................7

1.5.1 Aufreinigung M6P-markierter-Proteine aus MPR-defizienten Mausfibroblasten ........... 7

1.5.2 Analyse des lysosomalen Proteoms....................................................................... 7

1.6 Klonierung und stabile Expression des 66.3-kDa-Proteins ............................................10

1.7 MPR-Bindung und MPR-abhängige Internalisierung des 66.3-kDa-Proteins .............10

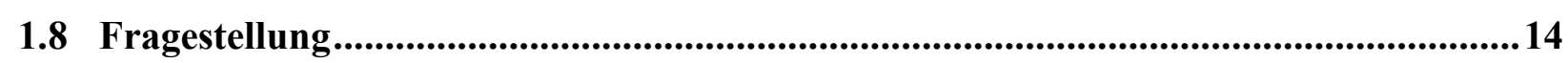

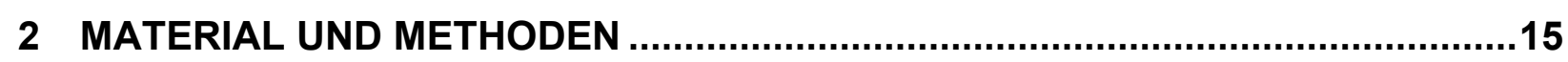

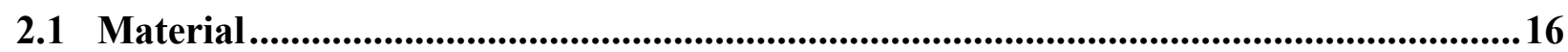

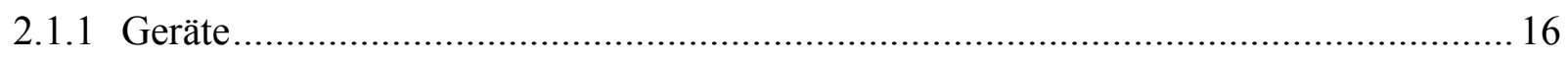

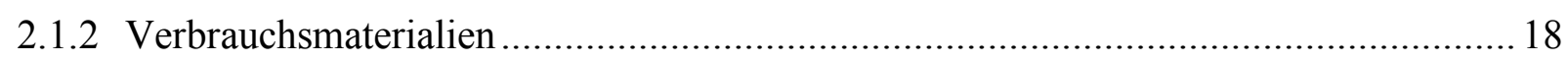

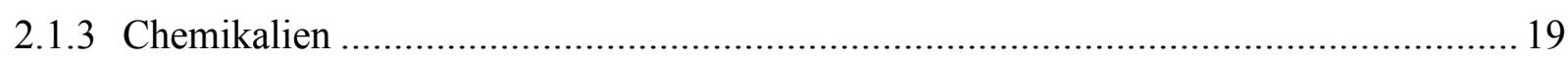

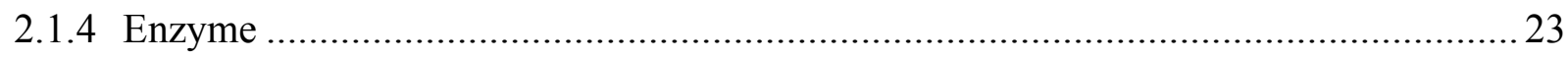

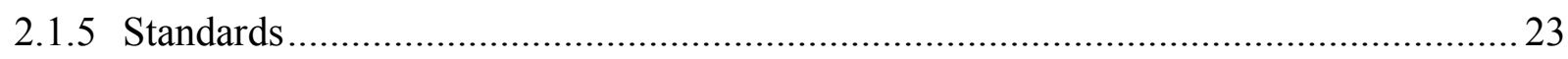

2.1.6 Kits für das Arbeiten mit RNA, DNA und Protein ............................................... 23

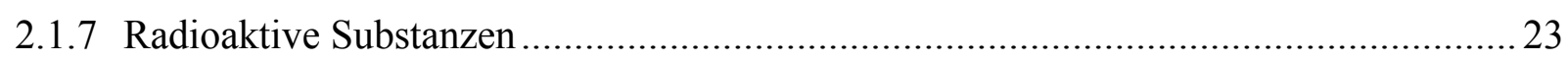

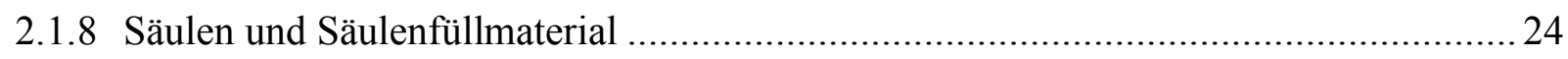

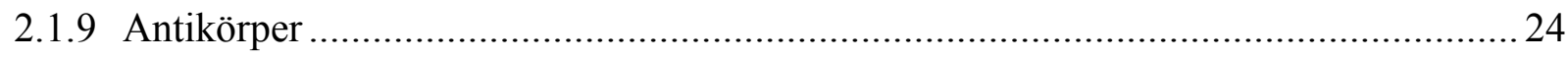

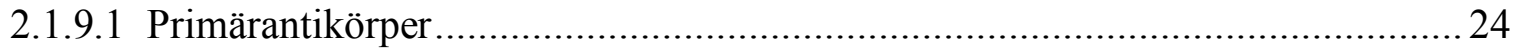

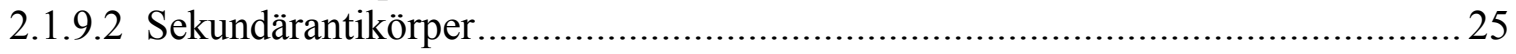

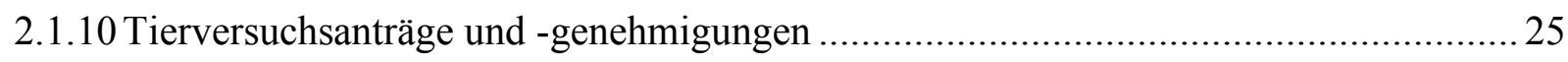

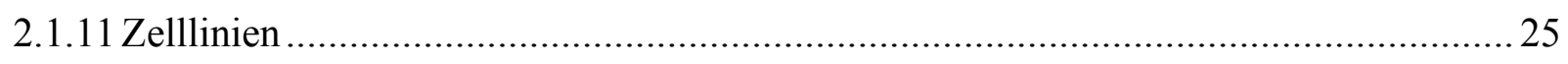

2.1.12 Häufig verwendete Puffer und Stammlösungen..................................................... 26 
2.1.13 Medien und Stammlösungen zur Anzucht eukaryoter Zellen....................................26

2.1.14 Medien zur Kultur prokaryoter Zellen............................................................ 27

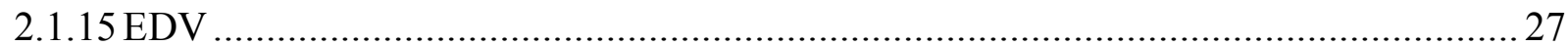

2.2 Molekularbiologische Methoden ............................................................................28

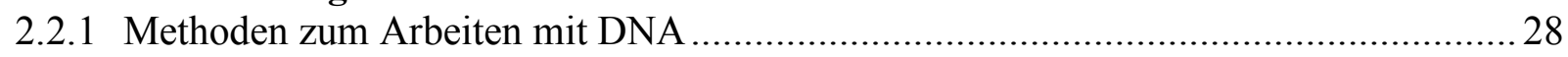

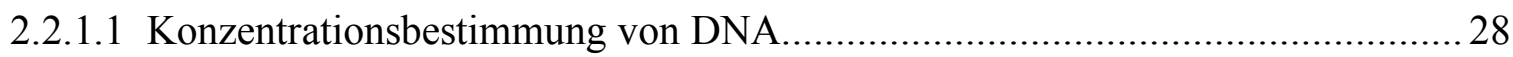

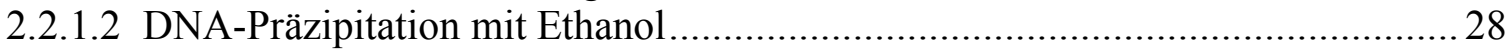

2.2.1.3 Spaltung von DNA mit Restriktionsendonukleasen ......................................29

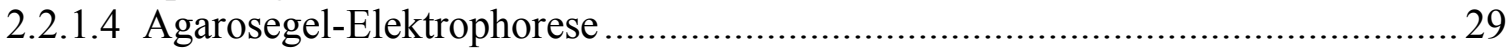

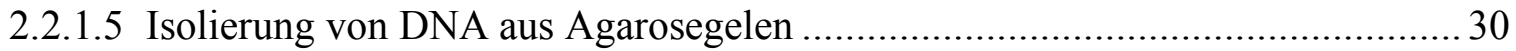

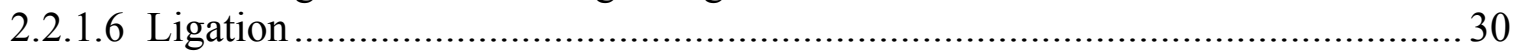

2.2.1.7 DNA-Amplifikation über die Polymerase-Ketten-Reaktion............................ 31

2.2.1.8 Herstellung chemisch kompetenter DH5 $\alpha$-Escherichia-coli ............................. 32

2.2.1.9 Transformation chemisch kompetenter DH5 $\alpha$-Escherichia-coli ....................... 32

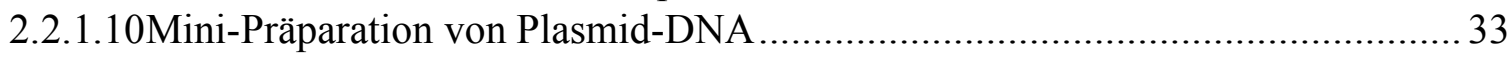

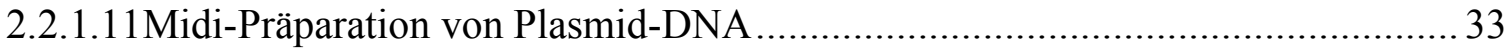

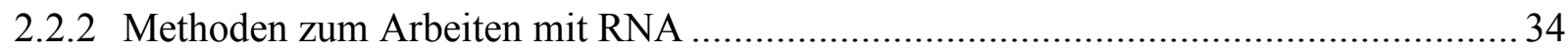

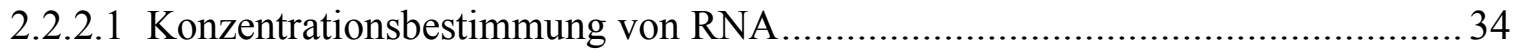

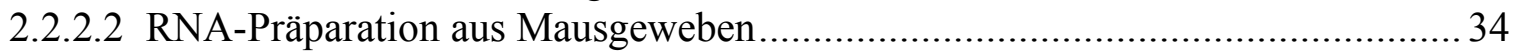

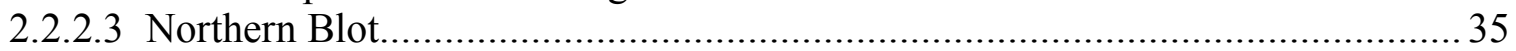

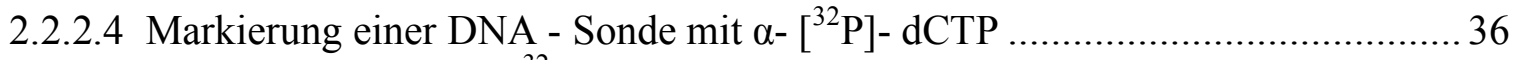

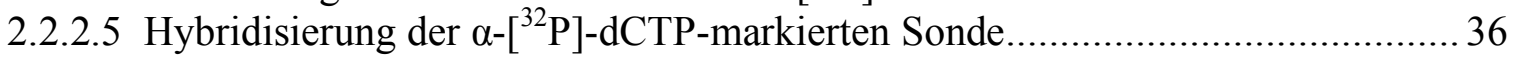

2.3 Zellbiologische Methoden .......................................................................................37

2.3.1 Methoden zum Arbeiten mit eukaryoten Zellen ................................................. 37

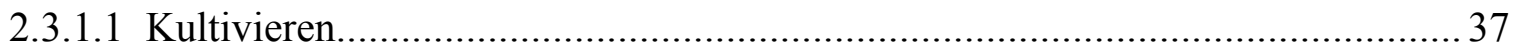

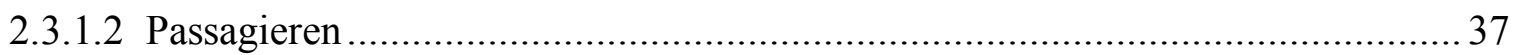

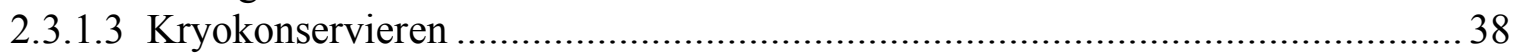

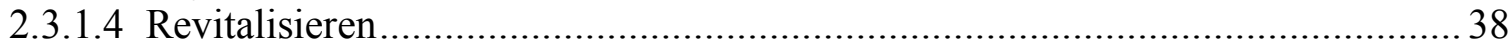

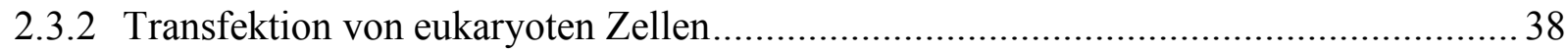

2.3.3 Gewinnung von Zellkulturmedium zur Proteinaufreinigung ................................... 39

2.4 Histologische Methoden.................................................................................................39

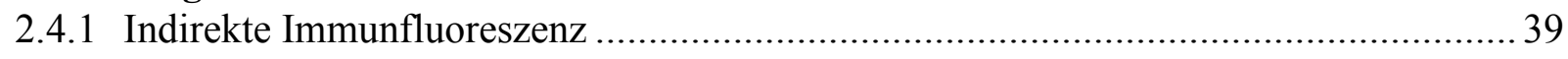

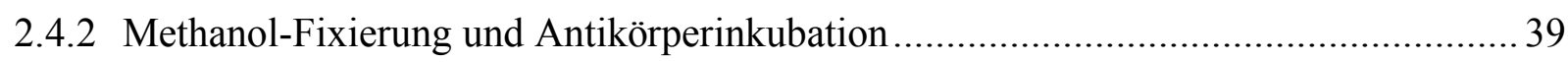

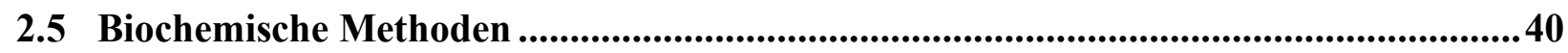

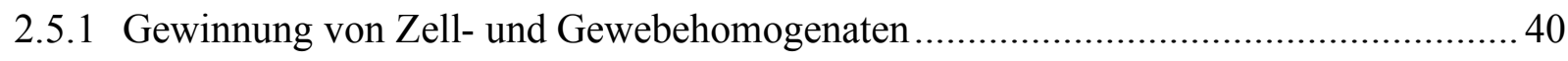

2.5.2 Proteinbestimmung mit dem BioRad-DC-Protein-Assay .......................................... 40

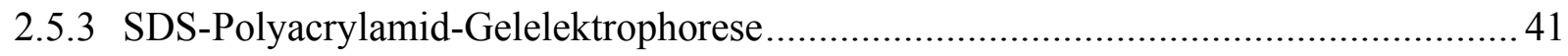

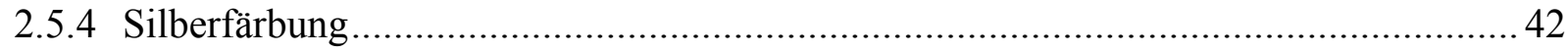




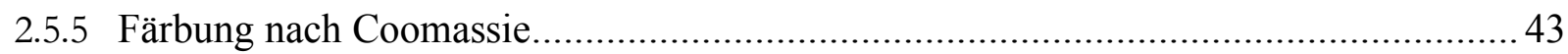

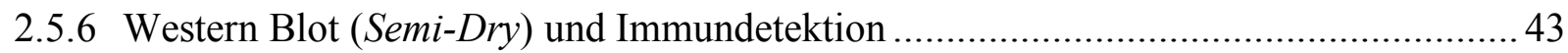

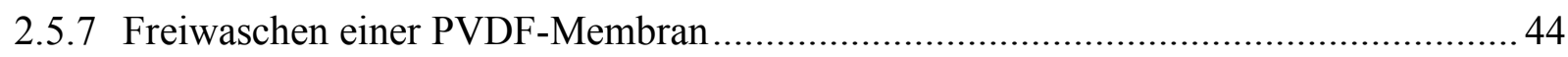

2.5.8 Färbung einer PVDF-Membran für die N-terminale Sequenzierung ........................... 45

2.5.9 Ni-NTA-Aufreinigung des 66.3-kDa-Proteins aus Zellkulturüberstand ..................... 45

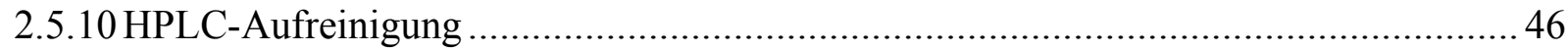

2.5.11 Herstellung eines polyklonalen Antiserums gegen das 66.3-kDa-Protein .................. 47

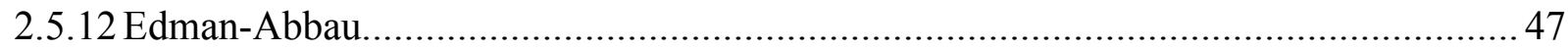

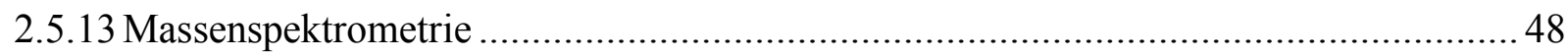

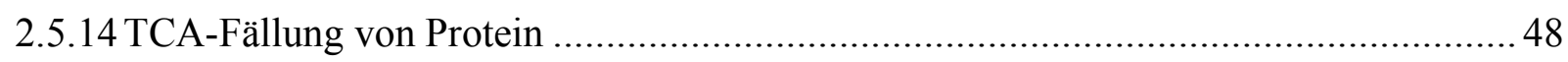

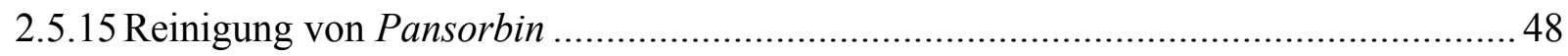

2.5.16 Metabolische Markierung von Proteinen mit $\left[{ }^{35} \mathrm{~S}\right]-$ Methionin/Cystein ....................... 49

2.5.17 Immunpräzipitation des metabolisch markierten 66.3-kDa-Proteins ......................... 49

2.5.18 Subzelluläre Fraktionierung (Tritosomenpräparation) …........................................ 50

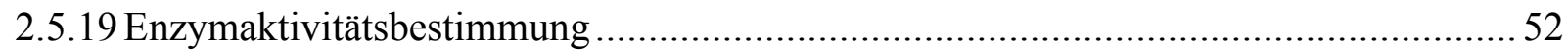

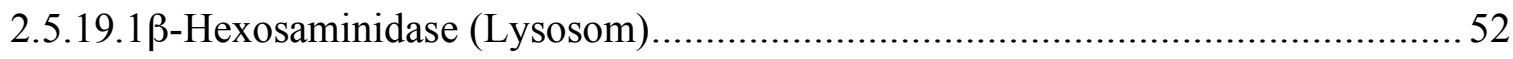

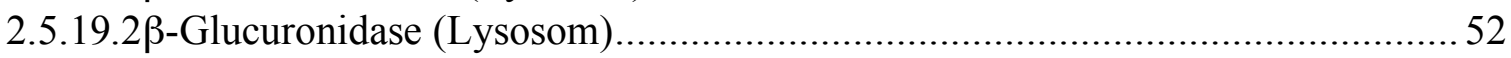

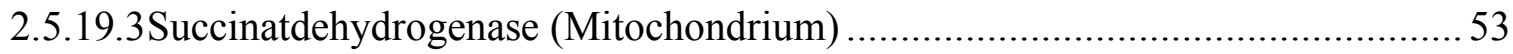

2.5.19.4Glukose-6-Phosphatase (Endoplasmatisches Retikulum) ................................ 53

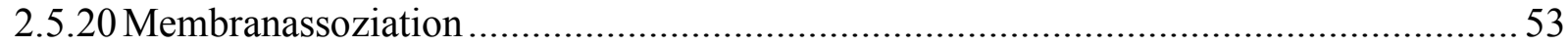

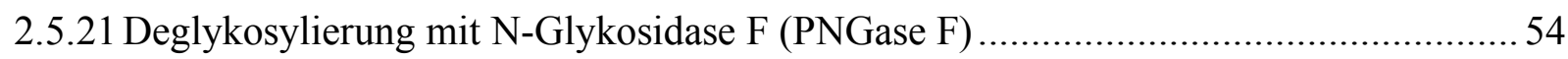

2.5.22 Affinitätschromatographie an 66.3-kDa-Protein-Affigel-10-Matrix............................ 54

2.5.23 Affinitätschromatographische Aufreinigung von Bindungspartnern ......................... 55

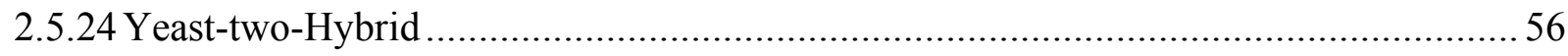

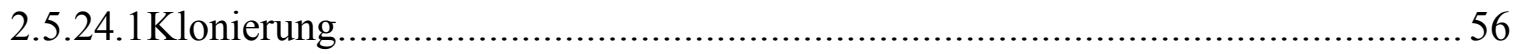

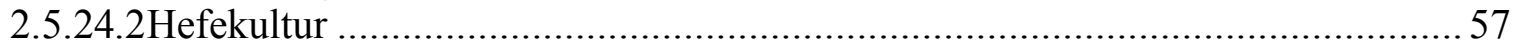

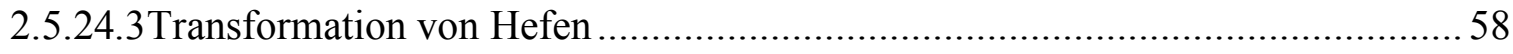

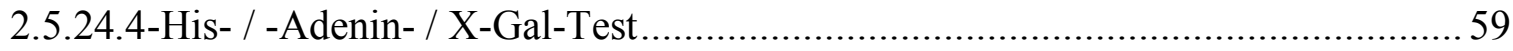

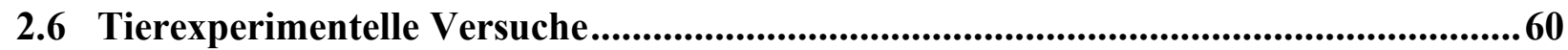

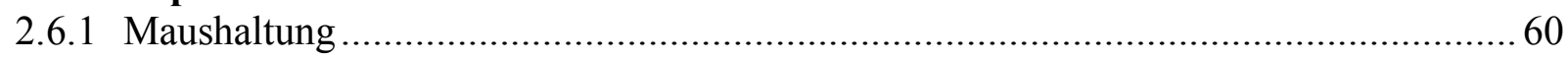

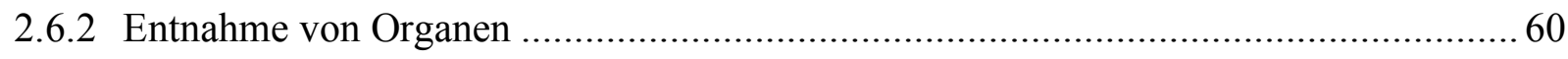


3 ERGEBNISSE 61

3.1 Klonierung und Expression des 66.3-kDa-Proteins 62

3.1.1 Klonierung des 66.3-kDa-Proteins mit RGS-His6-Markierung. 62

3.1.2 Stabile Expression des RGS-His6-markierten 66.3-kDa-Proteins in HT1080 62

3.2 Aufreinigung des 66.3-kDa-Proteins 63

3.3 Herstellung eines Antiserums. .65

3.4 Charakterisierung der aufgereinigten Polypeptide (75, 66, 40, 28 und 15 kDa) .........66

3.5 Expression des 66.3-kDa-Proteins in murinen Geweben. .68

3.5.1 Gewebespezifische Expression des 66.3-kDa-Proteins auf Transkriptebene .68

3.5.2 Proteinexpressionslevel im Western Blot auf murine Gewebe 69

3.6 Lysosomale Lokalisation des endogenen 66.3-kDa-Proteins. .70

3.6.1 Das endogene 66.3-kDa-Protein in der Immunfluoreszenz. 70

3.6.2 Nachweis des 66.3-kDa-Proteins mittels subzellulärer Fraktionierung von Mausleber. 72

3.7 Charakterisierung des 66.3-kDa-Proteins in HT1080 .76

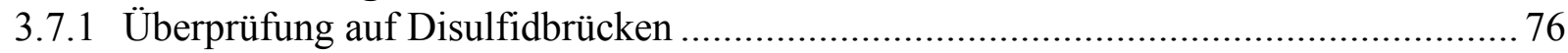

3.7.2 N-Glykosylierung des 66.3-kDa-Proteins in HT1080-Zellen................................... 77

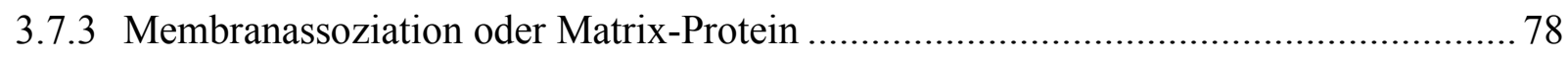

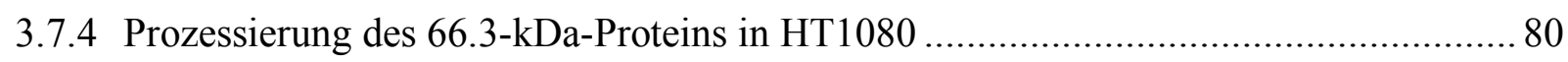

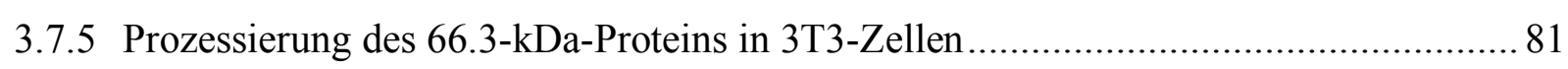

3.8 Funktionelle Analyse des 66.3-kDa-Proteins .......................................................82

3.8.1 Identifizierung von Interaktionspartnern durch Affinitätschromatographie................. 82

3.8.2 Yeast-two-Hybrid ( $Y 2 H)$ mit dem 66.3-kDa-Protein und Cathepsin D ........................ 87

3.8.3 Prozessierung des 66.3-kDa-Proteins in Abhängigkeit von Cathepsin D .................... 88

3.8.3.1 Verdau des 66.3-kDa-Proteins mit Cathepsin D ............................................ 89

3.8.3.2 Prozessierung des 66.3-kDa-Proteins in Cathepsin-D-defizienten MEF............. 89

3.8.4 Subzelluläre Verteilung des 66.3-kDa-Proteins in Abhängigkeit von Cathepsin D

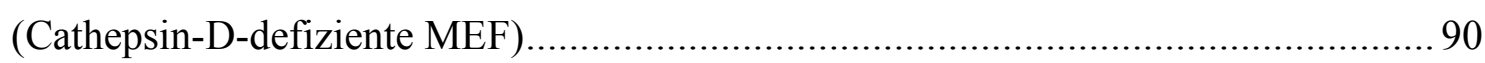




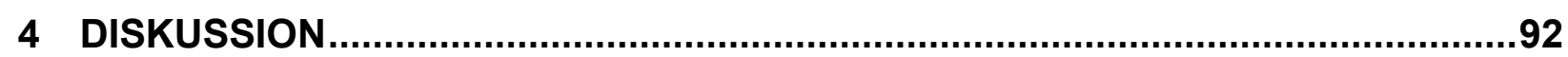

4.1 Bioinformatische Analyse ....................................................................................................93

4.1.1 Homologe Proteine des 66.3-kDa-Proteins............................................................... 94

4.2 Nachweis der subzellulären Lokalisation.........................................................................96

4.2.1 Expression und Aufreinigung des 66.3-kDa-Proteins ................................................. 96

4.2.2 Lysosomale Lokalisation des 66.3-kDa-Proteins.......................................................97

4.3 Molekulare Charakterisierung des 66.3-kDa-Proteins.......................................................98

4.3.1 Gewebesspezifische Expression des 66.3-kDa-Proteins ............................................... 98

4.3.2 Prozessierung des 66.3-kDa-Proteins .................................................................. 99

4.3.3 Posttranslationale Modifikation des 66.3-kDa-Proteins ............................................... 100

4.4 Funktionelle Analyse des 66.3-kDa-Proteins ..........................................................101

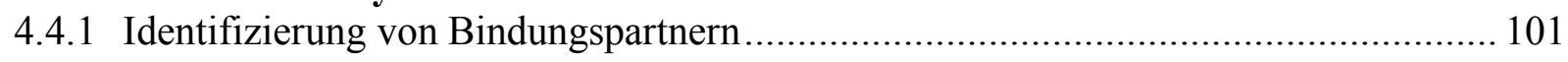

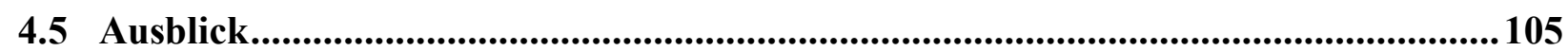

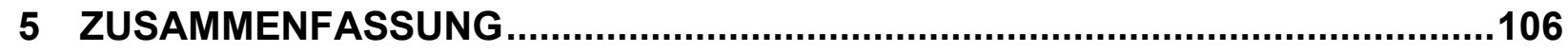

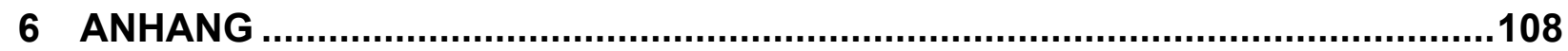

6.1 Ergebnis der Proteomanalyse von Kollmann et al. (2005) ...............................................109

6.2 Klonierung des 66.3-kDa-Proteins in HT1080 ……......................................................111

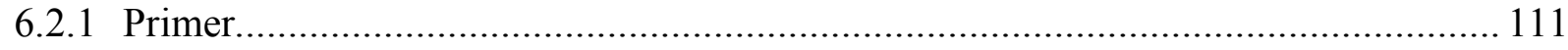

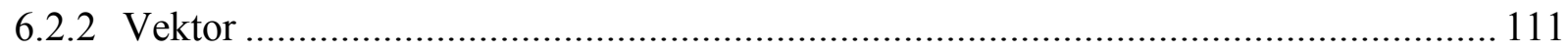

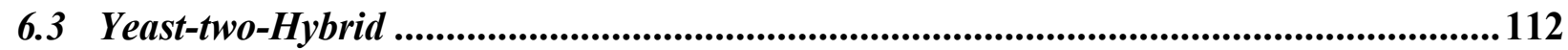

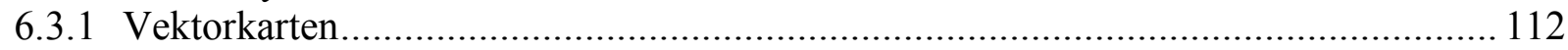

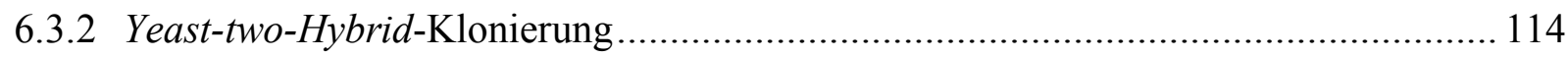

6.3.3 Sequenzvergleich des 66.3-kDa-Proteins mit homologen Proteinen ........................... 115

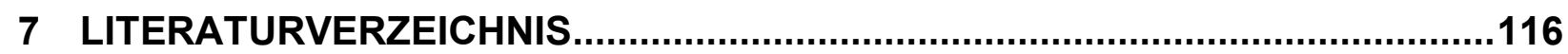




\section{Abkürzungsverzeichnis}

Abb.

Ac

Ade

APS

Arg

AS

Asp

$\beta$-Gluc.

$\beta$-Hex.

BHK21

BSA

bzw.

${ }^{\circ} \mathrm{C}$

C. familiaris

Cat-D

cDNA

$\mathrm{Ci}$

CMV

cpm

Cys

D. discoideum

dATP

dCTP

$\mathrm{ddH}_{2} \mathrm{O}$

DEPC

dFKS

dGTP

DMEM

DMSO

DNA

dNTP

DTT

dTTP
Abbildung

Acetat

Adenin

Ammoniumperoxodisulfat

Arginin

Aminosäure

Asparaginsäure

$\beta$-Glucuronidase

$\beta$-Hexosaminidase

Cell-type-Syrian-hamster-kidney-21

Rinderserumalbumin

beziehungsweise

Grad Celsius

Canis familiaris

Cathepsin D

komplementäre DNA

Curie $\left(2,22 \times 10^{6}\right.$ counts per minute $)$

Zytomegalievirus

Zählimpulse pro Minute (counts per minute)

Cystein

Dictyostelium discoideum

Desoxyadenosin-5'-Triphosphat

Desoxycytosin-5' -Triphosphat

doppelt destilliertes Wasser

Diethylpyrocarbonat

Dialysiertes, hitzeinaktiviertes FKS

Desoxyguanin-5'-Triphosphat

Dulbecco's modified eagles medium

Dimethylsulfoxid

Desoxyribonukleinsäure

die vier Desoxyribonukleosid-5'-Triphosphate

Dithiothreitol

Desoxythymidin-5' -Triphosphat 


\begin{tabular}{|c|c|}
\hline$\varepsilon$ & Extinktionskoeffizient \\
\hline E. coli & Escherichia coli \\
\hline EDTA & Ethylendiamintetraessigsäure \\
\hline Endo-H & Endo- $\beta$-N-Acetylglukosaminidase $\mathrm{H}$ \\
\hline ER & endoplasmatisches Retikulum \\
\hline ESI-MS und [-MS/MS] & Electrospray-ionisation-[tandem]-mass-spectrometry \\
\hline et al. & und andere (et alii) \\
\hline FKS & fötales Kälberserum \\
\hline g & Gramm \\
\hline$\times g$ & -fache Erdbeschleunigung \\
\hline G6P & Glukose-6-Phosphat \\
\hline G6Pase & Glukose-6-Phosphatase \\
\hline Gal & Galaktose \\
\hline H. sapiens & Homo sapiens \\
\hline Hepes & 4-(2-Hydroxyethyl)-piperazin-1-ethansulfonsäure \\
\hline His & Histidin \\
\hline HPLC & High performance liquid chromatography \\
\hline HRP & Horse-radish-peroxidase \\
\hline HSP60 & Heat-shock-protein-60 \\
\hline HT1080 & humane Fibrosarkom-Zelllinie \\
\hline HT1080-66 & 66.3-kDa-Protein-überexprimierende HT1080 \\
\hline IMM & Immunomix \\
\hline JAA & Jodacedamin \\
\hline $\mathrm{Kb}$ & Kilobasenpaare \\
\hline $\mathrm{kDa}$ & Kilodalton \\
\hline Konz. & Konzentration \\
\hline 1 & Liter \\
\hline LAMP-1/-2 & Lysosomal assoziiertes Membranglykoprotein-1/-2 \\
\hline Leu & Leucin \\
\hline LSD & $\begin{array}{l}\text { Lysosomale Speichererkrankung (Lysosomal Storage } \\
\text { Disorder) }\end{array}$ \\
\hline LSM & Laserscanmikroskop \\
\hline M & molar \\
\hline$\mu$ & mikro \\
\hline $\mathrm{m}$ & milli \\
\hline
\end{tabular}


MALDI-TOF-MS

MEF

MES

Met

MHCII

$\min$

M. musculus

Mops

MPR

MPR 300

MPR 46

MudPIT

M6P

$\mathrm{n}$

Ni-NTA

NP-40

$\mathrm{Nr}$.

OD

o.g.

PBS

PCR

PEG

$\mathrm{pH}$

PIMM

PMF

PMSF

PNGase F

PVDF

$\rho$

RGS-His6

RNA

RNAi

$\mathrm{Rpm}$
Matrix-assisted laser desorption ionization time-offlight mass spectrometry

embryonale Mausfibroblasten

2-(N-Morpholino)-Propansulfonsäure

Methionin

Major histocompatibility complex II

Minuten

Mus musculus

3-(N-Morpholino)-Propansulfonsäure

Mannose-6-Phosphat-Rezeptor

Mannose-6-Phosphat-Rezeptor mit 300 kDa

Mannose-6-Phosphat-Rezeptor mit 46 kDa

Multidimensional protein identification technology

Mannose-6-Phosphat

nano

Nickel-nitrilotriacetic acid

Nonidet P-40

Nummer

Optische Dichte

oben genannt

Phosphat-gepufferte Kochsalzlösung

Polymerase-Ketten-Reaktion

Polyethylenglykol

Pondus hydrogenii (negativ dekadischer Logarithmus der Protonenkonzentration)

Präzipitationsimmunomix

Peptide mass fingerprint

Phenylmethylsulfonylfluorid

Peptid-N-Glykosidase F

Polyvinylidenfluorid

Dichte

Arginin-Glycin-Serin-6x-Histidin

Ribonukleinsäure

RNA-interference

Umdrehungen pro Minute (rounds per minute) 


\begin{tabular}{ll} 
RT & Raumtemperatur \\
s. & siehe \\
SDH & Succinatdehydrogenase \\
SDS & Natriumdodecylsulfat \\
sec & Sekunden \\
Ser & Serin \\
SSC & Standard saline citrate \\
t & Zeit \\
Tab. & Tabelle \\
T. brucei & Trypanosoma brucei \\
TBS & Tris-gepufferte Kochsalzlösung \\
TCA & Trichloressigsäure \\
TE & Tris-EDTA \\
TEMED & N,N,N',N'-Tetramethylethylendiamin \\
TGN & Trans-Golgi-Netzwerk \\
Tris & Tris-(hydroxymethyl)-Aminomethan \\
Trp & Tryptophan \\
U & Einheit (Unit) \\
UAS & Upstream Activating Sequence \\
ü.N. & über Nacht \\
UV & ultraviolett \\
UZ & Ultrazentrifuge \\
V & Volt \\
V/cm & Volt/Zentimeter \\
v/v & Volumen zu Volumen \\
w/v & Gewicht zu Volumen \\
Y2H & Yeast-two-Hybrid \\
YPDA & Yeast peptone dextrose adenine \\
z. B. & zum Beispiel \\
& \\
\hline &
\end{tabular}

Chemische Elemente wurden mit den üblichen Buchstaben abgekürzt. Die Aminosäuren wurden entweder im Drei- oder Einbuchstabencode angegeben. Bei einigen Begriffen wurden die englischen Fachtermini benutzt, weil auch in der deutschsprachigen Fachliteratur eine Übersetzung dieser Begriffe unüblich und unzureichend ist. 


\section{Abbildungsverzeichnis:}

Abb. 1-1

Abb. 1-2

Abb. 1-3

Abb. 1-4

Abb. 1-5

Abb. 1-6

Abb. 2-1

Abb. 2-2

Abb. 3-1

Abb. 3-2

Abb. 3-3

Abb. 3-4

Abb. 3-5

Abb. 3-6

Abb. 3-7

Abb. 3-8

Abb. 3-9

Abb. 3-10

Abb. 3-11

Abb. 3-12

Abb. 3-13

Abb. 3-14

Abb. 3-15

Abb. 3-16

Abb. 3-17

Abb. 3-18

Abb. 3-19

Abb. 3-20

Abb. 3-21

Abb. 3-22

Abb. 3-23

Abb. 3-24

Abb. 4-1

Abb. 4-2

Abb. 6-1

Abb. 6-2

Abb. 6-3

Abb. 6-4

Abb. 6-5

Abb. 6-6

Abb. 6-7

\section{Tabellenverzeichnis:}

Tab. 2-1 ..................... 24

Tab. 2-2 ....................... 25

Tab. 2-3 .................... 30

Tab. 2-4 ....................... 40

Tab. 2-5 ...................... 41

Tab. 2-6 ..................... 46

Tab. 2-7 ...................... 47

Tab. 3-1 ...................... 66

Tab. 3-2 ...................... 74

Tab. 3-3 ..................... 86

Tab. 3-4 ..................... 88

Tab. 6-1 .................... 109

Tab. 6-2 .................... 114 
$1 \quad$ Einleitung 


\subsection{Lysosomen}

Zellen eukaryotischer Organismen sind in funktionell unterschiedliche Kompartimente, die so genannten Organellen, unterteilt. Das Lysosom als Organell wurde 1955 von de Duve erstmals beschrieben und ist von einer einfachen Membran umgeben (de Duve 1963; de Duve et al. 1955). Das Lumen des Lysosoms wird auch als lysosomale Matrix bezeichnet und die darin vorkommenden, löslichen Proteine als lysosomale Matrixproteine.

Die Hauptfunktion des Lysosoms ist die enzymatische Degradation von Makromolekülen durch saure Hydrolasen (de Duve 1983). Saure Hydrolasen sind hydrolytisch aktive Enzyme, die zum überwiegenden Teil der Gruppe der lysosomalen Matrixproteine zugeordnet werden. Es sind bislang über 50 Hydrolasen bekannt (Sleat et al. 2006b), die ihrer Funktion nach in Nukleasen, Proteasen, Glykosidasen, Lipasen, Phosphatasen, Sulfatasen und Phospholipasen eingeteilt werden. Lysosomale Hydrolasen entfalten ihr Funktionsoptimum bei einem sauren pH-Wert von 4,7-4,8 (Ohkuma und Poole 1978), der in den Lysosomen durch die membranständige $\mathrm{H}^{+}$-ATPase vom V-Typ (Cuppoletti et al. 1987) und den lysosomalen Chloridkanal CLC7 (Jentsch et al. 2002) generiert wird. Die abzubauenden Makromoleküle gelangen einerseits durch Phagozytose und rezeptorvermittelte Endozytose aus dem Extrazellulärraum (Goldstein et al. 1985) und andererseits in autophagozytotischen Vakuolen aus dem Zytoplasma in das Lysosom (Ahlberg et al. 1982; Arstila und Trump 1968). Nach dem Abbau im Lysosom gelangen die Abbauprodukte über spezifische Transportkanäle ins Zytoplasma zurück und stehen der Zelle dort erneut für den Stoffwechsel zur Verfügung (Gahl et al. 1982; Rome und Hill 1986).

Neben der katabolen Funktion werden dem Lysosom auch andere wichtige zelluläre Aufgaben zugesprochen (Sun-Wada et al. 2003), z.B. bei der Antigenpräsentation durch KlasseII-MHC-Proteine (Geuze 1998), der Regulation von Hormonen und Wachstumsfaktoren (Brix et al. 2001) und der Knochenumbildung (Baron et al. 1985; Saftig et al. 2000).

\subsection{Lysosomale Proteine}

\subsubsection{Synthese und Sortierung lysosomaler Matrixproteine}

Die meisten lysosomalen Matrixproteine werden anhand einer N-terminalen Signalsequenz, dem so genannten Signalpeptid, am rauen endoplasmatischen Retikulum (ER) synthetisiert und dabei in das Lumen des ER transloziert. Dort erfolgt die Abspaltung der Signalsequenz und die 
N-Glykosylierung an einem oder mehreren Asparaginresten (Kornfeld R und Kornfeld S 1985). Nach dem Transport in den Golgi-Apparat erfahren die Proteine weitere Modifikationen (von Fgura und Hasilik 1986). Die wichtigste Modifikation für lysosomale Matrixproteine ist die Mannose- $\underline{6}$ - $\underline{P h o s p h a t-M a r k i e r u n g ~(M 6 P) . ~ B e i ~ d i e s e r ~ d e n ~ l y s o s o m a l e n ~ M a t r i x p r o t e i n e n ~}$ spezifischen Modifikation wird im Cis-Golgi-Apparat ein Mannose-Rest der N-Glykane an Position 6 phosphoryliert (Pohlmann et al. 1982). Diese M6P-Markierung dient als Signal für den Transport in das lysosomal-endosomale Kompartiment.

Im Trans-Golgi-Kompartiment binden die M6P-haltigen Proteine an einen der beiden

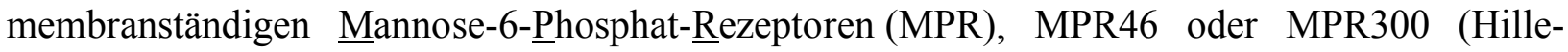
Rehfeld 1995). Mittels Clatrin-coated-Vesikeln werden die M6P-haltigen Proteine zu den Endosomen transportiert (Kornfeld S 1992) und dissoziieren dort pH-abhängig nach der Fusion von Vesikel und Endosom vom Rezeptor (Dahms et al. 1989). Die Proteine gelangen über den endosomal-lysosomalen Weg in die Lysosomen, während die Rezeptoren zurück zum TransGolgi-Netzwerk (TGN) zirkulieren oder zur Zellmembran gelangen (von Figura und Hasilik 1986). Die Vorläuferformen der lysosomalen Enzyme werden teilweise endosomal, jedoch zum größeren Teil lysosomal proteolytisch zu reifen Enzymen prozessiert (Hasilik 1992) und der M6P-Rest dephosphoryliert (Bresciani und Von Figura 1996; Kornfeld S und Mellman 1989).

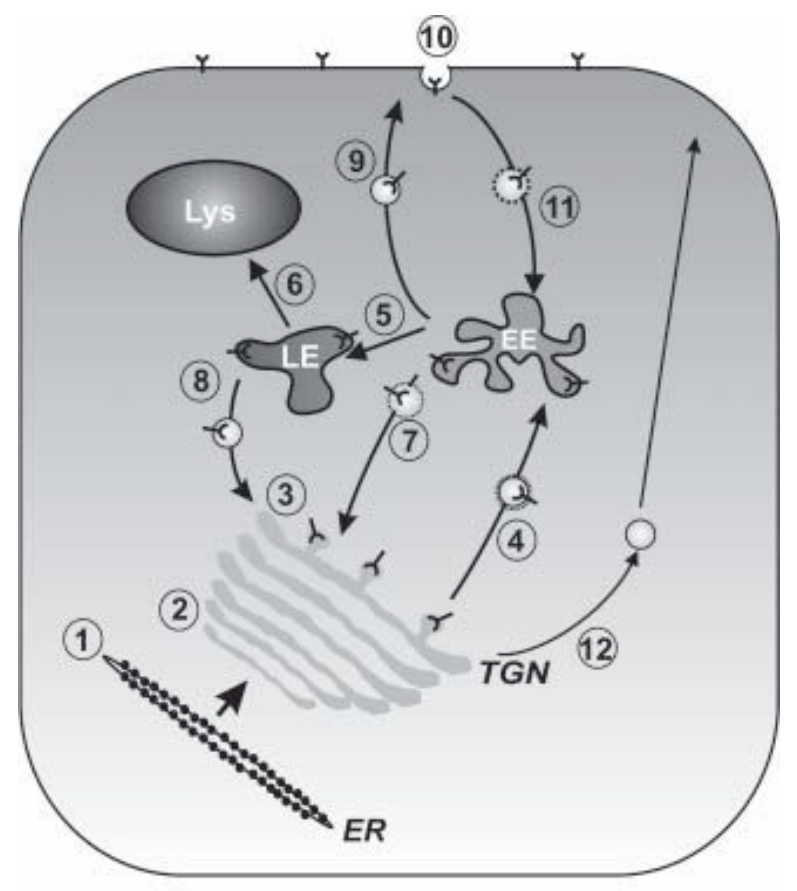

Abb. 1-1: $\quad$ Schema für den intrazellulären Transport von MPR's und Proteinen zum Lysosom

(1) Lösliche lysosomale Enzyme werden am ER synthetisiert und in das Lumen des ER transloziert. (2) Im Trans-Golgi-Netzwerk (TGN) werden die Enzyme mit M6P modifiziert und die Bindung (3) an die MPRs findet statt. (4) Der Liganden-RezeptorKomplex wird in Vesikeln zu den frühen Endosomen (Early Endosomes $=$ EE) transportiert. (5) Der saure pH-Wert in Endosomen führt zu einer Dissoziation der Rezeptor-Ligandenbindung. (6) Die Enzyme gelangen ins Lysosom und die Rezeptoren zirkulieren zurück zum TGN (7 und 8) oder zur Plasmamembran (9). (10) Exogene, M6P-markierte Proteine können über den MPR300 internalisiert werden und gelangen über den endozytotischen Weg (11) in das Lysosom. Lysosomale Proteine, die im TGN nicht an MPRs binden, werden in den extrazellulären Raum sezerniert (12). (Storch und Braulke, 2005, S. 18). 


\subsubsection{Mannose-6-Phosphat-Rezeptoren}

Mannose-6-Phosphat Rezeptoren (MPR) sind integrale Membranproteine (Dahms et al. 1987; Dahms et al. 1989), die M6P-haltige Proteine binden und somit für deren spezifischen Transport in die Lysosomen sorgen. Die MPRs unterscheiden sich zum einen durch ihre namensgebenden Molekulargewichte von 46- bzw. 300-kDa und zum anderen in ihrer Abhängigkeit Kationenabhängig (MPR46) bzw. Kationen-unabhängig (MPR300) M6P-haltige Proteine zu binden. Beide Rezeptoren kommen im Golgi-Apparat und den endosomalen Kompartimenten, nicht aber im Lysosom vor. In geringerer Anzahl sind MPRs auch an der Außenseite der Zellmembran lokalisiert, wobei jedoch nur der MPR300 extrazellulär M6P-Liganden zu binden und zu internalisieren vermag (Byrd und MacDonald 2000; Byrd et al. 2000; Stein et al. 1987; York et al. 1999).

\subsection{Lysosomale Speichererkrankungen}

Die Gruppe der lysosomalen Speichererkrankungen (engl. Lysosomal Storage Disorder = LSD) umfasst bislang über 40 Erkrankungen, die zumeist durch Defekte in lysosomalen Matrixproteinen hervorgerufen werden (Vellodi 2005). Gemeinsam ist dem Großteil der Erkrankungen die Akkumulation von nicht-degradierten Makromolekülen in Lysosomen und Speichervesikeln durch den Defekt eines Enzyms oder eines enzymalen Cofaktors (Gieselmann 1995). Die LSDs werden nach ihrem jeweiligen Defekt in fünf Gruppen eingeteilt: a) Defekte im Glykanabbau, b) Defekte im Lipidabbau, c) Defekte im Proteinabbau, d) Defekte lysosomaler Transporter und e) Defekte bei der lysosomalen Sortierung (Tollersrud und Berg 2005).

Fasst man die LSDs als Gruppe zusammen, kommt auf 8000 gesunde Neugeborene ein Neugeborenes mit einer LSD (Meikle et al. 1999; Poorthuis et al. 1999). Bis auf die FabryErkrankung (Masson et al. 2004), die Hunter-Erkrankung (Hopwood et al. 1993) und die DanonErkrankung (Nishino et al. 2000), die x-chromosomal vererbt werden, werden alle anderen bekannten LSDs autosomal-rezessiv vererbt. Der klinische Verlauf der meisten LSDs ist progressiv (Vellodi 2005). Jede LSD für sich betrachtet variiert in ihrer Prävalenz nicht nur geographisch, sondern auch zwischen einzelnen Ethnien erheblich. So treten z.B. die GaucherErkrankung (Horowitz et al. 1998) und die Tay-Sachs-Erkrankung (Myerowitz 1997) bei Askenasi-Juden 20-mal bzw. 10-mal häufiger als in der Durchschnittsbevölkerung auf.

Ebenso wie die Prävalenz variiert auch der Phänotyp lysosomaler Speichererkrankungen stark, so dass der Genotyp nur bedingt Aussagen über den Phänotyp zulässt. Dies ist zum einen abhängig vom Enzymdefekt und liegt zum anderen daran, dass es bei manchen Erkrankungen 
erst ab einer sehr geringen Restaktivität zur Ausprägung eines Phänotyps kommt (Conzelmann und Sandhoff 1983). Die Ausprägung verschiedener LSDs ist daher nicht nur bei Erkrankungen verschiedener Genese, sondern auch bei ein und derselben Erkrankung von Patient zu Patient sehr heterogen. Geringe enzymatische Restaktivität kann zum Beispiel bei der B-GalaktosidaseDefizienz zu einem milden Krankheitsverlauf (MPS IV) mit einem so genannten Late onset ohne neuronale Beteiligung führen, während sich bei einer Nullmutation des defekten Enzyms ohne entsprechende Restaktivität ein rasch fortschreitender Krankheitsverlauf (GM1-Gangliosidose) mit so genanntem Early onset und schwersten neurologischen Symptomen manifestiert (Suzuki et al. 2001).

Die Symptome einer LSD hängen neben der enzymatischen Restaktivität auch von den betroffenen Gewebe- bzw. Zelltypen ab. Zellen, in denen das Substrat besonders stark umgesetzt wird, bilden schnell große Speichervesikel und sind in ihrer Funktion eingeschränkt, wohingegen die Morphologie und Funktion anderer Zellen gänzlich erhalten bleiben kann (Neufeld und Muenzer 2001). Häufig sind besonders die Zellen des Nervensystems von der Überladung durch Speichervesikel beeinträchtigt, was die schweren neurologischen Defizite der meisten Patienten erklärt. So sind die Leitsymptome vieler lysosomaler Speichererkrankungen mentale Retardierung und Demenz, sowie motorische und sensorische Störungen. Aber auch Funktionsausfälle und Beeinträchtigung der viszeralen Organe, der Herz- und Skelettmuskeln, sowie der Knochen- und Knorpelgewebe sind je nach Erkrankung möglich (Futerman und van Meer 2004; Gieselmann 1995; Vellodi 2005).

\subsection{Therapie von lysosomalen Speichererkrankungen}

Es sind mehrere Ansätze zur Behandlung von LSDs beschrieben. Der Enzymersatztherapie wird wegen ihrer guten Erfolgsaussichten eine besondere Stellung eingeräumt. Sie bedient sich meist rekombinanter M6P-haltiger, lysosomaler Enzyme, die an den membranständigen MPR300 binden und von der Zelle aus dem Extrazellulärraum internalisiert und ins Lysosom transportiert werden können. Die funktionelle Enzymersatztherapie ist bereits in klinischer Anwendung, z.B. bei der Gaucher-Erkrankung (Barton et al. 1991; Weinreb et al. 2002; Whittington und Goa 1992), der Fabry-Erkrankung (Eng CM et al. 2001; Mignani und Cagnoli 2004) und der Hurler-Erkrankung (Kakkis et al. 2001; Wraith et al. 2004). Für andere Erkrankungen laufen klinische Studien, wie z.B. bei der Mucopolysaccharidose VI (Harmatz et al. 2006) oder vorklinische Studien im Tiermodell, wie z.B. bei der $\alpha$-Mannosidose (Roces et al. 2004). Die Enzymersatztherapie wird weiterhin die zentrale Rolle einnehmen, insbesondere 
wenn effizientere Wege für die Passage von therapeutisch wirksamen Enzymmengen über die Blut-Hirn-Schranke beschrieben werden und damit eine Verbesserung von neurologischen Phänotypen erreicht wird.

Ein zweiter, vielversprechender Ansatz ist die symptomatische Therapie durch die Inhibition der Substratbiosynthese, so z.B. bei der Tay-Sachs-Erkrankung (Platt et al. 1997) und der Sandhoff-Erkrankung (Jeyakumar et al. 1999). Weitere Ansätze zur Therapie von LSDs sind die Knochenmarkstransplantation wie z.B. bei der $\alpha$-Mannosidose (Wall et al. 1998) und die invivo-Gentherapie (Cheng und Smith 2003) durch adenoviralen Gentransfer wie z.B. im Mausmodell bei Mucopolysaccharidose VII (Ohashi et al. 1997) sowie die Optimierung der enzymatischen Restaktivität durch chemische Chaperone wie z.B. im Mausmodell bei GM1Gangliosidose (Matsuda et al. 2003). Für eine Übersicht der einzelnen Therapieansätze vergleiche Abb. 1-2.

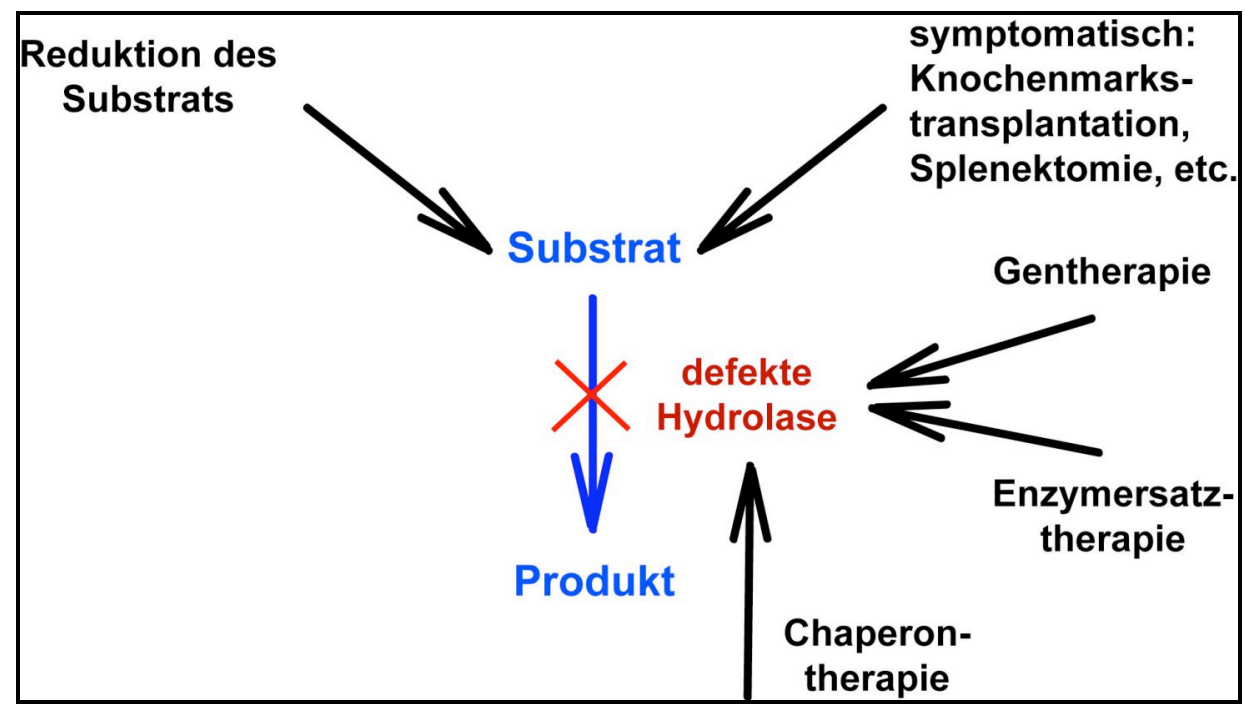

\section{Abb. 1-2: $\quad$ Therapieansätze lysosomaler Speichererkrankungen}

Therapien von lysosomalen Speichererkrankungen können in solche eingeteilt werden, die direkt auf Ebene der Hydrolase ansetzen, und solche, die symptomatisch entweder das umzusetzende Substrat reduzieren oder die Symptome behandeln. Modifiziert nach Futerman und van Meer (2004, S. 562).

Trotz der Fortschritte auf dem Gebiet der klinischen Diagnostik und Therapie lysosomaler Erkrankungen sind viele Erkrankungen mit lysosomaler Speicherung derzeit noch nicht therapierbar. Zudem gibt es immer noch Erkrankungen unbekannter Ätiologie, so z.B. die neuronale Ceroid-Lipofuszinose Typ 4 (CLN-4) (Berkovic et al. 1988). 


\subsection{Proteomanalyse des Lysosoms}

Im Allgemeinen ist das Proteom als die Gesamtheit aller in einem Organismus vorkommenden Proteine definiert. Das lysosomale Proteom umfasst als „Sub-Proteom“ demnach alle im Lysosom vorkommenden Proteine. Da bis jetzt annähernd jedem bekannten lysosomalen Matrixprotein eine lysosomale Erkrankung zugeordnet werden kann, soll das lysosomale Proteom möglichst vollständig analysiert werden.

In den Vorarbeiten zur vorliegenden Arbeit wurde eine Proteomanalyse lysosomaler Matrixproteine in der Maus durchgeführt. Das Mausmodell bietet dabei mehrere Vorteile, so z.B. die einfache Zugänglichkeit für Gewebeproben, die vollständige Analyse des Mausgenoms (über $90 \%$ Homologie zum Menschen) und die Möglichkeit, über Knock-out-Mäuse Krankheitsmodelle für lysosomale Speichererkrankungen $\mathrm{zu}$ etablieren. Die Arbeitsgruppe konnte bei der Proteomanalyse neben 34 bekannten lysosomalen Proteinen drei bis dahin unbekannte Proteine identifizieren (Kollmann et al. 2005). Die vorliegende Arbeit beschäftigt sich mit dem nach seiner Molekularmasse von $66.3 \mathrm{kDa}$ benannten, putativ lysosomalen 66.3kDa-Protein.

\subsubsection{Aufreinigung M6P-markierter-Proteine aus MPR-defizienten Mausfibroblasten}

Für eine Sub-Proteomanalyse müssen Organellen üblicherweise hoch rein aus Zellen isoliert werden. Lysosomale Matrixproteine lassen sich aufgrund ihres M6P-Restes (vgl. Kap. 1.2.2) von anderen Proteinen trennen. In der Abteilung sind embryonale Mausfibroblasten (MEF) etabliert, die defizient für MPRs sind (MPR46 -/- und MPR300 -/-) und M6P-haltige Proteine nicht in das Lysosom transportieren, sondern in den extrazellulären Raum bzw. in das Zellkulturmedium sezernieren. In Vorarbeiten der Arbeitsgruppe wurden M6P-haltige Proteine aus Zellkulturüberstand mittels Affinitätschromatographie über die Bindung von M6P an immobilisierten MPRs von den nicht M6P-haltigen Proteinen getrennt (Kollmann et al. 2005).

\subsubsection{Analyse des lysosomalen Proteoms}

Zur Identifizierung der M6P-haltigen Proteine wurden nach der Aufreinigung zwei unterschiedliche Verfahren angewendet. Im ersten Verfahren wurden die M6P-haltigen Proteine mittels zweidimensionaler Gelelektrophorese getrennt. In der ersten Dimension wurden die Proteine durch die isoelektrische Fokussierung anhand ihres isoelektrischen Punktes an einem immobilisierten ph-Gradienten getrennt. In der zweiten Dimension wurden sie elektrophoretisch durch SDS-PAGE nach ihrem Molekulargewicht separiert. Die Proteine wurden tryptisch 
verdaut, massenspektrometrisch (Matrix-assisted laser desorption ionization time-of-flight mass spectrometry $=$ MALDI-TOF-MS) analysiert und schließlich anhand ihrer PMF (Peptide mass fingerprint) über die NCBI Entrez Gene-Gendatenbank (http:/www.ncbi.nlm.nih.gov) identifiziert. Abb. 1-3A zeigt die aufgetrennten Proteine, Abb. 1-3B zeigt die Nummerierung und die dem 66.3-kDa-Protein zugeordneten Spots. 198 von 201 Spots wurden erfolgreich analysiert.

Beim zweiten Verfahren zur Analyse des lysosomalen Proteoms wurden die an der MPRMatrix isolierten Proteine mit der so genannten MudPIT-Analyse (Multidimensional-proteinidentification-technology) analysiert. Dabei werden die M6P-haltigen Proteine nach der Elution von der MPR-Säule tryptisch verdaut und durch zwei chromatographische Schritte anhand ihrer Ladung an einem starken Kationenaustauscher und anschließend anhand ihrer Hydrophobizität an einer reversed-phase-Säule aufgetrennt. Die Analyse der aufgetrennten Peptide erfolgte direkt über das angeschlossene ESI-MS und ESI-MS/MS (Electrospray Ionisation [tandem] Mass Spectrometry). Die Identifizierung der Proteine fand ebenfalls über die oben erwähnte Gendatenbank durch Abgleich der erhaltenen Aminosäuresequenzen statt. Dabei galt ein Protein als eindeutig identifiziert, wenn mindestens zwei unterschiedliche Peptide mit jeweils fünf Aminosäuren einem Protein zugeordnet werden konnten (vgl. Tab. 6-1).

Mittels 2D-Gelelektrophorese und MALDI-TOF konnten 28 bekannte lysosomale Proteine, ein bekanntes, aber nicht lysosomales Protein und drei noch nicht beschriebene Proteine identifiziert werden. Eines dieser nicht beschriebenen Proteine war das 66.3-kDa-Protein, das in 17 Spots (vgl. die Spot-Nummern in Abb. 1-3: Nr. 9, 67-70, 162-167, 177-181 und 200) identifiziert wurde. Es fand sich eine Gruppe von Spots mit einer apparenten Größe von 66 kDa bei pH 5 (67-70), eine Gruppe mit einer apparenten Größe von 40 kDa bei pH 6,5 (162-167, 200) und eine Gruppe mit einer apparenten Größe von 30 kDa bei pH 4,5 (177-181). Bei der MudPITAnalyse konnten neben 22 bereits in der MALDI-TOF-MS-Analyse identifizierten Proteinen zusätzlich sechs weitere bekannte lysosomale Proteine, sowie drei bekannte nicht-lysosomale Proteine und vier potentiell lysosomale Proteine identifiziert werden. Das 66.3-kDa-Protein konnte mit sechs spezifischen Peptiden (mit entsprechend sieben, sieben, neun, zehn, 13 und 15 Aminosäuren) identifiziert werden. Die Peptide deckten damit $16 \%$ der Proteinsequenz des 66.3-kDa-Proteins ab. 

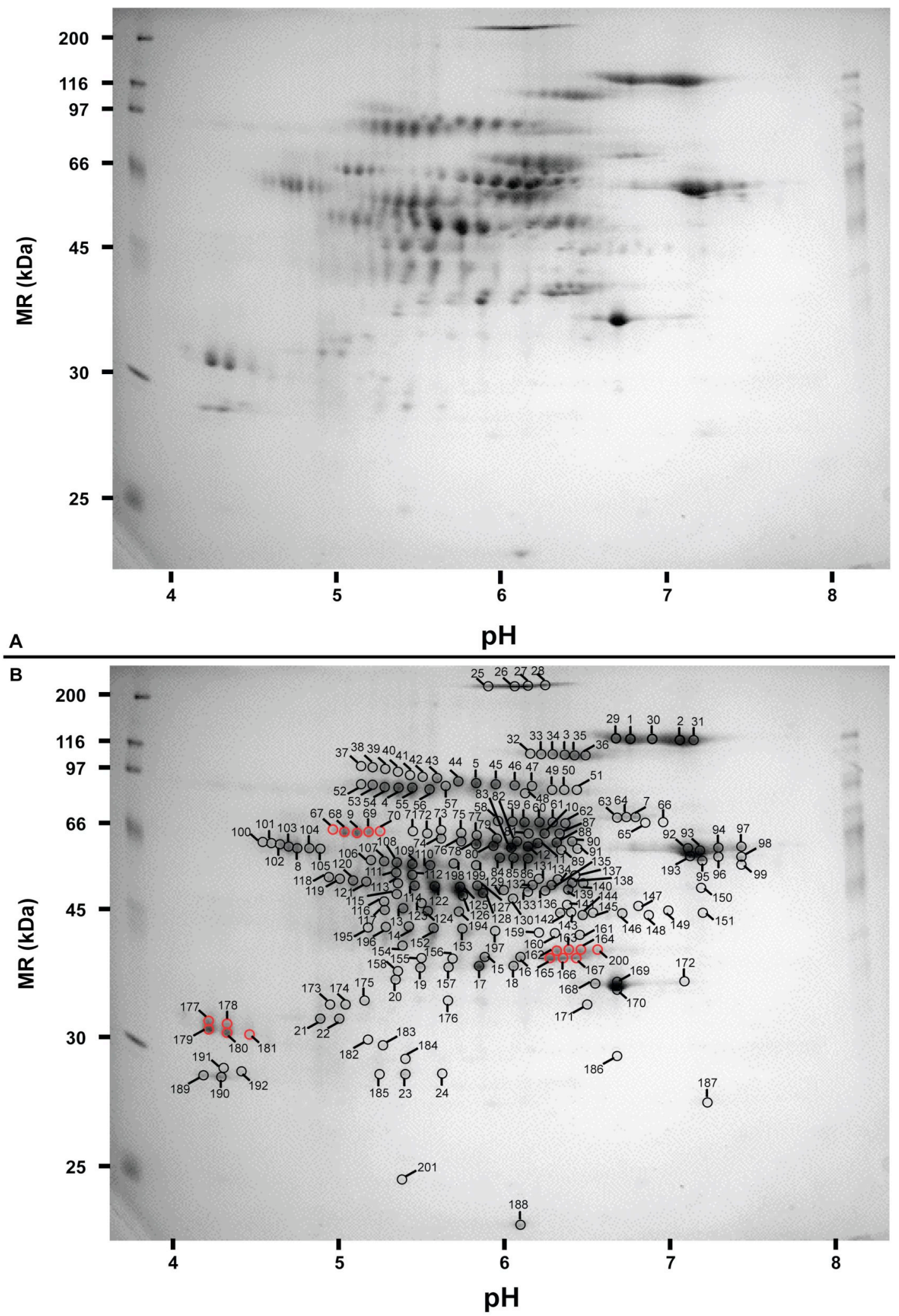

\section{Abb. 1-3: $\quad$ 2-D-Gel Elektrophorese}

Die von der MPR-Säule eluierten Proteine wurden in der ersten Dimension über einen immobilisierten pH-Gradienten und in der 2. Dimension über ein SDS-PAGE Gel aufgetrennt. Teil A: 2-D-Gel, Teil B: Alle detektierten Proteinspots wurden durchnummeriert. Die roten Kreise zeigen die Proteinspots an, die durch die Massenspektrometrie dem 66.3-kDa-Protein zugeordnet werden konnten (modifiziert nach Kollmann et al 2003, S. 3971). 


\subsection{Klonierung und stabile Expression des 66.3-kDa-Proteins}

Das 66.3-kDa-Protein besteht aus 594 Aminosäuren und besitzt ein N-terminales Signalpeptid mit 41 Aminosäuren (Datenbankeinträge: gi:24047307; cDNA Accession-No. BC038605; Protein Accession-No. AAH38605). Die Aminosäuresequenz enthält fünf putative N-Glykosylierungsstellen (-N-X-S/T-) und laut Pfam-Proteindatenbank (http://www.pfam.sanger.ac.uk; Stand Januar 2008) von Aminosäure 75 bis 594 eine Phospholipase-B-Domäne. Es existieren homologe Proteine u.a. in Homo sapiens (82\% Identität), Rattus norvegicus (94 \% Identität), Canis familiaris (74 \% Identität), Caenorhabditis elegans (43\% Identität), Dictyostelium discoideum (39\% Identität) und Trypanosoma brucei (33\% Identität). Die cDNA für das Protein wurde mittels Reverser Transkription und Polymerase-Kettenreaktion aus Gesamt-RNA der Mausleber amplifiziert. C-terminal wurde die cDNA mit einer Sequenz für einen V5-His6-Tag modifiziert und als solches in den eukaryotischen Expressionsvektor pcDNA-Dest40 inseriert. Nach der Transfektion wurde das murine 66.3-kDa-Protein in BHK21-Zellen exprimiert und aufgrund der hohen Expression in das Zellkulturmedium sezerniert. Aus dem Zellkulturmedium konnte das 66.3-kDa-Protein affinitätschromatographisch über die Bindung des His6-Tags an einer Ni-NTA-Matrix für weitere Versuche partiell aufgereinigt werden.

\subsection{MPR-Bindung und MPR-abhängige Internalisierung des 66.3-kDa- Proteins}

Mit dem partiell aufgereinigten Protein wurden Versuche zur Verifizierung der lysosomalen Lokalisation des 66.3-kDa-Proteins durchführt. Mittels einer MPR-Säule wurde die M6Pabhängige Bindung des 66.3-kDa-Proteins an MPRs nachgewiesen (Abb. 1-4). Dazu wurde das partiell aufgereinigte Protein mit der MPR-Matrix inkubiert, mit steigender Stringenz gewaschen und mit M6P eluiert (vgl. Abb. 1-4). Es konnte die Bindung einer 75-kDa- und einer 40-kDaForm des Proteins nachgewiesen werden. Letztere stellt aufgrund des nachgewiesenen His-Tags das C-terminale Ende des Proteins dar. 


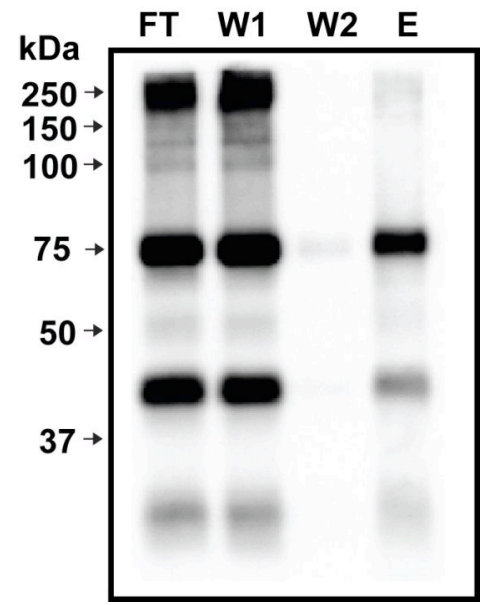

Abb. 1-4: Mannose-6-Phosphat-Rezeptor-Bindung des 66.3kDa-Proteins

Auf eine MPR-Affigel-10-Säule wurde im Überschuss V5-His6markiertes- und Ni-NTA-aufgereinigtes Protein gegeben. Nach einer Inkubation wurde die Säule gründlich gewaschen und Bindungspartner von der Säule eluiert. Es wurden die einzelnen Wasch- und Elutionsfraktionen TCA-gefällt, über SDS-PAGE aufgetrennt und im Western Blot mit dem $\alpha$-His-Antikörper analysiert. (FT) „Flowthrough" = Durchfluss, entspricht dem auf die Säule geladenen Material abzüglich der gebundenen Anteile. (W1)/(W2) 1. und 2. Waschdurchgang. (E) Elution der gebundenen Proteine durch einen Überschuss an M6P im Waschpuffer (Kollmann et al. 2005, S. 3975).

Darüber hinaus wurden Versuche mit Fibroblasten von Patienten mit I-cell-Erkrankung (Mucolipidose II) durchgeführt. Bei der I-cell-Erkrankung wird durch einen Defekt der GolgiPhosphotransferase (N-Acetylglucosamin-1-phosphotransferase) kein M6P-Rest generiert (Tiede et al. 2005). Somit wird der MPR-abhängige Transport von Hydrolasen in das Lysosom verhindert und folglich die lysosomale Proteaseaktivität reduziert. Dies führt zu einer Speicherung von abzubauendem Material in so genannten Speichervakuolen (Hickman und Neufeld 1972). I-cell-Fibroblasten wurden mit partiell aufgereinigtem 66.3-kDa-Protein inkubiert, um die Aufnahme des Proteins in die Zelle und den Transport ins Lysosom mittels Immunfluoreszenz nachzuweisen (Abb. 1-5). Um zu zeigen, dass die Internalisierung von 66.3kDa-Protein M6P-abhängig ist, wurden I-cell-Fibroblasten mit partiell aufgereinigtem 66.3-kDaProtein und zusätzlich entweder M6P oder G6P inkubiert. Abb. 1-6 zeigt, wie eine hohe M6PKonzentration die Aufnahme des Proteins in die Zelle verhindert, während die Aufnahme unter G6P nicht beeinflusst wird. Mit diesem experimentellen Ansatz konnte gezeigt werden, dass das 66.3-kDa-Protein M6P-abhängig in das Lysosom transportiert wird. 


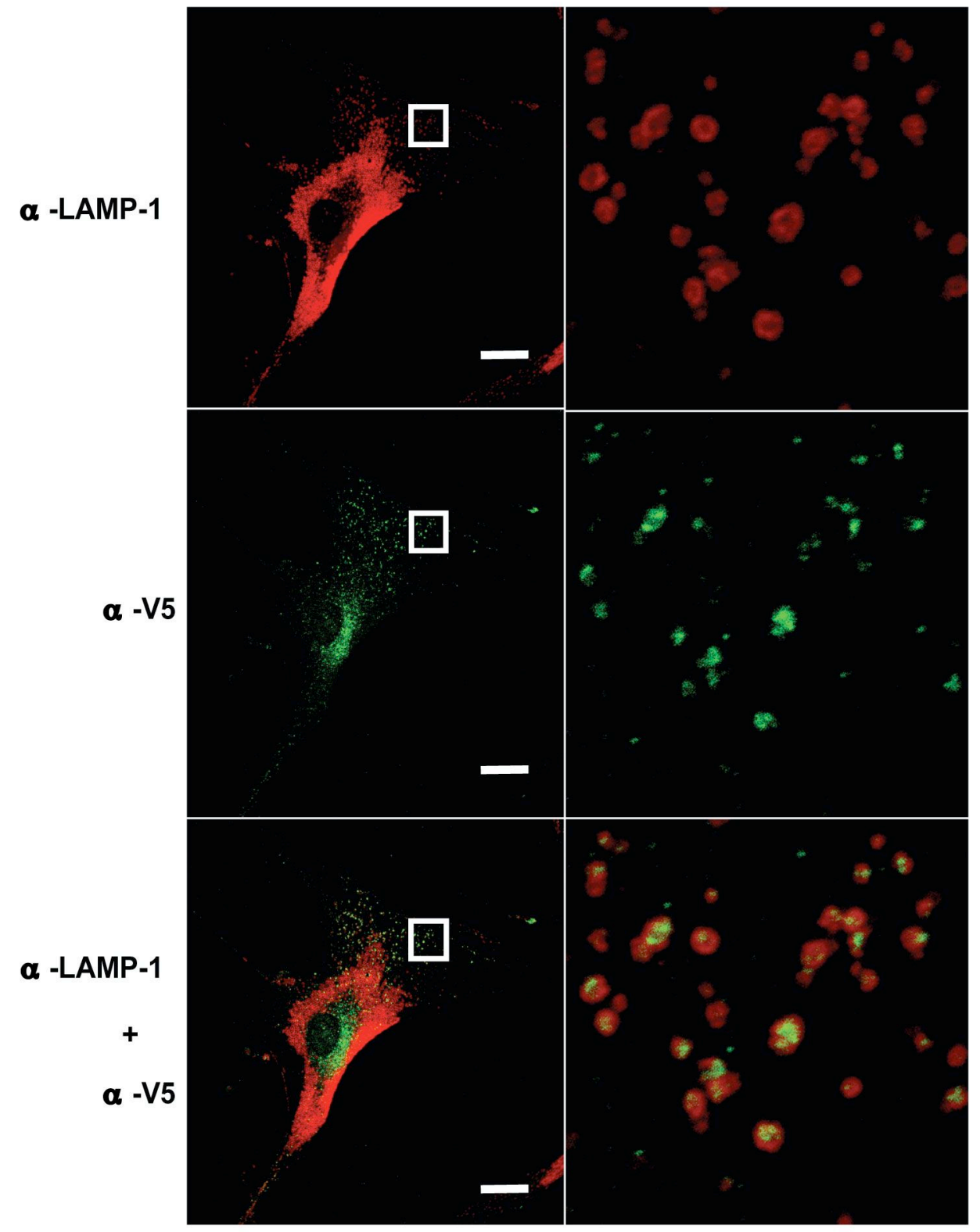

\section{Abb. 1-5: $\quad$ Internalisierung des 66.3-kDa-Proteins in I-Cell-Fibroblasten}

Immunfluoreszenzaufnahmen von I-Cell-Fibroblasten nach zweistündiger Inkubation mit dem partiell aufgereinigten Protein in Zellkulturmedium, Methanolfixierung und Immundetektion mit Antikörpern gegen das lysosomale Markerprotein LAMP-1 und den V5-Tag des 66.3-kDa-Proteins. Die Quadrate in der Übersichtsaufname auf der linken Seite geben die Lokalisation des Vergrößerungsausschnittes auf der rechten Seite an. Typisch für I-Cell-Fibroblasten ist die massive Akkumulation von Lysosomen. Die Balken entsprechen einer Länge von $20 \mu \mathrm{m}$ (Kollmann et al. 2005, S. 3976). 


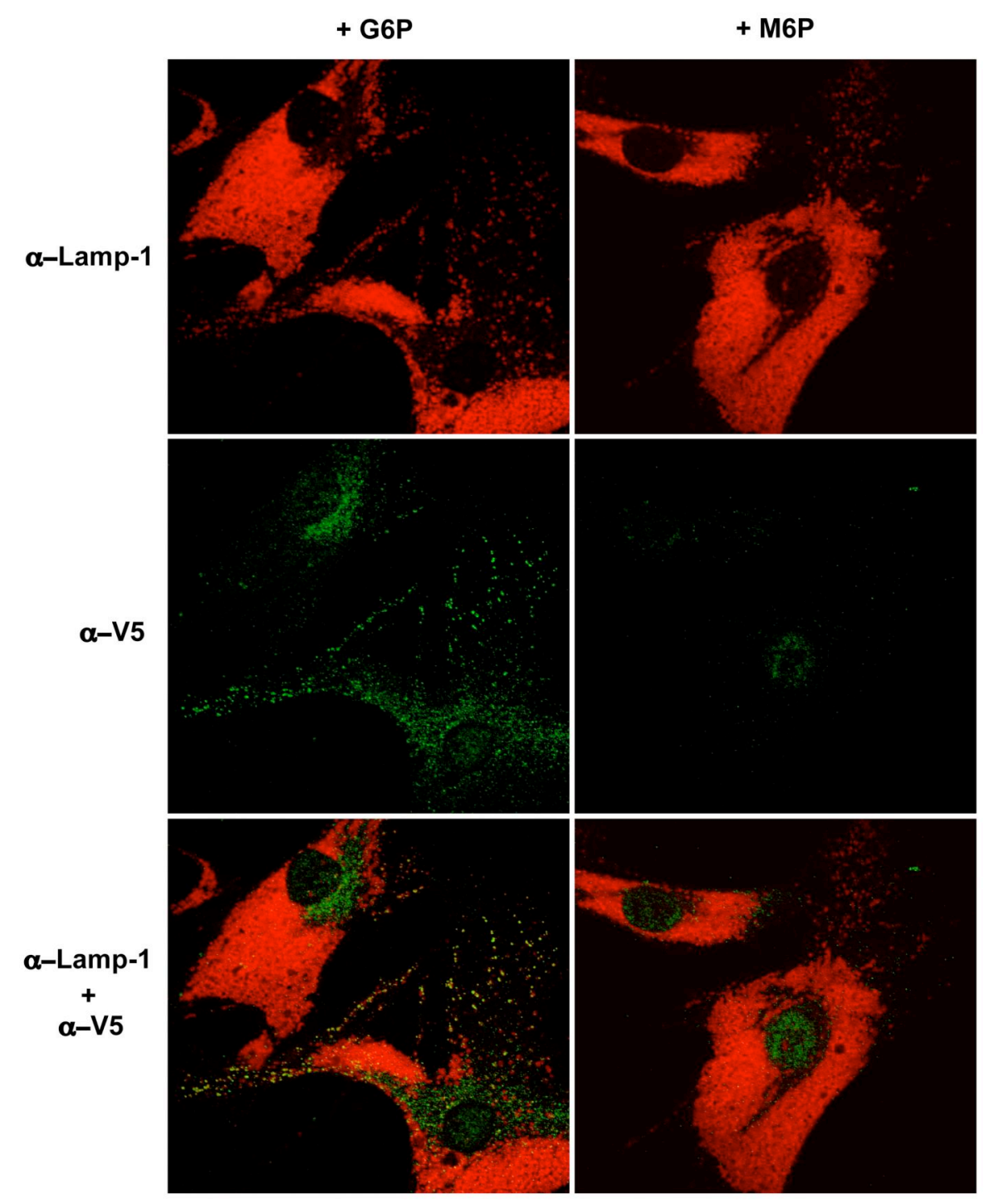

\section{Abb. 1-6: $\quad$ Proteinaufnahme unter Einfluss von M6P und G6P}

I-Cell-Fibroblasten wurden mit partiell aufgereinigtem Protein in Zellkulturmedium und zusätzlich entweder $5 \mathrm{mM}$ G6P oder $5 \mathrm{mM}$ M6P inkubiert und anschließend mit Methanol fixiert. Die Immundetektion wurde mit Antikörpern gegen das lysosomale Markerprotein LAMP-1 und den V5-Tag des 66.3-kDa-Proteins durchgeführt und Immunfluoreszenzaufnahmen angefertigt (Lübke 2006). 


\section{$1.8 \quad$ Fragestellung}

In Vorarbeiten zur vorliegenden Arbeit wurde anhand einer lysosomalen Proteomanalyse erstmals die murine Form des putativ lysosomalen 66.3-kDa-Proteins beschrieben. Es konnte gezeigt werden, dass eine C-terminal markierte Variante des Proteins an immobilisierte Mannose-6-Phosphat-Rezeptoren bindet bzw. Mannose-6-Phosphat-Rezeptor-abhängig von Fibroblasten internalisiert und zu Lysosomen transportiert wird. Diese Ergebnisse von Kollmann et al. (2005) wiesen somit auf die Identifizierung eines bis dato unbekannten Proteins mit lysosomaler Lokalisation hin. Ziel der vorliegenden Arbeit war der endogene Nachweis der lysosomalen Lokalisation, sowie die biochemische und die funktionelle Charakterisierung des murinen 66.3-kDa-Proteins.

Zu Beginn der Arbeit sollte eine Methode zur Aufreinigung des 66.3-kDa-Proteins aus dem Zellkulturüberstand von stabil exprimierenden Zellen etabliert werden. Das rekombinante Protein sollte für die Herstellung eines Antiserums genutzt werden, mit dessen Hilfe die subzelluläre Lokalisation des endogenen Proteins in der Immunfluoreszenz sowie die Gewebeverteilung des endogenen Proteins in Mausgewebe nachgewiesen werden sollte. Des Weiteren sollten das rekombinante Protein und die stabil exprimierenden Zellen für die biochemische und funktionelle Charakterisierung des Proteins genutzt werden.

Im zweiten Teil der Arbeit sollte eine funktionelle Analyse des murinen 66.3-kDa-Proteins vorgenommen werden. Dazu sollte die Analyse eines möglichen Phänotyps im $\underline{R N A}$ Interference-(RNAi)-Modell und Interaktionsstudien mit Yeast-two-Hybrid-Versuchen erste Hinweise auf die vollkommen unbekannte Funktion des murinen 66.3-kDa-Proteins geben. Zum anderen sollte über die Identifizierung von Interaktionspartnern die Einordnung des 66.3-kDaProteins in ein Funktionsumfeld vorgenommen werden. 
2 Material und Methoden 


\subsection{Material}

\subsubsection{Geräte}

\section{Allgemein}

Analysenwaagen Modell 1602 MP und M5P

Autoklav Modell Tecnoclav 50

Brutschrank Modell 2771

CCD-Kamera Modell Las-1000

Digitales pH-Meter

Drehrad für Eppendorfgefäße

Durchlicht-Mikroskop

Eismaschine Modell Scotsman MF 30

Elektrophoresekammer für Agarosegele

Elektrophoresekammer für Polyacrylamidgele

Flugzeit-Massenspektrometer Modell REFLEX

III (MALDI-TOF)

Fluoreszenzspektrophotometer Cary 50 Bio

Flüssigkeitsszintillationszähler LS 6500

Gefrierschrank $\left(-20^{\circ} \mathrm{C}\right)$

Gefrierschrank $\left(-85^{\circ} \mathrm{C}\right)$ Modell U57085

Geltrockner Modell Gel Air Dryer

Heizblock Modell Thermomixer

Heizblock Modell Thermostat 5320

HPLC-Proteinaufreinigung Modell Biocad-

Vision-Workstation

Imaging plate (Speicherfolie)

Inkubationsschüttler Modell G25

Laser-Scan Mikroskop Modell TCS Sp2 AOBS

Magnetrührer Modell Ika-Combimag Ret

Massenanalysegerät Modelle Reflex I und III
Sartorius, Göttingen

Tecnomara AG, Zürich, Schweiz

Köttermann, Häningsen

Fujifilm, Tokyo, Japan

Schütt, Göttingen

Eigenbau, Werkstatt der Fakultät

Zeiss, Oberkochen

Frimont, Mailand, Italien

Eigenbau, Werkstatt der Fakultät

Eigenbau, Werkstatt der Fakultät

Bruker Daltonik, Bremen

Varian, Darmstadt

Beckman, München

Liebherr, Bulle, Schweiz

New Brunswick Scientific,

Edison, USA

BioRad, Hercules, USA

Eppendorf, Hamburg

Eppendorf, Hamburg

Applied Biosystems,

Framingham, USA

FujiFilm, Düsseldorf

New Brunswick Scientific,

Edison, USA

Leica, Heidelberg

Janke \& Kunkel, Staufen

Bruker Daltonik, Bremen 
Mikroliterpipette Modell Exmire Microsyringe

Microplate Reader Modell Spectra II

Mikrowellenherd Modell M1719N

Multipette plus

Nass-Blot-System Modell Trans-Blot

Netzgerät für Agarosegelelektrophorese

Netzgerät Typ Power Pac 1000 für

Polyacrylamid-Gelelektrophorese

Phosphoimager Fujix BAS 1000

Photometer Modell UV 160 A

Procise cLC Sequenator

Schwenktisch

Semi-Dry Western-Blot-Apparatur

Steri-Kult Inkubator Modell 3035/200

Sterilbank Modelle A/B3 und SG 400

Stickstofftank Modell Biosafe Chronos

Teflon Homogenisator

Thermocycler Modell Gene Amp PCR 9600

Transilluminator Modell ETX 20 M

Ultraschall-Desintegrator Sonifier W-450

UV-Handlampe (312 nm, $254 \mathrm{~nm})$

Vakuum Konzentrator Modell Speed Vac SVC $100 \mathrm{H}$

Vortex Modell Genie 2

Waage Modelle 1264 MP und 1265

Wärmeschrank

Wasserbad Modelle GFL 1083 und HOR 7225
ITO, Fuji, Japan

Tecan, Crailsheim

Samsung, Schwalbach/Ts.

Eppendorf, Hamburg

BioRad, Hercules, USA

H. Hölzel, München

BioRad, München

Fuji, Tokio, Japan

Shimadzu, Kyoto, Japan

Applied Biosystems,

Framingham, USA

Eigenbau, Werkstatt der Fakultät

Cti GmbH, Idstein/Ts.

Forma Scientific, Marietta, USA

Baker Company, Sanford, USA

Messer Griesheim, Frankfurt/M.

B. Braun Melsungen, Melsungen

Perkin-Elmer Cetus, Norwalk,

USA

LTF Labortechnik, Wasserburg

Branson Ultrasonic, Carouge-

Geneve, USA

Bachhofer, Reutlingen

Bachhofer, Reutlingen

Bender \& Hobein, Zürich,

Schweiz

Sartorius, Göttingen

Memmert, Schwabach

Köttermann, Häningsen 


\section{Zentrifugen}

Biofuge A

Biofuge Fresco

Eppendorfzentrifuge Modelle 5414 und 5415 C

Kühlzentrifuge Modelle J-21 C und J2-MC mit

Rotoren JA-10 und JA-20

Labofuge GL

Tisch-Ultrazentrifuge Modell TL-100 mit

Rotoren TLA-100.3 und TLA-45

Ultrazentrifuge Modell Optima L90K mit

Rotoren SW 41 und 75 Ti

\section{Geräte zur Präparation von murinen Geweben}

Chirurgische Schere, gebogen

Chirurgischer Löffel

Pinzette, stumpf

Präparationstisch

\subsubsection{Verbrauchsmaterialien}

Braunülen Modell Jelco

Dialyseschlauch Typ 8, cut-off: 12-16 kDa,

Porengröße 25A

Einfrierkästen

Einfrierröhrchen

Einmalkanülen Modell Microlance 3

Einmalspritzen Modell Discardit II mit 5-, 10und $20 \mathrm{ml}$

Fixierpflaster Modell Leukosilk S

Gewebekulturflaschen Modell T25 und T75

Gewebekulturschalen mit 35-, 60-, 100- und 140 mm Durchmesser

Glaskolben mit 100-, 250- und $1000 \mathrm{ml}$
Heraeus Sepatech, Osterode

Heraeus Sepatech, Osterode

Eppendorf, Hamburg

Beckman, München

Heraeus Sepatech, Osterode

Beckman, München

Beckman Coulter, Krefeld

Aesculap, Tuttlingen

Aesculap, Tuttlingen

Aesculap, Tuttlingen

Eigenbau, Werkstatt der Fakultät

B. Braun Melsungen,

Melsungen

Biomol, Hamburg

National Lab, Mölln

Nunc, Wiesbaden

Becton Dickinson, Heidelberg

Becton Dickinson, Heidelberg

BSN medical, Hamburg

Greiner, Nürtingen

Greiner, Nürtingen

Schott, Mainz 
Hybond-N

Immersionsöl

Injektionsspritzen Modell Micro-Fine + Demi, $0,3 \mathrm{ml}$

Objektträger und Deckgläser

Parafilm ${ }^{\circledR} \mathrm{M}$

Pasteurpipetten

Plastikpipetten 5-, 10- und $25 \mathrm{ml}$

Plastikröhrchen 10 und $50 \mathrm{ml}$

Polyvinylidenfluorid (PVDF) Transfermembran

Qiagen-Säulen für DNA-Präparation

Reaktionsgefäße $0,5,1,5$ und $2 \mathrm{ml}$

Skalpelle

Spritzenfilter $0,2 \mu \mathrm{m}$ und $0,45 \mu \mathrm{m}$

Ultrazentrifugenröhrchen Modelle Microfuge

Tube 1,5 ml (Polyallomer) $14 \mathrm{x} 95 \mathrm{~mm}$ und $16 \mathrm{x}$

$76 \mathrm{~mm}$

Whatman-Papier, $3 \mathrm{~mm}$

Zellkulturplatten, 6- bzw. 24-Well

Zentrifugenröhrchen Modelle JA-10 und JA-20

(Polypropylen)

\subsubsection{Chemikalien}

Adeninhemisulfat

30\% Acrylamid / 0,8\% Bisacrylamid

Agar

Agarose

Albumin aus Rinderserum (BSA)

$\varepsilon$-Aminocapronsäure
Amersham Biosciences,

München

Zeiss, Oberkochen

Becton Dickinson, Heidelberg

Menzel-Gläser, Braunschweig

American National, Menasha,

USA

Schütt, Göttingen

Greiner, Nürtingen

Greiner, Nürtingen

Schleicher und Schüll, Dassel

Qiagen, Düsseldorf

Sarstedt, Nümbrecht

B. Braun Melsungen,

Melsungen

Heinemann Labortechnik,

Duderstadt

Beckman, München

Whatman, Göttingen

Greiner, Nürtingen

Beckman, München
Sigma, Deisenhofen

Roth, Karlsruhe

Sigma, Deisenhofen

Sigma, Deisenhofen

Serva, Heidelberg

Roth, Karlsruhe 
Ammoniumacetat

Ammoniumperoxodisulfat (APS)

Ammoniumsulfat $\left(\left(\mathrm{NH}_{4}\right)_{2} \mathrm{SO}_{4}\right)$

Ascorbinsäure

Bacto-Hefe-Extrakt

Bacto-Trypton

Borsäure

Bromphenolblau

Calciumchlorid $\left(\mathrm{CaCl}_{2}\right)$

Chlorwasserstoff $(\mathrm{HCl})$

Coomassie, Blue R-250

Dextransulfat

Dimethylformamid

Diethylpyrocarbonat (DEPC)

Dimethylsulfoxid (DMSO)

Dinatriumhydrogenphosphat $\left(\mathrm{Na}_{2} \mathrm{HPO}_{4}\right)$

Dinatriummethylendiaminotetraacetat (EDTA)

Dithiothreitol (DTT)

Essigsäure

Ethanol

Ethanolamin

Ethidiumbromid

Ethylacetat

Fluormount Medium

Formaldehydlösung (37 \%)

Formamid

Glucose

Glucose-6-Phosphat

Glutaraldehyd

Glycerol

Glycin

Harnstoff

Hefeextrakt
Sigma, Deisenhofen

Merck, Darmstadt

Merck, Darmstadt

Roth, Karlsruhe

Becton Dickinson, Heidelberg

Becton Dickinson, Heidelberg

Sigma, Deisenhofen

BioRad, München

Merck, Darmstadt

Roth, Karlsruhe

Serva, Heidelberg

Sigma, Deisenhofen

Roth, Karlsruhe

Sigma, Deisenhofen

Merck, Darmstadt

Merck, Darmstadt

Sigma, Deisenhofen

Serva, Heidelberg

Merck, Darmstadt

Merck, Darmstadt

Merck, Darmstadt

Serva, Heidelberg

Sigma, Deisenhofen

Biacore, Freiburg

Merck, Darmstadt

Roth, Karlsruhe

Merck, Darmstadt

Sigma, Deisenhofen

Serva, Heidelberg

Roth, Karlsruhe

Roth, Karlsruhe

BioRad, München

Roth, Karlsruhe 
Hefe Stickstoff-Base

Hering-Sperma-DNA

4-(2-Hydroxyethyl)-piperazin-1-

ethansulfonsäure (Hepes)

Imidazol

Isoamylalkohol

Isopropanol

Jodacetamid (JAA)

Kaliumacetat (KAc)

Kaliumchlorid $(\mathrm{KCl})$

Kaliumdihydrogenphosphat $\left(\mathrm{KH}_{2} \mathrm{PO}_{4}\right)$

Kaliumnatriumtartrat

Lipofectamine 2000

Lithiumacetat (LiAc)

Magermilchpulver

Magnesiumchlorid $\left(\mathrm{MgCl}_{2}\right)$

Magnesiumsulfat $\left(\mathrm{MgSO}_{4}\right)$

Maleinsäure

2-Mercaptoethanol

Methanol

Natriumacetat ( $\mathrm{NaAc})$

Natriumazid $\left(\mathrm{NaN}_{3}\right)$

Natriumcarbonat $\left(\mathrm{Na}_{2} \mathrm{CO}_{3}\right)$

Natriumchlorid $(\mathrm{NaCl})$

Natriumdesoxycholat

Natriumdihydrogenphosphat $\left(\mathrm{NaH}_{2} \mathrm{PO}_{4}\right)$

Natriumdodecylsulfat (SDS)

Natriumhydroxid $(\mathrm{NaOH})$

Natriumsuccinat

Natriumthiosulfatpentahydrat $\left(\mathrm{Na}_{2} \mathrm{~S}_{2} \mathrm{O}_{3} \times 5 \mathrm{H}_{2} \mathrm{O}\right)$

2-(N-Morpholino)-Propansulfonsäure (MES)

3-(N-Morpholino)-Propansulfonsäure (Mops)

$\mathrm{NNN}^{\prime} \mathrm{N}^{\prime}$-Tetramethylethylendiamin (TEMED)
Invitrogen, Karlsruhe

Sigma, Deisenhofen

Serva, Heidelberg

Merck, Darmstadt

Merck, Darmstadt

Merck, Darmstadt

Serva, Heidelberg

Merck, Darmstadt

Merck, Darmstadt

Merck, Darmstadt

Merck, Darmstadt

Invitrogen, Karlsruhe

Sigma, Deisenhofen

Engel, Darmstadt

Roth, Karlsruhe

Merck, Darmstadt

Roth, Karlsruhe

Sigma, Deisenhofen

Roth, Karlsruhe

Merck, Darmstadt

Sigma, Deisenhofen

Merck, Darmstadt

Merck, Darmstadt

Roth, Karlsruhe

Merck, Darmstadt

Sigma, Deisenhofen

Merck, Darmstadt

Roth, Karlsruhe

Sigma, Deisenhofen

Sigma, Deisenhofen

Sigma, Deisenhofen

Sigma, Deisenhofen 
Nonidet P-40 (NP-40)

Pansorbin

PEG 3350

Pepton

1,10-Phenanthroline

Phenylmethylsulfonylfluorid (PMSF)

p-Iodonitrotetrazolium (violett)

p-Nitrophenyl- $\beta$-D-glucopyranosid

p-Nitrophenyl- $\beta$-D-glucuronid

Polyethylenglykol (PEG)

Polyvinylpyrrolidon

Protaminsulfat

Rapid-Hyb Buffer

Saccharose (Sucrose)

Schwefelsäure $\left(\mathrm{H}_{2} \mathrm{SO}_{4}\right)$

Silbernitrat $\left(\mathrm{AgNO}_{3}\right)$

Stickstoff

Stimune Adjuvant

Trichloressigsäure (TCA)

Tri-Natriumcitrat-Dihydrat

Tris-(hydroxymethyl)-Aminomethan (Tris)

Triton X-100 (TX-100)

Tween-20

Tyloxapol (Triton WR-1339)

Ultrapure dNTP Set
Sigma, Deisenhofen

Calbiochem, Darmstadt

Sigma, Deisenhofen

Sigma, Deisenhofen

Roth, Karlsruhe

Serva, Heidelberg

Sigma, Deisenhofen

Sigma, Deisenhofen

Sigma, Deisenhofen

Roth, Karlsruhe

Roth, Karlsruhe

Roth, Karlsruhe

GE Healthcare, München

Merck, Darmstadt

Roth, Karlsruhe

Merck, Darmstadt

Messer Griesheim, Siegen

Cedi Diagnostic, Lelystad,

Niederlande

Merck, Darmstadt

Roth, Karlsruhe

Merck, Darmstadt

Sigma, Deisenhofen

Sigma, Deisenhofen

Sigma, Deisenhofen

Pharmacia, Uppsala,

Schweden 


\subsubsection{Enzyme}

PFx-DNA-Polymerase

Endoglykosidase F (PNGase F)

Restriktionsendonukleasen

Taq-DNA-Polymerase

Trypsin, modifiziert aus Rinderpankreas
Invitrogen, Karlsruhe

Roche Applied Science, Indianapolis, USA

NEB, Ipswich, USA

Roche Applied Science, Indianapolis, USA

Boehringer, Mannheim

\subsubsection{Standards}

TrackIt-1-kb-Plus-DNA-Ladder

0,5-10-kb-RNA-Ladder

All-Blue-Protein-Ladder
Invitrogen, Karlsruhe

Invitrogen, Karlsruhe

BioRad, München

\subsubsection{Kits für das Arbeiten mit RNA, DNA und Protein}

Bio-Rad D $\mathrm{D}_{\mathrm{C}}$-Assay Reagenz A/B/S

Supersignal West Pico Chemiluminescent

Substrat

Plasmid Midi Kit

Plasmid Mini Kit

QIAquick Gel Extraktion

Megaprime Labeling Kit

RNeasy Mini Kit

\subsubsection{Radioaktive Substanzen}

$\left[{ }^{35} \mathrm{~S}\right]$-Methionin/Cystein, wässrige Lösung,

$10 \mathrm{mCi} / \mathrm{ml}$

$\left[{ }^{32} \mathrm{P}\right]$-dCTP, $3000 \mathrm{Ci} / \mathrm{mmol}$
BioRad, München

Pierce, Rockford, USA

Qiagen, Hilden

Qiagen, Hilden

Qiagen, Hilden

Amersham Pharmacia, München

Qiagen, Hilden

Hartmann Analytik,

Braunschweig

Hartmann Analytik,

Braunschweig 


\subsubsection{Säulen und Säulenfüllmaterial}

Affigel-10

Ni-NTA-Agarose

Sephadex G50

Poros HQ
BioRad, München

Qiagen, Hilden

Pharmacia, Uppsala, Schweden

Applied Biosystems, Foster

City, USA

\subsubsection{Antikörper}

\subsubsection{Primärantikörper}

Tab. 2-1: Primärantikörper

\begin{tabular}{|c|c|c|c|c|}
\hline Name & $\begin{array}{l}\text { Antigen, } \\
\text { (H.-Name) } \\
\text { Ag-Spezies } \\
\end{array}$ & immun. Spezies & WB / IF / IP & Referenz/Hersteller \\
\hline 66-Antiserum & $\begin{array}{l}\text { 66.3-kDa-Protein } \\
\text { Murin }\end{array}$ & $\begin{array}{l}\text { Kaninchen, } \\
\text { polyklonal }\end{array}$ & 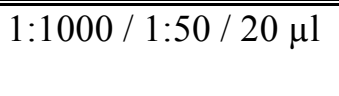 & $\begin{array}{l}\text { eigene Produktion } \\
\text { (Deuschl et al. 2006) }\end{array}$ \\
\hline$\alpha$-Cat-D & $\begin{array}{l}\text { Cathepsin D } \\
\text { Human }\end{array}$ & $\begin{array}{l}\text { Ziege (1004) } \\
\text { polyklonal }\end{array}$ & $1: 500 / 1: 50 /-$ & $\begin{array}{l}\text { zur Verfügung gestellt } \\
\text { von Prof. Dr. Hasilik, } \\
\text { Marburg, (Hasilik und } \\
\text { Neufeld 1980) }\end{array}$ \\
\hline$\alpha$-His & $\begin{array}{l}\text { RGS-His6-Epitop } \\
\text { (RGS-His) }\end{array}$ & $\begin{array}{l}\text { Maus } \\
\text { monoklonal }\end{array}$ & $1: 3000 /$ - / - & Qiagen, Hilden \\
\hline$\alpha-\mathrm{HSP60}$ & $\begin{array}{l}\text { Hitze-Schock- } \\
\text { Protein } 60 \\
\text { (Hspd1) } \\
\text { Murin }\end{array}$ & $\begin{array}{l}\text { Maus } \\
\text { monklonal }\end{array}$ & $1: 1000 /$ - / - & $\begin{array}{l}\text { Calbiochem, Darmstadt, } \\
\text { (Li et al. 2000) }\end{array}$ \\
\hline$\alpha$-Porin & $\begin{array}{l}\text { Porin } \\
\text { (31HL, Anti-VDAC) } \\
\text { Human }\end{array}$ & $\begin{array}{l}\text { Maus } \\
\text { monoklonal }\end{array}$ & $1: 1000 /$ - / - & Calbiochem, Darmstadt \\
\hline$\alpha$-LAMP-1 & $\begin{array}{l}\text { LAMP-1, } \\
\text { (1D4B, CD107a) } \\
\text { Murin }\end{array}$ & $\begin{array}{l}\text { Ratte, } \\
\text { monoklonal }\end{array}$ & $1: 250 / 1: 25 /-$ & Hybridomabank, USA \\
\hline
\end{tabular}




\subsubsection{Sekundärantikörper}

\section{Für Western Blot:}

Zweitantikörper für die Western-Blot-Analyse wurden standardmäßig in einer Verdünnung von 1:5000 eingesetzt.
Kaninchen-anti-Ziege, HRP-konjugiert
Dianova, Hamburg
Ziege-anti-Kaninchen, HRP-konjugiert
Dianova, Hamburg
Ziege-anti-Maus, HRP-konjugiert
Dianova, Hamburg
Ziege-anti-Ratte, HRP-konjugiert
Dianova, Hamburg

\section{Für Immunfluoreszenz:}

Zweitantikörper für die Immunfluoreszenz wurden standardmäßig 1:400 eingesetzt.

Ziege-anti-Ratte, Alexa-488-konjugiert

Ziege-anti-Kaninchen, Alexa-674-konjugiert

Esel-anti-Ratte, Alexa-488-konjugiert

Esel-anti-Ziege, Alexa-546-konjugiert

Esel-anti-Kaninchen, Alexa-674-konjugiert
Invitrogen, Karlsruhe Invitrogen, Karlsruhe Invitrogen, Karlsruhe Invitrogen, Karlsruhe Invitrogen, Karlsruhe

\subsubsection{Tierversuchsanträge und -genehmigungen}

Antikörperherstellung: 33.42502/01-A-02.05

Versuche mit Tyloxapol: 33.42502/A-011/06

Organentnahme: 33.42502/01-A-07.05

\subsubsection{Zelllinien}

Tab. 2-2: Zellinien

\begin{tabular}{lll}
\hline \hline Zelllinie & Beschreibung & Referenz \\
\hline \hline 3T3 (NIH-3T3) & murine embryonale Fibroblasten & $\begin{array}{l}\text { Sigma-Aldrich, St. } \\
\text { Louis, USA }\end{array}$ \\
HT1080 & humane Fibrosarkom-Zelllinie & Stratagene, La Jolla, \\
& & USA \\
MEF (Kontrolle) & primäre embryonale Mausfibroblasten & Zellen des Instituts \\
MEF CD -/- & primäre embryonale Mausfibroblasten, & Zellen des Instituts \\
& defizient für endogenes Cathepsin-D & (Saftig et al. 1995) \\
\hline
\end{tabular}




\subsubsection{Häufig verwendete Puffer und Stammlösungen}

Die verwendeten Lösungen und Puffer wurden nach den Vorschriften des Laborhandbuchs von Sambrook (Sambrook et al. 1989) hergestellt.

$10 \times$ PBS $\quad 400 \mathrm{~g} \mathrm{NaCl}, 10 \mathrm{~g} \mathrm{KCl}, 72 \mathrm{~g} \mathrm{Na}_{2} \mathrm{HPO}_{4} \times 2 \mathrm{H}_{2} \mathrm{O}$ und $10 \mathrm{~g} \mathrm{KH}_{2} \mathrm{PO}_{4}$ in

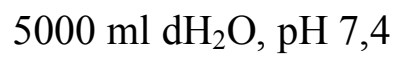

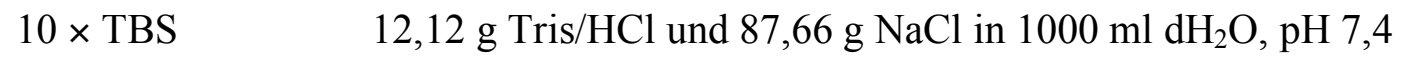

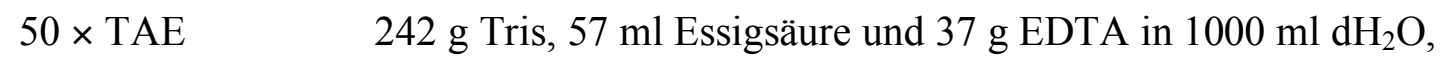
$\mathrm{pH} 8,0$

$20 \%$ SDS $\quad 20 \mathrm{~g}$ SDS in $100 \mathrm{ml} \mathrm{dH}_{2} \mathrm{O}$ bei $65^{\circ} \mathrm{C}$ gelöst und sterilfiltriert

0,5 M EDTA 181,1 g EDTA in $800 \mathrm{ml} \mathrm{ddH}_{2} \mathrm{O}$, $\mathrm{pH}$ 8,0; das Volumen auf $1000 \mathrm{ml}$ aufgefüllt und autoklaviert

$10 \times \mathrm{TE} \quad 12,1 \mathrm{~g}$ Tris/ $\mathrm{HCl} \mathrm{pH} \mathrm{7,6} \mathrm{und} \mathrm{2,92} \mathrm{g}$ EDTA in $1000 \mathrm{ml} \mathrm{d \textrm {H } _ { 2 } \mathrm { O }}$

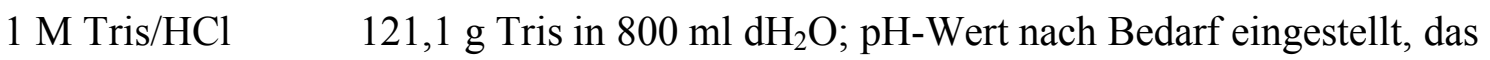
Volumen auf $1000 \mathrm{ml}$ aufgefüllt und autoklaviert

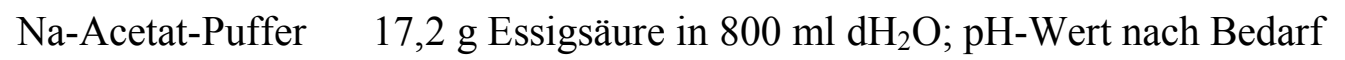
eingestellt und das Volumen auf $1000 \mathrm{ml}$ aufgefüllt

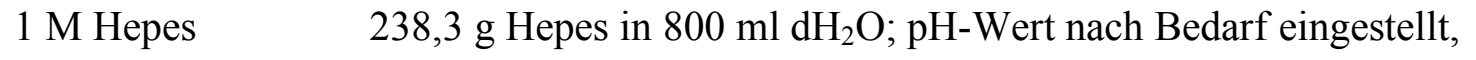
das Volumen auf $1000 \mathrm{ml}$ aufgefüllt und autoklaviert

\subsubsection{Medien und Stammlösungen zur Anzucht eukaryoter Zellen}

Dulbecco's Modified Eagle Medium (DMEM)

Fötales Kälberserum (FKS)

L-Glutamin (200 mM)

Nicht essentielle Aminosäuren

1,782 g $\alpha$-Alanin, 2,642 g $\alpha$-Asparagin,

1,502 g Glycin, 2,302 g $\alpha$-Prolin und

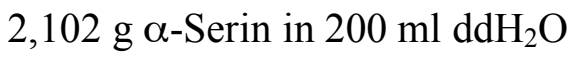

0,05\% (w/v) Trypsin-EDTA-Lösung

Ampicillin

Hygromycin B

Neomycin (G418)

Penicillin/Streptomycin
Gibco Invitrogen, Karlsruhe Gibco Invitrogen, Karlsruhe Gibco Invitrogen, Karlsruhe Gibco Invitrogen, Karlsruhe

Gibco Invitrogen, Karlsruhe Calbiochem, Frankfurt

Calbiochem, Frankfurt

Sigma, Deisenhofen

Biochrom, Berlin 
PBS (für Zellkultur):

$40 \mathrm{~g} \mathrm{NaCl}, 1 \mathrm{~g} \mathrm{KCl}$,

$7,2 \mathrm{Na}_{2} \mathrm{HPO}_{4}+2 \mathrm{H}_{2} \mathrm{O}$,

$1 \mathrm{~g} \mathrm{KH}_{2} \mathrm{PO}_{4}$ und

$0,1 \mathrm{~g}$ Phenolrot in $5000 \mathrm{ml}$

$\mathrm{ddH}_{2} \mathrm{O} \mathrm{pH} 7,4$

\section{Hitzeinaktivierung und Dialyse von fötalem Kälberserum:}

Das Serum wurde für 45 min bei $56^{\circ} \mathrm{C}$ in einem geschlossenen Wasserbad inkubiert und ü.N. bei $4{ }^{\circ} \mathrm{C}$ gegen 51 PBS in einem Dialyseschlauch (Porengröße: 12-14 kDa) dialysiert.

\subsubsection{Medien zur Kultur prokaryoter Zellen}

LB-Medium $10 \mathrm{~g}$ Bacto-Trypton, $5 \mathrm{~g}$ Bacto-Hefe-Extrakt und $5 \mathrm{~g} \mathrm{NaCl}$ in

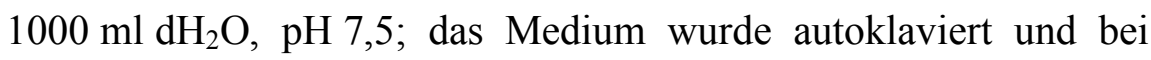
$4{ }^{\circ} \mathrm{C}$ gelagert. Vor dem Gebrauch wurde dem Medium bei Bedarf $125 \mu \mathrm{g} / \mathrm{ml}$ Ampicillin oder $50 \mu \mathrm{g} / \mathrm{ml}$ Kanamycin zugesetzt.

LB- Agarplatten Dem LB-Medium wurde für die Bakterienkultur auf Agarplatten Ampicilin/ vor dem Autoklavieren $15 \mathrm{~g}$ Agar pro Liter $\mathrm{dH}_{2} \mathrm{O}$ zugefügt. Nach Kanamycin- $\quad$ dem Autoklavieren und dem Abkühlen auf $50{ }^{\circ} \mathrm{C}$ wurde Ampicillin in einer Endkonzentration von $125 \mu \mathrm{g} / \mathrm{ml}$ und Kanamycin in einer Endkonzentration von $50 \mu \mathrm{g} / \mathrm{ml}$ zugefügt. Die Agarlösung wurde in $10 \mathrm{~cm}$ Zellkulturschalen gegossen, bei RT abgekühlt und anschließend bei $4{ }^{\circ} \mathrm{C}$ und unter Lichtausschluss gelagert.

\subsubsection{EDV}

\section{Hardware:}

Drucker HP LaserJet 4050

Drucker Z65

iBook G4

iMac

PC Pentium 4
Hewlett\&Packard, Palo Alto, USA

Lexmark, Lexington, USA

Apple, Cupertino, USA

Apple, Cupertino, USA

Dell, Round Rock, USA 


\section{Software:}

$\begin{array}{ll}\text { Adobe Illustrator CS2 } & \text { Adobe, San Jose, USA } \\ \text { Adobe-Photoshop CS2 } & \text { Adobe, San Jose, USA } \\ \text { AIDA Image analysing software } & \text { FujiFilm, Düsseldorf } \\ \text { Image Gauge 3.0 } & \text { FujiFilm, Düsseldorf } \\ \text { Image Reader } & \text { FujiFilm, Düsseldorf } \\ \text { Mac OS X } & \text { Apple, Cupertino, USA } \\ \text { Microsoft Office für Mac 2004 } & \text { Microsoft, Redmond, USA } \\ \text { Vektor NTA Suite } & \text { Invitrogen, Carlsbad, USA } \\ \text { WinCam 2.2 } & \text { Cybertech, Berlin } \\ \text { Windows XP/98 } & \text { Microsoft, Redmond, USA }\end{array}$

\subsection{Molekularbiologische Methoden}

\subsubsection{Methoden zum Arbeiten mit DNA}

Die Methoden wurden, soweit nicht anders erwähnt, dem Handbuch Molecular Cloning (Sambrook et al. 1989) entnommen.

\subsubsection{Konzentrationsbestimmung von DNA}

Die DNA-Konzentration wurde photometrisch über die Absorption bei $\lambda=260 \mathrm{~nm}$ in einer Quarzküvette gegen $\mathrm{dH}_{2} \mathrm{O}$ oder TE ermittelt. Eine $\mathrm{OD}_{260}=1$ entspricht der Konzentration von $50 \mu \mathrm{g} / \mathrm{ml}$ doppelsträngiger DNA. Die Reinheit der Probe wurde über das Verhältnis der Extinktionen für Nukleinsäurebasen $(\lambda=260 \mathrm{~nm})$ und für Dipeptidbindungen $(\lambda=280 \mathrm{~nm})$ ermittelt. Ein Wert zwischen 1,8 und 2 wurde angestrebt.

\subsubsection{DNA-Präzipitation mit Ethanol}

Einem Volumen zu präzipitierender DNA-Lösung wurde 1/10 Volumen $3 \mathrm{M} \mathrm{NaAc}$, 1/10 Volumen 125 mM EDTA und 5 Volumen Ethanol (100\%) zugegeben, vorsichtig gemischt und für $15 \mathrm{~min}$ bei $14000 \mathrm{rpm}$ zentrifugiert. Anschließend wurde der Überstand vorsichtig abgenommen und durch 7 Volumen Ethanol (70\%) ersetzt. Es folgte eine fünfminütige Zentrifugation bei $14000 \mathrm{rpm}$. Das DNA-Pellet wurde für 2 min in der Speedvak getrocknet und anschließend im gewünschten Volumen $\mathrm{ddH}_{2} \mathrm{O}$ oder TE-Puffer aufgenommen. 


\subsubsection{Spaltung von DNA mit Restriktionsendonukleasen}

Für die Spaltung von DNA mit Restriktionsendonukleasen wurde das System von New England Biolabs (NEB) verwendet. Der Hersteller liefert neben den Enzymen auch das Puffersystem, bestehend aus vier Basispuffern (Zusammensetzung in einfacher Konzentrationen angegeben):

NEB 1:

$10 \mathrm{mM}$ Tris/HCl pH 7, $10 \mathrm{mM} \mathrm{MgCl} 2$ und $1 \mathrm{mM}$ DTT

NEB 2:

$10 \mathrm{mM}$ Tris/HCl pH 8, $10 \mathrm{mM} \mathrm{MgCl} 2,1 \mathrm{mM}$ DTT und $50 \mathrm{mM} \mathrm{NaCl}$

NEB 3: $50 \mathrm{mM}$ Tris/HCl pH 8, $10 \mathrm{mM} \mathrm{MgCl}_{2}, 1 \mathrm{mM}$ DTT und $100 \mathrm{mM} \mathrm{NaCl}$

NEB 4: $20 \mathrm{mM}$ Tris/HCl pH 8, $10 \mathrm{mM} \mathrm{MgAc} 2,1 \mathrm{mM}$ DTT und $50 \mathrm{mM} \mathrm{KAc}$

Die Aktivität von Restriktionsendonukleasen wird in Units (U) angegeben. Eine Unit ist definiert als die Menge an Restriktionsenzym, die benötigt wird, um in einer Stunde $1 \mu \mathrm{g}$ Lambda-DNA vollständig zu schneiden.

Reaktionsansatz:

$$
\begin{aligned}
& \mathrm{x} \mu \mathrm{l}\text { DNA (ca. } 2 \mu \mathrm{g}) \\
&+\quad 2 \mu \mathrm{l} \text { Enzym-spezifischer 10x-Puffer } \\
&+\quad 2 \mu \mathrm{l} \text { Restriktionsendonuklease }(1 \mu \mathrm{l}=1 \mathrm{U}) \\
&+\quad \mathrm{y} \mu \mathrm{l} \quad \mathrm{dH}_{2} \mathrm{O} \\
& \hline \mathbf{2 0} \boldsymbol{\mu l} \text { Ansatz }
\end{aligned}
$$

Der Reaktionsansatz wurde für $2 \mathrm{~h}$ bei $37^{\circ} \mathrm{C}$ inkubiert und anschließend zur Analyse durch Agarosegel-Elektrophorese aufgetrennt. Für einen präparativen Verdau wurde das Volumen des Ansatzes sowie die Menge an 10×-Puffer und Enzym entsprechend angepasst.

\subsubsection{Agarosegel-Elektrophorese}

DNA-Proben-Puffer $\quad 0,25 \%(w / v)$ Bromphenolblau und $40 \%(w / v)$ Saccharose in $1 \times-T A E$

Die Zusammensetzung des Agarosegels richtete sich nach der erwarteten Größe der DNAFragmente (vgl. Tab. 2-3). Für die Herstellung eines Agarosegels wurde die benötigte Menge Agarose in der Mikrowelle mit $300 \mathrm{ml}$ 1×-TAE aufgekocht. Unter ständigem Rühren wurde die flüssige Agarosemasse auf $55^{\circ} \mathrm{C}$ abgekühlt und Ethidiumbromid auf eine Endkonzentration von $0,5 \mu \mathrm{g} / \mathrm{ml}$ hinzugefügt. Die Agaroselösung wurde in eine Gelform gegossen bei RT abgekühlt und nach dem Erhärten bei $4{ }^{\circ} \mathrm{C}$ bis zum Gebrauch gelagert. 
Tab. 2-3: Agagrosekonzentrationen

\begin{tabular}{ll}
\hline \hline Agarosekonzentration (\%) & Trennbereich $(\mathrm{kb})$ \\
\hline \hline $\mathbf{0 , 6}$ & $20-1$ \\
$\mathbf{0 , 9}$ & $7-0,5$ \\
$\mathbf{1 , 2}$ & $6-0,4$ \\
$\mathbf{1 , 5}$ & $4-0,2$ \\
$\mathbf{2 , 0}$ & $3-0,1$ \\
\hline
\end{tabular}

Zur Aufreinigung von DNA-Fragmenten nach DNA-Verdau oder zur Analyse von PCRProdukten wurde die bearbeitete DNA über ein Agarosegel aufgetrennt. Dem DNA-Ansatz wurde $15 \%$ des DNA-Proben-Puffers zugesetzt. Die DNA wurde bei einer Spannung von $4 \mathrm{~V} / \mathrm{cm}$ aufgetrennt. Die Auftrennung konnte durch das in die DNA interkalierende Ethidiumbromid mit einer UV-Handlampe verfolgt werden. Das Ergebnis wurde mit einer Kamera über dem UV-Transilluminator festgehalten.

\subsubsection{Isolierung von DNA aus Agarosegelen}

(Qiagen QIAquick® Spin Handbook 2002)

Die Isolierung von DNA aus Agarosegelen wurde mit dem Kit von Qiagen (Qiagen Gel Extraction Kit) durchgeführt. Qiagen stellt einen Puffer zum Auflösen des Agarosegels (QG-Puffer) und einen Waschpuffer (PE-Puffer) zur Verfügung, gibt aber die Zusammensetzung nicht bekannt. Die DNA-Bande wurde mit einem sterilen Skalpell aus dem Gel ausgeschnitten, gewogen und in drei Volumen (w/v) QG-Puffer für $10 \mathrm{~min}$ bei $50^{\circ} \mathrm{C}$ aufgelöst. Der Lösung wurde ein Volumen Isopropanol zugesetzt und gründlich vermischt. Die Lösung wurde in einer Qiaquick-Säule für $1 \mathrm{~min}$ bei $13000 \mathrm{rpm}$ zentrifugiert, um die DNA an das Säulenmaterial zu binden. Die DNA wurde nacheinander mit $500 \mu \mathrm{l}$ QG-Puffer und $750 \mu \mathrm{l}$ PE-Puffer gewaschen. Reste des PE-Puffers wurden durch erneute Zentrifugation entfernt und die DNA mit 30-50 $\mu 1$ $\mathrm{ddH}_{2} \mathrm{O}$ eluiert.

\subsubsection{Ligation}

Über eine Ligationsreaktion wurden DNA-Fragmente mit dem Enzym Ligase in einen Vektor integriert. Dazu wurde der Vektor durch Inkubation mit zwei spezifischen Restriktionsendonukleasen im Klonierungsabschnitt geschnitten und linearisiert. Über Agarosegel-Elektrophorese wurde der linearisierte Vektor aufgetrennt und aus dem Gel isoliert. Die Menge des in der Ligation eingesetzten Inserts errechnete sich durch folgende Formel: 
$\frac{100 \mathrm{ng} \text { Vektor } \times \text { kb Länge Insert }}{\text { kb Länge Vektor }} \times \frac{3}{1}=x$ ng Insert

Die Ligation des zu inserierenden DNA-Fragmentes und des Vektors erfolgte nach folgendem Ansatz:

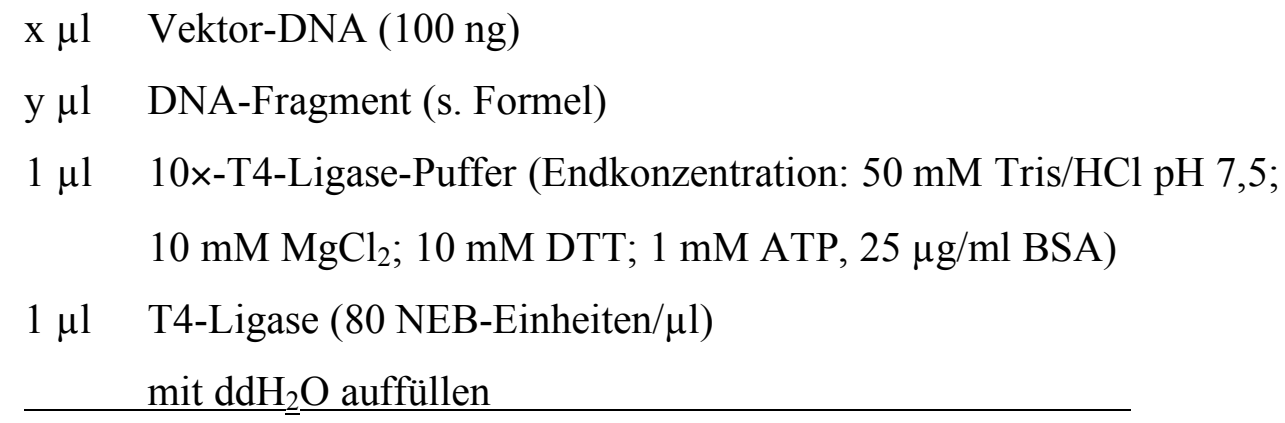

\section{$10 \mu \mathrm{l} \quad$ Ansatz}

Die Ligation erfolgte ü.N. bei $16{ }^{\circ} \mathrm{C}$ im Wasserbad.

\subsubsection{DNA-Amplifikation über die Polymerase-Ketten-Reaktion}

(Mullis et al. 1986)

Die Polymerase-Ketten-Reaktion (PCR) ist eine Standardmethode, um DNA-Abschnitte einer DNA-Sequenz selektiv zu amplifizieren. Für PCRs in dieser Arbeit wurde, wenn nicht anders erwähnt, Taq-Polymerase verwendet. Ein PCR-Ansatz wurde wie folgt zusammengesetzt:

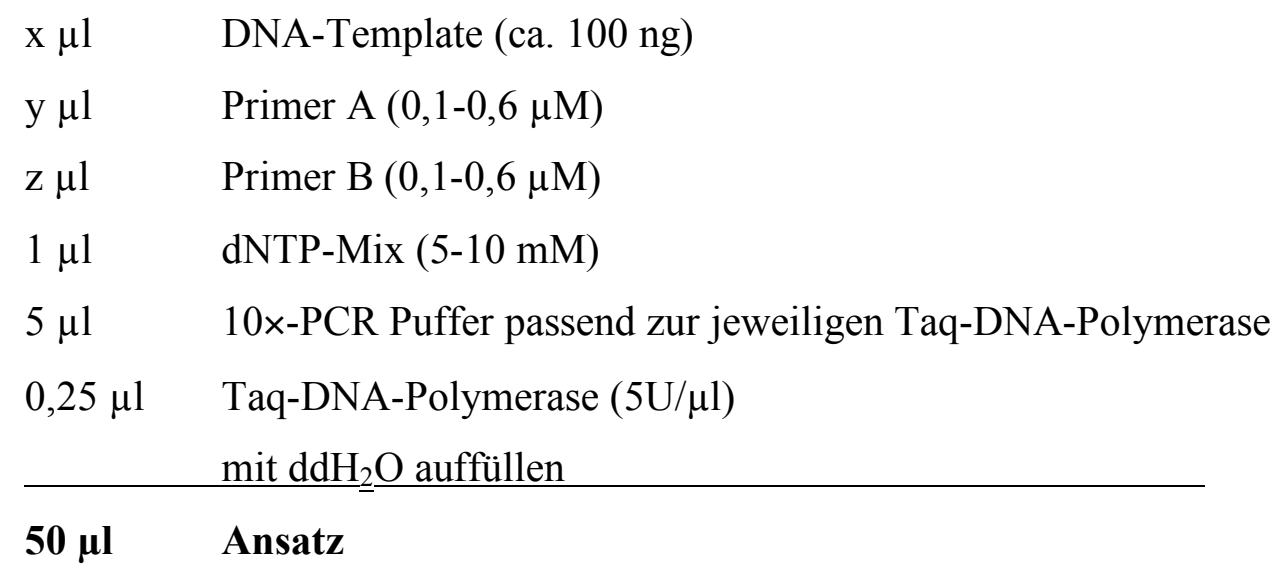


Der Ansatz wurde nach folgendem Temperaturschema im PCR-Cycler inkubiert, wobei die Annealing-Temperatur vom Schmelzpunkt der Primer abhing.

2 min $\quad 94^{\circ} \mathrm{C} \quad$ initiale Denaturierung des DNA-Doppelstranges

$\underline{35 x}$ :

$30 \mathrm{sec} \quad 94^{\circ} \mathrm{C} \quad$ Denaturierung des DNA-Doppelstranges

30-60 sec $\quad 55^{\circ} \mathrm{C}-65^{\circ} \mathrm{C}$ Annealing (Bindung) der Primer an Einzelstränge

3 min $\quad 72^{\circ} \mathrm{C} \quad$ Extension der DNA mit Ausgangspunkt an den Primern

$10 \mathrm{~min} \quad 72^{\circ} \mathrm{C} \quad$ finale Extension an zuvor nicht komplettierten Produkten

$4{ }^{\circ} \mathrm{C} \quad \infty$

\subsubsection{Herstellung chemisch kompetenter DH5 $\alpha$-Escherichia-coli}

(Nishimura et al. 1990)

Medium A: $\quad 10 \mathrm{mM} \mathrm{MgSO}_{4} \times 7 \mathrm{H}_{2} \mathrm{O}$ und $0,2 \%$ Glucose in LB-Medium, $\mathrm{pH}$ 7,0

Medium B: $\quad 12 \mathrm{mM} \mathrm{MgSO}_{4} \times 7 \mathrm{H}_{2} \mathrm{O}, 36 \%$ Glycerin, $12 \%$ PEG (MW 7500) in LBMedium, $\mathrm{pH} 7,0$

Einen Tag vor der Präparation wurden $3 \mathrm{ml}$ LB-Medium mit DH5 $\alpha$ (E. coli) angeimpft und ü.N. bei $37^{\circ} \mathrm{C}$ im Schüttelinkubator inkubiert. Am folgenden Tag wurden $99 \mathrm{ml}$ Medium A mit $1 \mathrm{ml}$ der Vorkultur angeimpft und bis zu einer $\mathrm{OD}_{600}$ von 0,4-0,6 im Schüttelinkubator bei $37^{\circ} \mathrm{C}$ inkubiert, für $10 \mathrm{~min}$ auf Eis abgekühlt und für $15 \mathrm{~min}$ bei $4{ }^{\circ} \mathrm{C}$ und $4000 \mathrm{rpm}$ zentrifugiert. Der Überstand wurde abgegossen und das Zellpellet vorsichtig in $1 \mathrm{ml}$ kaltem Medium A aufgenommen und unter Zugabe von 2,5 ml Medium B vermischt. Die Zellsuspension wurde in 100- $\mu$-Aliquots abgefüllt, in flüssigem Stickstoff gefroren und bei $-80{ }^{\circ} \mathrm{C}$ gelagert.

\subsubsection{Transformation chemisch kompetenter DH5 $\alpha$-Escherichia-coli}

Kompetente DH5 $\alpha$ wurden langsam auf Eis aufgetaut. Zu dem 100- $\mu$ l-Ansatz wurde $1 \mathrm{ng}$ Plasmid-DNA gegeben und der Ansatz für 20 min bei $4{ }^{\circ} \mathrm{C}$ auf Eis inkubiert. Der Ansatz wurde für $2 \mathrm{~min}$ bei $42^{\circ} \mathrm{C}$ einem Hitzschock ausgesetzt und anschließend sofort für weitere $20 \mathrm{~min}$ bei $4{ }^{\circ} \mathrm{C}$ auf Eis inkubiert. Nach Zugabe von $500 \mu \mathrm{l}$ LB-Medium wurde der Ansatz für 60 min bei $37^{\circ} \mathrm{C}$ auf dem Drehrad inkubiert. Danach wurden $100 \mu 1$ des Ansatzes auf einer Agarplatte mit entsprechendem Selektionsantibiotikum (vgl. Kap. 2.1.14) ausgestrichen. Die Platten wurden ü.N. bei $37^{\circ} \mathrm{C}$ im Brutschrank inkubiert und gewachsene Klone am nächsten Morgen in $5 \mathrm{ml}$ LB- Medium (mit Selektionsantibiotikum) bei $37^{\circ} \mathrm{C}$ im Schüttelinkubator in Kultur genommen. Aus den Kulturen wurden die Plasmide durch Mini-Präparationen (vgl. Kap. 2.2.1.10) isoliert. 
Bakterienkulturen wurden in Form von Glycerinkulturen aufbewahrt. Ein Volumen von $500 \mu$ überprüfter DH5 $\alpha$ wurden mit 0,25 Volumen 80 \%igen Glycerins versetzt und bei $-80{ }^{\circ} \mathrm{C}$ gelagert. Aus Glycerinkulturen transformierter Bakterien konnten zu einem späteren Zeitpunkt eine Flüssigkultur zur Präparation von Plasmid-DNA (s. 2.2.1.10 und 2.2.1.11) angeimpft werden.

\subsubsection{Mini-Präparation von Plasmid-DNA}

(Qiagen Miniprep Handbook 2003)

Die Plasmidpräparationen wurden nach Vorschrift des Herstellers Qiagen unter Verwendung der mitgelieferten Puffer P1, P2, N3, PB, PE und EB durchgeführt, deren Zusammensetzung vom Hersteller nicht angegeben wird.

$2 \mathrm{ml}$ einer bei $37^{\circ} \mathrm{C}$ ü.N. im Schüttelinkubator inkubierten E.-coli-Kultur (s. 2.2.1.9) wurde für 5 min bei $13000 \mathrm{rpm}$ in der Tischzentrifuge abzentrifugiert. Das Zellpellet wurde in $250 \mu 1$ $4{ }^{\circ} \mathrm{C}$-kaltem P1-Puffer resuspendiert und mit $250 \mu 1$ P2-Puffer (Lysispuffer) durch vorsichtiges Schwenken vermischt. Nach erfolgter Lyse wurden $350 \mu 1$ N3-Puffer zugesetzt, durch sofortiges und vorsichtiges Schwenken vermischt und der Ansatz für $10 \mathrm{~min}$ bei $13000 \mathrm{rpm}$ in der Tischzentrifuge zentrifugiert. Der Überstand wurde in eine Qiaprep-Spin-Säule überführt und für 1 min bei $13000 \mathrm{rpm}$ zentrifugiert. Die Säule wurde nacheinander mit $500 \mu 1$ PB-Puffer und $750 \mu 1$ PE-Puffer gewaschen, für eine weitere Minute bei 13000 rpm von restlichem PE-Puffer befreit und die DNA mit $50 \mu$ EB-Puffer eluiert.

\subsubsection{Midi-Präparation von Plasmid-DNA}

\section{(Qiagen Plasmid Purification Handbook 2003)}

Die Plasmidpräparationen wurden nach Vorschrift des Herstellers Qiagen unter Verwendung der mitgelieferten Puffer P1, P2, P3, QBT, QC, QF und TE durchgeführt, deren Zusammensetzung vom Hersteller nicht angegeben wird.

$100 \mathrm{ml}$ einer ü.N. bei $37^{\circ} \mathrm{C}$ inkubierten E.-coli-Kultur wurden für $15 \mathrm{~min}$ bei $4{ }^{\circ} \mathrm{C}$ und $6000 \mathrm{rpm}$ (JA-10, Beckman) zentrifugiert, der Überstand verworfen, die Zellen in $4 \mathrm{ml}$ P1-Puffer resuspendiert und mit $4 \mathrm{ml} \mathrm{P2-Puffer} \mathrm{vorsichtig} \mathrm{vermischt.} \mathrm{Nach} \mathrm{erfolgter} \mathrm{Lyse} \mathrm{wurden} 4 \mathrm{ml}$ P3Puffer zugesetzt, durch sofortiges und vorsichtiges Schwenken vermischt und für 20 min bei $4{ }^{\circ} \mathrm{C}$ auf Eis inkubiert. Anschließend wurde die Suspension für $30 \mathrm{~min}$ bei $4{ }^{\circ} \mathrm{C}$ und $16000 \mathrm{rpm}$ (JA-20, Beckman) zentrifugiert. Der Überstand wurde sofort abgenommen und erneut für 15 min bei $4{ }^{\circ} \mathrm{C}$ und $16000 \mathrm{rpm}$ zentrifugiert. Der Überstand wurde auf eine mit QBT-Puffer 
äquilibrierte Qiagen-tip100-Säule gegeben. Die auf der Säule gebundene Plasmid-DNA wurde zweimal mit $10 \mathrm{ml}$ QC-Puffer gewaschen und in ein 50-ml-Falkon mit $5 \mathrm{ml}$ QF-Puffer eluiert. Der Lösung wurden $3,5 \mathrm{ml}$ Isopropanol zugesetzt und die DNA für 60 min bei $4{ }^{\circ} \mathrm{C}$ und $5000 \mathrm{rpm}$ in der Labofuge präzipitiert. Der Überstand wurde vorsichtig abgenommen, die DNA mit $2 \mathrm{ml} 70 \%$ igem Ethanol gewaschen, erneut für $60 \mathrm{~min}$ bei $4{ }^{\circ} \mathrm{C}$ und $5000 \mathrm{rpm}$ zentrifugiert. Der Überstand wurde verworfen und die DNA für 10 min bei RT getrocknet. Das getrocknete



\subsubsection{Methoden zum Arbeiten mit RNA}

Die Methoden wurden, soweit nicht anders erwähnt, dem Handbuch „Molecular Cloning“ (Sambrook et al. 1989) entnommen.

\subsubsection{Konzentrationsbestimmung von RNA}

Die RNA-Konzentration wurde photometrisch über die Absorption bei $260 \mathrm{~nm}$ in einer Quarzküfette gegen $\mathrm{dH}_{2} \mathrm{O}$ oder TE ermittelt. Eine $\mathrm{OD}_{260}=1$ entspricht einer Konzentration von $40 \mu \mathrm{g} / \mathrm{ml}$ RNA.

\subsubsection{RNA-Präparation aus Mausgeweben}

\section{(Qiagen RNeasy® Mini Handbook 1999)}

Die RNA-Präparation wurde nach Vorschrift des Herstellers Qiagen unter Verwendung der mitgelieferten Puffer durchgeführt. Der Hersteller gibt die Zusammensetzung der Puffer nicht bekannt. Bei dem RLT-Puffer handelt es sich um einen Lysispuffer und bei den Puffern RW1 und RPE handelt es sich um Waschpuffer.

$20 \mu \mathrm{g}$ frisch entnommenes Mausgewebe (vgl. Kapitel 2.6.2) wurde in $350 \mu 1$ RLT-Puffer aufgenommen und im Teflon-Homogenisator gründlich homogenisiert. Das Lysat wurde für 3 min bei $10000 \times$ g zentrifugiert, der Überstand abgenommen, mit $350 \mu 170 \%$ igem Ethanol versetzt, durch Pipettieren vermischt, auf eine RNeasy-Säule geladen und für $15 \mathrm{sec}$ bei $8000 \times \mathrm{g}$ zentrifugiert. Der Durchbruch wurde verworfen und die auf der Säule gebundene RNA jeweils einmal mit $500 \mu 1$ RW1-Puffer und einmal RPE-Puffer gewaschen. Die Säule wurde ein zweites Mal mit $500 \mu$ RPE-Puffer gewaschen und für 2 min bei $10000 \times$ g zentrifugiert, die Membran dadurch getrocknet und die RNA mit $30 \mu 1$ RNase-freiem Wasser in ein neues Eppendorfgefäß eluiert. Die RNA-Konzentration wurde bestimmt. 


\subsubsection{Northern Blot}

DEPC- $\mathrm{H}_{2} \mathrm{O} \quad 0,1 \%$ Diethylpyrocarbonat (DEPC) ü.N. in dd $_{2} \mathrm{O}$ gerührt und autoklaviert

$5 \times$-Ladepuffer

$16 \mu 1$ gesättigte Bromphenolblaulösung, $80 \mu 1500$ mM EDTA, $720 \mu 1$ Formaldehyd (37 \%), 2 ml Glycerol, 3,1 ml Formamid, $4 \mathrm{ml}$ 10x-Laufpuffer in $10 \mathrm{ml}$ DEPC- $\mathrm{H}_{2} \mathrm{O} \mathrm{pH} 8,0$

10x-Laufpuffer $200 \mathrm{mM}$ Mops pH 7,0 , $50 \mathrm{mM}$ Natriumcitrat und $10 \mathrm{mM}$ EDTA $20 \times-\mathrm{SSC}$

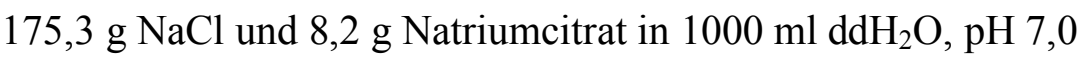

Zur Herstellung eines RNA-Gels wurden $20 \mathrm{ml}$ 10x-Laufpuffer, $180 \mathrm{ml}$ DEPC- $\mathrm{H}_{2} \mathrm{O}$ und 2 g Agarose kurz aufgekocht und anschließend auf $65^{\circ} \mathrm{C}$ abgekühlt. Die abgekühlte Lösung wurde auf $2 \%(\mathrm{w} / \mathrm{v})$ Formaldehyd eingestellt und $20 \mu \mathrm{l}$ einer $10 \mathrm{mg} / \mathrm{ml}$-EthidiumbromidLösung zugegeben.

Der Northern Blot wurde verwendet, um in den verschiedenen Mausgeweben RNAExpressionslevel des 66.3-kDa-Proteins $\mathrm{zu}$ analysieren. $10 \mu \mathrm{g}$ isolierter-RNA des jeweiligen Gewebes (zur Isolierung vgl. Kap. 2.2.2.2) wurde mit Ladepuffer versetzt und für 5 min bei $65{ }^{\circ} \mathrm{C}$ denaturiert. Die Proben wurden über ein RNA-Gel bei $40 \mathrm{~mA}$ für $6-7 \mathrm{~h}$ aufgetrennt und das Gel mit einem Referenzlineal abfotografiert. Danach wurde das Gel in 20x-SSC-Puffer äquilibriert und die RNA auf eine Nylonmembran transferiert (für Aufbau vgl. Abb. 2-1). Durch kurze Exposition mit UV-Licht $(30 \mathrm{sec})$ wurde die RNA an die Membran gebunden und anschließend bei $60^{\circ} \mathrm{C}$ getrocknet. 


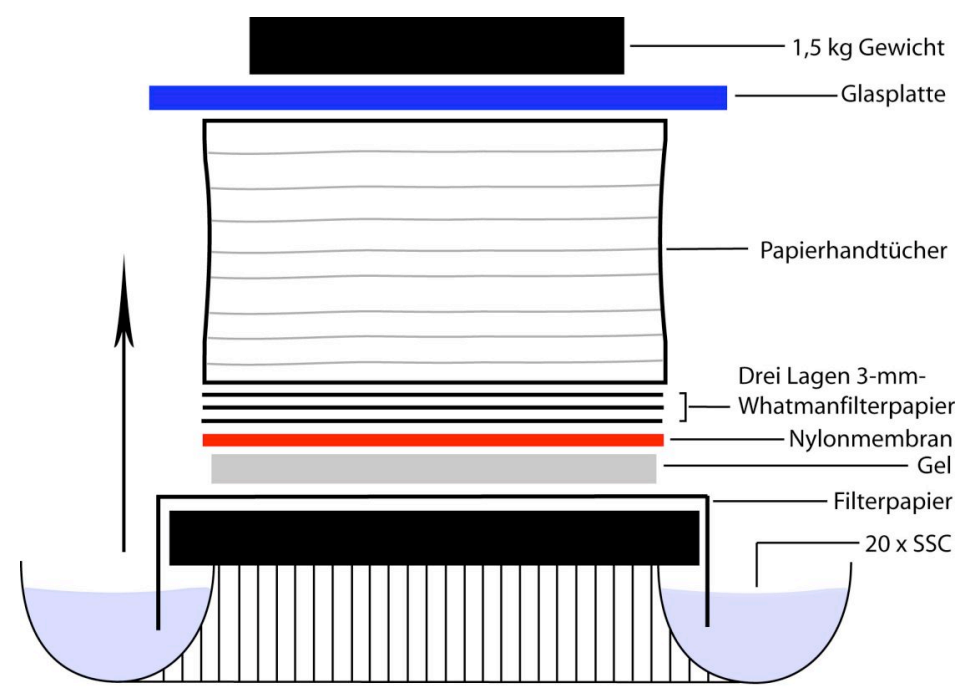

\section{Abb. 2-1: $\quad$ Northern-Blot-Versuchsaufbau}

Über zwei Gefäße mit 20x-SSC (s. 2.2.2.4) wurde in folgender Reihenfolge eine Glasplatte, ein Blatt Filterpapier, das die 20x-SSC-Lösung leitet, das Gel, eine in 20x-SSC getränkte Nylonmembran, eine Lage in 20x-SSC getränktes Whatmanfilterpapier, zwei Lagen trockenes Whatmanfilterpapier, eine ca. $15 \mathrm{~cm}$ dicke Schicht aus Papierhandtüchern, eine Glasplatte und ein ca. 1,5 kg schweres Gewicht gelegt.

\subsubsection{Markierung einer DNA - Sonde mit $\alpha-\left[{ }^{32} P\right]-\mathrm{dCTP}$}

Mit aufgereinigten PCR-Produkten (Full-length-66.3-kDa-Protein-cDNA und GAPDHcDNA) wurden radioaktiv markierte Sonden hergestellt. $50 \mathrm{ng}$ eines PCR-Produktes wurden in

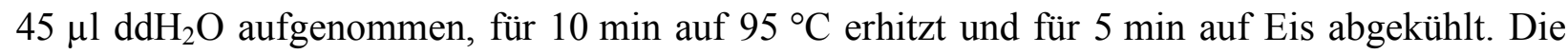
DNA-Lösung wurde in ein Reaktionsgefäß mit Rediprime-II-Random-PrimeHybridisierungsmix (Amersham Bioscience) überführt, $5 \mu 1 \quad \alpha-\left[{ }^{32} \mathrm{P}\right]-\mathrm{dCTP}$ (entspricht $50 \mu \mathrm{Ci}$ ) zugefügt, die Lösung durch Pipettieren vermischt und für $15 \mathrm{~min}$ bei $37^{\circ} \mathrm{C}$ inkubiert. Anschließend wurde die DNA-Sonde durch das Quiagen-PCR-Purification-Kit für radioaktive PCR-Produkte aufgereinigt und $10 \mu \mathrm{l}$ der DNA-Sonde im Flüssigkeitsszintillationszähler analysiert. $\mathrm{Zu}$ einer DNA-Sonde mit $5 \times 10^{6} \mathrm{cpm}$ wurde $50 \mu 1$ Herings-Sperma-DNA gegeben und für 5 min bei $95^{\circ} \mathrm{C}$ denaturiert.

\subsubsection{Hybridisierung der $\alpha-\left[{ }^{32} \mathrm{P}\right]-\mathrm{dCTP}-$ markierten Sonde}
Waschlösung 1
$2 \times-$ SSC mit $0,1 \%$ SDS
Waschlösung 2
$0,2 \times-\mathrm{SSC}$ mit $0,1 \%$ SDS

Die Hybridisierung wurde mit einer Full-length-Sonde des 66.3-kDa-Proteins bzw. einer GAPDH-Sonde durchgeführt. Die getrocknete Nitrocellulose-Membran (vgl. Kap. 2.2.2.3) wurde in ein Hybridisierungsröhrchen überführt und für 30 min bei $65{ }^{\circ} \mathrm{C}$ unter Rotation mit $5 \mathrm{ml}$ Rapid-Hyb-Puffer (GE Healthcare) inkubiert. Anschließend wurden $5 \mathrm{ml}$ Rapid-Hyb-Puffer ersetzt, der komplette Ansatz markierter und denaturierter DNA-Sonde (vgl. Kap. 2.2.2.4) in das 
Hybridisierungsröhrchen gegeben und ü.N. unter Rotation bei $65^{\circ} \mathrm{C}$ inkubiert. Die Membran wurde zweimal für $10 \mathrm{~min}$ bei RT mit Waschlösung 1, zweimal für $10 \mathrm{~min}$ bei RT mit Waschlösung 2 und zweimal für 10 min bei $65^{\circ} \mathrm{C}$ mit Waschlösung 2 gewaschen, in Folie eingeschweißt und ü.N. auf einem Bio-Imager-Screen exponiert.

Der Northern Blot konnte erneut verwendet werden. Dafür wurde $\mathrm{H}_{2} \mathrm{O}$ mit $0,1 \% \mathrm{SDS}$ in der Mikrowelle kurz aufgekocht und mit der Membran inkubiert, bis die Lösung RT hatte. Danach wurde der Northern Blot zweimal mit 2x-SSC gewaschen, in Folie eingeschweißt und ü.N. mit einem BioImager-Screen exponiert. War kein Signal zu detektieren, konnte die Membran mit einer anderen Sonde hybridisiert werden.

\subsection{Zellbiologische Methoden}

\subsubsection{Methoden zum Arbeiten mit eukaryoten Zellen}

\subsubsection{Kultivieren}

Alle in Tab. 2-2 aufgeführten Zelllinien wurden in wassergesättigter Atmosphäre unter $5 \% \mathrm{CO}_{2}$ bei $37^{\circ} \mathrm{C}$ kultiviert. Medien und Lösungen wurden, soweit nicht anders angegeben, auf $37^{\circ} \mathrm{C}$ vorgewärmt. Im Allgemeinen erfolgte die Kultivierung der Zellen mit folgendem Medium: DMEM + $10 \%$ FKS + $100 \mathrm{U} / \mathrm{ml}$ Penicillin G und $100 \mu \mathrm{g} / \mathrm{ml}$ Streptomycin. Medien für stabil transfizierte Zellen enthielten zusätzlich $600 \mu \mathrm{g} / \mathrm{ml}$ Hygromycin B.

\subsubsection{Passagieren}

Trypsin-EDTA-Lösung: $\quad$ 0,05\% (w/v) Trypsin und 0,02\% (w/v) EDTA in PBS

Zellen in Kultur wurden nach Erreichen der Konfluenz oder um die Zellen für Versuche in der gewünschten Dichte auszuplattieren passagiert. Dazu wurde das Zellkulturmedium entfernt und die Zellen einmal mit PBS gewaschen. Nach dem Absaugen des PBS wurden die Zellen etwa für 5 min mit Trypsin-EDTA-Lösung auf einer $37^{\circ} \mathrm{C}$-Wärmeplatte unter mikroskopischer Kontrolle bis zur Abrundung der Zellen inkubiert. Durch die Zugabe von Zellkulturmedium wurde die Trypsin-Reaktion gestoppt, die Zellen durch gründliches Pipettieren vereinzelt und die Zellzahl in der Neubauer-Zählkammer bestimmt. Die Zellen wurden in der gewünschten Dichte ausplattiert. 


\subsubsection{Kryokonservieren}

Einfriermedium:

$10 \%(\mathrm{v} / \mathrm{v})$ DMSO in Zellkulturmedium

Für die Kryokonservierung wurden Zellen trypsiniert, in Zellkulturmedium aufgenommen und für $5 \mathrm{~min}$ bei $1000 \mathrm{rpm}$ in der Labofuge zentrifugiert. Nach dem Absaugen des Zellkulturmediums wurden die Zellen in $4{ }^{\circ} \mathrm{C}$ kaltem Einfriermedium resuspendiert und jeweils $1 \mathrm{ml}$ in Einfrierröhrchen überführt. Die Zellen wurden für eine Woche bei $-80{ }^{\circ} \mathrm{C}$ im Gefrierschrank und anschließend in flüssigem Stickstoff gelagert.

\subsubsection{Revitalisieren}

Das Kryoröhrchen wurde aus dem flüssigen Stickstoff entnommen, für 1 min bei RT erwärmt und anschließend in $70 \%$ Ethanol bei $37^{\circ} \mathrm{C}$ inkubiert bis im Zellkulturmedium lediglich ein kleiner Eiskern zu sehen war. Die Zellsuspension wurde in $5 \mathrm{ml} 4{ }^{\circ} \mathrm{C}$ kaltem Zellkulturmedium aufgenommen und für 5 min bei $1000 \mathrm{rpm}$ in der Labofuge zentrifugiert. Der Überstand wurde abgenommen, da DMSO bei Kultivierungstemperatur zytotoxisch wirkt. Das Zellpellet wurde in $5 \mathrm{ml} 4{ }^{\circ} \mathrm{C}$ kaltem Zellkulturmedium ohne Selektionsantibiotikum resuspendiert. Am folgenden Tag wurde das Medium gewechselt und gegebenenfalls Antibiotikum zur Selektion beigefügt.

\subsubsection{Transfektion von eukaryoten Zellen}

\section{(Invitrogen Lipofectamine 2000 Transfection Reagent Users Manual 2006)}

Die Etablierung einer stabil transfizierten Zelllinie, die das 66.3-kDa-Protein überexprimiert, wurde nach der Anleitung des Transfektionsreagenzherstellers Invitrogen durchgeführt. $2 \times 10^{5}$ Zellen wurden in einer 35-mm-Platte ü.N. kultiviert. Es wurden $250 \mu 1$ serumfreies Zellkulturmedium mit $10 \mu \mathrm{l}$ Lipofectamine 2000 vermischt und für 5 min bei RT inkubiert. Parallel wurden $4 \mu \mathrm{g}$ DNA in $250 \mu \mathrm{l}$ Serum-freiem Zellkulturmedium aufgenommen und für 5 min bei RT inkubiert. Beide Ansätze wurden vereint und nach vorsichtigem Durchmischen für 20 min bei RT inkubiert. In der Inkubationsphase wurden die Zellen einmal mit PBS gewaschen und mit $2 \mathrm{ml}$ Zellkulturmedium überdeckt. Der DNA-Lipofectamine-2000-Komplex wurde tröpfchenweise auf das Medium gegeben und die Zellkulturplatte zur gleichmäßigen Durchmischung vorsichtig geschwenkt. Nach 24-stündiger Inkubation wurden die Zellen auf eine 14-cm-Platte überführt und nach weiteren $24 \mathrm{~h}$ mit dem Zusatz von $600 \mu \mathrm{g} / \mathrm{ml}$ Hygromycin (stabil exprimierende HT1080) unter Selektionsdruck gesetzt. Nach zehn Tagen wurden Einzelklonkolonien isoliert und von 24-well-Platten über T25-Flaschen bis in T75-Flaschen passagiert. 


\subsubsection{Gewinnung von Zellkulturmedium zur Proteinaufreinigung}

Das 66.3-kDa-Protein stabil exprimierende BHK21 und HT1080-Zellen wurden von einer konfluent bewachsenen T-75 Zellkulturflasche auf drei 14-cm-Platten aufgeteilt. Nach $24 \mathrm{~h}$ wurde das Zellkulturmedium vorsichtig abgenommen und mit $20 \mathrm{ml}$ Sammelmedium (DMEM mit $0,05 \%$ FKS und 1x-Penicillin/Streptomycin) aufgefüllt. Nach weiteren $48 \mathrm{~h}$ und danach max. dreimal im Intervall von $48 \mathrm{~h}$ wurden die Zellkulturüberstände abgenommen und mit $0,5 \mathrm{~g}$ $\left(\mathrm{NH}_{4}\right)_{2} \mathrm{SO}_{4} / \mathrm{ml}$ Zellkulturüberstand zur Proteinfällung versetzt. Überstände wurden bis zur Aufreinigung bei $4{ }^{\circ} \mathrm{C}$ gelagert.

\subsection{Histologische Methoden}

\subsubsection{Indirekte Immunfluoreszenz}

Die Immunfluoreszenz wurde mit MEF und Cathepsin-D-defizienten MEF durchgeführt. Um eine starke Adhärenz der Zellen auf den Deckgläschen zu erreichen, wurden sterile Deckgläschen in einer 24-Loch-Platte für $10 \mathrm{~min}$ mit einer $1 \%$ igen Gelatinelösung bei $37^{\circ} \mathrm{C}$ inkubiert. Die Gelatine wurde abgesaugt und die Zellen auf den vorbereiteten Deckgläschen ausplattiert.

\subsubsection{Methanol-Fixierung und Antikörperinkubation}

Nach dem gründlichen Waschen mit PBS wurden die Zellen für 5 min mit $-20^{\circ} \mathrm{C}$ kaltem Methanol bei $4{ }^{\circ} \mathrm{C}$ fixiert und permeabilisiert. Anschließend wurden die Zellen zweimal gründlich mit PBS gewaschen und bis zur weiteren Verwendung bei $4{ }^{\circ} \mathrm{C}$ in PBS aufbewahrt oder direkt mit dem 1. Antikörper inkubiert. Die Inkubation mit Antikörpern (vgl. Tab. 2-4) wurde in einer feuchten Kammer, die Waschschritte in der 24-Loch-Platte durchgeführt. Um einen frühzeitigen Intensitätsverlust der Fluoreszenzfarbstoffe $\mathrm{zu}$ verhindern wurden die Inkubationsschritte im Dunkeln durchgeführt. Nach dem Waschen mit $\mathrm{dH}_{2} \mathrm{O}$ wurden die Deckgläschen mit einem Tropfen Fluormount (Biacore) auf einem Objektträger eingebettet. Danach konnten die fixierten Zellen mit einem konfokalen Laser-Scan-Mikroskop ausgewertet werden. 
Tab. 2-4: Immunfluoreszenz

\begin{tabular}{|c|c|}
\hline Zeit (min) & Anwendung \\
\hline 15 & Blocken mit $1 \%$ BSA in PBS \\
\hline 60 & Inkubation mit Erstantikörper \\
\hline $3 \times 5$ & Waschen mit PBS \\
\hline 15 & Blocken mit Serum des Zweitantikörpers \\
\hline 60 & Inkubation mit Zweitantikörper \\
\hline $5 \times 5$ & Waschen mit PBS \\
\hline $3 \times 1$ & Mit $\mathrm{H}_{2} \mathrm{O}$ spülen \\
\hline
\end{tabular}

\subsection{Biochemische Methoden}

\subsubsection{Gewinnung von Zell- und Gewebehomogenaten}

Für Homogenate von Zellen aus der Zellkultur wurden trypsinierte Zellen zweimal mit PBS gewaschen und im gewünschten Puffer aufgenommen. Auf Eis wurden die Zellen durch $5 \times 20 \mathrm{sec}$ Ultraschall homogenisiert und für $5 \mathrm{~min}$ bei $1000 \mathrm{rpm}$ zentrifugiert. Es folgte eine Proteinbestimmung (s. Kap. 2.5.2). Für Homogenate aus murinen Organen wurden die frisch entnommenen Organe (vgl. Kap. 2.6.2) in zehnfachem Volumen TBS-Puffer (+ Proteaseinhibitoren $1 \mathrm{mM}$ EDTA, $1 \mathrm{mM}$ PMSF und $5 \mathrm{mM} \mathrm{JAA}$ ) aufgenommen und mit dem Dounce-Homogenisator homogenisiert. Anschließend wurden Membranbestandteile für $30 \mathrm{~min}$ bei $4{ }^{\circ} \mathrm{C}$ und $12000 \mathrm{rpm}$ abzentrifugiert und eine Proteinbestimmung durchgeführt (vgl. Kap. 2.5.2).

\subsubsection{Proteinbestimmung mit dem BioRad-DC-Protein-Assay}

(Lowry et al. 1951; Peterson 1979)

Reagenz A Alkalische Kupfer-Tartrat-Lösung

Reagenz B Folin-Reagenz

Reagenz S Die Zusammensetzung wird vom Hersteller nicht bekannt gegeben.

Reagenz A` $\quad 1 \mathrm{ml}$ Reagenz A und $20 \mu \mathrm{l}$ Reagenz S (immer frisch angesetzt)

Bei der Proteinbestimmungsmethode der Firma BioRad werden Detergenzien, wie Triton-X 100, SDS und Tween-20 in bis $\mathrm{zu}$ einprozentiger Konzentration toleriert. Die Proteinbestimmung fand im Mikromaßstab und durch Erhebung von Doppelwerten in unbeschichteten 96-Loch-Platten statt. Zur Erstellung einer Eichgraden wurden 0-, 2-, 4-, 8-, $12-$ 
und $16 \mu 1$ einer $0,5 \mathrm{mg} / \mathrm{ml}$ BSA-Standardlösung in die 96-Loch-Platte pipettiert (Doppelwerte) und mit $\mathrm{ddH}_{2} \mathrm{O}$ auf $100 \mu \mathrm{l}$ aufgefüllt. Die zu bestimmenden Proben wurden je nach Bedarf verdünnt. Für die Probenwerte wurden jeweils $10 \mu 1$ der verdünnten Probe pro Loch eingesetzt und auf $100 \mu \mathrm{l}$ mit ddH $\mathrm{H}_{2} \mathrm{O}$ aufgefüllt. Anschließend wurden zu allen Proben $25 \mu 1$ Reagenz A' und $200 \mu 1$ Reagenz B pipettiert. Nach Inkubation für 15 min bei RT wurde die Absorption im Microplate-Reader (Tecan) bei einer Wellenlänge von $690 \mathrm{~nm}$ gemessen und der Proteingehalt über die Eichgerade bestimmt.

\subsubsection{SDS-Polyacrylamid-Gelelektrophorese}

(Laemmli 1970)

Anodenpuffer

Kathodenpuffer

2x-Probenpuffer

(wahlweise reduzierend)

Trenngelpuffer

Sammelgelpuffer

Acrylamidlösung

Ammoniumperoxid-

sulfatlösung (APS)
$50 \mathrm{mM}$ Tris pH 8,6 und $380 \mathrm{mM}$ Glycin in $\mathrm{dH}_{2} \mathrm{O}$

$0,1 \%(\mathrm{w} / \mathrm{v})$ SDS und 0,001\%(w/v) Bromphenolblau in

Anodenpuffer

$100 \mathrm{mM}$ Tris $\mathrm{pH}$ 6,8; 4 \% (w/v) SDS, $20 \%$ (v/v) Glycerin, und wahlweise $2 \% \beta$-Mercaptoethanol in $\mathrm{dH}_{2} \mathrm{O}$

1,5 M Tris pH 8,8 und $0,4 \%(\mathrm{w} / \mathrm{v})$ SDS

$0,5 \mathrm{M}$ Tris $\mathrm{pH} 6,8$ und $0,4 \%(\mathrm{w} / \mathrm{v})$ SDS

$30 \%(\mathrm{w} / \mathrm{v})$ Acrylamid und 0,8 \% (w/v) Bisacrylamid in $\mathrm{dH}_{2} \mathrm{O}$

$10 \%(\mathrm{w} / \mathrm{v})$ Ammoniumperoxidsulfat in $\mathrm{dH}_{2} \mathrm{O}$

Tab. 2-5: Zusammensetzung von Trenngel und Sammelgel bei SDS-PAGE

\begin{tabular}{llll|c}
\hline & \multicolumn{3}{c}{ Trenngel } & Sammelgel \\
\hline \hline Acrylamid-Konz. & $\mathbf{1 0} \%$ & $\mathbf{1 2 , 5} \%$ & $\mathbf{1 5 \%}$ & $\mathbf{4} \%$ \\
\hline \hline Acrylamid-Lösung $(\mathbf{m l})$ & 10,5 & 13,1 & 17,75 & 1,3 \\
Trenngelpuffer $(\mathbf{m l})$ & 7,5 & 7,5 & 7,5 & - \\
Sammelgelpuffer $(\mathbf{m l})$ & - & - & - & 2,5 \\
APS $(\boldsymbol{\mu l})$ & 250 & 250 & 250 & 100 \\
TEMED $(\boldsymbol{\mu l})$ & 25 & 25 & 25 & 10 \\
ddH2O & Ad $30 \mathrm{ml}$ & Ad $30 \mathrm{ml}$ & Ad $30 \mathrm{ml}$ & Ad $10 \mathrm{ml}$ \\
\hline
\end{tabular}

Die elektrophoretische Trennung von Proteingemischen erfolgte mittels diskontinuierlicher SDS-Polyacrylamid-Gelelektrophorese (SDS-PAGE) in einer Apparatur aus vertikal ausgerichteten Glasplatten $(16 \mathrm{~cm} \times 18 \mathrm{~cm})$. Das Trenngel wurde zwischen die Glasplatten 
gegossen und gegen die Austrocknung mit Isopropanol überschichtet. Nach der Polymerisation für ca. 30 min bei RT wurde das Isopropanol entfernt, die Oberfläche des Trenngels mit $\mathrm{H}_{2} \mathrm{O}$ gespült, das Sammelgel eingegossen und der Probenkamm eingefügt. Nach der Polymerisation für ca. 30 min bei RT wurde das Gel in einer feuchten Kammer bis zur Verwendung für max. vier Tage bei $4{ }^{\circ} \mathrm{C}$ gelagert. Vor Gebrauch wurde der Probenkamm entfernt und die Probentaschen mit $\mathrm{H}_{2} \mathrm{O}$ gespült. Gelreste wurden aus den Taschen entfernt. Die Proben wurden mit $2 \times$-Probenpuffer $1: 1$ verdünnt, für $5 \mathrm{~min}$ bei $95^{\circ} \mathrm{C}$ denaturiert und die Probe für $30 \mathrm{sec}$ bei 14000 rpm abzentrifugiert. Die Probe wurde mit einer Mikroliterpipette in die Taschen unter den Kathodenpuffer geschichtet. Die Elektrophorese erfolgte bei $25 \mathrm{~mA}$, bis die Proben in das Trenngel eingelaufen waren, und anschließend bei $50 \mathrm{~mA}$.

\subsubsection{Silberfärbung}

(Heukeshoven und Dernick 1988)

Fixierlösung 1: $\quad 30 \%(\mathrm{v} / \mathrm{v})$ Ethanol und $10 \%(\mathrm{v} / \mathrm{v})$ Essigsäure in $\mathrm{ddH}_{2} \mathrm{O}$

Fixierlösung 2: $\quad 0,5 \mathrm{M} \mathrm{NaAc}, 30 \%(\mathrm{v} / \mathrm{v})$ Ethanol, $0,5 \%$ Glutaraldehyd und 0,2\% $\mathrm{Na}_{2} \mathrm{~S}_{2} \mathrm{O}_{3} \times 5 \mathrm{H}_{2} \mathrm{O}$ in $\mathrm{ddH}_{2} \mathrm{O}$

Silberfärbelösung: $\quad 0,1 \%(\mathrm{w} / \mathrm{v}) \mathrm{AgNO}_{3}$ und $0,02 \%(\mathrm{v} / \mathrm{v})$ Formaldehyd in $\mathrm{ddH}_{2} \mathrm{O}$

Entwicklungslösung: $\quad 2,5 \%(\mathrm{w} / \mathrm{v}) \mathrm{Na}_{2} \mathrm{CO}_{3}$ und $0,01 \%(\mathrm{v} / \mathrm{v})$ Formaldehyd in $\mathrm{ddH}_{2} \mathrm{O}$

Stopplösung: $\quad 0,05 \mathrm{M}$ Glycin in $\mathrm{ddH}_{2} \mathrm{O}$

Alle Lösungen wurden frisch angesetzt. Alle Inkubationsschritte wurden bei leichtem Schütteln durchgeführt.

Nach dem Auftrennen der Proteine durch SDS-PAGE wurde das Gel in $250 \mathrm{ml}$ Fixierlösung 1 für 1,5 h bei RT fixiert und anschließend in $250 \mathrm{ml}$ Fixierlösung 2 für $2 \mathrm{~h}$ bei RT oder ü.N. bei $4{ }^{\circ} \mathrm{C}$ inkubiert. Anschließend wurde das Gel dreimal für $20 \mathrm{~min}$ in $\mathrm{ddH}_{2} \mathrm{O}$ gewaschen und in $125 \mathrm{ml}$ Silberfärbelösung für $1 \mathrm{~h}$ bei RT inkubiert und im Anschluss für $2 \mathrm{~min}$ in $\mathrm{ddH}_{2} \mathrm{O}$ gewaschen.

Unter leichtem Schwenken wurde das Gel zweimal mit $125 \mathrm{ml}$ und nach leichter Braunfärbung (nach ca. $1 \mathrm{~min}$ ) mit weiteren $125 \mathrm{ml}$ Entwicklungslösung für 1-4 min entwickelt bis die gewünschte Intensität der Färbung erreicht war. Das Abstoppen der Entwicklungsreaktion erfolgte durch Zugabe von $125 \mathrm{ml}$ Stopplösung. Nach dreimaligem Waschen mit $\mathrm{ddH}_{2} \mathrm{O}$ konnte das Gel fotografiert und getrocknet werden. 


\subsubsection{Färbung nach Coomassie}

(Neuhoff et al. 1988)

Coomassie-Stammlösung $\quad 0,1 \%(\mathrm{w} / \mathrm{v})$ Coomassie-Brilliant-Blue G250, $2 \%$ (w/v)

Orthophosphorsäure und $10 \%$ Ammoniumsulfat in $\mathrm{ddH}_{2} \mathrm{O}$

Coomassie-Färbelösung $\quad 80 \%$ Coomassie-Stammlösung und $20 \%$ Methanol

Fixierlösung $\quad 40 \%$ Ethanol und $10 \%$ Essigsäure in $\mathrm{ddH}_{2} \mathrm{O}$

Entfärber-Lösung $\quad 1 \%$ Essigsäure in $\mathrm{ddH}_{2} \mathrm{O}$

Das SDS-Gel wurde direkt nach der Elektrophorese für $1 \mathrm{~h}$ bei RT auf einer Wippe in der Fixierlösung inkubiert und anschließend für 10 min gewässert. Danach erfolgte ü.N. bei RT die Färbung mit frisch angesetzter Coomassie-Färbelösung. Das gefärbte Gel wurde abschließend mit der Entfärberlösung bis zur gewünschten Farbintensität entfärbt. Das Gel konnte nach erneuter Wässerung entweder getrocknet oder aber eingeschweißt und der Massenanalytik zugeführt werden.

\subsubsection{Western Blot (Semi-Dry) und Immundetektion}

Anodenpuffer $\quad 75 \mathrm{mM}$ Tris/ $\mathrm{HCl} \mathrm{pH} \mathrm{7,4} \mathrm{und} 20 \%$ Methanol

Blotto $\quad 5 \%$ Milchpulver in PBST

Kathodenpuffer $\quad 40 \mathrm{mM}$ \&-Aminocapronsäure, $20 \mathrm{mM}$ Tris/ HCl, pH 9,0 und $20 \%(\mathrm{v} / \mathrm{v})$ Methanol

PBST $\quad 10 \mathrm{mM}$ PBS und $0,1 \%$ Tween 20 in $\mathrm{ddH}_{2} \mathrm{O}$

Nach Durchführung der SDS-PAGE (vgl. Kap. 2.5.3) wurden das Trenngel und eine PVDFMembran (letztere nach einminütiger Aktivierung in Methanol) für $10 \mathrm{~min}$ in Kathodenpuffer äquilibriert. Drei Whatman-Filterpapiere $(3 \mathrm{~mm})$ wurden in Kathodenpuffer und drei weitere Whatman-Filterpapiere (3 mm) in Anodenpuffer getränkt. Der Transfer des im Gel gebundenen Proteins auf die PVDF-Membran erfolgte im Semi-Dry-Blot-Verfahren bei $1 \mathrm{~mA} / \mathrm{cm}^{2}$ für $70 \mathrm{~min}$ bei RT in der dafür vorgesehenen Western-Blot-Apparatur (für Aufbau vgl. Abb. 2-2). 


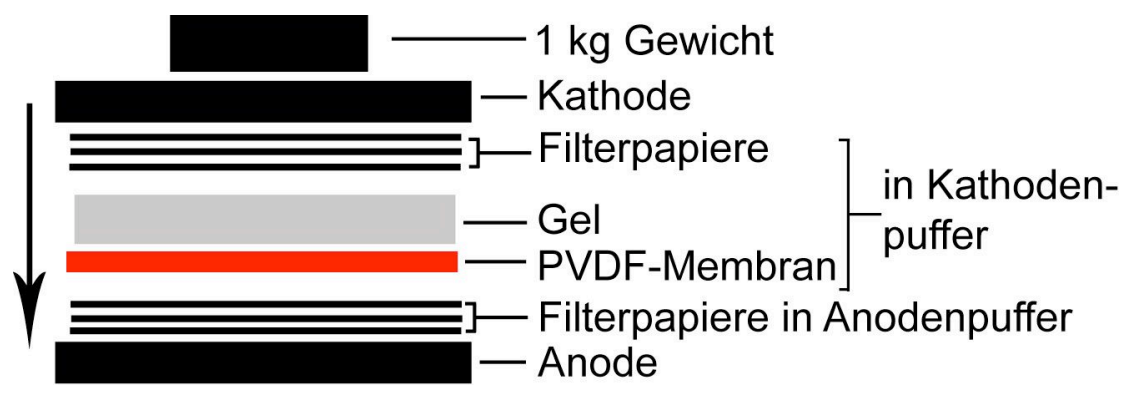

\section{Abb. 2-2: $\quad$ Aufbau Western Blot}

Die Abbildung zeigt den Aufbau des Western Blots für die Semi-Dry-Transfer Methode. Wichtig ist die luftblasenfreie Schichtung der einzelnen Bestandteile zwischen den Elektroden.

Die Immundetektion von Proteinen wurde über Primärantikörper (vgl. Tab. 2-1) und passende Sekundärantikörper (vgl. Kap. 2.1.9.2) über die Detektion eines Chemolumineszenzsignals vorgenommen. Bis auf den $\alpha$-His-Antikörper, der mit einer 3 \%igen Lösung von BSA in PBST bessere Ergebnisse erzielte, wurden alle anderen Antikörper mit Blotto verdünnt und die PVDFMembran nach folgendem Schema inkubiert:
Blocken
$2 \mathrm{~h}$ bei RT in Blotto
Inkubation Primärantikörper
ü.N. bei $4{ }^{\circ} \mathrm{C}$ in Blotto
Waschen
$6 \times 10$ min bei RT in PBST
Inkubation Sekundärantikörper
1,5 h bei RT in Blotto
Waschen
$6 \times 10$ min bei RT in PBST.

Die Membran wurde mit einer 1:1 Mischung der beiden Lösungen des SupersignalDetection-Systems (Pierce) unter leichtem Schwenken für 5 min inkubiert. Das Chemolumineszenzsignal wurde mit der CCD-Kamera detektiert und als elektronisches Bild gespeichert. Die Expositionszeiten variierten zwischen $10 \mathrm{sec}$ und $10 \mathrm{~min}$ und richteten sich nach der Stärke des Signals.

\subsubsection{Freiwaschen einer PVDF-Membran}

Um eine PVDF-Membran mehrmals für die Immundetektion mit verschiedenen Antikörpern benutzen zu können, wurde die Membran durch Freiwaschen mit 0,2 M NaOH-Lösung von gebundenen Antikörpern befreit. Dazu wurde die Membran unter gleichmäßiger Bewegung auf dem Wipptisch für 5 min in $\mathrm{dH}_{2} \mathrm{O}$ gewässert, für zweimal 5 min mit 0,2 $\mathrm{M} \mathrm{NaOH}$ freigewaschen (Auflösung der Antigen-Antikörperbindung) und anschließend fünfmal für 5 min in $\mathrm{dH}_{2} \mathrm{O}$ gewässert. Nach dem Freiwaschen konnte die Membran einer weiteren Immundetektion zugeführt werden (vgl. Kap. 2.5.6). 


\subsubsection{Färbung einer PVDF-Membran für die N-terminale Sequenzierung}

(Weber und Osborn 1969)

Coomassie-Lösung $\quad 0,5 \%(\mathrm{w} / \mathrm{v})$ Coomassie-Blau-R, $50 \%(\mathrm{v} / \mathrm{v})$ Methanol und $10 \%$ (v/v) Essigsäure in $\mathrm{ddH}_{2} \mathrm{O}$

Entfärber-Lösung $\quad 50 \%$ Methanol und $10 \%$ Essigsäure in $\mathrm{ddH}_{2} \mathrm{O}$

Die PVDF-Membran wurde ü.N. bei RT (oder $2 \mathrm{~h}$ bei $37^{\circ} \mathrm{C}$ ) auf einer Wippe in CoomassieLösung gefärbt und in der Entfärber-Lösung ü.N. wieder entfärbt. Die Entfärber-Lösung wurde mehrmals gewechselt. Das Gel wurde anschließend zweimal für 15 min gewässert und getrocknet.

\subsubsection{Ni-NTA-Aufreinigung des 66.3-kDa-Proteins aus Zellkulturüberstand}

(The QIAexpressionist - Handbook for high-level expression and purification of 6xHis-tagged proteins 2003)

$\begin{array}{ll}\text { Waschpuffer 1 (W1) } & 50 \mathrm{mM} \mathrm{NaH}_{2} \mathrm{PO}_{4}, \mathrm{pH} 8,0 ; 300 \mathrm{mM} \mathrm{NaCl} \\ \text { Waschpuffer 2(W2) } & \mathrm{W} 1+10 \mathrm{mM} \text { Imidazol } \\ \text { Elutionspuffer 1 (E1) } & \mathrm{W} 1+100 \mathrm{mM} \text { Imidazol } \\ \text { Elutionspuffer 2(E2) } & \mathrm{W} 1+250 \mathrm{mM} \text { Imidazol }\end{array}$

Um Proteindegeneration vorzubeugen wurde die Umgebungstemperatur, sowie die Temperatur der Träger- und Dialyseflüssigkeiten und Zentrifugen für die gesamte Aufreinigungsdauer auf $4{ }^{\circ} \mathrm{C}$ eingestellt. Die Proteinaufreinigung wurde mit fünf Litern des mit $\left(\mathrm{NH}_{4}\right)_{2} \mathrm{SO}_{4}$ versetzten Zellkulturmediums durchgeführt (vgl. Kap. 2.3.3).

Zuerst wurde das gefällte Protein für $30 \mathrm{~min}$ bei $10000 \mathrm{rpm}$ im JA10-Rotor gesammelt und in $50 \mathrm{ml}$ PBS resuspendiert. Unter kontinuierlichem Rühren erfolgte eine Dialyse gegen 51 PBS im Dialyseschlauch (Biomol), wobei der Dialysepuffer dreimalig ausgewechselt wurde. Das Dialysat wurde für $15 \mathrm{~min}$ bei $5000 \mathrm{rpm}$ in der Kühltischzentrifuge zentrifugiert, um ausgefallenes Protein abzutrennen. Danach wurden dem Überstand 0,5 ml Ni-NTA pro gesammeltem Liter Zellkulturmedium zugegeben und zur Bindung des Proteins an das Säulenmaterial die Suspension ü.N. auf dem Drehrad inkubiert. Die Suspension wurde für 5 min bei $400 \times \mathrm{g}$ zentrifugiert. Der Überstand wurde verworfen und das Ni-NTA-Pellet wurde in W1 resuspendiert. Dieser Waschvorgang wurde bis zu einer $\mathrm{OD}_{280}=0$ wiederholt. Dann wurde die Suspension auf eine 10-ml-MoBiTec-Säule (35 $\mu \mathrm{m}$ Porengröße) gegeben, der Überstand abgelassen, verworfen und das Säulenmaterial mit W2 bis zur $\mathrm{OD}_{280}=0$ gewaschen. Danach wurde, um das Protein vom Säulenmaterial zu lösen, dreimal mit $1 \mathrm{ml} \mathrm{E1} \mathrm{und} \mathrm{danach} \mathrm{dreimal}$ 
mit $1 \mathrm{ml}$ E2 eluiert. Die Eluate wurden ü.N. im Dialyseschlauch gegen den gewünschten Puffer (10 mM Tris, pH 8,0 oder 10 mM Hepes, pH 8,0) dialysiert. Für die Analyse in Western Blot und die Darstellung im Silbergel wurden $0,1 \%$ des Eluates entnommen. Das Ni-NTAaufgereinigte Protein wurde zur weiteren Aufreinigung auf die HPLC-Anlage aufgetragen.

\subsubsection{HPLC-Aufreinigung}

Puffer A $\quad 10 \mathrm{mM}$ Hepes $\mathrm{pH} 8,0$

Puffer B $\quad 10 \mathrm{mM}$ Hepes und $1 \mathrm{M} \mathrm{NaCl}, \mathrm{pH} 8,0$

Die HPLC-Aufreinigung des 66.3-kDa-Proteins fand an der Vision-Workstation (Applied Biosystems) statt. Das Ni-NTA-aufgereinigte Protein wurde in einem Volumen von ca. 8-9 ml gegen Puffer A (Auftragspuffer für Anionenaustauscher) dialysiert. Es folgte eine Anionenaustauscherchromatographie an der Poros-HQ-Matrix mit einem Stufengradienten (vgl. Tab. 2-6). Da maximal $4 \mathrm{ml}$ Proteinlösung auf die Säule geladen werden konnten, wurden sukzessive bis zu drei Läufe vorgenommen. Die einzelnen Fraktionen der Aufreinigungen wurden gepoolt und $1 \%$ jeder Fraktion wurden zur Analyse in Silbergel und Western Blot ( $\alpha$-His-Antikörper) eingesetzt. Fraktionen, die das entsprechende Protein enthielten, wurden lyophilisiert, in PBS im entsprechenden Volumen aufgenommen, gegen PBS dialysiert und bei $20^{\circ} \mathrm{C}$ bis zur Verwendung gelagert. Die Aufreinigung konnte wahlweise auch in einem PufferSystem mit $10 \mathrm{mM}$ Tris, $\mathrm{pH}$ 8,0 durchgeführt werden.

Tab. 2-6: Laufbedingungen der HPLC-Aufreinigung des 66.3-kDa-Proteins

\begin{tabular}{lccc}
\hline \hline Methode & Säulenvolumen & Puffer A & Puffer B \\
\hline \hline Injektion der Probe & Max. $4 \mathrm{ml}$ & in Puffer A & \\
Konstante Stufe & 2 & $100 \%$ & $0 \%$ \\
Linearer Gradient & 5 & $85 \%$ & $15 \%$ \\
Konstante Stufe & 3 & $85 \%$ & $15 \%$ \\
Linearer Gradient & 5 & $70 \%$ & $30 \%$ \\
Konstante Stufe & 3 & $70 \%$ & $30 \%$ \\
Linearer Gradient & 5 & $50 \%$ & $50 \%$ \\
Konstante Stufe & 3 & $50 \%$ & $50 \%$ \\
Linearer Gradient & 5 & $0 \%$ & $100 \%$ \\
Konstante Stufe & 4 & $0 \%$ & $100 \%$
\end{tabular}

Die Aufreinigung fand bei konstanter Flussgeschwindigkeit von $5 \mathrm{ml} / \mathrm{min}$ statt. Das Säulenvolumen betrug 1,662 ml. Puffer $A=10 \mathrm{mM}$ Hepes (pH 8,0), Puffer $B=10 \mathrm{mM}$ Hepes ( $p H$ 8,0), $1 \mathrm{M} \mathrm{NaCL}$. 


\subsubsection{Herstellung eines polyklonalen Antiserums gegen das 66.3-kDa-Protein}

Das aufgereinigte Protein (vgl. Kap. 2.5.10) wurde ü.N. gegen PBS dialysiert und 1:1 in Stimune-Adjuvans (Cedi Diagnostics) aufgenommen und in vier Immunisierungsschritten (vgl. Tab. 2-7) einem Kaninchen injiziert. Vor der ersten Immunisierung wurde dem Kaninchen zur Gewinnung von Präimmunserum 6,5 ml Blut abgenommen, um den Immunstatus vor Immunisierung festzustellen. Zwischen den Immunisierungen wurden Blutentnahmen vorgenommen, um die Immunisierungswirkung zu überprüfen (Titerbestimmung). Am Tag 104 nach der ersten Immunisierung fand die Ausblutung des Kaninchens statt. Das Blut wurde ü.N. bei $4{ }^{\circ} \mathrm{C}$ gelagert. Danach wurden in der Tischkühlzentrifuge bei $5000 \times \mathrm{g}$ die zellulären Blutbestandteile vom Serum getrennt. Das gewonnene Antiserum wurde aliquotiert und zur weiteren Verwendung bei $-20^{\circ} \mathrm{C}$ gelagert. Das Serum konnte für die Western-Blot-Analyse, die Immunfluoreszenz und die Immunpräzipitation verwendet werden (vgl. Tab. 3-1). Die einzelnen Immunisierungen, die Abnahme von Serum und das Ausbluten wurde von Mitarbeitern der „Zentrale Tierexperimentele Einrichtung“ der Georg-August Universität Göttingen durchgeführt.

\section{Tab. 2-7: Immunisierungsprotokoll}

\begin{tabular}{|c|c|}
\hline Tag & Behandlung \\
\hline 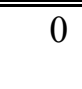 & $\begin{array}{l}\text { Blutentnahme von } 6,5 \mathrm{ml} \text { (Gewinnung des Präimmunserums) } \\
\text { Injektion von } 0,3 \mathrm{ml} \text { Immunisierungslösung ( } 300 \mu \mathrm{g} \text { Protein) }\end{array}$ \\
\hline 28 & Injektion von $0,3 \mathrm{ml}$ Immunisierungslösung ( $150 \mu \mathrm{g}$ Protein) \\
\hline 42 & Blutentnahme von $6,5 \mathrm{ml}$ \\
\hline 56 & Injektion von $0,1 \mathrm{ml}$ Immunisierungslösung (150 $\mu \mathrm{g}$ Protein) \\
\hline 68 & Blutentnahme von $7,5 \mathrm{ml}$ \\
\hline 83 & Injektion von $0,1 \mathrm{ml}$ Immunisierungslösung (150 $\mu \mathrm{g}$ Protein) \\
\hline 95 & Blutentnahme von $7,5 \mathrm{ml}$ \\
\hline 104 & Ausblutung ergab ca. $80 \mathrm{ml}$ Blut \\
\hline
\end{tabular}

\subsubsection{Edman-Abbau}

Die bei der HPLC-Aufreinigung aufgereinigten Proteinfragmente des 66.3-kDa-Proteins wurden über SDS-PAGE aufgetrennt, auf eine PVDF-Membran übertragen und mit CoomassieBlau (vgl. Kap. 2.5.5) angefärbt. Proteinbanden wurden ausgeschnitten und der automatischen N-terminalen Sequenzierung im Procise cLC sequenator (Applied Biosystems) zugeführt. Die Edman-Analyse wurde nach Abgabe der vorbereiten Membran von Dr. Bernhard Schmidt und Klaus Neifert der Abteilung Biochemie II durchgeführt. 


\subsubsection{Massenspektrometrie}

Massenanalytische Identifizierung von Proteinen und Proteinfragmenten wurde nach Abgabe der vorbereiteten Proben (gefärbte Coomassiegele) von Dr. Bernhard Schmidt und Nicole Eiselt der Abteilung Biochemie II am MALDI-TOF/TOF-MS (Reflex I/III, Bruker Daltonik) der Proteomics-Gruppe des MPI für Experimentelle Medizin Göttingen durchgeführt.

Der bei o.g. Versuchen benutzte Mascot-Score errechnet sich aus $-10 \times \log (\mathrm{P})$, wobei P der Wahrscheinlichkeit entspricht, dass die analysierte Übereinstimmung zwischen detektierten Massen und den Massen aus der Datenbank ein zufälliges Ergebnis ist (die Berechnung erfolgt nach einem von der Firma nicht näher definierten Algorithmus).

\subsubsection{TCA-Fällung von Protein}

Die Fällung von Protein aus Proteinlösungen wurde mittels TCA vorgenommen. Mit $100 \%$ TCA wurde eine Probe auf eine TCA-Endkonzentration von $10 \%$ gebracht, gründlich vermischt und das Protein ü.N. bei $4{ }^{\circ} \mathrm{C}$ gefällt. Anschließend wurde das gefällte Protein für $15 \mathrm{~min}$ bei $14000 \mathrm{rpm}$ in der Tischzentrifuge pelletiert und der Überstand abgenommen. Das Pellet wurde mit $400 \mathrm{ml}-20{ }^{\circ} \mathrm{C}$ kaltem, $100 \%$ igem Ethanol überdeckt und erneut für 10 min bei $14000 \mathrm{rpm}$ zentrifugiert. Der Überstand wurde verworfen und das Pellet für $30 \mathrm{~min}$ bei $37^{\circ} \mathrm{C}$ und mit offenem Deckel getrocknet.

\subsubsection{Reinigung von Pansorbin}

(Lemansky et al. 1985)

NET-Puffer

NET/BSA-Puffer

Lagerungspuffer
$50 \mathrm{mM}$ Tris/ $\mathrm{HCl} \mathrm{pH} 7,4 ; 150 \mathrm{mM} \mathrm{NaCl}$ und $5 \mathrm{mM}$ EDTA in $\mathrm{dH}_{2} \mathrm{O}$

NET-Puffer, $5 \mathrm{mg} / \mathrm{ml}$ BSA und 0,5\% TX-100

$10 \mathrm{mg} / \mathrm{ml} \mathrm{BSA}$ und $0,04 \% \mathrm{NaN}_{3}$ in PBS

Eppendorfgefäße wurden abgewogen, mit $1 \mathrm{ml}$ ungewaschenem Pansorbin gefüllt und für 2 min bei $12000 \mathrm{rpm}$ in der Tischzentrifuge zentrifugiert. Der Überstand wurde verworfen, das Pellet in je $1 \mathrm{ml}$ NET-Puffer resuspendiert und die Proben für $30 \mathrm{~min}$ bei $85^{\circ} \mathrm{C}$ inkubiert. Anschließend wurde für 2 min bei $12000 \mathrm{rpm}$ zentrifugiert, der Überstand verworfen, das Pellet in $1 \mathrm{ml} \mathrm{NET-Puffer} \mathrm{mit} 1 \%(\mathrm{w} / \mathrm{v}) \mathrm{SDS}$ resuspendiert und für $5 \mathrm{~min}$ bei $95^{\circ} \mathrm{C}$ inkubiert. Die Pellets wurden dreimal mit $1 \mathrm{ml}$ NET/BSA-Puffer und zweimal mit PBS gewaschen. Danach wurden die Pellets gewogen, mit Lagerungspuffer auf eine Pansorbin-Konzentration von $100 \mathrm{mg} / \mathrm{ml}$ eingestellt und bis zur weiteren Verwendung bei $4{ }^{\circ} \mathrm{C}$ gelagert. 


\subsubsection{Metabolische Markierung von Proteinen mit $\left[{ }^{35} \mathrm{~S}\right]-M e t h i o n i n / C y s t e i n$}
Hungermedium
$1 \%$ Glutamin und $5 \%$ hitzeinaktiviertes sowie dialysiertes FKS in DMEM (ohne Methionin und Cystein)
Markierungsmedium
Hungermedium und $100 \mu \mathrm{Ci} / \mathrm{ml}\left[{ }^{35} \mathrm{~S}\right]$-Methionin/Cystein
Lysispuffer
$1 \times$ TBS mit 0,1 \% TX-100, 1 mM EDTA, 1 mM PMSF und $5 \mathrm{mM}$
JAA (Proteaseinhibitoren)

Am Vortag der metabolischen Markierung wurden die zu markierenden Zellen in 3-10 cm großen Zellkulturschalen ausplattiert. Nach 12 h waren die Zellen zu 80 \% konfluent. Die Zellen wurden mit PBS gewaschen und für eine Stunde mit Hungermedium inkubiert. Danach erfolgte die halb- bis einstündige Inkubation der Zellen mit Markierungsmedium (im Weiteren mit dem engl. Fachterminus Pulse bezeichnet), bei der die Inkorporation der radioaktiv markierten Aminosäuren stattfand. Anschließend wurde das Medium durch normales Zellkulturmedium ersetzt. Die Inkubationszeit vom Ende der Markierung bis zur Gewinnung der Zell- und Mediumproben (im Weiteren mit dem engl. Fachterminus Chase bezeichnet) variierte von 0-72 h. Nach Abschluss der Chase-Zeit wurde das Medium abgenommen und für 5 min mit $1000 \times \mathrm{g}$ zentrifugiert, um Zellen und Zelltrümmer zu entfernen. Der Überstand wurde in ein neues Gefäß überführt, das Pellet verworfen. Die Zellen wurden in der Zellkulturschale zweimal mit $4{ }^{\circ} \mathrm{C}$-kaltem TBS gewaschen, mit einem Zellschaber vom Untergrund gelöst, in zweimal $200 \mu 14{ }^{\circ} \mathrm{C}$-kaltem Lysispuffer aufgenommen und entweder sofort in der Immunpräzipitation weiter benutzt oder bei $-20^{\circ} \mathrm{C}$ gelagert.

\subsubsection{Immunpräzipitation des metabolisch markierten 66.3-kDa-Proteins}

Protaminsulfat

Immunomix (IMM)

Präzipitationsimmunomix (PIMM)

Neufeldpuffer
$3 \%(w / v)$ in $\mathrm{ddH}_{2} \mathrm{O}$ gelöst

$0,5 \%$ Natriumdesoxycholat und $1 \%$ TX-100 in PBS

$0,2 \%$ SDS und $10 \%$ BSA in IMM mit $1 \mathrm{mM}$ EDTA, $1 \mathrm{mM}$ PMSF und 5 mM JAA

$10 \mathrm{mM}$ Tris/ $\mathrm{HCl} \mathrm{pH} 8,5,0,6 \mathrm{M} \mathrm{NaCl}, 0,1 \%$ SDS und $0,05 \%$

Nonidet P-40

Zellen und Zellkulturmedium wurden nach der metabolischen Markierung (vgl. Kap. 2.5.16) auf Eis gelagert. Die Zellen wurden für $3 \times 20 \mathrm{sec}$ bei $4{ }^{\circ} \mathrm{C}$ durch Ultraschall homogenisiert. Den Medien und Zellhomogenaten wurden 0,8 Volumen PIMM zugesetzt. Um die genomische DNA aus den Proben zu entfernen, wurde die Lösung auf 0,03\% Protaminsulfat eingestellt und für $15 \mathrm{~min}$ auf Eis inkubiert. Die ausgefallene DNA wurde für $10 \mathrm{~min}$ bei $4{ }^{\circ} \mathrm{C}$ und $12000 \times \mathrm{g}$ 
abzentrifugiert und der Überstand in ein neues 15-ml-Falcon-Gefäße überführt. Dann wurden jeweils $20 \mu \mathrm{l}$ Präimmunserum des 66-Antiserums und $60 \mu \mathrm{l}$ ungewaschenes Pansorbin zugegeben und für $6 \mathrm{~h}$ bei $4{ }^{\circ} \mathrm{C}$ auf dem Drehrad inkubiert. Durch eine Zentrifugation für 15 min bei $4{ }^{\circ} \mathrm{C}$ und $100000 \times \mathrm{g}$ (TLA 45) wurden unspezifisch an das Serum und das Pansorbin bindende Proteine aus der Lösung entfernt. Der Überstand wurde in ein neues 15-ml-FalconGefäße überführt und der Lösung $10 \mu \mathrm{l}$ des Antiserums zugesetzt. Die Bildung der AntigenAntikörperkomplexe erfolgte ü.N. bei $4{ }^{\circ} \mathrm{C}$ auf dem Drehrad. Am nächsten Morgen wurden $60 \mu \mathrm{l}$ gewaschenes Pansorbin hinzugefügt, für $2 \mathrm{~h}$ bei $4{ }^{\circ} \mathrm{C}$ auf dem Drehrad inkubiert und anschließend bei $12000 \times \mathrm{g}$ zentrifugiert. Der Waschvorgang bestand aus vier sukzessiven Waschschritten mit je $800 \mu 14^{\circ} \mathrm{C}$ kaltem Neufeldpuffer, Immunomix, $2 \mathrm{M} \mathrm{KCl}+$ Immunomix und 1x-PBS. Bei jedem Waschdurchgang wurde das Pellet durch sorgfältiges Resuspendieren gewaschen, das Pansorbin mit den gebundenen Antikörper-Antigenkomplexen für 1 min bei $12000 \times \mathrm{g}$ abzentrifugiert und der Überstand verworfen. Nach dem letzten Waschdurchgang wurde das Pellet in $75 \mu 1$ 1,5×-SDS-Ladepuffer (reduzierend) aufgenommen und die Lösung für 8 min auf $98^{\circ} \mathrm{C}$ erhitzt. Das Pansorbin wurde abzentrifugiert und der Überstand über ein $15 \%$ iges SDS-Gel aufgetrennt. Das Gel wurde eingeschweißt, getrocknet und für 3-7 Tage auf einem BioImager-Screen exponiert.

\subsubsection{Subzelluläre Fraktionierung (Tritosomenpräparation)}

(Leighton et al. 1968; Wattiaux et al. 1963)

Bei der Tritosomenpräparation werden Lysosomen in zwei Stufen durch differentielle Zentrifugation und durch Zentrifugation in einem diskontinuierlichen Sucrosegradienten von anderen Zellbestandteilen insbesondere den Mitochondrien zu trennen (Leighton et al. 1968). Das Leberhomogenat wurde dazu durch Zentrifugation in eine nukleäre Fraktion $(\mathrm{N})$ und einen post-nukleären Überstand (E) aufgetrennt. Anschließend wurde $\mathrm{E}$ in eine mitochondriale Fraktion (M), eine lysosomale und mitochondrial Fraktion (L), eine mikrosomale Fraktion (P) und einen zytosolischen Überstand (S) aufgetrennt. Die Fraktion L wurde anschließend unter einen diskontinuierlichen Sucrosegradienten geschichtet und durch Zentrifugation in die Fraktionen 1-4 aufgetrennt (vgl. Abb. 3-10).

Den Mäusen wurden 3-4 Tage vor der Präparation 0,75 mg/g Körpergewicht Tyloxapol (Triton WR-1339) intraperitoneal injiziert. Tyloxapol führt zu einer Abnahme der Dichte von Lysosomen. Am Tag der Präparation wurden die Mäuse mit $\mathrm{CO}_{2}$ narkotisiert und dekapitiert. Nach dem Ausbluten wurde den Mäusen die Leber über einen Bauchschnitt entnommen. Für 
jeden Gradienten wurden $2 \mathrm{~g}$ Lebergewebe eingewogen und nach Zugabe von 2,5 Volumen $4{ }^{\circ} \mathrm{C}$-kalter $0,25 \mathrm{M}$ Sucrose (in $\mathrm{ddH}_{2} \mathrm{O}$ ) im Teflon-Homogenisator homogenisiert. Das Homogenat wurde mit 0,25 M Sucrose auf ein Gesamtvolumen von $12 \mathrm{ml}$ gebracht und für $10 \mathrm{~min}$ bei $4{ }^{\circ} \mathrm{C}$ mit $2300 \mathrm{rpm}$ (Labofuge) zentrifugiert. Der Überstand (E1), ca. $9 \mathrm{ml}$, wurde

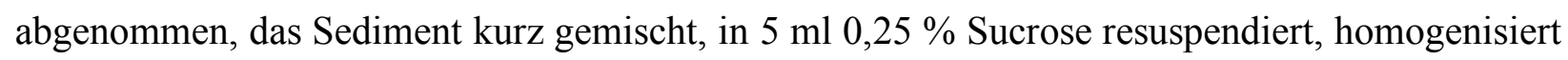
(s.o.), mit 0,25\% Sucrose auf ein Endvolumen von $12 \mathrm{ml}$ gebracht und erneut für $10 \mathrm{~min}$ bei $4{ }^{\circ} \mathrm{C}$ mit $2300 \mathrm{rpm}$ zentrifugiert. Der Überstand (E2), ca. $9 \mathrm{ml}$, wurde abgenommen, mit E1 vereinigt und auf ein Volumen von $22 \mathrm{ml}$ gebracht. Das Sediment stellt $\mathrm{N}$, die nukleäre Fraktion dar. Jeweils $10 \mathrm{ml}$ des vereinten Überstandes wurden auf zwei UZ-Rörchen $(14 \times 95 \mathrm{~mm}$, Beckman) verteilt und für $3 \mathrm{~min}$ bei $4{ }^{\circ} \mathrm{C}$ mit $13000 \mathrm{rpm}$ (Ultrazentrifuge, Rotor SW41) zentrifugiert. Der Überstand (LPS1) wurde abgenommen, das Sediment mit einem Glasstab in

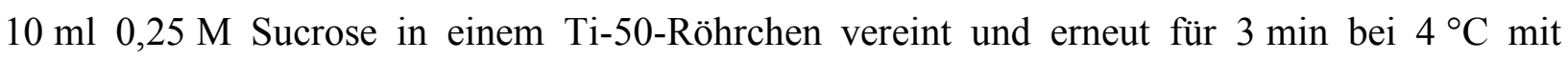
13000 rpm zentrifugiert. Der Überstand (LPS2) wurde mit LPS1 vereint und das Sediment, die Fraktion M, wurde zur Analyse in 0,25 M Sucrose aufgenommen. LPS wurde für 7 min bei $4{ }^{\circ} \mathrm{C}$ mit $25000 \mathrm{rpm}$ zentrifugiert. Der Überstand (PS1) wurde quantitativ abgenommen und das Pellet (Fraktion L) mit einem Glasstab resuspendiert und mit $10 \mathrm{ml}$ Sucrose gewaschen. Es folgte eine weitere Zentrifugation für $7 \mathrm{~min}$ bei $4{ }^{\circ} \mathrm{C}$ mit $25000 \mathrm{rpm}$. Die Überstände (PS2) wurden erneut quantitativ abgenommen und mit PS1 vereint $(\mathrm{PS} 1+\mathrm{PS} 2=\mathrm{PS}=$ ca. $30 \mathrm{ml})$.

Fraktion L wurde mit einem Glasstab in $1.21 \rho$ Sucrose resuspendiert. Der Gradient wurde wie folgt geschichtet (UZ-Röhrchen, $16 \times 76 \mathrm{~mm}$, Beckman): 3,5 ml L in $1.21 \rho$ Sucrose, $3 \mathrm{ml}$ $1.15 \rho$ Sucrose, mit $3 \mathrm{ml} 1.14 \rho$ Sucrose und $\sim 2 \mathrm{ml} 1.06 \rho$ Sucrose. Der Gradient wurde für $150 \mathrm{~min}$ bei $4{ }^{\circ} \mathrm{C}$ mit $25000 \mathrm{rpm}$ in der Ultrazentrifuge bei langsamer Beschleunigung und Bremsung (Rotor 75Ti) zentrifugiert. Anschließend wurden folgende vier Fraktionen abgenommen. F1 entsprach der 1,06 $\rho$ Sucrose-Schicht. Die lysosomale Fraktion (F2), entsprach der Interphase zwischen 1,06 $\rho$ und 1,14 $\rho$ Sucrose. F3 entsprach den Schichten mit 1,14 $\rho$ und 1,15 $\rho$ Sucrose. Die mitochondriale Fraktion (F4) entsprach der Schicht mit 1.21 $\rho$ Sucrose und dem Pellet. 


\subsubsection{Enzymaktivitätsbestimmung}

Im Anschluss an die Tritosomenpräparation wurde für jede gewonnene Fraktion eine Enzymbestimmung der folgenden Enzyme durchgeführt.

\subsubsection{1 $\beta$-Hexosaminidase (Lysosom)}

Puffer $\quad 0,1 \mathrm{M}$ Natriumcitrat $\mathrm{pH} 4,6,0,04 \% \mathrm{NaN}_{3}$ und $0,2 \% \mathrm{BSA}$

Substrat $\quad 10 \mathrm{mM}$ p-Nitrophenyl- $\beta$-D-glucopyranosid in Puffer

Stopplösung $\quad 0,4 \mathrm{M}$ Glycin/ $\mathrm{NaOH}$ pH 10,4

$10 \mu 1$ Probenvolumen in $0,1 \%$ Triton X-100 und $100 \mu$ l Substrat wurden für bis zu 60 min bei $37^{\circ} \mathrm{C}$ im Schüttelwasserbad inkubiert und die Reaktion mit $500 \mu 10,4 \mathrm{M}$ Glycin/ $\mathrm{NaOH}$ (pH 10,4) gestoppt. Es wurden ebenfalls ein Enzymleerwert und Substratleerwert erhoben. Die Extinktion wurde bei $405 \mathrm{~nm}$ gemessen. Der molare Extinktionskoeffizient $\varepsilon$ beträgt $18,5 \mathrm{~cm}^{2} / \mathrm{mol}$. Die Aktivität wurde nach Formel 1 berechnet.

$\frac{\Delta \mathrm{E}_{405} \times \text { Gesamtvolumen }[\mathrm{ml}]}{\varepsilon \times \text { Probenvolumen }[\mathrm{ml}] \times \mathrm{t}[\mathrm{min}] \times 1 \mathrm{~cm}} \times$ Verdünnung $=$ Aktivität $[\mathrm{mU} / \mathrm{ml}]$

Formel 1: $\Delta E=$ Extinktion bei $405 \mathrm{~nm}$; Gesamtvolumen = Reaktionsvolumen nach Abstoppen der Reaktion; Verdünnung = Verdünnung der Probe; $\varepsilon=$ Extinktionskoeffizient; Probenvolumen = Menge der eingesetzten Probe; $t=$ Zeit.

\subsubsection{2 $\beta$-Glucuronidase (Lysosom)}

Puffer $\quad 0,1 \mathrm{M}$ Natriumcitrat $\mathrm{pH} 4,6,0,04 \% \mathrm{NaN}_{3}, 0,4 \%$ BSA

Substrat $20 \mathrm{mM}$ p-Nitrophenyl- $\beta$-D-glucuronid in Puffer

Stopplösung $\quad 0,4 \mathrm{M}$ Glycin/ $\mathrm{NaOH}$ pH 10,4

$50 \mu$ Probenvolumen, $100 \mu 1$ Substratlösung und $50 \mu \mathrm{l} \mathrm{NaCl}$ wurden für 120 min bei $37^{\circ} \mathrm{C}$ im Schüttelwasserbad inkubiert und die Reaktion mit $1 \mathrm{ml} 0,4 \mathrm{M}$ Glycin/ $\mathrm{NaOH}(\mathrm{pH} 10,4)$ gestoppt. Es wurden ein Enzymleerwert und Substratleerwert erhoben. Die Extinktion wurde bei $405 \mathrm{~nm}$ gemessen. Der molare Extinktionskoeffizient $\varepsilon$ beträgt $18,5 \mathrm{~cm}^{2} / \mathrm{mol}$. Die Aktivität wurde nach Formel 1 berechnet. 


\subsubsection{Succinatdehydrogenase (Mitochondrium)}

(Lester und Smith 1961)

Puffer

Substrat

Indikatorlösung
$50 \mathrm{mM}$ Phosphatpuffer $\mathrm{pH} 7,5$

$10 \mathrm{mM}$ Natriumsuccinat und $50 \mathrm{mM}$ Phosphatpuffer $\mathrm{pH}$ 7,5

$0,25 \%$ p-Iodonitrotetrazolium (violett) in $50 \mathrm{mM}$ Phosphatpuffer $\mathrm{pH} 7,5$

Stopplösung 5/11 Ethylacetat, 5/11 Ethanol und 1/11 TCA

$10 \mu 1$ Probenvolumen wurden für $10 \mathrm{~min}$ bei $37^{\circ} \mathrm{C}$ inkubiert. Danach erfolgte die Zugabe von $100 \mu \mathrm{l}$ Indikatorlösung und eine weitere Inkubation von $10 \mathrm{~min}$, die durch $1 \mathrm{ml}$ Stopplösung beendet wurde. Es wurden ebenfalls ein Enzymleerwert, Indikatorleerwert und Substratleerwert erhoben. Die Proben wurden für 5 min bei $13000 \mathrm{rpm}$ zentrifugiert und die Extinktion bei $490 \mathrm{~nm}$ gemessen. Der molare Extinktionskoeffizient $\varepsilon$ beträgt $18,3 \mathrm{~cm}^{2} / \mathrm{mol}$. Die Aktivität wurde nach Formel 1 berechnet.

\subsubsection{Glukose-6-Phosphatase (Endoplasmatisches Retikulum)}

Puffer $116 \mathrm{mg}$ Maleinsäure in $\mathrm{ddH}_{2} \mathrm{O}$ und $10 \mathrm{mM}$ Kaliumnatriumtartrat $\mathrm{pH}$ 6,5

Substrat 0,1 M Glukose-6-Phosphatlösung $\mathrm{pH}$ 6,5

Stopplösung $8 \%$ TCA in $\mathrm{ddH}_{2} \mathrm{O}$

Phosphatreagenz 1/6 A und 5/6 B auf Eis: A) $10 \%$ Ascorbinsäure (frisch); B) 28,6 ml konz. $\mathrm{H}_{2} \mathrm{SO}_{4}, 4,2 \mathrm{~g}$ Ammoniummolybdat $\times 4 \mathrm{H}_{2} \mathrm{O}$ auf $1000 \mathrm{ml}$ mit $\mathrm{H}_{2} \mathrm{O}$ auffüllen.

$50 \mu 1$ Probenvolumen, $300 \mu \mathrm{l}$ Puffer und $100 \mu \mathrm{l}$ Substrat wurden für $1 \mathrm{~h}$ bei $37^{\circ} \mathrm{C}$ inkubiert mit Stopplösung versetzt und anschließend für $10 \mathrm{~min}$ bei $13000 \mathrm{rpm}$ zentrifugiert. Für den Phosphatnachweis wurden $300 \mu 1$ des Überstandes mit $700 \mu 1$ Phosphatreagenz für $1 \mathrm{~h}$ bei $37^{\circ} \mathrm{C}$ inkubiert. Anschließend wurde die OD bei $820 \mathrm{~nm}$ gegen $\mathrm{H}_{2} \mathrm{O}$ gemessen. Eine $\mathrm{OD}=0,260$ entspricht $0,01 \mathrm{mM}$ Phosphat.

\subsubsection{Membranassoziation}

Die HT1080-66-Zellen wurden trypsiniert, mit PBS gewaschen und in Lysepuffer $(50 \mathrm{mM}$ Tris-HCl, $\mathrm{pH}$ 7,5; $10 \mathrm{mM}$ EDTA, $1 \mathrm{mM}$ PMSF und $5 \mathrm{mM} \mathrm{JAA)} \mathrm{aufgenommen.} \mathrm{Die} \mathrm{Zellen}$ wurden $4 \times 30 \mathrm{sec}$ durch Ultraschall homogenisiert und Zelltrümmer für $5 \mathrm{~min}$ bei $4{ }^{\circ} \mathrm{C}$ bei $500 \times \mathrm{g}$ abzentrifugiert. Danach wurde vom Überstand eine Proteinbestimmung durchgeführt, das Homogenat auf eine Konzentration von 1,3 $\mu \mathrm{g} / \mu 1$ eingestellt und jeweils $150 \mu 1$ (ca. $200 \mu \mathrm{g}$ ) 
in UZ-stabile Eppendorfgefäße überführt. In die verschiedenen Eppendorfgefäße wurde jeweils entweder $150 \mu$ Lysepuffer, $150 \mu 12 \mathrm{M}$ Kaliumacetat, $150 \mu 1 \mathrm{Na}_{2} \mathrm{CO}_{3}, 150 \mu 1$ 2,5 M Harnstoff oder $2 \%$ Triton X-100 gegeben, kurz durchmischt und dann für 45 min auf Eis inkubiert. Anschließend folgte eine Zentrifugation für $45 \mathrm{~min}$ mit $100000 \times \mathrm{g}$ bei $4{ }^{\circ} \mathrm{C}$, durch die Membranen pelletiert und Matrixbestandteile isoliert wurden. Der Überstand wurde vorsichtig abgenommen und ü.N. mit TCA gefällt. Das Sediment wurde in $50 \mu$ l SDS-Ladepuffer aufgenommen. Die Proteine wurden über ein SDS-Gel aufgetrennt und das 66.3-kDa-Protein mit dem 66-Antiserum detektiert.

\subsubsection{Deglykosylierung mit N-Glykosidase F (PNGase F)}

(Roche PNGase F Produktbeschreibung 2003)

Zellhomogenat von HT1080-66-Zellen wurden mit PBS auf eine Proteinkonzentration von $5 \mu \mathrm{g} / \mu \mathrm{l}$ gebracht. $50 \mu \mathrm{g}$ Protein und $25 \mu \mathrm{l}$ 0,1 M ß-Mercaptoethanol mit $1 \%$ SDS wurden für $5 \mathrm{~min}$ bei $100{ }^{\circ} \mathrm{C}$ erhitzt. Anschließend wurde dieser Lösung auf Eis $30 \mu 1$ einer 0,5 M Tris/HClLösung (pH 8,0) mit 50 mM EDTA, 11,7 $\mu$ l Triton X-100 (10\% v/v), 11,7 $\mu 1$ 0,1 M 1,10-Phenanthroline/MetOH und $2 \mu 1$ PNGase F (100 U/mg, Roche) zugegeben. Die Ansätze wurden im Inkubator bei $37^{\circ} \mathrm{C}$ je nach gewünschter Zeit inkubiert. Bei Inkubationszeiten über $12 \mathrm{~h}$ wurde nach $12 \mathrm{~h}$ jeweils $2 \mu \mathrm{l}$ PNGase F ergänzt. Zum Abstoppen der Reaktion wurden die Ansätze für 5 min auf $100{ }^{\circ} \mathrm{C}$ erhitzt und anschließend ü.N. mit TCA gefällt. Die Proben wurden in SDS-Ladepuffer aufgenommen und eine Analyse im Western Blot durchgeführt.

\subsubsection{Affinitätschromatographie an 66.3-kDa-Protein-Affigel-10-Matrix}

(BioRad Activated Immunoaffinity Supports for Affi-Gel-10 2000)

Zur Immobilisierung von 66.3-kDa-Protein wurde aufgereinigtes 66.3-kDa-Protein an AffiGel-10-Material gekoppelt. Die Bindungskapazität der Affi-Gel-10-Matrix beträgt ungefähr $30 \mathrm{mg}$ Protein pro Milliliter Säulenmaterial. Die Kopplung des Proteins erfolgt über eine Reaktion der freien Aminogruppe des Proteins mit den an die Agarose-Matrix gekoppelten N-hydroxysuccinimid-Estern. Die Kopplung des Proteins an die Matrix fand bei $4{ }^{\circ} \mathrm{C}$ im Kühlraum mit gekühlten Lösungen statt, um proteolytische Degradation des Proteins zu verhindern. Die Matrix wurde zuerst mit zwei Matrixvolumen $\mathrm{dH}_{2} \mathrm{O}$ gewaschen und anschließend mit zwei Matrixvolumen des jeweiligen Bindungspuffers äquilibriert. Anschließend erfolgte die Inkubation mit dem zu immobilisierenden Protein in Bindungspuffer (aufgereinigtes 66.3-kDa-Protein in 0,1 M Hepes, pH 8,0 und BSA in 0,1 M MES-Puffer, 
pH 4,8) in einem Verhältnis von 3:1 zum Matrixvolumen ü.N. bei $4{ }^{\circ} \mathrm{C}$ auf dem Drehrad. Nach der Inkubation wurde der Durchfluss aufgefangen und analysiert. Freie Bindungsstellen der AffiGel-10-Matrix wurden durch eine dreistündige Inkubation mit einem Säulenvolumen $200 \mathrm{mM}$ Ethanolamin, pH 8,0 abgesättigt. Die Säule wurde mit Bindungspuffer bis zu einer $\mathrm{OD}_{260}=0$ gewaschen und anschließend bis zum Gebrauch in $0,02 \% \mathrm{NaN}_{3}$ in PBS bei $4{ }^{\circ} \mathrm{C}$ gelagert.

\subsubsection{Affinitätschromatographische Aufreinigung von Bindungspartnern}

Bindungspuffer: $100 \mathrm{mM} \mathrm{NaAc-Puffer} \mathrm{pH} \mathrm{5,2,} 5 \mathrm{mM} \mathrm{MgCl}_{2}, \quad 150 \mathrm{mM} \mathrm{NaCl}$. Proteaseinhibitoren, $1 \mathrm{mM}$ EDTA, $1 \mathrm{mM}$ PMSF und $5 \mathrm{mM}$ JAA (frisch dazugegeben)

Der gesamte Versuch wurde im Kühlraum bei $4{ }^{\circ} \mathrm{C}$ mit vorgekühlten Puffern durchgeführt. Eine F2-Fraktion (vgl. Kap. 2.5.18) wurde $6 \times 30 \mathrm{sec}$ durch Ultraschallbehandlung homogenisiert und mit Bindungspuffer 1:4 verdünnt. Im ersten Schritt fand eine Präadsorption auf der BSA-Säule statt, um unspezifisch an das Säulenmaterial oder BSA-bindendes Protein aus der F2-Fraktion zu entfernen. Dafür wurde die F2-Fraktion auf der BSA-Säule für 30 min auf dem Drehrad inkubiert. Der Durchfluss wurde direkt auf die mit Bindungspuffer äquilibrierte 66.3-kDa-Protein-Säule gegeben und für eine Stunde auf dem Drehrad inkubiert. Die 66.3-kDaProtein-Säule wurde anschließend mit Bindungspuffer bis $\mathrm{zu}$ einer $\mathrm{OD}_{280 \mathrm{~nm}} \approx 0$ gewaschen. Bindungspartner wurden mit steigender Salzkonzentration in Bindungspuffer eluiert $(\mathrm{E} 1=500 \mathrm{mM} \mathrm{NaCl}, \quad \mathrm{E} 2=1 \mathrm{M} \mathrm{NaCl}, \quad \mathrm{E} 3=1,5 \quad \mathrm{M} \mathrm{NaCl}, \quad \mathrm{E} 4=3 \mathrm{M} \mathrm{NaCl}) . \quad$ Für jede Salzkonzentration wurden dreimal hintereinander 1,5 ml Elutionspuffer für 1 min auf der Säule inkubiert und anschließend in Eppendorfgefäßen aufgefangen. Die Elutionsfraktionen wurden ü.N. durch TCA gefällt, die drei Sedimente der jeweiligen Elution wurden vereint und über Coomassie-, Silbergel- oder Western-Blot-Analyse ausgewertet. Die Säulen wurden nach dem Gebrauch mit zehn Säulenvolumen Bindungspuffer und 1,5 M NaCl, mit 20 Säulenvolumen Bindungspuffer und mit 20 Säulenvolumen PBS gewaschen und in $0,02 \% \mathrm{NaN}_{3}$ bei $4{ }^{\circ} \mathrm{C}$ abgestellt. 


\subsubsection{Yeast-two-Hybrid}

(Clontech Matchmaker GAL4 Two-Hybrid System 3 \& Libraries User Manual 1999)

Durch das Yeast-two-Hybrid-(Y2H)-System lassen sich Proteinwechselwirkungen in vivo untersuchen (Fields und Song 1989). Für einen funktionsfähigen Transkriptionsfaktor Gal4 der Hefe S. cerevisiae müssen sich die GAL4-DNA-Bindungsdomäne und die GAL4Aktivierungsdomäne sterisch annähern. Im Matchmaker-GAL4-Two-Hybrid-System-3 (Clontech) kodiert der pGBKT7-Vektor die DNA-Bindungsdomäne und der pGADT7-Vektor die Aktivierungsdomäne. In den Vektoren lassen sich Zielproteine als Fusionsproteine (bait und prey Protein) mit der jeweiligen GAL4-Domäne in S. cerevisiae exprimieren. Interagieren die Zielproteine miteinander, so führt die sterische Annäherung der GAL4-DNA-Bindungs- und Aktivierungsdomäne zu einem funktionellen Transkriptionsfaktor und somit zur Expression von Reportergenen. Dabei lassen sich über den Wachstum auf Mangelmedium Rückschlüsse über die Intensität der Proteininteraktion ziehen. So wachsen Hefen bei schwacher Interaktion lediglich auf His-Mangelmedium und bei starker Proteininteraktion auf His-/Ade-Mangelmedium. Als Positivkontrolle für eine starke Interaktion gilt die Interaktion von p53 und SV40-large-TAntigen und als Negativkontrolle das Mitführen von mock-Vektoren.

\subsubsection{Klonierung}

Über Add-on-PCR auf das pcDNA3.1/Hygro+66.3-kDa-Protein-Konstrukt (vgl. Kap. 3.1.1) wurden verschiedene Fragmente des 66.3-kDa-Proteins unter Einführung der benötigten Schnittstellen amplifiziert; mit den Primern A und E (für Vektoren und Primer vgl. Kap. 6.3) die Prä-Proform (AS Met1 - Asp594), mit den Primern B und E die Proform (AS Leu47 - Asp594 ), mit den Primern B und G das 28-kDa-Fragment (AS Leu47 - Ser248 ), mit den Primern C und E das 40-kDa-Fragment (AS Cys249 - Asp594), mit den Primern D und E das 15-kDa-Fragment ( AS Ser514 - Asp594) und mit den Primern C und F ein Mittelfragment (AS Cys249 - Arg513). Die Fragmente wurden am 5'-Ende über EcoR1 und am 3'-Ende über BamH1 als Fusionsprotein mit der Gal-Domäne in den pGBKT7-Vektor ligiert. Die Cathepsin-D-cDNA (R\&D System, Cat. 1029AS) wurde in den pcDNA3.1-Hygro-Vektor kloniert. Aus diesem Konstrukt wurden über Add-on-PCR mit den Primern $\mathrm{H}$ und $\mathrm{J}$ die Full-length-Form von Cathepsin D mit den Schnittstellen Nde1 (5') und Sal1 (3') amplifiziert und in den pGADT7-Vektor ligiert. 


\subsubsection{Hefekultur}

(Clontech Yeast Protocols Handbook 2001)

Die Versuche wurden mit der Unterstützung von Peter Braun durchgeführt.

Reagenzien und Lösungen:

50x-Aminosäure-Cocktail

(-His/ -Trp/ -Leu)

Adeninhemisulfat-Stammlösung

Histidin-Stammlösung

Glukose-Stammlösung

10x-Lithiumacetat-Puffer

1×-Lithiumacetat/TE-Puffer

50 \% PEG-LiAc-Lösung

65 \% Gycerol/ $\mathrm{MgSO}_{4}$-Lösung

YPDA-Medium
300 mg L-Lysin-HCl, 200 mg Uracil, $\quad 1500$ mg L-Valin, 300 mg L-Isoleucin, $200 \mathrm{mg}$ L- Arginin-HCl, $200 \mathrm{mg}$ L-Methionin, $300 \mathrm{mg}$ L-Tyrosin, $500 \mathrm{mg}$ LPhenylalanin, $1000 \mathrm{mg}$ L-Glutamat, $3750 \mathrm{mg}$ L-Serin und $2000 \mathrm{mg}$ L-Threonin in $200 \mathrm{ml} \mathrm{ddH}_{2} \mathrm{O}$ in der Mikrowelle erwärmt

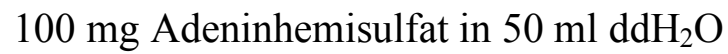

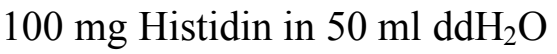
$20 \%(\mathrm{w} / \mathrm{v})$ Glucose in $11 \mathrm{ddH}_{2} \mathrm{O}$ gelöst und sterilfiltriert

$1 \mathrm{M}$ Lithiumacetat auf $\mathrm{pH} 7,5$ mit verdünnter Essigsäure eingestellt und autoklaviert

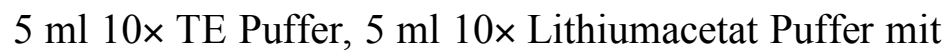
$\mathrm{ddH}_{2} \mathrm{O}$ auf $50 \mathrm{ml}$ aufgefüllt $25 \mathrm{~g}(\mathrm{w} / \mathrm{v})$ PEG3350 mit $50 \mathrm{ml}$ 1× Lithiumacetat/TEPuffer versetzt und zur Lösung in der Mikrowelle aufgekocht

$65 \%(\mathrm{v} / \mathrm{v}) \quad$ Glycerol, $100 \mathrm{mM} \mathrm{MgSO}_{4}$ und $25 \mathrm{mM}$ Tris/ $\mathrm{HCl} \mathrm{pH} 8,0$

$20 \mathrm{~g}$ Pepton, $10 \mathrm{~g}$ Hefeextrakt und $15 \mathrm{ml}$ 0,2\%ige Adeninhemisulfat-Stammlösung pH 6,5 mit $\mathrm{dH}_{2} \mathrm{O}$ auf $900 \mathrm{ml}$ aufgefüllt und autoklaviert. Nach Abkühlung auf ca. $55^{\circ} \mathrm{C}$ wurden $100 \mathrm{ml}$ sterile, $20 \%$ ige GlukoseStammlösung zugesetzt 
SD-Medien
3,35 g Yeast- $\mathrm{N}_{2}$-Base, $10 \mathrm{ml}$ 50×-Aminosäure-Cocktail (-His/-Trp/-Leu und ohne Adenin) und $5 \mathrm{ml}$ der jeweiligen 100x-Aminosäure-Stammlösung bzw. Adenin (für Platten $10 \mathrm{~g}$ Agar zugeben) mit $\mathrm{ddH}_{2} \mathrm{O}$ auf $450 \mathrm{ml}$ aufgefüllt und autoklaviert, nach Abkühlung auf ca. $55^{\circ} \mathrm{C}$ wurden $50 \mathrm{ml}$ Glukose-Stammlösung zugeben

Für die Y2H-Versuche wurde der Hefestamm AH109 verwendet. Er besitzt drei Reportergene (HIS3, Ade2, lacZ), deren Transkription von verschiedenen Gal4-UAS (Upstream Activating Sequences) und TATA-Boxes kontrolliert wird. Über die Reportergene HIS3 und Ade2 können starke und schwache Proteinwechselwirkungen detektiert werden. Dem Hefestamm fehlen außerdem die Gene für die Synthese von Trp und Leu. Diese Gene sind in den beiden Vektoren pGADT7 und pGADT7 (s. 2.5.24.1) enthalten, was die Selektion von transformierten Hefen auf Selektionsmedium/-agar ermöglicht.

Hefevorkulturen wurden aus Glycerolstocks (Hefe in YPDA-Medium mit $50 \%$ [v/v] Glycerol) auf YPD-Agarplatten angeimpft. Nach 3-4 Tagen bei $30{ }^{\circ} \mathrm{C}$ konnten die Kulturen zum Animpfen von Flüssigkulturen in YPDA-Medium verwendet werden.

\subsubsection{Transformation von Hefen}

(Clontech Matchmaker GAL4 Two-Hybrid System 3 \& Libraries User Manual 1999)

Die Transformation von Hefen wurde unter Verwendung von Lithiumacetat durchgeführt. Eine etwa eine Woche alte AH109 Hefekolonie wurde in $10 \mathrm{ml}$ YPDA aufgenommen und ü.N. bei $30{ }^{\circ} \mathrm{C}$ und $230 \mathrm{rpm}$ inkubiert. $300 \mathrm{ml}$ YPDA wurden mit der Vorkultur versetzt und für $3 \mathrm{~h}$ bei $30{ }^{\circ} \mathrm{C}$ und $230 \mathrm{rpm}$ bis zu einer $\mathrm{OD}_{600}$ von $0,5-0,7$ inkubiert. Die Zellen wurden für 5 min bei RT und $1000 \times \mathrm{g}$ abzentrifugiert, mit $50 \mathrm{ml} \mathrm{ddH}_{2} \mathrm{O}$ gewaschen und in $1,5 \mathrm{ml} 1 \times-$ TE/Lithiumacetatlösung (frisch angesetzt) aufgenommen. Eine $50 \%$ PEG/Lithiumacetat/TELösung wurde frisch angesetzt und auf RT abgekühlt. Die Hering-Sperma-DNA wurde für 10 min auf $95^{\circ} \mathrm{C}$ erhitzt und sofort auf Eis gestellt.

Für einen Transformationsansatz wurden 0,1 ug bait-DNA, 0,1 ug prey-DNA, 0,1 mg HeringSperma-DNA und $100 \mathrm{ul}$ Zellsuspension sorgfältig vermischt, bevor $600 \mu 1$ einer $50 \%$ igen PEG/Lithiumacetat/TE-Lösung zum Ansatz gegeben werden. Es folgte eine Inkubation für $30 \mathrm{~min}$ bei $30^{\circ} \mathrm{C}$. Anschließend wurde der Ansatz für $15 \mathrm{~min}$ bei $42{ }^{\circ} \mathrm{C}$ einem Hitzschock unterzogen und für 2 min auf Eis abgekühlt. Es folgte eine zweiminütige Zentrifugation bei $4{ }^{\circ} \mathrm{C}$ 
und $2500 \mathrm{rpm}$, der Überstand wurde verworfen und die Zellen in $250 \mu 11 \mathrm{x}$ TE aufgenommen, auf SD-Platten (-Leu/ -Trp) ausplattiert und für 2-4 Tage bei $30^{\circ} \mathrm{C}$ inkubiert.

Die Platten wurden für 3-4 h bei $4{ }^{\circ} \mathrm{C}$ gelagert, die Kolonien mit $5 \mathrm{ml}$ TE Puffer abgeschabt und die Platten dreimal mit TE-Puffer gespült. Die Zellen wurden für $5 \mathrm{~min}$ bei $1000 \times \mathrm{g}$ abzentrifugiert, der Überstand verworfen und die Zellen in 2,5 $\mathrm{ml} \mathrm{TE}$ und 2,5 $\mathrm{ml} 65$ \%igem Glycerol/ $\mathrm{MgSO}_{4}$ resuspendiert und für eine Woche bei $4{ }^{\circ} \mathrm{C}$ und für bis zu einem Jahr bei $-80{ }^{\circ} \mathrm{C}$ gelagert

\subsubsection{4 -His- / -Adenin- / X-Gal-Test}

(Clontech Matchmaker GAL4 Two-Hybrid System 3 \& Libraries User Manual 1999)

$\begin{array}{ll}\text { Z-Puffer } & 60 \mathrm{mM} \mathrm{Na}_{2} \mathrm{HPO}_{4}, 10 \mathrm{mM} \mathrm{KCl} \text { und } 1 \mathrm{mM} \mathrm{MgSO} \text { mit pH 7,0 } \\ & \text { autoklaviert } \\ & 50 \mathrm{mg} / \mathrm{ml} \mathrm{X-Gal} \mathrm{in} \mathrm{DMF} \mathrm{lösen,} \mathrm{Lagerung} \mathrm{bei}-20{ }^{\circ} \mathrm{C}, \\ \text { X-Gal-Stammlösung } & \text { (lichtgeschützt) } \\ & 5 \mathrm{ml} \text { Z-Puffer, 13,5 ul } \beta \text {-Mercaptoethanol, } 100 \text { ul X-Gal- } \\ \text { Z-Puffer/X-Gal-Lösung } & \text { Stammlösung }\end{array}$

In $4 \mathrm{ml} \mathrm{SD-T/-L-Medium} \mathrm{wurde} \mathrm{eine} \mathrm{Vorkultur} \mathrm{ü.} \mathrm{N}$ bei $30^{\circ} \mathrm{C}$ und $230 \mathrm{rpm}$ mit den zu untersuchenden Klonen angelegt. Am nächsten Tag mit der Vorkultur $5 \mathrm{ml}$ SD-Trp/-LeuMedium angeimpft und bis zu einer $\mathrm{OD}_{600}$ von $0,6-0,7$ bei $30^{\circ} \mathrm{C}$ und $230 \mathrm{rpm}$ inkubiert. Es wurde mit $\mathrm{ddH}_{2} \mathrm{O}$ eine Verdünnungsreihe hergestellt. Anschließend wurden auf SD-Trp/-Leu-, SD-His/-Trp/-Leu- und SD-Adenin/-His/-Trp/-Leu-Verdünnungen mit einer $\mathrm{OD}_{600}$ von 0,5, 0,25 und 0,1 ausplattiert. Die Platten wurden für 1-3 Tage bei $30^{\circ} \mathrm{C}$ inkubiert und das Wachstum dokumentiert (Digitalkamera).

Auf eine SD-His/-Trp/-Leu-Platte oder einer SD-Trp/-Leu-Platte wurde mit einem dünnen Whatman-Filterpapier ein Abklatsch der Hefekolonien gemacht. Dazu wurde das Filterpapier vorsichtig und luftblasenfrei auf die Platte gelegt bis es durchtränkt war. Filterpapier und Platte wurden markiert. Das Filterpapier wurde abgezogen, auf eine neue Agarplatte gelegt und ü.N. bei $30^{\circ} \mathrm{C}$ inkubiert. Das Filterpapier wurde abgenommen und die Zellen durch dreimaliges Schockgefrieren mit flüssigem Stickstoff für jeweils $20 \mathrm{sec}$ permeabilisiert. Ein zweites Filterpapier wird in Z-Puffer/X-Gal-Lösung benetzt und auf das andere Filterpapier gelegt. Dadurch entstand eine Übertragung der lysierten Zellen. Es folgte eine einstündige oder ü.N.Inkubation bei $30^{\circ} \mathrm{C}$. Spätestens nach $12 \mathrm{~h}$ war eine Blaufärbung der Positivkontrollen sichtbar. 


\subsection{Tierexperimentelle Versuche}

\subsubsection{Maushaltung}

Die in dieser Arbeit verwendeten Kontrollmäuse aus institutseigener Zucht (C 57 BL/B6J × $129 \mathrm{SV} / \mathrm{J}$ ) dienten der Gewinnung von Mausleberproben für die subzelluläre Fraktionierung (vgl. Kapitel 2.5.18) und der Gewinnung von Geweben zum Nachweis der Gewebsverteilung des endogenen 66.3-kDa-Proteins in Western und Northern Blot (vgl. Kapitel 2.5.6 und 2.2.2.2.) Die Kontrollmäuse wurden in der „Zentralen Tierstalleinrichtung“ (ZTE) der Universität Göttingen und im Mausstall des Instituts (Biochemie II, Universität Göttingen) bei $19-21{ }^{\circ} \mathrm{C}$, ca. 45-60 \% Luftfeuchtigkeit und einem zwölfstündigen Hell-Dunkel-Rhythmus (hell von 6-18 Uhr) gehalten. Die Ernährung bestand aus ständig zugänglichem pelletiertem Alleinfutter für Mäusezucht und Leitungswasser.

\subsubsection{Entnahme von Organen}

Mäuse wurden nach $\mathrm{CO}_{2}$-Narkose durch zervikale Dislokation getötet und auf dem Präparationstisch fixiert. Die Brust- und Bauchhaut wurde mit $70 \%$ Ethanol desinfiziert, entlang der Mittellinie durchtrennt und seitlich auf dem Präparationstisch befestigt. Abdomen und Thorax wurde entlang der Mittellinie eröffnet, die Aorta durchtrennt, die Maus ausgeblutet und die Organe entnommen. Für die Entnahme des Gehirns wurde die Maus auf dem Präparationstisch gedreht, die Kopfhaut mit $70 \%$ Ethanol desinfiziert und durch einen Rundschnitt entfernt. Die Schädelkalotte wurde vom Foramen magnum ausgehend vorsichtig abpräpariert und das Gehirn mit einem chirurgischen Löffel entnommen. 
3 Ergebnisse 


\subsection{Klonierung und Expression des 66.3-kDa-Proteins}

\subsubsection{Klonierung des 66.3-kDa-Proteins mit RGS-His6-Markierung}

Bei einer Proteomanalyse mit M6P-haltigen Proteinen konnte das 66.3-kDa-Protein als bis dahin unbekanntes Protein identifiziert werden (vgl. Kap. 1.5). In Vorarbeiten konnte ferner gezeigt werden, dass eine C-terminal markierte Variante des Proteins an immobilisierte Mannose-6-Phosphat-Rezeptoren (MPR) bindet bzw. MPR-abhängig von Fibroblasten internalisiert und zu den Lysosomen transportiert wird (vgl. Kap. 1.7).

Für den Nachweis der intrazellulären Lokalisation des endogenen 66.3-kDa-Proteins und für weitere biochemische und molekulare Untersuchungen wurde ein Antikörper bzw. ein polyklonales Antiserum benötigt. Für die Herstellung eines Antiserums in Kaninchen sollte 66.3-kDa-Protein stabil in BHK21-Zellen exprimiert und aus dem Zellkulturmedium aufgereinigt werden. Die Proteinexpression des auf BHK21-basierenden Systems war jedoch nicht so effizient (vgl. Abb. 3-1), als dass sie ausreichend große Mengen an 66.3-kDa-Protein für die Immunisierung von Kaninchen ergab, so dass in Vorarbeiten verschiedene eukaryotische und prokaryotische Expressionssysteme etabliert wurden. Diese wiesen jedoch durchweg eine unzureichende Expression auf.

Die eigenen Arbeiten beginnen mit der Klonierung der cDNA des 66.3-kDa-Proteins aus dem in Vorarbeiten verwendeten pcDNA-DEST40-Vektor in den pcDNA3.1/Hygro-Vektor. Dieser Expressionsvektor besitzt einen CMV-Promotor und ein Hygromycin-Resistenzgen, welches die Selektion von positiven Zellklonen zulässt. Der zuvor benutzte V5-His6-Tag (vgl. Abb. 1-6) wurde durch einen einfachen RGS-His6-Tag ersetzt. Für die Klonierung wurde der cDNA des 66.3-kDa-Proteins über add-on-PCR vor dem ATG-Startcodon eine EcoRVSchnittstellensequenz angefügt. Am 3'-Ende der cDNA wurde das ursprüngliche STOP-Codon deletiert und durch die RGS-His6-Sequenz mit nachfolgendem STOP-Codon und einer NotISchnittstellensequenz ersetzt (vgl. Kap. 6.2).

\subsubsection{Stabile Expression des RGS-His6-markierten 66.3-kDa-Proteins in HT1080}

Die humane Fibrosarkom-Zelllinie HT1080 wurde mit dem 66.3-kDa-Protein-Konstrukt transfiziert, auf 14-cm-Platten ausplattiert und Einzelklone mit $600 \mathrm{U} / \mathrm{ml}$ Hygromycin selektioniert. Die stabil transfizierten Einzelklone zeigten eine starke Expression des 66.3-kDaProteins und sezernierten einen großen Anteil des Proteins in das Zellkulturmedium, aus dem das Protein aufgereinigt werden konnte. Wie in den Vorarbeiten konnte im Zellkulturüberstand eine 75-kDa-Form und ein C-terminales 40-kDa-Fragment des 66.3-kDaProteins mit dem $\alpha$-His- 
Antikörper detektiert werden. Um kontaminierende Proteine bei der späteren Aufreinigung aus dem Zellkulturmedium zu reduzieren, wurden die Zellen testweise bei geringeren FKSKonzentrationen kultiviert. Die Proteinmenge des 66.3-kDa-Proteins im Zellkulturüberstand wurde mit dem $\alpha$-His-Antikörper im Western Blot dargestellt und densitometrisch gemessen (Abb. 3-1), wobei mit dem RGS-His6-Érmylglycine-Generating-Enzyme (FGE) ein in der Abteilung aufgereinigtes Protein als Proteinstandard verwendet wurde (Preusser-Kunze et al. 2005).

In Abb. 3-1 wurde für den Klon 5 bei 0,05 \% FKS-Konzentration 70 ng RGS-His6-66.3-kDaProtein quantifiziert (in $60 \mu \mathrm{l}$ ). Im Vergleich zu Klon 5 hat Klon 7 bei gleicher FKSKonzentration eine um $~ 30 \%$ und die BHK21-Zelllinie mit dem pcDNA-Dest40-Konstrukt eine um $\sim 80 \%$ niedrigere Signalstärke. Der Klon 5 wurde expandiert und in dieser Arbeit unter dem Namen HT1080-66 in allen weiteren Versuchen verwendet.

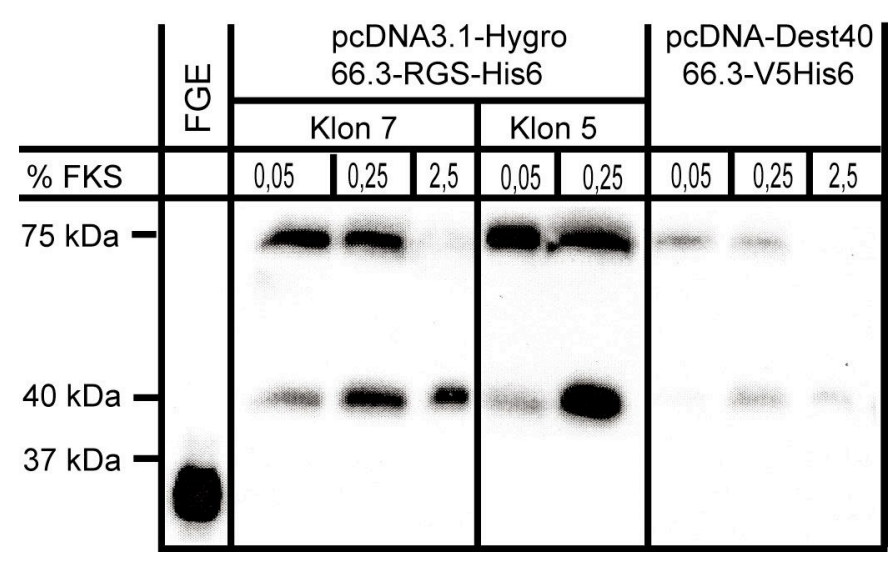

Abb. 3-1: $\quad$ Überexpression in HT1080Zellen

Stabil exprimierende Zellen wurden mit $600 \mu \mathrm{g} / \mathrm{ml}$ Hygromycin und unter verschiedenen FKS-Konzentrationen kultiviert. $60 \mu \mathrm{l}$ Zellkulturüberstand der einzelnen Klone und $80 \mathrm{ng}$ FGE-RGS-His6 als Proteinstandard wurden über SDS-PAGE aufgetrennt, auf eine PVDF-Membran übertragen und mit dem $\alpha$-His-Antikörper nachgewiesen. Zum Vergleich wurden die in Vorarbeiten etablierten BHK21-Zellen aufgetragen.

Zur Aufreinigung von $1 \mathrm{mg}$ 66.3-kDa-Protein wurden etwa 41 Zellkulturüberstände von HT1080-66 benötigt. Dazu wurde alle $48 \mathrm{~h}$ der Zellkulturüberstand abgenommen, mit 0,5 g Ammoniumsulfat / ml Zellkulturmedium gefällt und bei $4{ }^{\circ} \mathrm{C}$ bis zur Aufreinigung gelagert.

\subsection{Aufreinigung des 66.3-kDa-Proteins}

Das mit Ammoniumsulfat gefällte 66.3-kDa-Protein (vgl. Kap. 3.1.2) wurde pelletiert, gegen PBS dialysiert und mittels Affinitätschromatographie an einer Ni-NTA-Matrix partiell gereinigt. Danach erfolgte ein weiterer Aufreinigungsschritt mittels Anionenaustauscherchromatographie. Dazu wurde das gegen Bindungspuffer dialysierte Eluat der Ni-NTA-Matrix auf die Ionenaustauschersäule geladen und mit einem Stufengradienten aus Bindungspuffer und 0 - $1 \mathrm{M} \mathrm{NaCl}$ fraktionsweise eluiert (vgl. Abb. 3-2). 


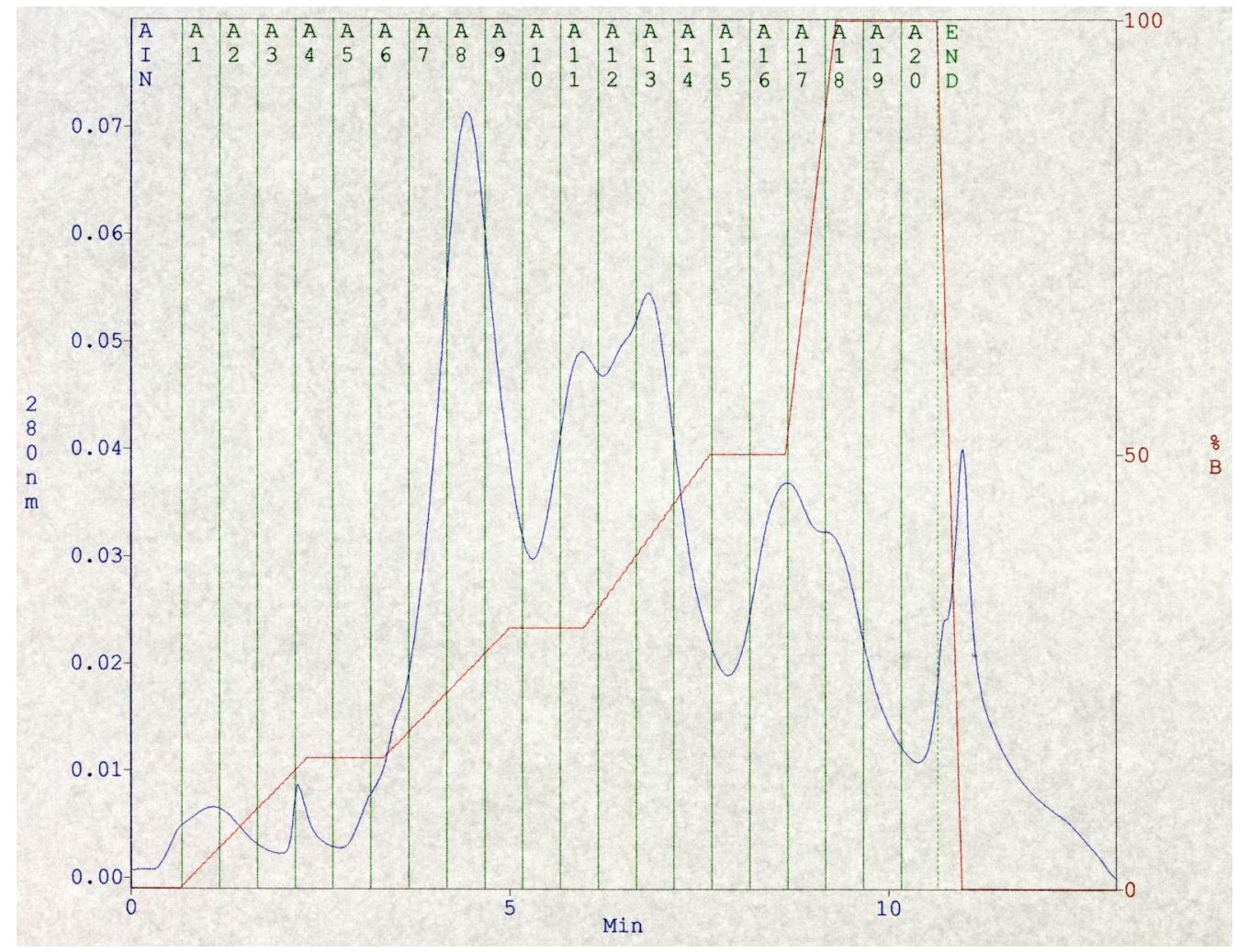

\section{Abb. 3-2: $\quad$ Aufreinigungsprofil des 66.3-kDa-Proteins}

Die Abbildung zeigt das Protein-Elutionsprofil (blau) in Abhängigkeit von der Zeit. Auf der x-Achse ist die Zeit, auf der $y$-Achse links die Absorption bei einer Wellenlänge von $280 \mathrm{~nm}$ und rechts die Konzentration des Elutionspuffers (10 mM Hepes und $1 \mathrm{M} \mathrm{NaCl}, \mathrm{pH} 8,0)$ aufgetragen (rot). Die Zahlen oberhalb des Graphen bezeichnen die jeweiligen Fraktionen, in denen das eluierte Protein gesammelt wurde (grün).

Die Qualität der Aufreinigung wurde anhand von Silbergel- und Western-Blot-Analyse (vgl. Abb. 3-3) mit dem $\alpha$-His-Antikörper und einem Antiserum gegen das 66.3-kDa-Protein (66-Antiserum) bestimmt (vgl. Kap. 3.3). Die Fraktionen 7 - 10 enthalten große Mengen des 66.3-kDa-Proteins, das als 75-kDa-Polypeptid mit einem Antikörper gegen das RGS-His6-Tag nachweisbar ist und zu einem späteren Zeitpunkt (vgl. Kap. 3.4) als Proform des 66.3-kDaProteins identifiziert wurde. Das starke Signal bei $40 \mathrm{kDa}$ entspricht dem C-Terminus des Proteins mit dem RGS-His6-Tag (Abb. 3-3b). Mit dem 66-Antiserum lassen sich zusätzlich die Banden bei $66 \mathrm{kDa}$ und bei $28 \mathrm{kDa}$ als weitere Formen des 66.3-kDa-Proteins identifizieren (Abb. 3-3c). Von den drei aus der 2D-Gelelektrophorese (vgl. Abb. 1-3) bekannten Formen des 66.3-kDa-Proteins lassen sich die 40-kDa-Form besonders effizient, die 66-kDa- und 28-kDaFormen dagegen nur in vergleichsweise geringen Mengen aufreinigen. Durch die zwei sukzessiven Aufreinigungsschritte konnte ausreichend reines 66.3-kDa-Protein für die Immunisierung gewonnen werden. Für nachfolgende Versuche mit aufgereinigtem, rekombinantem Protein wurden Fraktionen 8 und 9 (F8/9) bzw. 7 und 10 (F7/10) vereint. 


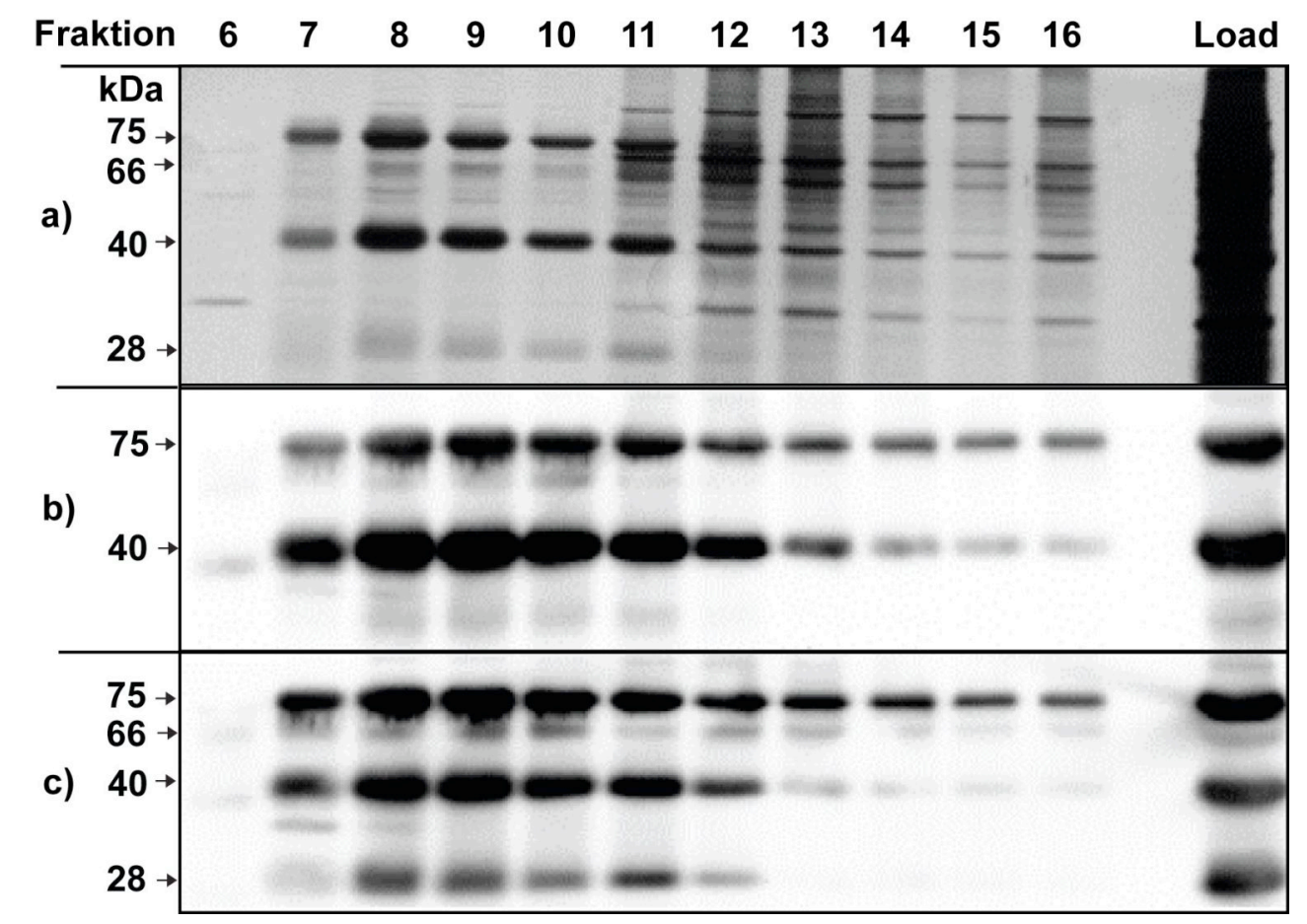

Abb. 3-3: $\quad$ Proteinaufreinigung aus Zellkulturüberständen

Die Fraktionen der HPLC-Aufreinigung (6-16) wurden über SDS-PAGE aufgetrennt und a) im Silbergel oder im Western Blot mit b) dem $\alpha$-His-Antikörper bzw. später auch mit c) dem 66-Antiserum (vgl. Kapitel 3.3) analysiert. Es wurde jeweils $1 \%$ pro Fraktion (6-16) und 0,1\% der Ni-NTA aufgereinigten Proteinlösung (Load) eingesetzt.

\subsection{Herstellung eines Antiserums}

Der bis zu diesem Zeitpunkt verwendete monoklonale $\alpha$-His-Antikörper ließ nur den Nachweis des rekombinanten 66.3-kDa-Proteins mit RGS-His6-Tag zu. Zum Nachweis des endogenen 66.3-kDa-Proteins sollte ein polyklonales Antiserum gegen das 66.3-kDa-Protein hergestellt werden, das auch endogene 66.3-kDa-Protein-Polypeptide ohne RGS-His6-Tag detektiert. Dazu wurden Kaninchen mit dem aufgereinigten Protein immunisiert (vgl. Tab. 2-7). Das gewonnene Antiserum wird im Folgenden 66-Antiserum genannt. Das 66-Antiserum wurde vergleichend mit dem Präimmunserum auf die Erkennung des 66.3-kDa-Proteins als Antigen getestet (vgl. Abb. 3-8).

Das 66-Antiserum detektiert in Homogenaten von HT1080-66 eine 75-kDa-, eine 66-kDa-, eine 40-kDa-, eine 28-kDa- und eine 15-kDa-Bande (vgl. Abb. 3-4). In Homogenaten von HT1080 konnten auf endogenem Expressionsniveau schwache Banden bei 66 kDa bzw. 15 kDa nachgewiesen werden. Bei der Analyse weiterer Zelllinien konnte in Homogenaten von MEF schwache Signale bei $75-\mathrm{kDa}$, 66-kDa und 30-kDa detektiert werden. In Homogenaten von 3T3-Zellen wurde eine Hauptbande bei $28 \mathrm{kDa}$ und eine schwache Bande bei $66 \mathrm{kDa}$ detektiert. 


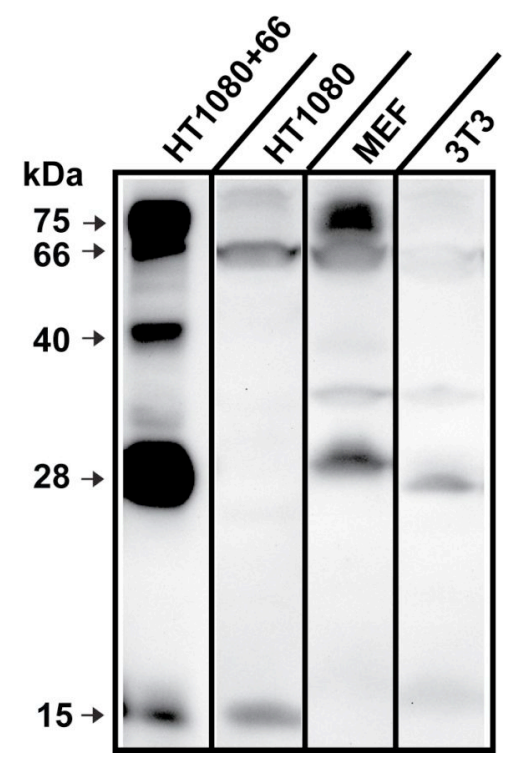

Abb. 3-4: Antikörpertest an verwendeten Zelllinien

$50 \mu \mathrm{g}$ Zellhomogenat von HT1080-66 und $400 \mu \mathrm{g}$ Zellhomogenat von HT1080, von MEF und von 3T3-Zellen wurden über SDS-PAGE aufgetrennt, auf eine PVDF-Membran übertragen und im Western Blot mit dem 66-Antiserum detektiert.

Tab. 3-1: Anwendung des 66-Antiserum

\begin{tabular}{lc}
\hline \hline Anwendung & Konzentration \\
\hline \hline Western Blot & $1: 1000$ \\
Immunfluoreszenz & $1: 50-1: 100$ \\
Immunpräzipitation & $1: 300-1: 900$ \\
\hline
\end{tabular}

Das 66-Antiserum wurde im weiteren Verlauf des Projektes im Western Blot, in der Immunfluoreszenz und für die Immunpräzipitationen verwendet (für Konzentrationen vgl. Tab. $3-1)$.

\subsection{Charakterisierung der aufgereinigten Polypeptide (75, 66, 40, 28 und $15 \mathrm{kDa})$}

Zur genauen Analyse der unterschiedlichen Fragmente des 66.3-kDa-Proteins wurden die Fragmente mittels N-teminaler Proteinsequenzierung (Edman-Abbau) analysiert. Dazu wurde 300 omol des aufgereinigten Proteins über SDS-PAGE aufgetrennt, auf eine PVDF-Membran übertragen und mit Coomassie-Blau gefärbt.

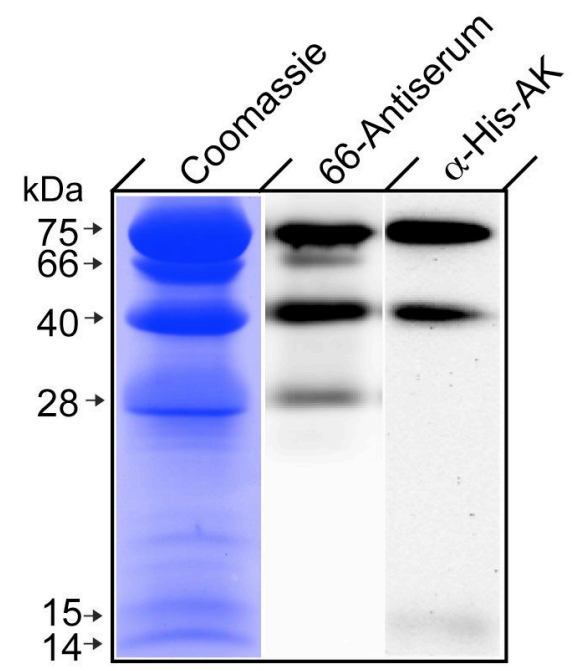

Abb. 3-5: Edman-Abbau

300 omol aufgereinigtes Protein wurde über SDS-PAGE aufgetrennt, auf eine PVDF-Membran übertragen und mit Coomassie-Blau gefärbt. Die Banden wurden ausgeschnitten und durch N-terminale Sequenzierung (Edman-Abbau) analysiert. Zum Vergleich wurde aufgereinigtes Protein im Western Blot mit dem 66-Antiserum und dem $\alpha$-His-Antikörper $(\alpha$-His-AK) detektiert.

Mittels der Edman-Analyse konnten die N-terminalen Aminosäuren von fünf Fragmenten des 66.3-kDa-Proteins bestimmt werden. Das 75-kDa-Fragment beginnt mit Leu47 und kann mit 
dem $\alpha$-His-Antikörper detektiert werden. Das 75-kDa-Fragment (Proform) geht demnach über die Abspaltung des Signalpeptids aus der Prä-Proform hervor. Das 66-kDa-Fragment beginnt $\mathrm{N}$-terminal mit Leu47 und ist mit dem 66-Antiserum, jedoch nicht mit dem $\alpha$-His-Antikörper zu detektieren, was für eine proteolytische Abspaltung des RGS-His6-Tags spricht. Das 40-kDaFragment beginnt mit Cys249, ist mit dem $\alpha$-His-Antikörper nachweisbar und stellt somit den C-terminalen Bereich des Gesamtproteins dar. Das 28-kDa-Fragment ist nur mit dem 66-Antiserum zu detektieren. Da es zudem N-terminal mit Leu47 beginnt, handelt es sich um den N-terminalen Bereich des Gesamtproteins. Das 15-kDa-Fragment ist mit dem 66-Antiserum und dem $\alpha$-His-Antikörper zu detektieren und beginnt mit Ser514. Abb. 3-6 zeigt eine schematische Darstellung der Prä-Proform, der Proform sowie der verschiedenen prozessierten Fragmente des 66.3-kDa-Proteins. Die Edman-Analyse wurde von Dr. Bernhard Schmidt und Klaus Neifert der Abteilung Biochemie II durchgeführt.

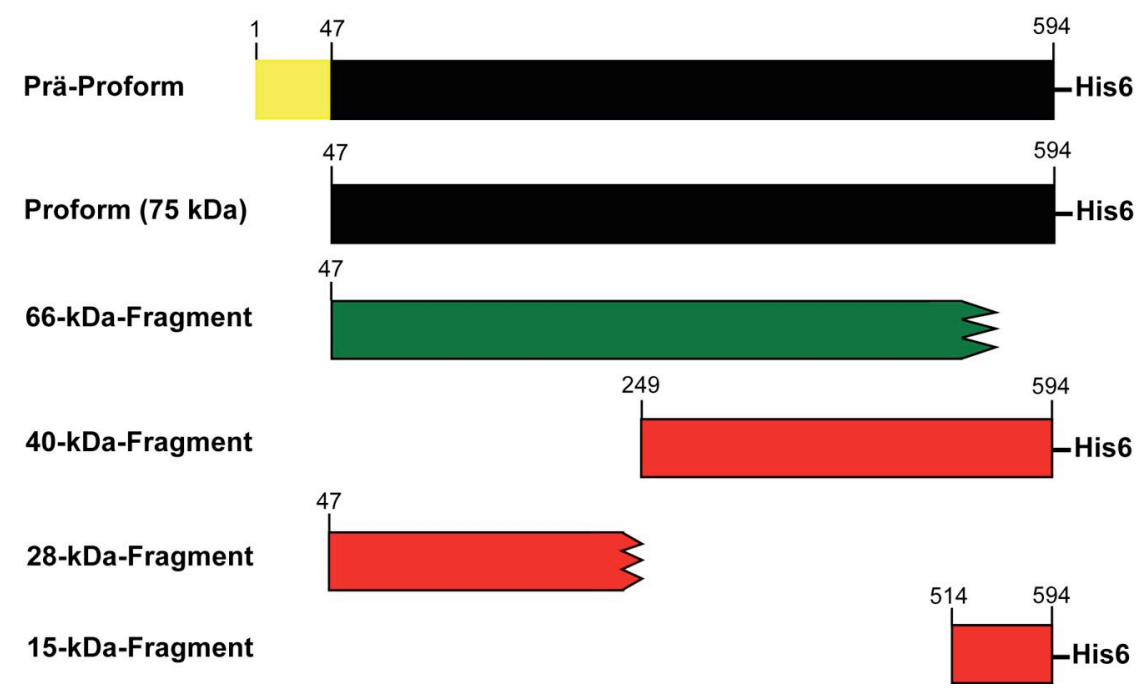

Abb. 3-6: $\quad$ Schematische Darstellung des 66.3-kDa-Proteins

Schematische Darstellung des 66.3-kDa-Proteins von der Prä-Proform bis zu den einzelnen Fragmenten, die anhand der Ergebnisse aus Edman-Abbau (N-Terminus) und Western Blot (Vorhandensein des RGSHis6-Tags am C-Terminus) erstellt wurde. Zahlen geben die Position der Aminosäuren an, mit denen ein prozessiertes Fragment beginnt und endet. Das Signalpeptid befindet sich zwischen AS 1-46 (gelb). 


\subsection{Expression des 66.3-kDa-Proteins in murinen Geweben}

Zur Überprüfung der Expression des 66.3-kDa-Proteins in verschiedenen Geweben wurden Northern- und Western-Blot-Analysen durchgeführt.

\subsubsection{Gewebespezifische Expression des 66.3-kDa-Proteins auf Transkriptebene}

Zur gewebsspezifischen Analyse der 66.3-kDa-Protein-Transkripte wurde ein Northern Blot mit Gesamt-RNA verschiedener Mausgewebe mit einer 66.3-kDa-Protein-spezifischen Sonde (Full-length) durchgeführt und gegen Glycerinaldehyd-3-Phosphatdehydrogenase (GAPDH) normalisiert.

Im Northern Blot (vgl. Abb. 3-7) wurden Transkripte des 66.3-kDa-Proteins mit unterschiedlicher molekularer Größe zwischen $2 \mathrm{~kb}$ und $4 \mathrm{~kb}$ detektiert und große Unterschiede im Transkriptionsniveau der unterschiedlichen Gewebe festgestellt. Im Lungengewebe lässt sich nach der Normalisierung mit dem GAPDH-Signal das höchste Transkriptionsniveau nachweisen.

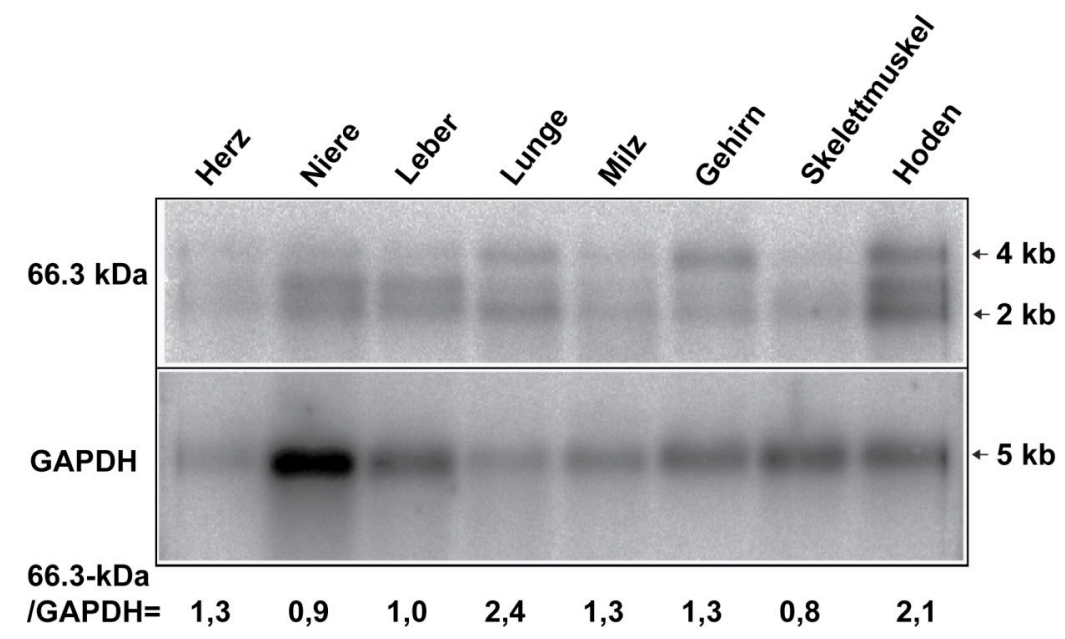

\section{Abb. 3-7: 66.3-kDa-Protein im Northern Blot}

Es wurden $10 \mu \mathrm{g}$ RNA pro Ladebahn elektrophoretisch in einem Formaldehyd-Agarosegel aufgetrennt und auf eine Nylonmembran übertragen. Anschließend wurden mit radioaktiv markierten Sonden die Transkripte des 66.3-kDa-Proteins und der GAPDH detektiert.

Ein ähnlich hohes Transkriptionsniveau konnte in Hodengewebe gezeigt werden. In Herz-, Milz- und Gehirngewebe konnte ein mittleres Transkriptionsniveau und in Leber-, Nieren- und Skelettmuskelgewebe ein niedrigeres Transkriptionsniveau nachgewiesen werden. Die drei Transkripte zeigen untereinander gewebeabhängig variierende Signalstärken. Beim gewebeinternen Vergleich zeigt die 4-kb-Bande in Herz, Niere, Leber, Milz, Skelettmuskel und Hoden das schwächste Signal, in Gehirngewebe jedoch das stärkste. Die mittlere Bande dominiert in Herz, Nieren und Leber. Die 2-kb-Bande ist in Lungen, Milz, Skelettmuskel und Hoden dominant und liefert im Gehirn das schwächste Signal. 


\subsubsection{Proteinexpressionslevel im Western Blot auf murine Gewebe}

Zur Überprüfung des Expressionsniveaus wurde Mausgewebe homogenisiert, über SDSPAGE aufgetrennt und für die Western-Blot-Analyse auf eine PVDF-Membran übertragen.

Die Western-Blot-Analyse verschiedener Gewebe (vgl. Abb. 3-8) zeigte, dass die Expressionshöhe des 66.3-kDa-Proteins in den untersuchten Geweben stark variierte und dass je nach Gewebe Fragmente unterschiedlicher Größe nachzuweisen sind. In Gehirn, Lunge und Milz konnte ein hohes Expressionsniveau auf Proteinebene mit dem 66-Antiserum nachgewiesen werden, wobei die Expression in der Lunge am höchsten war. Im Vergleich dazu wurde ein schwächeres Expressionsniveau in Herzgewebe und ein kaum nachweisbares in Hoden-, Leberund Nieregewebe festgestellt.
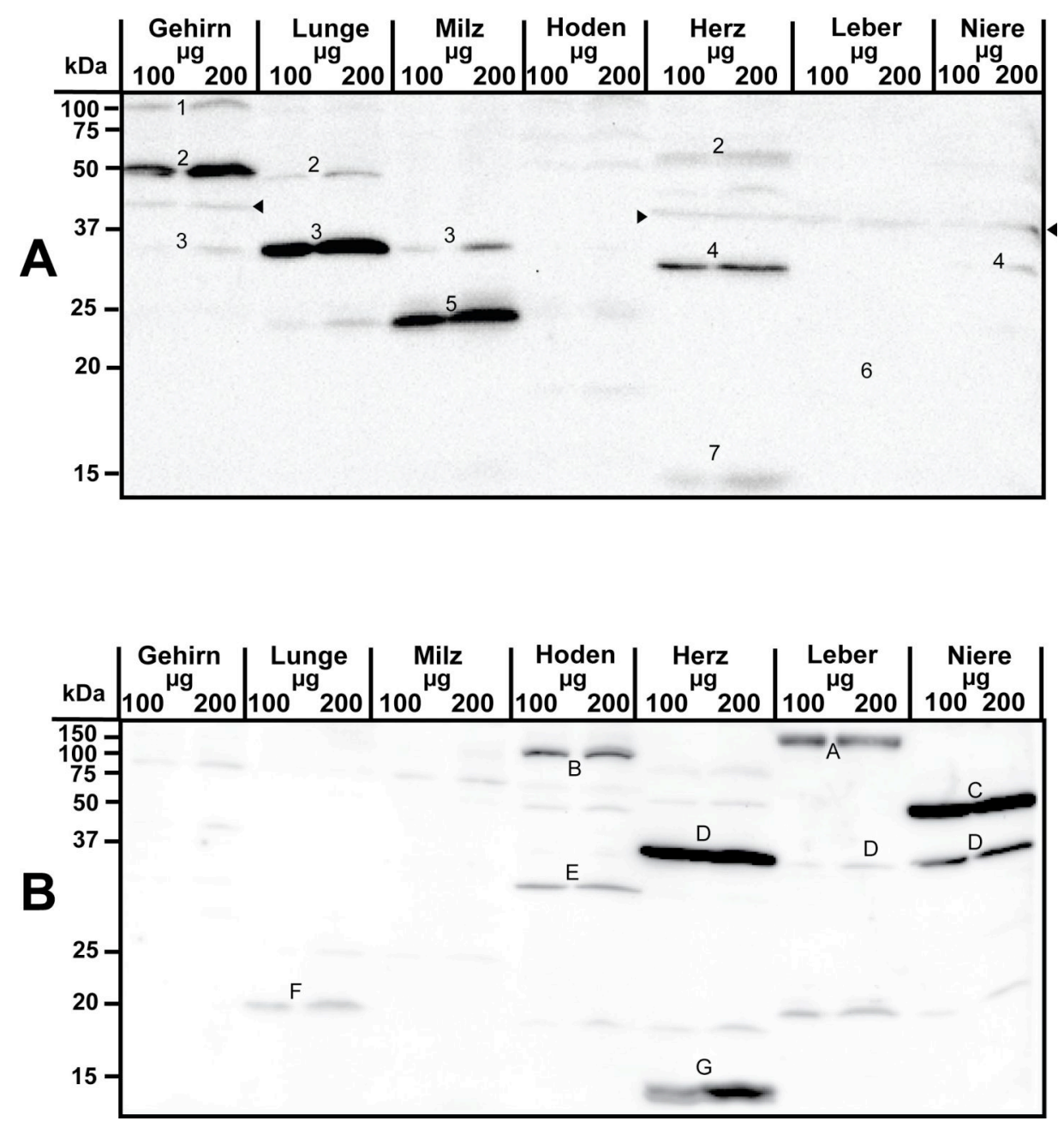

Abb. 3-8: $\quad$ Vorkommen des 66.3-kDa-Proteins in Mausgewebe

Mausgewebe wurden homogenisiert und jeweils $100 \mu \mathrm{g}$ und $200 \mu \mathrm{g}$ Homogenat unter reduzierenden Bedingungen über SDS-PAGE aufgetrennt und per Western Blot mit dem 66-Antiserum (Abbildung A) und dem Präimmunserum (Abbildung B) analysiert (für die Gewinnung des Präimmunserums vgl. Kap. 3.3). Die mit den gefüllten Pfeilspitzen markierten Banden ließen sich auch mit dem Präimmunserum detektieren und sind aus diesem Grund nicht dem 66.3-kDa-Protein zuzuordnen. Banden wurden mit 1-7 und A-G durchnummeriert (s. Text). 
In Gehirngewebe wurde mit dem 66-Antiserum (vgl. Abb. 3-8A) eine prominente 50-kDaBande (2) und zwei schwache Banden bei $100 \mathrm{kDa}$ (1) und $34 \mathrm{kDa}$ (3) detektiert. In der Lunge dagegen wurde mit einer dominanten 34-kDa-Bande (3) und zwei schwachen Banden bei ca. $50 \mathrm{kDa}(2)$ und $24 \mathrm{kDa}(5)$ eine abweichende Expression festgestellt. In Milzgewebe konnte eine starke Bande bei $24 \mathrm{kDa}(5)$ und eine schwache Bande bei $34 \mathrm{kDa}(3)$ nachgewiesen werden. In Hodengewebe ließen sich nur bei $200 \mu \mathrm{g}$ Protein sehr schwache Banden bei 75-, 50und $24 \mathrm{kDa}$ nachweisen. In Herzgewebe dagegen dominierte eine Bande bei $32 \mathrm{kDa}$ (4) neben zwei schwachen Banden bei $50 \mathrm{kDa}$ (2) und $15 \mathrm{kDa}$ (7). In der Leber ließ sich über den Western Blot auch bei Beladung mit $200 \mu \mathrm{g}$ kein 66.3-kDa-Protein und in Nierengewebe nur eine schwache 34-kDa-Bande (4) nachweisen, so dass in diesen Geweben von einer schwachen Proteinexpression ausgegangen werden muss. In der Leber konnte in einer lysosomalen Fraktion nach 50-facher Anreicherung durch subzelluläre Fraktionierung eine Expression der endogenen 28- und 15-kDa Fragmente gezeigt werden (vgl. Kap. 3.6.2).

Parallel zu der Expressionsanalyse verschiedener Gewebe mit dem 66-Antiserum wurde ein Western Blot bei gleicher Beladung mit dem entsprechenden Präimmunserum (Gewinnung des Präimmunserums vgl. Kap. 3.3) inkubiert. Mit dem Präimmunserum (vgl. Abb. 3-8B) wurden in der Leber bei $150 \mathrm{kDa}(\mathrm{A})$, in Hodengewebe bei $100 \mathrm{kDa}(\mathrm{B})$ und bei $33 \mathrm{kDa}(\mathrm{E})$, in Nierengewebe bei $60 \mathrm{kDa}(\mathrm{C})$, in Lungengewebe bei $20 \mathrm{kDa}(\mathrm{F})$ und in Herzgewebe bei $13 \mathrm{kDa}$ (G) Banden detektiert. Diese Signale haben kein Äquivalent bei der Immundetektion mit dem Antiserum. In Herz und Niere und in Leber ist eine Bande bei $40 \mathrm{kDa}$ (D) zu detektieren, die auch mit dem Antiserum nachzuweisen ist und als unspezifisches Signal einzuordnen ist.

\subsection{Lysosomale Lokalisation des endogenen 66.3-kDa-Proteins}

\subsubsection{Das endogene 66.3-kDa-Protein in der Immunfluoreszenz}

Mit dem Nachweis einer M6P-abhängigen Internalisierung des 66.3-kDa-Proteins und der Darstellung von rekombinantem 66.3-kDa-Protein in MEF durch Immunfluoreszenz konnten bereits erste Hinweise auf eine lysosomale Lokalisation erbracht werden (vgl. Kap. 1.7). Die intrazelluläre Lokalisation des endogenen 66.3-kDa-Proteins in MEF wurde durch indirekte Immunfluoreszenz am konfokalen Laserścanmikroskop (LSM) untersucht. Bei dieser Darstellungsmethode werden einzelne Ebenen der Präparate gescannt. So erscheinen die Lysosomen durch die Signale der integralen Membranproteine (LAMP-1) als ringförmige Strukturen. In der Überlagerung der Bilder bildet sich das Signal des 66.3-kDa-Proteins 
innerhalb der LAMP-1-markierten, lysosomalen Membran ab, was für eine Lokalisation des 66.3-kDa-Proteins in der lysosomalen Matrix spricht.

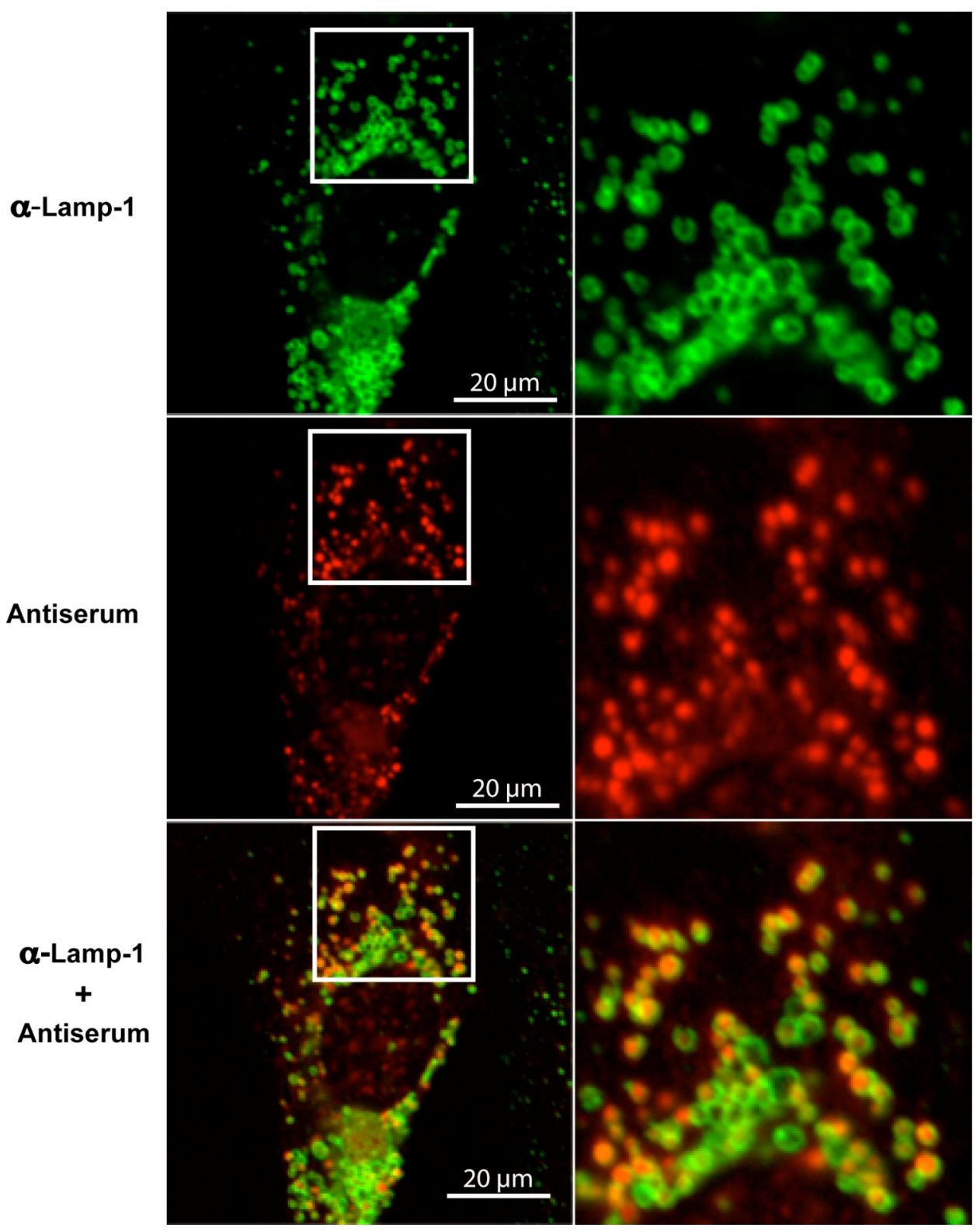

Abb. 3-9: $\quad$ Endogener Nachweis in MEF durch Immunfluoreszenz

MEF wurden mit Methanol fixiert und mittels indirekter Immunfluoreszenz mit dem $\alpha$-LAMP-1-Antikörper und dem 66-Antiserum mit dem konfokalen LSM analysiert. In der rechten Bildhälfte sieht man die Vergrößerung der in der linken Bildhälfte markierten Bildausschnitte. 


\subsubsection{Nachweis des 66.3-kDa-Proteins mittels subzellulärer Fraktionierung von Mausleber}

Die lysosomale Lokalisation des endogenen 66.3-kDa-Proteins sollte mit einem zweiten experimentellen Ansatz bestätigt werden. Durch die Behandlung der Mäuse mit Tyloxapol (Triton WR 1339) verringert sich insbesondere die Dichte von Lysosomen der Hepatozyten (sog. Tritosomen). Durch die verringerte Dichte können Tritosomen durch differentielle Zentrifugation und anschließend durch Zentrifugation in einem diskontinuierlichen Sucrosegradienten von anderen Organellen getrennt werden (de Duve et al. 1955; Leighton et al. 1968). Bei der differentiellen Zentrifugation wurden die Homogenate zuerst in die nukleäre Fraktion (N) und die Fraktion des postnukleären Überstandes (E) fraktioniert (vgl. Abb. 3-10). Durch die Zentrifugation von E entstanden eine mitochondriale Fraktion (M), eine lysosomale Fraktion (L), eine mikrosomale Fraktion (P) und eine zytosolische Fraktion (S). Die Lysosomenangereicherte Fraktion L wurde unter einen diskontinuierlichen Sucrosegradienten geschichtet. Durch Zentrifugation sammeln sich die Lysosomen in der Interphase zwischen den 1,14- $\rho$ - und 1,06- $\rho$-Sucrose-Schichten (Fraktion 2; F2).

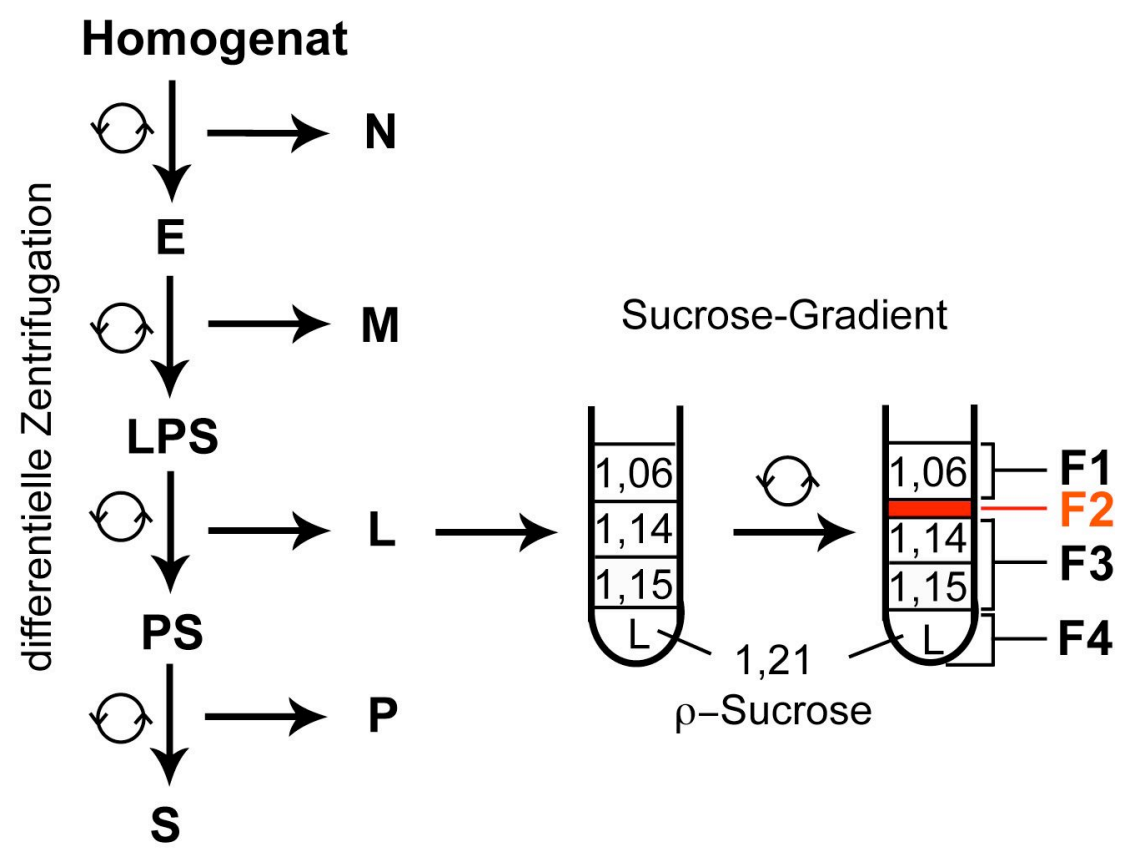

Abb. 3-10 Schema der Tritosomenpräparation (Erklärung s. Text) 
In Tab. 3-2 wurde die Analyse der einzelnen Fraktionen der subzellulären Fraktionierung hinsichtlich der Aktivität von ausgewählten Leitenzymen unterschiedlicher Organellen differentiell dargestellt. Dabei sind $\beta$-Hexosaminidase ( $\beta$-Hex) und $\beta$-Glucuronidase ( $\beta$-Gluc) lysosomale Leitenzyme, die Succinatdehydrogenase (SDH) ist ein mitochondriales Leitenzym und die Glukose-6-Phosphatase (G6Pase) ein Leitenzym des ER. Die Aktivität des jeweiligen Enzyms im Homogenat wurde als $100 \%$ definiert. Alle übrigen Enzymaktivitäten sind als prozentualer Anteil dieser Aktivität angegeben. Aus Tab. 3-2 geht hervor, dass es in L zu einer etwa 3-fachen Anreicherung von $\beta$-Hex (49\% Aktivität des Homogenates bei $15 \%$ Proteingehalt) und einer etwa 2,5-fachen Anreicherung für $\beta$-Gluc (38\% Aktivität bei $15 \%$ Proteingehalt) kommt. In F2 ist eine 200-fache Abnahme des Proteingehaltes gegenüber dem Homogenat (100\% zu 0,5\%) festzustellen. In F2 beträgt die Aktivität von $\beta$-Hex $32 \%$ und von $\beta$-Gluc $19 \%$ der Aktivität des Homogenates. Das entspricht in Bezug auf den Gesamtproteingehalt einer Anreicherung für $\beta$-Hex um das 64-fache (32\% $\beta$-Hex Aktivität in $0,5 \%$ des Gesamtproteins) und für $\beta$-Gluc um das 40-fache (19\% Aktivität in 0,5\% des Gesamtproteins). Die SDH-Aktivität zeigt in F2 dagegen eine Abreicherung um den Faktor fünf und in F4 eine Anreicherung um den Faktor drei (42\% der Aktivität des Homogenates). Gleichermaßen wird für die G6Pase in F2 eine Abreicherung um das 25-fache und in der mikrosomalen Fraktion (P) eine Anreicherung um das 3,7-fache gezeigt (74 \% der Aktivität des Homogenates). Die Analyse der Leitenzyme zeigte eine 40- bis 60-fache Anreicherung lysosomaler Proteine in F2.

In weiteren Versuchen wurden auch die Leitenzyme anderer Organellen, wie z.B. der Peroxisomen (Katalase) und des Golgi-Apparates (Galaktosyl-Transferase), gemessen. 
Tab. 3-2: Analyse von Leitenzymen nach der subzellulären Fraktionierung

\begin{tabular}{|c|c|c|c|c|c|}
\hline & $\begin{array}{l}\text { Proteingehalt } \\
\text { in }[\%]\end{array}$ & $\begin{array}{l}\text { B-Hex-A. } \\
\text { in }[\%]\end{array}$ & $\begin{array}{l}\text { B-Gluc-A. } \\
\text { in [\%] }\end{array}$ & $\begin{array}{l}\text { SDH-A. } \\
\text { in [\%] }\end{array}$ & $\begin{array}{l}\text { G6Pase-A. } \\
\text { in [\%] }\end{array}$ \\
\hline Homogenat & 100 & 100 & 100 & 100 & 100 \\
\hline N (nukleär) & 14 & 9 & 5 & 9 & 7 \\
\hline E (post-nukleär) & 80 & 91 & 95 & 91 & 93 \\
\hline M (mitochondrial) & 11 & 14 & 6 & 49 & 2 \\
\hline $\begin{array}{l}\text { L (lysosomal und } \\
\text { mitochondrial) }\end{array}$ & 15 & 49 & 38 & 36 & 16 \\
\hline P (mikrosomal) & 20 & 21 & 32 & 5 & 74 \\
\hline $\begin{array}{l}\text { S (zytosolische } \\
\text { Fraktion) }\end{array}$ & 39 & 7 & 19 & 2 & $\begin{array}{l}3,7 \text {-fach } \\
\text { angereichert } \\
1\end{array}$ \\
\hline F2 (Lysosomen) & 0,5 & 32 & 19 & 0,11 & 0,02 \\
\hline & & & $\begin{array}{l}\text { 40-fach } \\
\text { angereichert }\end{array}$ & $\begin{array}{l}\text { 5-fach } \\
\text { abgereichert }\end{array}$ & $\begin{array}{l}25 \text {-fach } \\
\text { abgereichert }\end{array}$ \\
\hline F3 (Mitochondrien) & 0,25 & & 3 & 0,11 & 0,15 \\
\hline F4 (Mitochondrien) & 14 & 13 & 15 & $\begin{array}{l}42 \\
3 \text {-fach } \\
\text { angereichert }\end{array}$ & 14 \\
\hline
\end{tabular}

Neben der Analyse der Leitenzyme einiger Organellen wurden die einzelnen Fraktionen der subzellulären Fraktionierung auch im Western Blot analysiert. Dazu wurden $50 \mu \mathrm{g}$ jeder Fraktion über SDS-PAGE aufgetrennt, auf eine PVDF-Membran übertragen und mit Antikörpern/-seren gegen LAMP-1 als lysosomales Membranprotein, Cathepsin D als lysosomales Matrixprotein, sowie den mitochondrialen Proteinen $\underline{\text { Heat- }}$ Shock-Protein 60 (HSP60) und Porin (Voltage-Dependent-Anion-Channel) analysiert, da Mitochondrien die Hauptkontamination der lysosomalen Präparation darstellen.

Das 66.3-kDa-Protein konnte in den Fraktionen L und F2 detektiert werden (vgl. Abb. 3-11A). Während in L nach 3-facher Anreicherung nur ein schwaches Signal bei $28 \mathrm{kDa} \mathrm{zu}$ detektieren war, ist in F2 nach einer 40- bis 60-fachen Anreicherung (vgl. Tab. 3-2: $\beta$-Hex und $\beta$-Gluc) der Lysosomen eine 28-kDa- und eine 15-kDa-Bande zu detektieren. Die in Fraktion S detektierte 40-kDa-Bande wurde schon im Western Blot mit Lebergewebe (vgl. Kapitel 3.5.2) als unspezifische Bande erkannt. Das lysosomale Matrixprotein Cathepsin D und das lysosomale Membranprotein LAMP-1 lassen sich bereits in Fraktion L nachweisen (vgl. Abb. 3-11B). Nach 
weiterer Anreicherung waren beide lysosomalen Proteine als sehr starke Signale in F2 zu detektieren. Die schwächeren Cathepsin-D- und LAMP-1-Signale in den Fraktionen F1 und F3 sind auf die Fraktionierung von F2 aus dem Sucrosegradienten zurückzuführen, da F2 nur zu $\sim 80 \%$ abgenommen wird und die übrigen 20\% auf F1 und F3 entfallen. Die mitochondrialen Proteine HSP60 und Porin wurden in Abb. 3-11C dargestellt. Während in F2 weder für HSP60 noch für Porin ein Signal detektiert wurde, wurden in F4 starke Signale bei $60 \mathrm{kDa}$ für HSP60 und bei $25 \mathrm{kDa}$ für Porin detektiert. Weiterhin ließen sich für HSP60 in den Fraktionen N, E, M und L und für Porin in den Fraktionen M, L und P Signale nachweisen.

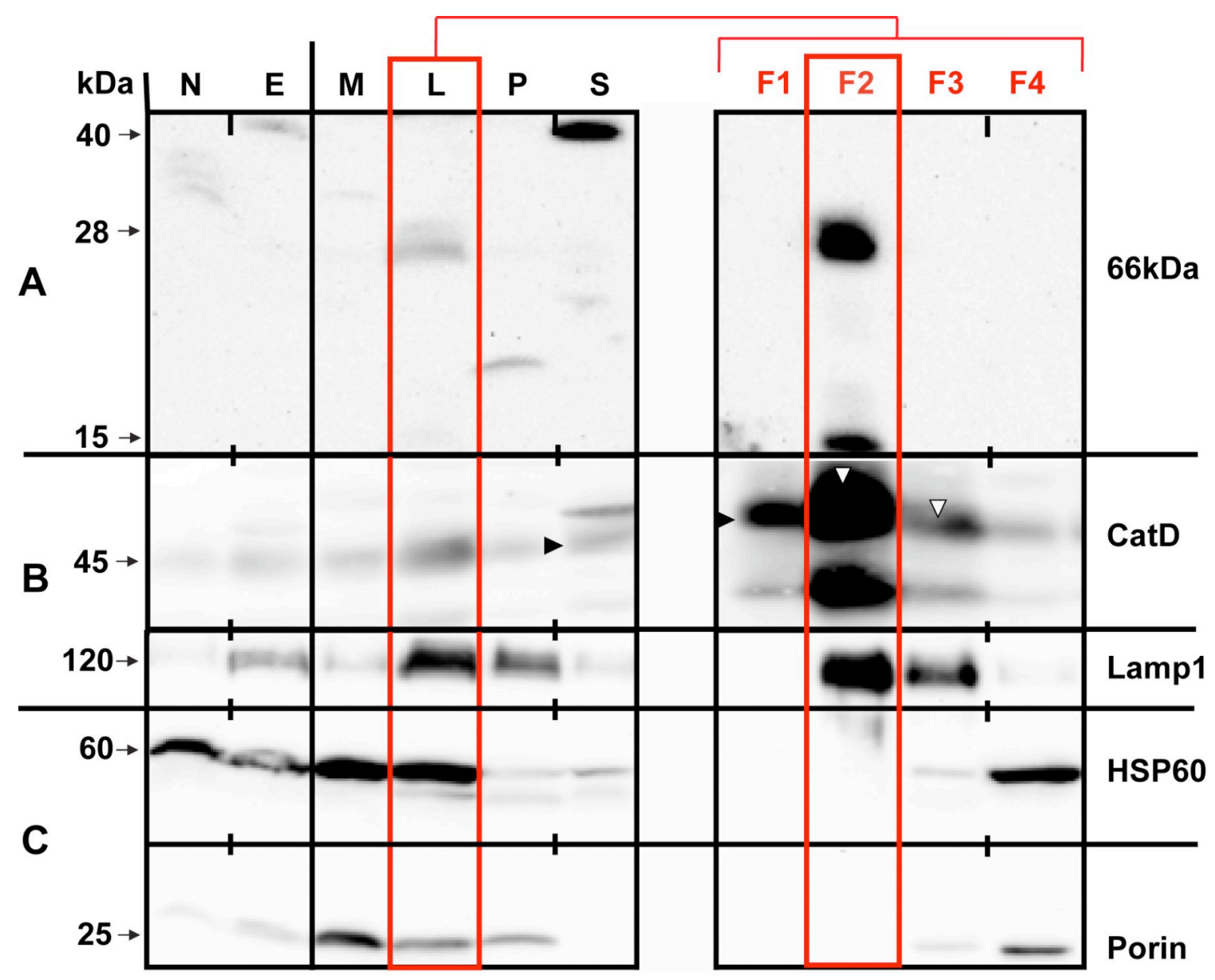

\section{Abb. 3-11: Tritosomenpräparation}

$50 \mu g$ Protein jeder Fraktion der subzellulären Fraktionierung wurden über SDS-PAGE aufgetrennt, auf eine PVDF-Membran übertragen und mit dem 66-Antiserum und den Antikörpern gegen CatD, LAMP-1, HSP60 und Porin analysiert. (N) nukleäre Fraktion; (E) post-nukleärer Überstand; (M) mitochondriale Fraktion; (L) lysosomale/mitochondriale Fraktion; (P) mikrosomale Fraktion; (S) zytosolische Fraktion; (F2) isolierte Lysosomen; (F3) und (F4) isolierte Mitochondrien. 75-kDa- und 66-kDa-Banden sind in Lebergewebe nicht detektierbar (vgl. Abb. 3-8). 


\subsection{Charakterisierung des 66.3-kDa-Proteins in HT1080}

\subsection{1 Überprüfung auf Disulfidbrücken}

Bei einer Reihe von lysosomalen Matrixproteinen, die einer limitierten Proteolyse unterliegen, sind die prozessierten Fragmente über Disulfidbrücken miteinander verbunden (z.B. Ceramidase, Cathepsin B und Cathepsin D). Das 66.3-kDa-Protein besitzt sieben Cysteine an den Positionen 147, 157, 249, 347, 500, 497 und 562 der Aminosäuresequenz. Es sollte überprüft werden, ob zwischen den drei Fragmenten von 40-, 28- und 15 kDa Disulfidbrücken existieren. Dazu wurden Zellhomogenate von HT1080-66 unter reduzierenden Bedingungen (mit $\underline{\beta}$-Mercaptoethanol $=\beta-\mathrm{ME}$ ) und nicht reduzierenden Bedingungen (ohne $\beta$-ME) hinsichtlich des Laufverhaltens der verschiedenen Fragmente des 66.3-kDa-Proteins im SDS-PAGE und anschließender Western-Blot-Analyse untersucht. Abb. 3-12 zeigt eine weitgehend identische Bandenverteilung der 75-, 40-, 28- und 15-kDa-Banden unter beiden Bedingungen. Lediglich bei $14 \mathrm{kDa}$ ist eine zusätzliche schwache Bande unter reduzierenden Bedingungen zu detektieren, wobei das 15-kDa-Fragment keinen Cysteinrest aufweist und daher keine Disulfidbrücken bilden kann. Die weitgehend gleiche Bandenverteilung unter reduzierenden und nicht-reduzierenden Bedingungen spricht gegen die Bildung von Disulfidbrücken zwischen Fragmenten des 66.3kDa-Proteins in HT1080-66.

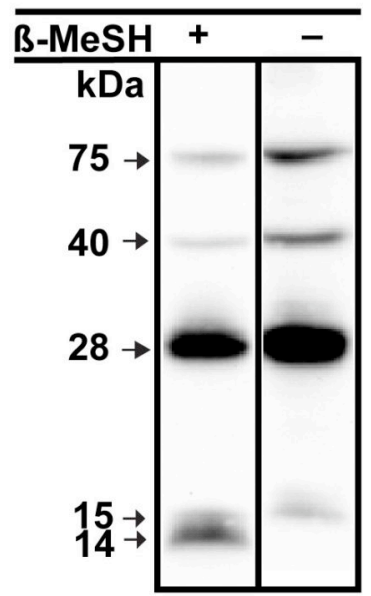

Abb. 3-12: 66.3-kDa-Protein unter reduzierenden und nichtreduzierenden Bedingungen

Homogenate von HT1080-66 (50 $\mu \mathrm{g})$ wurden unter reduzierenden $(+\beta-M e)$ und nicht-reduzierenden Bedingungen $(-\beta$-Me) mittels SDS-PAGE aufgetrennt, auf eine PVDF-Membran übertragen und mit Western-BlotAnalyse mit dem 66-Antiserum analysiert. 


\subsubsection{N-Glykosylierung des 66.3-kDa-Proteins in HT1080-Zellen}

Das murine 66.3-kDa-Protein besitzt fünf potentielle N-Glykosylierungsstellen $(\mathrm{N}-\mathrm{X}-\mathrm{S} / \mathrm{T})$ an Position 93, 115, 236, 441 und 520. Zur Analyse des Glykosylierungsstatus des 66.3-kDaProteins wurden $50 \mu \mathrm{g}$ Homogenat von HT1080-66 mit N-Glykosidase F (PNGase F) behandelt.

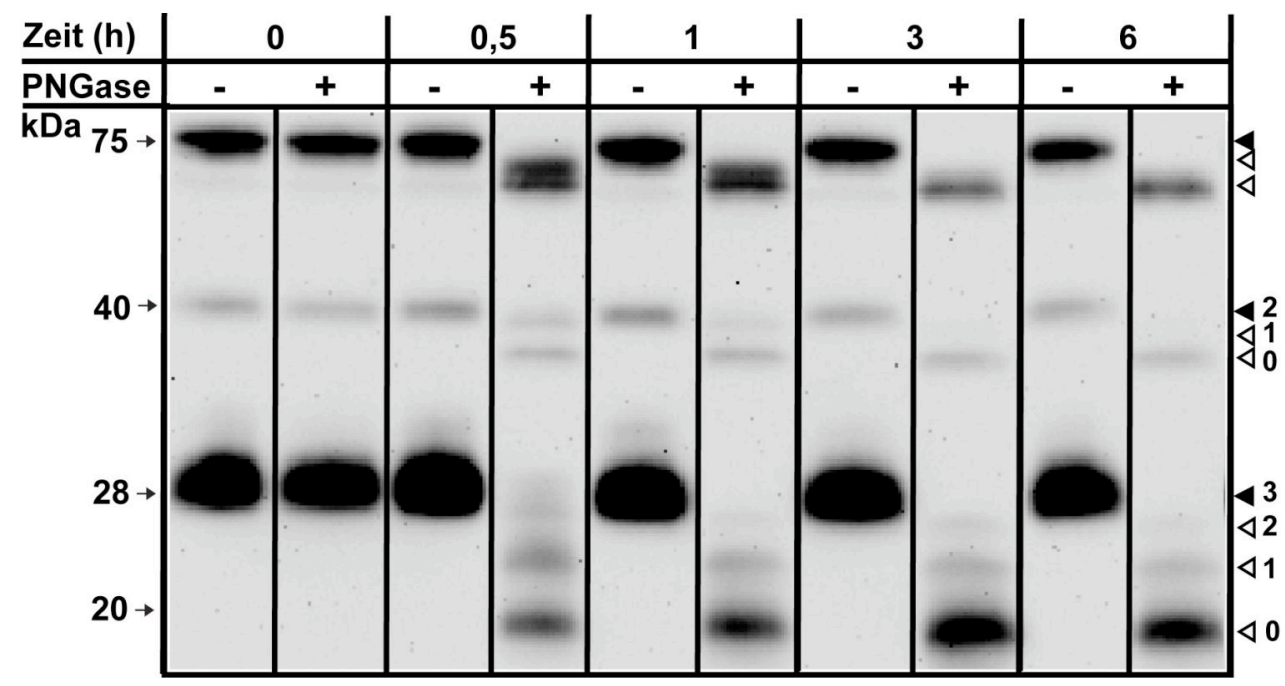

Abb. 3-13: Glykosylierung

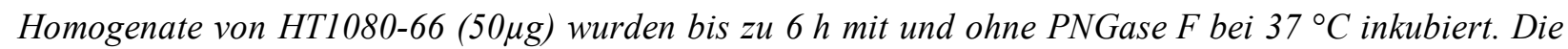
Peptide wurden über SDS-PAGE unter reduzierenden Bedingungen aufgetrennt und mit dem 66-Antiserum im Western Blot detektiert. Gefüllte Pfeilspitzen zeigen auf die vollständig N-glykosylierten Polypeptide, leere Pfeilspitzen auf teilweise deglykosylierte Polypeptide. Die Zahlen stehen für die Anzahl der an dem markierten Polypeptid abspaltbaren N-Glykane.

Nach 30- bzw. 60-minütigem PNGase-F-Verdau wurde die Proform (75-kDa) über eine $\sim$ 70-kDa-Zwischenform und nach $3 \mathrm{~h}$ bzw. $6 \mathrm{~h}$ in eine 66-kDa-Form deglykosyliert (Abb. 3-13).

Die Abnahme des Molekulargewichtes um 9-10 kDa entspricht fünf abspaltbaren N-Glykanen ( 2 - 2,5 kDa pro N-Glykan). Das 40-kDa-Fragment wurde nach 30- bzw. 60-minütigem PNGase-F-Verdau zu einer Zwischenform von $38 \mathrm{kDa}$ und nach dreistündigem Verdau zu einem 35-kDa-Fragment deglykosyliert. Das 40-kDa-Fragment sollte demnach mit zwei N-Glykanen modifiziert sein. Das 28-kDa-Fragment wird über eine $\sim 26-\mathrm{kDa}$ - und eine $\sim 23-\mathrm{kDa}-$ Zwischenform in eine deglykosylierte 19-kDa-Form überführt. Es könnte demnach mit drei NGlykanen modifiziert sein. In HT1080-66 werden demnach alle fünf potentiellen N-Glykosylierungsstellen des 66.3-kDa-Proteins genutzt. In Abb. 3-14 wurde das 66.3-kDaProteins mit den N-Glykosylierungsstellen schematisch dargestellt. 

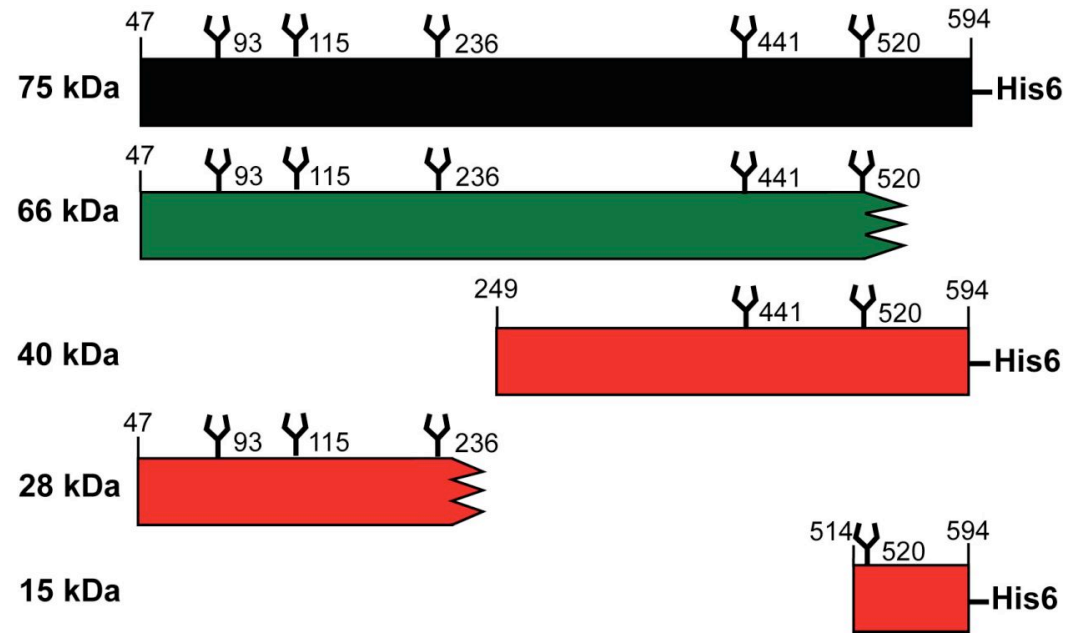

\section{Abb. 3-14: Glykosylierungspositionen}

Schematische Darstellung der Proform (75 kDa) und der Fragmente des 66.3-kDa-Proteins. Die Zahlen an $\mathrm{N}$ - und $\mathrm{C}$-Terminus geben die bekannten $\mathrm{N}$ - und $\mathrm{C}$-terminalen Aminosäuren der Fragmente an, die Zahlen innerhalb der Polypeptide die N-glykosylierten Asparaginreste.

\subsubsection{Membranassoziation oder Matrix-Protein}

Abb. 3-15 zeigt eine graphische Darstellung der Hydrophobizität der Aminosäuresequenzen homologer Proteine des 66.3-kDa-Proteins. Daraus geht hervor, dass das homologe Protein, p67, in T. brucei eine C-terminale Transmembrandomäne besitzt. Das humane und murine Protein weisen keine Transmembrandomäne auf. Dies schließt eine Membranassoziation allerdings nicht aus.

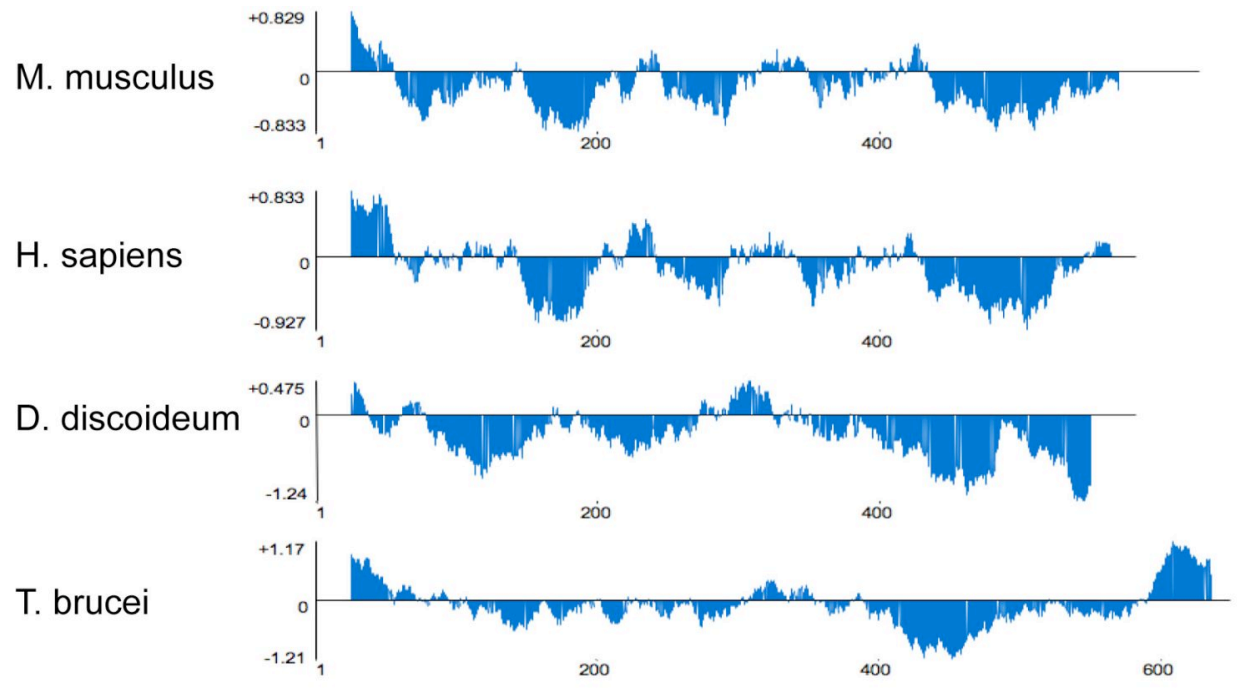

\section{Abb. 3-15: Graphische Darstellung der Hydrophobizität}

Das 66.3-kDa-Protein und die homologen Proteine in H. sapiens, D. discoideum und T. brucei wurden auf ihre Hydrophobizität (Kyte und Doolittle 1982) untersucht. Ausschläge die oberhalb der eingezeichneten Nullline liegen zeigen hydrophobe, Ausschläge unterhalb hydrophile Proteinanteile an. Die X-Achse gibt die Aminosäurezahl an. Die Abbildung wurde mit dem Programm VectorNTI Advance V.10 (Invitrogen) erstellt. 
Um die potentielle Membranassoziation des 66.3-kDa-Proteins zu untersuchen, wurden Homogenate von HT1080-66 unter verschiedenen Pufferbedingungen inkubiert und die Membranen nach der Inkubation mittels Zentrifugation von den löslichen Proteinen getrennt. Das 66.3-kDa-Protein liegt unter allen getesteten Bedingungen in den HT1080-66 als lösliches Protein vor, so dass auch eine lockere Membranassoziation ausgeschlossen werden kann.

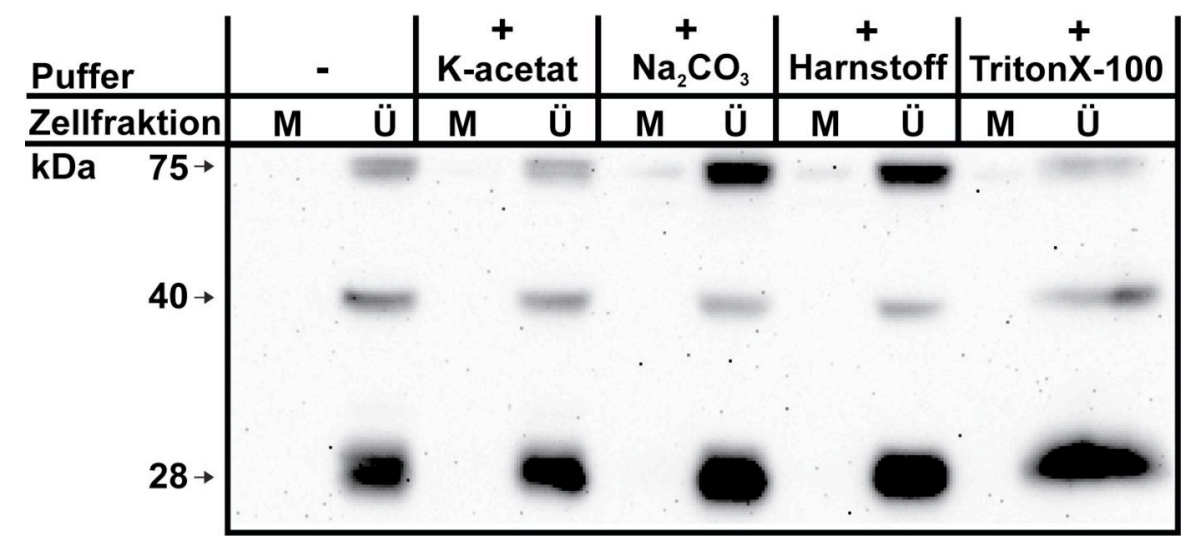

\section{Abb. 3-16: Membranassoziation}

Homogenate von HT1080-66 wurden 45 min auf Eis mit Lysepuffer und den jeweiligen Pufferbedingungen inkubiert und anschließend bei $100000 \times g$ für 45 min bei $4{ }^{\circ} \mathrm{C}$ zentrifugiert. Der Überstand wurde abgenommen, gefällt und wie das Membranpellet in SDS-Ladepuffer aufgenommen. Die Proteine wurden über SDS-PAGE aufgetrennt und das 66.3-kDa-Protein mit dem 66-Antiserum detektiert. $M=$ Membran; $\ddot{U}=\ddot{U b e r s t a n d}$. $200 \mu \mathrm{g} /$ Ansatz $(=M+\ddot{U})$. 


\subsubsection{Prozessierung des 66.3-kDa-Proteins in HT1080}

Zur Analyse der Prozessierungskinetik des 66.3-kDa-Proteins von der Proform zu gereiften Proteinfragmenten wurden HT1080-66 und HT1080 für 0,5 h mit $\left[{ }^{35} \mathrm{~S}\right]-$ Methionin/Cystein metabolisch markiert (Pulse), nach verschieden langen Inkubationszeiten (Chase) homogenisiert und das 66.3-kDa-Protein mit dem 66-Antiserum immunpräzipitiert.
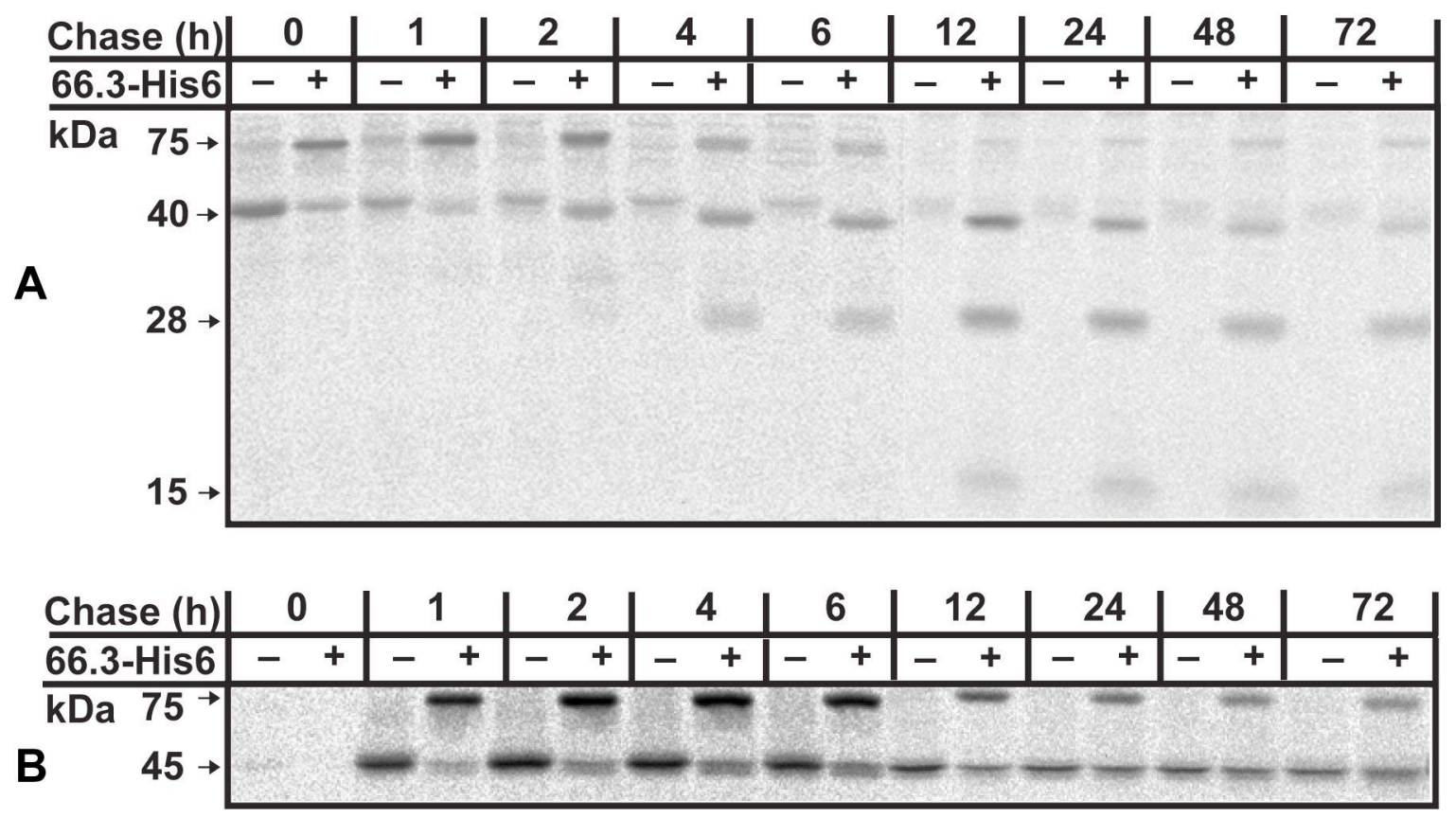

Abb. 3-17: $\quad$ Prozessierung in HT1080-66

A) Zellen B) Medium. HT1080 und HT1080-66 wurden radioaktiv markiert und nach der Markierung unterschiedlich lange in Kultur gehalten (Chase). Mit dem 66-Antiserum wurden durch Immunpräzipitation alle immunreaktiven Polypeptide aus den Medien und den Zellhomogenaten isoliert. Um die vollständige Prozessierung in einer Abbildung darzustellen, wurden jeweils zwei SDS-PAGEGele zusammengefügt (0-6 $h$ und 12-72 h).

Abb. 3-17 A zeigt die intrazelluläre Prozessierung des 66.3-kDa-Proteins in HT1080 und HT1080-66. In HT1080 war zwischen 0 h und $2 \mathrm{~h}$ ein schwaches Signal der endogenen Proform $(75 \mathrm{kDa}) \mathrm{zu}$ detektieren. Andere Fragmente des 66.3-kDa-Proteins waren bei der Immunpräzipitation in HT1080 nicht nachweisbar. Daneben wurde in HT1080 ein Protein mit einem Molekulargewicht von $\sim 40 \mathrm{kDa}$ präzipitiert, das über die gesamte Chase-Periode nachweisbar war. In HT1080-66 war dieses Protein nur zu Beginn der Chase-Periode zu detektieren. Bei diesem Signal handelt es sich um ein unspezifisches Signal, das auch schon im Gewebewestern (vgl. Abb. 3-8) und bei der subzellulären Fraktionierung (vgl. Fraktion S in Abb. 3-11) zu detektieren war. 
In HT1080-66 war die Proform schon zur Chase-Zeit 0 h zu detektieren (Abb. 3-17A). Die Proform konnte über $2 \mathrm{~h}$ in konstanter Signalstärke und von $4 \mathrm{~h}$ bis $72 \mathrm{~h}$ mit abnehmender Signalstärke detektiert werden. Während die Proform an Signalstärke abnahm, konnten das 40und das 28-kDa-Fragment verstärkt nachgewiesen werden. Das 40-kDa-Fragment wurde erstmals nach $1 \mathrm{~h}$ detektiert. Die Signalstärke nahm innerhalb der ersten zwölf Stunden an Intensität zu und danach langsam bis zur Chase-Zeit $72 \mathrm{~h}$ wieder ab. Das 28-kDa-Fragment war nach 2 h erstmals zu detektieren. Die Signalstärke nahm bis zur Chase-Zeit $24 \mathrm{~h}$ zu und danach langsam wieder ab. Das 15-kDa-Fragment konnte vom Zeitwert $12 \mathrm{~h}$ bis $72 \mathrm{~h}$ nachgewiesen werden.

Im Medium der HT1080-66 ist bereits nach einer Stunde die 75-kDa-Vorläuferform des 66.3kDa-Proteins zu detektieren (vgl. Abb. 3-17B). Diese war für $6 \mathrm{~h}$ stabil, ehe eine langsame Reduktion der Signalstärke bis zur Chase-Zeit $72 \mathrm{~h} \mathrm{zu}$ registrieren war. Bei $45 \mathrm{kDa}$ wurde ein Signal detektiert, das allerdings sowohl in HT1080-66 als auch in HT1080 nachgewiesen werden konnte und daher ein unspezifisches Signal darstellt. Andere Fragmente wurden nicht detektiert.

\subsubsection{Prozessierung des 66.3-kDa-Proteins in 3T3-Zellen}

Nach der Prozessierung in HT1080-66 wurde die Prozessierung des endogenen 66.3-kDaProteins in 3T3-Zellen untersucht. Aufgrund der niedrigen Expressionshöhe des 66.3-kDaProteins in 3 T3 (vgl. Abb. 3-4) wurde die fünffache Menge an Zellen für $1 \mathrm{~h}$ metabolisch markiert. Auch in 3T3-Homogenaten wurde eine Kreuzreaktion mit einem Protein bei ca. 40/43 kDa in Zellkulturmedium und den Zellen festgestellt (vgl. $>$ in Abb. 3-18).

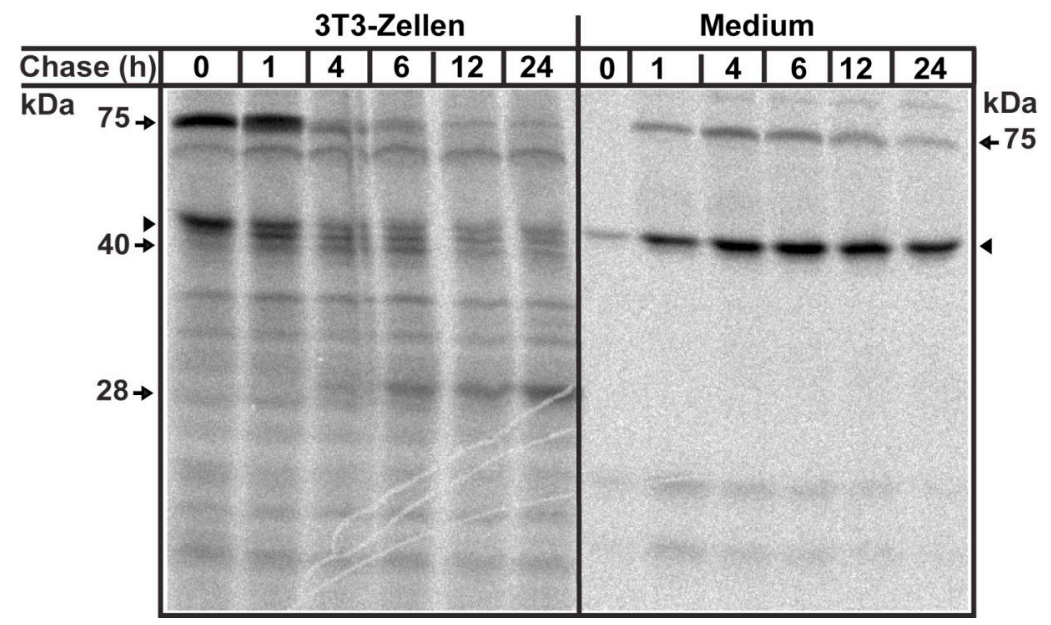

Abb. 3-18: Endogene Prozessierung in 3T3-Zellen

Die Abbildung zeigt in 3T3-Zellen radioaktiv markierte Proteine, die wie in Abb. 3-17 mit dem Antiserum immundetektiert und über SDS$P A G E$ aufgetrennt wurden. ( Kreuzreaktion des Antikörpers mit einem Protein bei $43 \mathrm{kDa}$.

Die Proform (75 kDa) des 66.3-kDa-Proteins wurde direkt nach der Markierung und nach einer Stunde Chase-Zeit detektiert (Abb. 3-18). Das Auftreten der Proform zum Zeitpunkt $0 \mathrm{~h}$ lässt sich durch die verlängerte Pulse-Zeit erklären. Nach 4 h Chase-Zeit nimmt die Intensität 
des Signals der Proform zunehmend ab, während Signale bei 40 kDa und 28 kDa zu detektieren sind. Die 28-kDa-Bande scheint in 3T3-Zellen die stabilste Form des 66.3-kDa-Proteins zu sein. Im Zellkulturmedium konnte ab der Chase-Zeit $1 \mathrm{~h}$ die Proform detektiert werden.

\subsection{Funktionelle Analyse des 66.3-kDa-Proteins}

Das murine 66.3-kDa-Protein wurde von Kollmann et al. (2005) erstmals identifiziert und ist in seiner Funktion nicht beschrieben. Eine Möglichkeit zur Funktionsanalyse stellen $R N A$ interference-(RNAi)-Versuche oder Knock-out-Modelle dar. Im Rahmen dieser Arbeit durchgeführte $R N A i$-Versuche führten zu nicht verwendbaren Ergebnissen und sind daher nicht dargestellt. Ein Knock-out-Modell in der Maus wurde parallel zu dieser Arbeit in der Arbeitsgruppe konzipiert. Die Identifizierung von Bindungspartnern des 66.3-kDa-Proteins ist eine weitere Methode, um Rückschlüsse auf das Funktionsumfeld eines Proteins vorzunehmen.

\subsubsection{Identifizierung von Interaktionspartnern durch Affinitätschromatographie}

Für die Identifikation möglicher Interaktionspartner des 66.3-kDa-Proteins wurde rekombinantes 66.3-kDa-Protein an eine AffiGel-10-Säule gekoppelt und in drei unabhängigen Versuchen (V1-3) mit hoch aufgereinigten lysosomalen Proteinen inkubiert (vgl. Subzelluläre Fraktionierung, F2-Fraktion: $\mathrm{V} 1=2 \mathrm{mg}, \mathrm{V} 2=8 \mathrm{mg}$ und $\mathrm{V} 3=2 \mathrm{mg}$ ). Die F2-Fraktionen wurden vorher über eine BSA-Säule gegeben, um unspezifische Bindungspartner zu entfernen. Die AffiGel-10-Säule mit immobilisiertem 66.3-kDa-Protein wurde nach der Inkubation mit der F2Fraktion zuerst intensiv gewaschen. Anschließend wurden mögliche Bindungspartner mit steigenden Salzkonzentrationen eluiert (vgl. Abb. 3-19). Wasch- und Elutionsfraktionen wurden mit 10\% TCA gefällt, über SDS-PAGE aufgetrennt und mit Coomassie-Blau (V1 und V2) bzw. im Western Blot (V3) analysiert. Aus den Coomassie-Gelen (vgl. Abb. 3-19 A) wurden sichtbare Banden ausgestanzt, die Proteine im Gel mit Trypsin verdaut und die Peptide massenspektrometrisch analysiert (MALDI-TOF-MS und -MS/MS). Im dritten Versuch (V3) wurden die Elutionsfraktionen im Western Blot analysiert (vgl. Abb. 3-19B). 
A

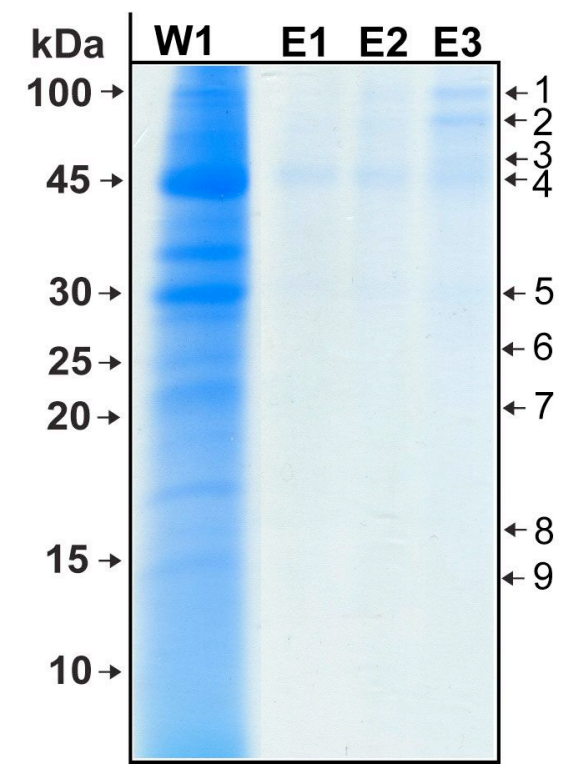

B

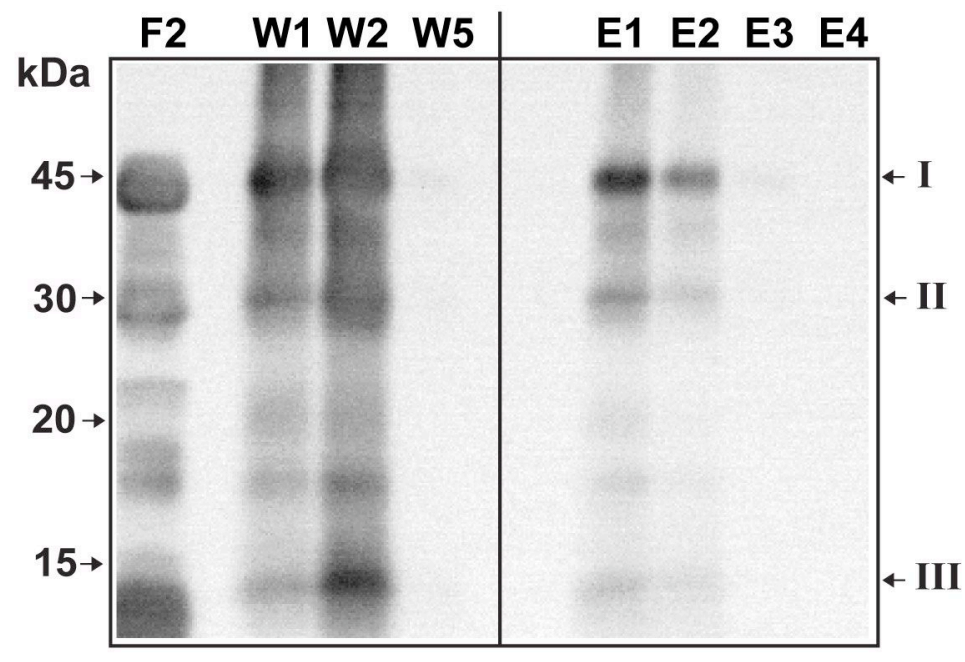

\section{Abb. 3-19: Affinitätschromatographie}

Eine Lysosomen-angereicherte-Fraktion (Fraktion 2 [F2] der subzellulären Fraktionierung, vgl. Kap. 3.6.2) wurde nach 30-minütiger Präinkubation auf einer BSA-Säule für 60 min bei einem $p H$-Wert von 5,2 mit immobilisiertem 66.3-kDa-Protein inkubiert. Nicht-gebundenes Protein wurde mit Bindungspuffer (bis $O D_{280}=0$ ) gewaschen (W1-W5) und mögliche Bindungspartner anschließend mit schrittweise steigenden Salzkonzentrationen eluiert (E1-E4). Lade-, Wasch- und Elutionsfraktionen wurden mit $10 \%$ TCA gefällt, über SDS-PAGE aufgetrennt, mit Coomassie-Blau angefärbt (A) oder im Western Blot mit dem Cat-D-Antikörper (B) dargestellt. Aus den Coomassie-Gelen (in V2 exemplarisch gezeigt) wurden die Banden 1-9 der Elutionsfraktionen 1-3 (E1-3) ausgestanzt, die Proteine mit Trypsin verdaut und die Peptide massenspektrometrisch analysiert (vgl. Tab. 3-3). Im digitalen Bild des Gels sind Banden 6-9 nicht mehr zu erkennen, ihre Position ist jedoch mit Pfeilen angedeutet. Die Elution erfolgte mit $0,5 \mathrm{M} \mathrm{NaCl}$ (E1), $1 \mathrm{M} \mathrm{NaCl}$ (E2), $1,5 \mathrm{M} \mathrm{NaCl}$ (E3) und $3 \mathrm{M} \mathrm{NaCl}$ (E4); Aufgetragene Proteinmenge $50 \mu \mathrm{g}$ (F2), $10 \%$ des TCA-gefällten Proteins (W1 und W2), $100 \%$ des TCA-gefällten Proteins (W5, E1, E2, E3 und E4).

Die ermittelten Massen wurden mit Hilfe des Programms Mascot (Matrix-Science) mit den Einträgen von in silico verdauten Proteinen mit der Proteindatenbank NCBInr (http://www.ncbi.nlm.nih.gov; Stand 17.05.07) verglichen. Für jede Übereinstimmung zwischen experimentell bestimmten Daten und den theoretischen Daten eines Datenbankeintrages wurde ein Mascot-Score ermittelt. Ein Protein galt als identifiziert, wenn der Mascot-Score einem pWert <0,05 entsprach (vgl. Abb. 3-20 B). Bei der massenspektrometrischen Untersuchung wurden in allen neun Banden Proteine identifiziert (vgl. Tab. 3-3). 


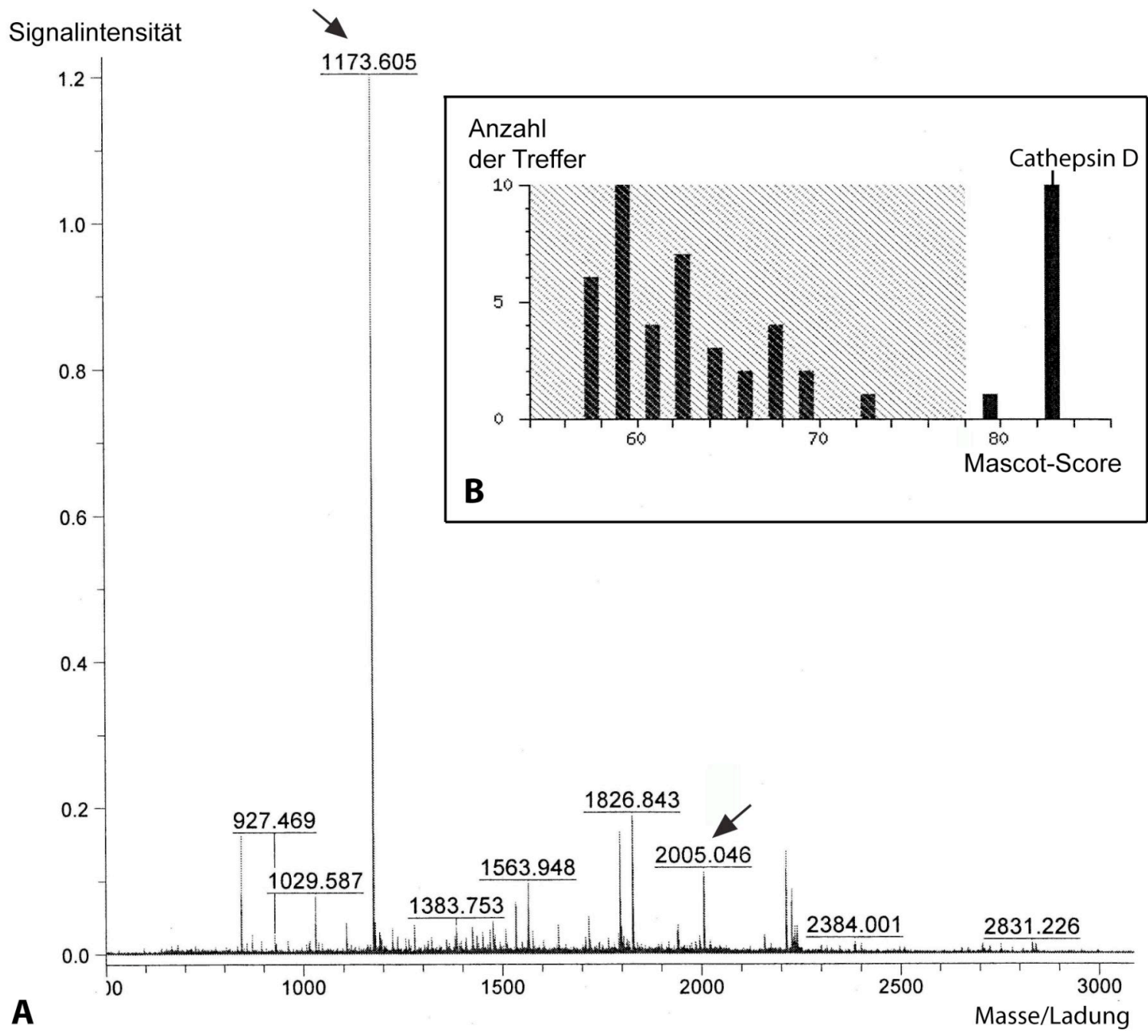

Abb. 3-20: MALDI-TOF Massenspektrum und Datenbankanalyse

(A) Über MALDI-TOF-MS ermitteltes Massenspektrum von Bande 4 (VI) (vgl. Bande 4 CoomassieGel in Abb. 3-19 und Bande 4 [V1] in Tab. 3-3). Pfeile markieren die Massen, die auch durch MS/MS Analyse Cathepsin D zugeordnet werden konnten. (B) Häufigkeitsverteilung der Datenbankeinträge mit einem bestimmten Mascot-Score für die Analyse von Bande 4 (VI) (vgl. Coomassie-Gel in Abb. 3-19 und Bande 4 [V1] in Tab. 3-3). Der Eintrag für Cathepsin D ist markiert. Der nicht signifikante Bereich $(p \geq 0,05)$ ist grau hinterlegt.

Die Kriterien für eine Identifizierung von Interaktionspartnern waren wie folgt definiert: ein Protein musste sowohl in beiden Versuchen (V1/V2) mit signifikantem Score und durch MALDITOF-MS als auch durch MALDI-TOF-MS/MS identifiziert werden. Des Weiteren mussten potentielle Bindungspartner der Spezies Maus angehören und lysosomale Proteine oder nach bioinformatischer Überprüfung potentiell lysosomale Proteine sein.

In den Banden 1, 2 und 3 (V1 und V2) wurden humanes Albumin und Keratin detektiert, die typische Kontaminanten bei massenspektrometrischen Versuchen darstellen. Das in den Banden 
6 und 7 (V2) detektierte Keratin (Bos taurus) stammt von der Vorreinigung an der BSA-Säule. Des Weiteren wurde in der Bande 1 das murine Protein Partitioningdefective protein $\underline{3}$ homolog isoform 1 (GI61888844, auch Par3) und in Bande 2 die murinen Proteine Odf21(GI18043255) und Glial fibrillary acidic protein (GI387164, auch GFAP) detektiert. Diese drei Proteine sind zytosolisch lokalisiert und daher keine potentiellen Interaktionspartner für das 66.3-kDa-Protein.

Die in Bande 4, 5 und 9 identifizierte lysosomale Aspartat-Peptidase Cathepsin D erfüllte alle Kriterien eines potentiellen Interaktionspartners für das 66.3-kDa-Protein (vgl. [V1] Abb. 3-19 A Bande 4, 5 und 9; Tab. 3-3). Im Western Blot [V3] mit dem Cat-D-Antikörper konnte Cathepsin D ebenfalls in den Elutionsfraktionen der Affinitätschromatographie dargestellt werden (vgl. Abb. 3-19 B, Bande I, II und III). Die Interaktion des Cathepsin D mit dem 66.3kDa-Protein sollte durch einen weiteren experimentellen Ansatz bestätigt werden, da die Möglichkeit einer unspezifischen Bindung von Cathepsin D an das 66.3-kDa-Protein oder die Affigel-10-Matrix nicht ausgeschlossen werden konnte.

Im Anschluss wurden daher Co-Immunopräzipitationen und in Kooperation mit Prof. Dr. Stefan Höning (Köln) Interaktionsstudien mit dem Biacore-Analysegerät durchgeführt. Aus technischen Gründen waren diese beiden Ansätze nicht aussagekräftig (vgl. dazu Diskussion Kap. 4.4). Für weitere Interaktionsstudien wurden Yeast-two-Hybrid-Versuche durchgeführt.

Die Massenanalytik wurde von Bernhard Schmidt und Nicole Eiselt der Abteilung Biochemie II am MALDI-TOF/TOF-MS (Reflex I/III, Bruker Daltonik) der Proteomics-Gruppe des MPI für Experimentelle Medizin Göttingen durchgeführt. 
Tab. 3-3: Ergebnisse der Massenanalyse

\begin{tabular}{|c|c|c|c|c|c|}
\hline Bande & Versuch & $\begin{array}{l}\text { Mascot- } \\
\text { Score } \\
\end{array}$ & $\begin{array}{l}\text { GI- } \\
\text { Nummer }\end{array}$ & Proteinname & $\begin{array}{l}\text { Peptid-Massen } \\
\text { identifiziert durch } \\
M S(M S / M S) \\
\end{array}$ \\
\hline \multirow[t]{3}{*}{1} & V1 & 106 & $=55669910$ & $\begin{array}{l}\text { Chain A, Crystal structure of the } \\
\text { Ga Module Complexed with } \\
\text { human serum Albumin } \\
\text { (H. sapiens) }\end{array}$ & $19(1)$ \\
\hline & V2 & 63 & 61888844 & $\begin{array}{l}\text { Partitioning-defective protein } 3 \\
\text { homolog isoform } 1 \text { (M. musculus) }\end{array}$ & $17(11)$ \\
\hline & V2 & 132 & 7428712 & $\begin{array}{l}\text { Keratin 1, type II, cytoskeletal } \\
\text { (H. sapiens) }\end{array}$ & $13(1)$ \\
\hline \multirow[t]{4}{*}{2} & V1 & 122 & 763431 & $\begin{array}{l}\text { Similar to human albumin, Swiss- } \\
\text { Prot Accession Number P02768 } \\
\text { (H. sapiens) }\end{array}$ & $16(2)$ \\
\hline & V1 & 70 & 18043255 & Odf21 protein (M. musculus) & $15(-)$ \\
\hline & V2 & 77 & 387164 & $\begin{array}{l}\text { Glial fibrillary acidic protein } \\
\text { (M. musculus) }\end{array}$ & $16(-)$ \\
\hline & $\mathrm{V} 2$ & 95 & 7331218 & Keratin1 (H. sapiens) & $34(-)$ \\
\hline \multirow[t]{2}{*}{3} & V1 & 104 & 11493459 & PRO2619 / Albumin (H. sapiens) & $13(2)$ \\
\hline & $\mathrm{V} 2$ & 239 & 40354192 & Keratin (H. sapiens) & $37(-)$ \\
\hline \multirow[t]{2}{*}{4} & V1 & 83 & 74220823 & Cathepsin D (M. musculus) & $8(2)$ \\
\hline & V2 & 40 & 74220823 & Cathepsin D (M. musculus) & $2(1)$ \\
\hline 5 & $\mathrm{~V} 2$ & $\mathrm{p}>0,05$ & 74204799 & Cathepsin D (M. musculus) & $5(1)$ \\
\hline $6 / 7$ & V2 & 236 & 76649747 & $\begin{array}{l}\text { Predicted: similar to type I hair } \\
\text { keratin KA28 (B. taurus) }\end{array}$ & $16(2)$ \\
\hline 9 & V2 & 158 & 74204799 & Cathepsin D (M. musculus) & $8(2)$ \\
\hline
\end{tabular}

Massenspektrometrisch ermittelte Peptide wurden mit Hilfe des Mascot-Programmes mit der NCBInrProtein-Datenbank verglichen. Alle Proteine mit signifikantem Mascot-Score $(p-W e r t<0,05)$ wurden in der Tabelle zusammengefasst. Proteine sind der Bande des Coomassie-Gels zugeordnet, in der sie detektiert wurden (vgl. Abb. 3-19). Murine Proteine sind grau hinterlegt. (V1, V2) Versuch, bei dem das jeweilige Protein identifiziert wurde. (MS) MALDI-TOF-MS; (MS/MS) MALDI-TOF MS/MS. 


\subsubsection{Yeast-two-Hybrid (Y2H) mit dem 66.3-kDa-Protein und Cathepsin D}

Zur weiteren Analyse der Interaktion wurde das 66.3-kDa-Protein und Cathepsin D im Y2H-System untersucht. Dazu wurde das Matchmaker GAL4 Two-Hybrid System 3 (Clontech) mit den Vektoren pGADT7 (prey-Vektor) und pGBKT7 (bait-Vektor) verwendet (vgl. Kap. 6.3).

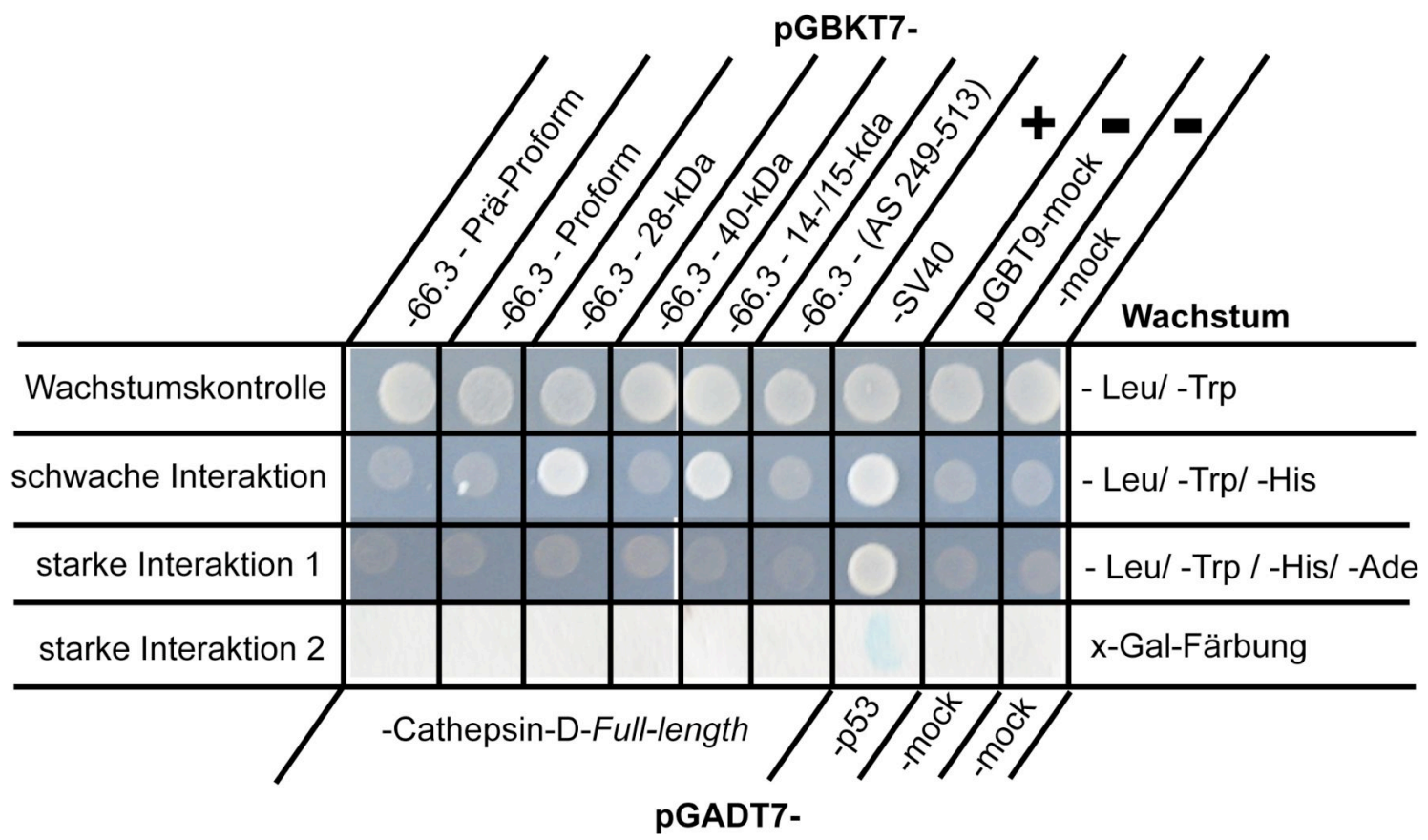

\section{Abb. 3-21: $\quad$ Interaktion von 66.3-kDa-Protein und Cathepsin D}

Im Yeast-two-Hybrid-Versuch wurden im prey-Vektor (pGADT7) die Full-length-Form von Cathepsin D und im bait-Vektor ( $p G B K T 7$ ) die verschiedenen Fragmente des 66.3-kDa-Proteins in Hefe exprimiert. Die Interaktion zwischen SV-40 und p53 diente als Positivkontrolle. Die Verwendung von mock-Vektoren diente als Negativkontrolle. Das Wachstum wurde auf Mangelnährböden ohne Tryptophan (-Trp), ohne Leucin (-Leu); ohne Histidin (-His) und ohne Adenin (-Ade) untersucht.

Hefen wurden mit Cathepsin D und jeweils einem Fragment des 66.3-kDa-Proteins (PräProform, Proform, 40-, 28- und 15-kDa-Fragmente) doppel-transfiziert. Das Wachstum der Hefen auf Selektionsmedium ohne die Aminosäuren Leu und Trp diente als Transfektionskontrolle. Das Wachstum auf Selektionsmedium ohne Leu/Trp und His diente als Nachweis einer schwachen Interaktion. Wachstum auf Selektionsmedium ohne Leu/Trp/His und Adenin, sowie eine positive X-Gal-Färbung (5-Brom-4-Chlor-3-Indoxyl- $\beta$-D-Galactopyranosid) diente als Nachweis einer starken Interaktion. Für das 28-kDa-Fragment und das 15-kDaFragment lässt sich mit der Cathepsin-D-Full-length-Form eine Interaktion detektieren. Die Positivkontrolle mit large-T und p53 war in allen vier Tests positiv, die Negativkontrollen der leeren mock-Vektoren miteinander waren negativ. Die beiden mit Cathepsin D interagierenden 
Fragmente, das 28- und 15-kDa-Fragment, waren die Fragmente des 66.3-kDa-Proteins, die in der Mausleber nachgewiesen wurden (vgl. Abb. 3-11). Dieses Ergebnis ist ein weiterer Hinweis auf eine Interaktion zwischen Cathepsin D und dem 66.3-kDa-Protein, wobei anzumerken ist, dass es sich bei den Versuchsbedingungen um ein unphysiologisches Milieu bei pH 7,4 im Zellkern der Hefe handelt. Die Y2H-Versuche wurden unter Mitarbeit von Dipl. Biologe Peter Braun durchgeführt.

Tab. 3-4: Yeast-two-hybrid

\begin{tabular}{|c|c|}
\hline & Cathepsin D (full-length) \\
\hline Prä-Proform (AS 1-594) & - \\
\hline 75-kDa-Proform (AS 47-594) & - \\
\hline 28-kDa-Fragment (AS 47-248) & + \\
\hline 40-kDa-Fragment (AS 249-594) & - \\
\hline 15-kDa-Fragment (AS 514-594) & + \\
\hline Mittelfragment (AS 249-513 & - \\
\hline
\end{tabular}

\subsubsection{Prozessierung des 66.3-kDa-Proteins in Abhängigkeit von Cathepsin D}

Mit dem Hinweis einer Interaktion zwischen dem 66.3-kDa-Protein und Cathepsin D ergaben sich verschiedene Überlegungen zur möglichen Funktion. So wäre es denkbar, dass Cathepsin D im endosomalen oder lysosomalen Kompartiment bei der proteolytischen Prozessierung des 66.3-kDa-Proteins beteiligt ist. Um eine solche Cathepsin-D-abhängige Prozessierung des 66.3kDa-Proteins zu untersuchen, wurde aufgereinigtes 66.3-kDa-Protein mit aktiviertem, rekombinantem Cathepsin D inkubiert. Darüber hinaus wurde ein pulse-chase-Experiment mit MEF im Vergleich zu Cathepsin-D-defizienten MEF durchgeführt. 


\subsubsection{Verdau des 66.3-kDa-Proteins mit Cathepsin D}

Aufgereinigtes 66.3-kDa-Protein (400 ng) wurde mit katalytischen Mengen (10 ng) von aktiviertem, rekombinantem Cathepsin D (R\&D System, Cat. 1029AS) bei einem lysosomalen $\mathrm{pH}$ von 4,5 bis $\mathrm{zu} 1 \mathrm{~h}$ inkubiert, über SDS-PAGE aufgetrennt und im Western Blot mit 66-Antiserum analysiert (vgl. Abb. 3-22). Cathepsin D wurde zuvor für 30 min bei pH 4,5 in 0,1 M NaAcetat-Puffer autokatalytisch aktiviert. Es zeigten sich keine Veränderung im Prozessierungsmuster des 66.3-kDa-Proteins. Auch beim Einsatz von $100 \mathrm{ng}$ Cathepsin D zeigten sich keine Veränderung in der Bandenverteilung des 66.3-kDa-Proteins. Eine Prozessierung des 66.3-kDa-Proteins durch Cathepsin D ist somit unwahrscheinlich.

\begin{tabular}{|c|c|c|c|c|c|c|}
\hline Cat.D [ng] & 10 & 10 & 10 & 10 & 100 & - \\
\hline Zeit [min] & 0 & 10 & 30 & 60 & 60 & 60 \\
\hline $\begin{array}{c}\text { kDa } \\
75 \\
66\end{array} \rightarrow$ & 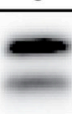 & $\rightarrow$ & 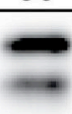 & 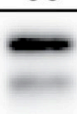 & - & 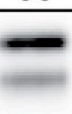 \\
\hline $40 \rightarrow$ & 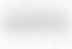 & 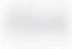 & 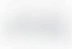 & & 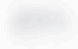 & 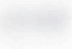 \\
\hline $28 \rightarrow$ & in & 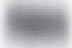 & at & $\sqrt{2+2}$ & 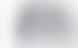 & $x=$ \\
\hline
\end{tabular}

Abb. 3-22: Inkubation von 66.3-kDa-Protein mit Cathepsin D

400 ng 66.3-kDa-Protein wurden mit jeweils $10 \mathrm{ng}$ und $100 \mathrm{ng}$ Cathepsin D für bis zu $1 \mathrm{~h}$ bei $37^{\circ} \mathrm{C}$ in 0,1 M NaAcetat-Puffer, pH 4,5 inkubiert. Das Protein wurde über SDS-PAGE aufgetrennt und mit dem 66-Antiserum analysiert.

\subsubsection{Prozessierung des 66.3-kDa-Proteins in Cathepsin-D-defizienten MEF}

Cathepsin-D-defiziente MEF bzw. Kontroll-MEF wurden für eine Stunde mit $\left[{ }^{35} \mathrm{~S}\right]-$ Methionin/Cystein metabolisch markiert. Das 66.3-kDa-Protein wurde anschließend mit dem 66-Antiserum immunpräzipitiert, autoradiographisch analysiert und densitometrisch quantifiziert.

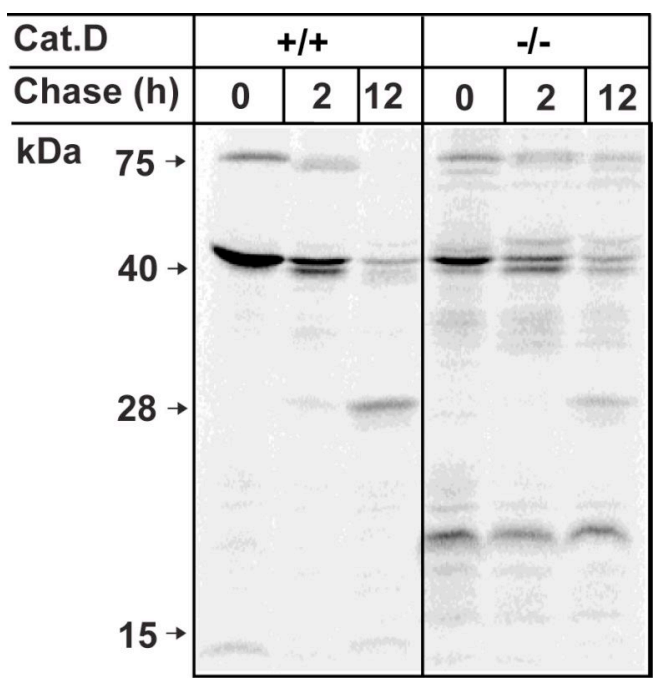

Abb. 3-23: $\quad$ Prozessierung des 66.3-kDa-Proteins in Cathepsin-D-defizienten $\mathrm{MEF}$

Cathepsin-D-defiziente MEF und Kontroll-MEF wurden $1 \mathrm{~h}$ metabolisch markiert, das 66.3-kDa-Protein mittels Immunpräzipitation mit dem 66-Antiserum isoliert und über SDS-PAGE aufgetrennt. Das Gel wurde getrocknet und autoradiographisch analysiert. Cat.D =Cathepsin D. 
Die 75-kDa-Proform des 66.3-kDa-Proteins wurde nach 0 h Chase-Zeit in Kontroll-MEF und in Cathepsin-D-defizienten MEF mit fast identischer Signalstärke detektiert (vgl.

Abb. 3-23). Nach 2 h Chase-Zeit wurde in Kontroll-MEF ein etwa $15 \%$ schwächeres Signal als in den Cathepsin-D-defizienten MEF festgestellt. Nach 12 h Chase-Zeit war das Signal der Proform in Kontroll-MEF 50 \% schwächer als in Cathepsin-D-defizienten MEF. Die 40-kDaForm konnte in beiden Zelllinien nach $2 \mathrm{~h}$ Chase-Zeit mit intensiver Signalstärke und nach $12 \mathrm{~h}$ Chase-Zeit mit abgeschwächter Signalstärke detektiert werden. In Cathepsin-D-defizienten MEF wurde ein schwaches 40-kDa-Signal bereits bei $0 \mathrm{~h}$ Chase-Zeit detektiert. Das 28-kDa-Signal war nach $12 \mathrm{~h}$ Chase-Zeit in beiden Zelllinien detektierbar, in Kontroll-MEF allerdings mit 30 \% höherer Intensität als in den Cathepsin-D-defizienten MEF. Zusätzlich konnte in Cathepsin-Ddefizienten MEF eine Bande bei etwa 20 kDa präzipitiert werden, die zu allen drei Chase-Zeiten detektierbar war.

Anhand der metabolischen Markierung und Immunpräzipitation konnte gezeigt werden, dass das 66.3-kDa-Protein in MEF und in Cathepsin-D-defizienten MEF annähernd gleich prozessiert wird. Cathepsin-D-defiziente MEF zeigen lediglich ein Polypeptid bei $20 \mathrm{kDa}$, das jedoch bereits nach $0 \mathrm{~h}$ Chase-Zeit nachweisbar ist und daher als unspezifisches Signal angesehen werden kann. Diese Ergebnisse lassen darauf schließen, dass Cathepsin D keine essentielle proteolytische Rolle bei der Prozessierung des 66.3-kDa-Proteins übernimmt. Die Prozessierung des 66.3-kDa-Proteins findet in Cathepsin-D-defizienten MEF statt, jedoch mit einer langsameren Prozessierungskinetik.

\subsubsection{Subzelluläre Verteilung des 66.3-kDa-Proteins in Abhängigkeit von Cathepsin D (Cathepsin-D-defiziente MEF)}

Zur Untersuchung der intrazellulären Verteilung des 66.3-kDa-Proteins in Abhängigkeit von Cathepsin D wurden Cathepsin-D-defiziente MEF und Kontroll-MEF auf gelatinierten Deckplättchen ü.N. kultiviert, fixiert und mittels indirekter Immunfluoreszenz mit dem LSM hinsichtlich der intrazellulären Verteilung des 66.3-kDa-Proteins, Cathepsin D und LAMP-1 analysiert. In Abb. 3-24 wurde das 66.3-kDa-Protein rot, LAMP-1 blau, und Cathepsin D grün dargestellt. In Cathepsin-D-defizienten MEF konnte erwartungsgemäß kein spezifisches Signal für Cathepsin D detektiert werden. 


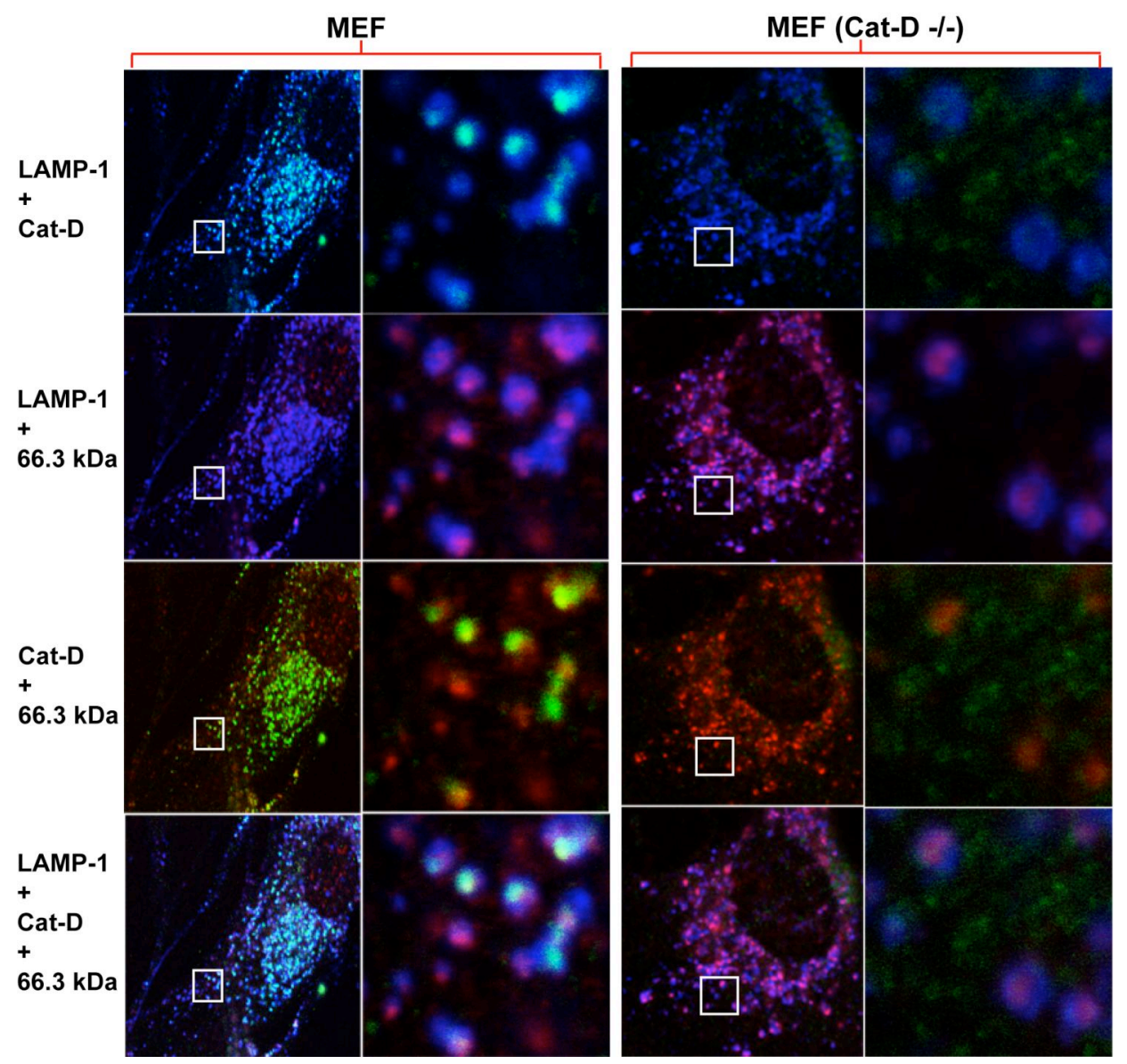

Abb. 3-24: Zelluläre Verteilung des 66.3-kDa-Proteins in Abhängigkeit von Cathepsin D

Immunfluoreszenzaufnahmen von MEF und Cathepsin-D-defizienten MEF nach Immundetektion mit dem $\alpha$-LAMP-1-Antikörper und den 66.3-kDa-Protein- und Cat-D-Antiseren. Die Quadrate in der Übersichtsaufname auf der linken Seite geben die Lokalisation des Vergrößerungsausschnittes auf der rechten Seite an. Blau = LAMP-1; Grün = Cathepsin D (Cat-D); Rot =66.3-kDa-Protein .

In der Immunfluoreszenz weisen MEF eine eindeutige Co-Lokalisation mit LAMP-1 und Cathepsin D auf, wobei das integrale Membranprotein LAMP-1 im LSM-Bild als ringförmiges Signal um das luminale Cathepsin-D-Signal detektiert wird (obere Reihe, links). In den Cathepsin-D-defizienten MEF wurde erwartungsgemäß nur LAMP-1 detektiert (obere Reihe, rechts). In der zweiten Reihe sind LAMP-1 und das 66.3-kDa-Protein dargestellt. Es konnte in beiden Zelllinien gleichermaßen LAMP-1 als ringförmige Struktur und luminal davon das 66.3kDa-Protein detektiert werden. In der dritten Reihe wurden Cathepsin D und das 66.3-kDaProtein dargestellt. In MEF auf der linken Abbildungsseite konnte eine Co-Lokalisation nachgewiesen werden. Auf der rechten Abbildungsseite wurde lediglich das Signal des 66.3kDa-Proteins detektiert. In der vierten Reihe sind in den Kontroll-MEF alle drei lysosomalen Proteine übereinander dargestellt. In Cathepsin-D-defizienten MEF konnte lediglich das 66.3kDa-Protein und LAMP-1 detektiert werden. Die intrazelluläre Verteilung des 66.3-kDa-Proteins in Cathepsin-D-defizienten MEF im Vergleich zu MEF ist identisch. 
Diskussion 
Es sind ca. 50 lysosomale Matrixproteine bekannt und etwa 40 humane Erkrankungen konnten bislang mit Defekten in diesen Proteinen in Verbindung gebracht werden. Es ist sehr wahrscheinlich, dass durch die Identifikation und Charakterisierung bislang unbekannter lysosomaler Proteine auch unbekannte lysosomale Erkrankungen identifiziert werden können (Naureckiene et al. 2000; Sleat et al. 1997). Im Idealfall können nach eingehender molekularer und biochemischer Charakterisierung der Proteine und der Erkrankungen Therapien entwickelt werden, so wie z.B. bereits für die Glucocerebrosidase bei Morbus Gaucher (Barton et al. 1991; Weinreb et al. 2002), für die $\alpha$-Galactosidase bei Morbus Fabry (Baehner et al. 2003; Brady et al. 2001; Hajioff et al. 2003) und für die $\alpha$-Glucosidase bei Morbus Pompe (Glykogenose Typ II) (Van den Hout et al. 2001; Winkel et al. 2003) beschrieben. Im Mittelpunkt der vorliegenden Arbeit steht das murine 66.3-kDa-Protein, das erstmals von Kollmann et al. (2005) im Rahmen einer Proteomanalyse als putativ lysosomales Matrixprotein beschrieben wurde (vgl. Kap. 1.5). In dieser Analyse gab es erste Hinweise auf eine lysosomale Lokalisation des 66.3-kDa-Proteins. So konnte gezeigt werden, dass eine C-terminal markierte Variante des 66.3-kDa-Proteins MPRabhängig von Fibroblasten internalisiert und in Lysosomen transportiert wird (vgl. Kap. 1.7) (Kollmann et al. 2005). In der vorliegenden Arbeit wurde das 66.3-kDa-Protein hinsichtlich seines molekularen Aufbaus, seines Expressionsmusters und seiner Funktion untersucht.

\subsection{Bioinformatische Analyse}

Eine Sequenzanalyse des 66.3-kDa-Proteins (Accession-Nr. AAH38605) in Proteindatenbanken wie Pfam und ExPASy (http://www.sanger.ac.uk/Software/Pfam und http://expasy.org; Stand Januar 2008) zählt das Protein zur Phospholipase-B-Familie (Domäne von AS 75 - AS 594; pfam-Nummer: pfam04916). Zuvor wurde diese Proteinfamilie in den Datenbanken lange Zeit als Laminin-A-Familie geführt, da sie nach ihrer Sequenzhomologie des erstbeschriebenen Proteins dieser Familie, Lama (lamina ancestor) aus Drosophila melanogaster, benannt wurde (Perez und Steller 1996). Mit dem Nachweis der PhosopholipaseB-Aktivität des homologen Proteins im Schleimpilz Dictyostelium discoideum wurde die Proteinfamilie nach dieser Lipase umbenannt (Morgan et al. 2004). Es existieren homologe Proteine des 66.3-kDa-Proteins sowohl in anderen Säugern (u.a. Rattus norvegicus, Bos taurus, Canis familiaris und Homo sapiens) als auch in Trypanosoma brucei (T. brucei) und D. discoideum, nicht aber in der S. cerevisiae (vgl. Abb. 4-1). 


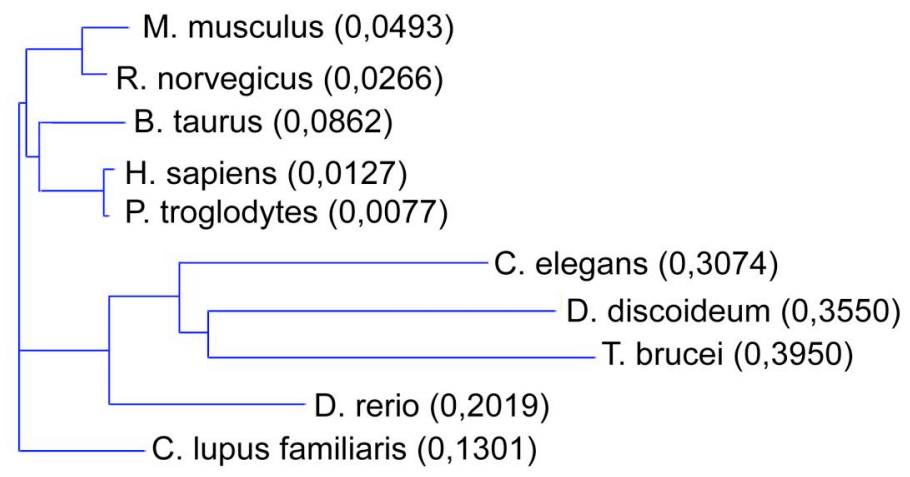

Abb. 4-1: Phylogenetischer Stammbaum ausgesuchter homologer Proteine des 66.3-kDaProteins

Die Berechnung erfolgte nach dem „Neighbor Joining Algorithmus“ (Saitou und Nei 1987). Die Abbildung wurde mit VectorNTI Advance V.10 (Invitrogen) erstellt.

\subsubsection{Homologe Proteine des 66.3-kDa-Proteins}

Bislang wurde nur für das homologe Protein in D. discoideum eine Funktion beschrieben (Morgan et al. 2004). Das Protein spaltet beide Fettsäuren von Phosphoglyceriden, wie Phosphatidylcholin, Phosphatidylethanolamin und Phosphatidylinositol ab (Morgan et al. 2004) und besitzt somit sowohl Phospholipase- $\mathrm{A}_{1}$-Aktivität, da es die Esterbindung am $\mathrm{C}_{1}$-Atom des Glycerins hydrolysiert, als auch Phospholipase- $\mathrm{A}_{2}$-Aktivität, da es die Esterbindung am $\mathrm{C}_{2}$-Atom des Glycerins hydrolysiert. Daraus ergibt sich definitionsgemäß eine Phospholipase-B-Aktivität (vgl. Abb. 4-2) (Waite 1985). Die Aminosäuresequenz dieses Proteins weist eine $36 \%$ ige Identität zu der des 66.3-kDa-Proteins auf. Morgan et al. (2004) zeigten, dass die Sequenz -NSGTYNNQ- (vgl. Aminosäure 410 und 417 in Abb. 6-7) eine in D. discoideum, M. musculus und H. sapiens hoch konservierte Sequenz der Phospholipase-B ist, in der Serin potentiell an der Hydrolyse beteiligt sein könnte (Morgan et al. 2004). In M. musculus und H. sapiens gibt es mit der Sequenz GxSxG (zwischen Aminosäure 430 und 435 in Abb. 6-7) eine weitere Sequenz, in der Serin als katalytisches Zentrum mit Lipaseaktivität fungieren könnte (Morgan et al. 2004).

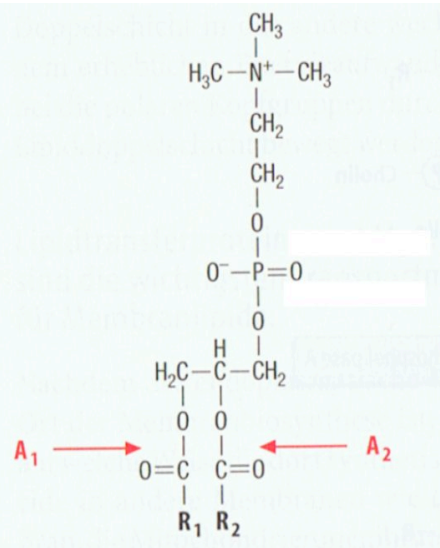

\section{Abb. 4-2 Phospholipase B}

Dargestellt ist die Funktion der Phospholipase B am Beispiel von Phosphatidylcholin. Die Pfeile markieren die Angriffspunkte der Phospholipase-A1-Aktivität am C1-Atom und der Phospholipase-A2Aktivität am C2-Atoms des Glycerins (modifiziert nach Löffler und Petrides 2003, S. 606). 
Das homologe Protein des 66.3-kDa-Proteins in T. brucei, p67, ist ein integrales Membranprotein, mit lysosomal-endosomaler Lokalisation. Die Aminosäuresequenz von p67 weist eine $28 \%$ ige Identität $\mathrm{zu}$ der des murinen 66.3-kDa-Proteins auf. p67 besitzt ein Signalpeptid, eine große mit 14 putativen N-Glykosylierungsstellen hoch glykosylierte, N-terminale, luminale Domäne, eine Typ-1-Transmembrandomäne (vgl. Abb. 3-15) und eine kurze, C-terminale zytoplasmatische Domäne (Kelley et al. 1999) und ähnelt damit den integralen lysosomalen Membranproteinen LAMP-1 und LAMP-2 (Lysosomen-assoziierte Membranproteine). Im Vektororganismus Glossina morsitans (Tsetsefliege) gelangt p67 ohne Modifikationen der N-Glykane im Golgi-Apparat als 100-kDa-Glykoprotein zum Lysosom (Kelley et al. 1995). Im menschlichen Wirtsorganismus gelangt p67 als 100-kDa-Glykoprotein nach Modifikationen der N-Glykane im Golgi-Apparat als 150-kDa-Polypeptid zum Lysosom (Brickman und Balber 1994). Interessanterweise werden die jeweiligen Formen beider Lebenszyklen im endosomalen/lysosomalen Kompartiment gleichermaßen proteolytisch zuerst in eine etwa 75-kDa- und eine 32-kDa-Form abgebaut. Die 75-kDa-Form wird anschließend in eine 42-kDa- und eine 28-kDa-Form prozessiert (Brickman und Balber 1994; Kelley et al. 1999; Kelley et al. 1995). Dies bedeutet, dass die 150-kDa-Form im Lysosom parallel zur oder kurz vor der proteolytischen Spaltung die Modifikationen an den N-Glykanen durch endogene Glykosidaseaktivität wieder verliert (Alexander et al. 2002). Alexander et al. (2002) vermuten, dass die Modifikationen an N-Glykanen den vorzeitigen Abbau des Proteins in den wesentlich aktiveren Lysosomen der Lebensform im Wirtsorganismus verhindern soll. Vorläufige und unveröffentlichte Ergebnisse der Arbeitsgruppe Alexander et al. (2002) deuten in T. brucei auf einen letalen Knock-down des p67 durch RNAi hin (Alexander et al. 2002). Über die Analyse der 66.3-kDa-Protein-Knock-out-Maus können demnächst Aussagen über eine mögliche Letalität in der Maus getroffen werden.

Aufgrund seiner Molekühlstruktur (vgl. oben) ähnelt das p67 den integralen lysosomalen Membranproteinen LAMP-1 und LAMP-2 (Kelley et al. 1999). LAMP-2 kann in verschiedenen Isoformen vorkommen. Durch alternatives Spleißen des primären LAMP-2-mRNA-Transkriptes entstehen die Isoformen LAMP-2A / -2B/ -2C. Diese zeigen eine gewebespezifische Expression (Gough und Fambrough 1997; Konecki et al. 1995; Lichter-Konecki et al. 1999).

Die Funktion von LAMP-1 und LAMP-2 wurde lange Jahre besonders in einer Schutzfunktion der lysosomalen Membran gegenüber sauren Hydrolasen der lysosomalen Matrix gesehen (Kornfeld S und Mellman 1989). Insbesondere für das LAMP-2-Protein werden noch weitere Funktionen beschrieben. In Hepatozyten von Mäusen mit LAMP-2-Defizienz wurde die vermehrte Bildung von autophagozytotischen Vakuolen, eine Fehlsortierung von MPR46 und 
eine Sekretion von Cathepsin D in das Zellkulturmedium beschrieben (Eskelinen et al. 2002). LAMP-2A fungiert u. a. als Rezeptor und Mediator für die Chaperon-vermittelte und autophagozytotische Aufnahme von zytosolischen Proteinen in das Lysosom (Cuervo und Dice 1996, 1998, 2000). Zudem spielt LAMP-2A eine Rolle bei der Präsentation zytosolischer Peptide über den MHC-II-Rezeptor (Zhou et al. 2005). Verschiedene Mutationen im Gen für LAMP-2 konnten mit der Danon-Erkrankung in Verbindung gebracht werden (Nishino et al. 2000). Die Danon-Erkrankung wurde erstmals als „Lysosomale Glykogenspreichererkrankung mit normaler Aktivität der sauren $\alpha-1,4-G l u k o s i d a s e “$ beschrieben und manifestiert sich in Form einer Kardiomyopathie, Myopathie und mentalen Retardierung (Danon et al. 1981). Für LAMP-2C ist noch keine Funktion beschrieben.

\subsection{Nachweis der subzellulären Lokalisation}

\subsubsection{Expression und Aufreinigung des 66.3-kDa-Proteins}

Prinzipiell können Proteine mit wenig Aufwand und in großer Menge rekombinant in prokaryotischen Systemen synthetisiert und aufgereinigt werden. In diesen Systemen sind jedoch co- und posttranslationale Modifikationen, wie N-Glykane oder M6P-Reste, sowie die Bildung von Disulfidbrücken nicht möglich (vgl. Kap. 1.2). Da diese Modifikationen für lysosomale Proteine und Proteine des sekretorischen Weges von besonderer Bedeutung sind, wurde das 66.3-kDa-Protein in einem eukaryotischen Zellsystem exprimiert, in dem das Protein zum überwiegenden Teil in das Zellkulturmedium sezerniert wurde.

Die in den Vorarbeiten von Kollmann et al. (2005) etablierte Aufreinigung des V5-His6markierten 66.3-kDa-Proteins aus BHK-Zellen ergab vergleichsweise geringe Proteinmengen. Daher wurde in der vorliegenden Arbeit die cDNA als RGS-His6-Variante in den pcDNA3.1/Hygro-Vektor kloniert. Diese RGS-His6-Variante wurde stabil in HT1080 transfiziert und ein Einzelklon (HT1080-66) isoliert, der gegenüber dem alten Expressionsystem eine etwa sechsfach höhere Sekretion des Proteins in den Zellkulturüberstand aufwies (vgl. Abb. 3-1). Aus dem Zellkulturüberstand von HT1080-66 konnten etwa 0,25 mg/1 66.3-kDa-Protein durch eine zweistufige chromatographische Aufreinigung mittels Ni-NTA und Anionenaustauschchromatographie aufgereinigt werden (vgl. Abb. 3-2 und Abb. 3-3).

Bei der qualitativen Analyse der Proteinaufreinigung im Silbergel konnten zwei dominante Proteinfragmente mit Molekulargewichten von $75 \mathrm{kDa}$ und $40 \mathrm{kDa}$, sowie zwei weitere Proteinfragmente mit Molekulargewichten von $66 \mathrm{kDa}$ und $28 \mathrm{kDa}$ nachgewiesen werden (vgl. Abb. 3-3). Das 75-kDa-Vorläufer-Fragment ist die Proform des Proteins und geht durch die 
Abspaltung des Signalpeptids (AS 1-46) aus der Prä-Proform hervor. Die übrigen Fragmente entstehen durch limitierte Proteolyse der Proform. Alle vier Formen konnten durch die N-terminale Sequenzierung als Fragmente des 66.3-kDa-Proteins identifiziert werden (vgl. Abb. 3-5 und Abb. 3-6), wobei die Proform und die Fragmente mit $66 \mathrm{kDa}$ und $28 \mathrm{kDa}$ N-terminal erst mit der Aminosäure Leu47 beginnen und damit nicht mit Aminosäure Pro42, wie von Kollmann et al. (2005) anhand bioinformatischer Analysen postuliert.

Zur weiteren Charakterisierung des endogenen bzw. des rekombinanten Proteins wurde das aufgereinigte, rekombinante 66.3-kDa-Protein zur Generierung eines Antiserums in Kaninchen genutzt. Das 66-Antiserum detektierte die verschiedenen Fragmente des 66.3-kDa-Proteins in der Western-Blot-Analyse (vgl. Abb. 3-4) und konnte auch für den Nachweis der lysosomalen Lokalisation des Proteins durch indirekte Immunfluoreszenz (vgl. Abb. 3-9) und für die Immunpräzipitation des metabolisch markierten 66.3-kDa-Proteins verwendet werden (vgl. Abb. 3-17 und Abb. 3-18). Neben den schon bekannten Fragmenten des 66.3-kDa-Proteins detektierte das 66-Antiserum ein zuvor nicht beschriebenes 15-kDa-Fragment. Mit der N-terminalen Sequenzierung konnte bestätigt werden, dass es sich um ein Fragment des 66.3-kDa-Proteins handelt, das mit AS 514 beginnt. Zudem konnte das 15-kDa-Fragment mit dem $\alpha$-HisAntikörper detektiert werden, so dass dieses Fragment C-terminal nicht prozessiert wurde (vgl. Abb. 3-5). Mit dem 66-Antiserum ist zudem ein 40-kDa Polypeptid im Western Blot (vgl. Abb. 3-8) und der Immunpräzipitation (vgl. Abb. 3-17) zu detektieren, das nicht dem 66.3-kDaProtein zugeordnet werden kann. Aufgrund der Ergebnisse des zugehörigen Präimmunserums wurde diese Interaktion als Kreuzreaktion beschrieben (vgl. Abb. 3-8 und Abb. 3-11).

\subsubsection{Lysosomale Lokalisation des 66.3-kDa-Proteins}

Das 66.3-kDa Protein besitzt mit dem Signalpeptid und mehreren N-Glykosylierungsstellen die Eigenschaften eines lysosomalen Matrixproteins. Mittels Immunfluoreszenz mit dem 66-Antiserum konnte erstmals das endogene 66.3-kDa-Protein in Lysosomen von MEF durch die Co-Lokalisation mit LAMP-1-markierten Lysosomen und mit dem lysosomalen Matrixprotein Cathepsin D gezeigt werden (vgl. Abb. 3-9). Bei der subzellulären Fraktionierung von Mausleberhomogenaten wurde das 66.3-kDa-Protein in der lysosomalen Fraktion zusammen mit den lysosomalen Proteinen $\beta$-Hexosaminidase, $\beta$-Glucuronidase, LAMP-1 und Cathepsin D angereichert und co-fraktioniert (vgl. Abb. 3-11 und Tab. 3-2). Anhand dieser beiden Methoden konnte eindeutig gezeigt werden, dass es sich bei dem 66.3-kDa Protein um ein lysosomal lokalisiertes Protein handelt. In einer Analyse des humanen homologen Proteins (p76) und des 
murinen Proteins konnten Jensen et al. (2007) die Ergebnisse durch die Immunfluoreszenz bzw. die subzelluläre Fraktionierung bestätigen.

\subsection{Molekulare Charakterisierung des 66.3-kDa-Proteins}

\subsubsection{Gewebesspezifische Expression des 66.3-kDa-Proteins}

Bei der Northern-Blot-Analyse verschiedener Mausgewebe wurden mit einer full-lengthSonde des 66.3-kDa-Proteins drei Transkripte zwischen $2 \mathrm{~kb}$ und $4 \mathrm{~kb}$ detektiert (vgl. Abb. 3-7). Dabei variieren sowohl die Stärke der Transkription in den untersuchten Geweben als auch die relativen Mengen der drei Transkripte untereinander. Auf Proteinebene fallen bei der WesternBlot-Analyse verschiedener Mausgewebe 66.3-kDa-Protein-Fragmente verschiedener Größen in einer gewebsspezifischen Verteilung und einer gewebespezifischen Expressionshöhe auf (vgl. Abb. 3-8). So wurden in Gehirn-, Herz- und Milzgewebe Proteine bei 50, 34 bzw. 24 kDa detektiert, während in Hoden-, Leber- und Nierengewebe nur sehr schwache oder keine Signale des 66.3-kDa-Proteins zu detektieren waren. Dagegen konnte nach 40- bis 60-facher Anreicherung von Lysosomen aus Leberhomogenat nach der subzellulären Fraktionierung das 28- und 15-kDa-Fragment detektiert werden, so dass davon auszugehen ist, dass die Expression in der Leber unterhalb der Nachweisgrenze unserer Western Blots lag (vgl. Abb. 3-11).

Die beschriebene gewebsspezifische Expression und Prozessierung unterscheidet das 66.3kDa-Protein von den meisten anderen lysosomalen Proteinen und könnte auf gewebespezifische Funktionen des Proteins hinweisen. Für ein anderes lysosomales Protein, die lysosomale SerinProtease Cathepsin A, wurde zuvor eine solche gewebespezifische Transkription (Galjart et al. 1990) und Expression beschrieben (Luedtke et al. 2000). In Northern-Blot-Analysen lassen sich für das Cathepsin A in allen untersuchten Mausgeweben Transkripte mit sehr unterschiedlicher Transkriptionshöhe nachweisen. Während in der Niere und der Plazenta sehr große Mengen eines $2 \mathrm{~kb}$ großen Transskriptes vorkommen, sind es im Hoden sehr geringe. Zusätzlich findet sich ein mittleres Transkript im Gehirn und ein wesentlich größeres in Gehirn und Niere (Galjart et al. 1990). In licht- und elektronenmikroskopischen Aufnahmen konnte für das Hoden- und Nebenhodengewebe ( $R$. norvegicus) eine ausgeprägte zellspezifische Expression beschrieben werden. So konnten Cathepsin A in Sertoli- und Leydig-Zellen, nicht aber in Keimzellen nachgewiesen werden (Luedtke et al. 2000).

Die lysosomale Serin-Protease Cathepsin A besitzt neben ihrer Carboxypeptidaseaktivität bei pH 5,6, Esterase- und Deamidaseaktivität bei neutralem pH (Itoh et al. 1993). Darüber hinaus aktiviert und stabilisiert Cathepsin A die Neuraminidase (van der Spoel et al. 1998) und fungiert 
als so genanntes „protektives Protein“ in einem Multienzymkomplex aus $\beta$-Galaktosidase und Neuraminidase (D'Azzo et al. 1982; Hoogeveen et al. 1983; Morreau et al. 1992). Eine Defizienz von Cathepsin A führt zu der lysosomalen Speichererkrankung Galaktosialidose, die durch eine mangelnde Aktivität von $\beta$-Galaktosidase und Neuraminidase gekennzeichnet ist (D'Azzo et al. 1982). Das 66.3-kDa-Protein weist in Expression und Prozessierung Ähnlichkeiten zu Cathepin A auf und so besteht die Möglichkeit, dass das 66.3-kDa-Protein ebenfalls multiple Funktionen ausführen könnte. Ein Protein, das verschiedene Funktionen ausübt, interagiert möglicherweise mit unterschiedlichen Bindungspartnern. Über die Identifizierung von Bindungspartnern könnten somit wichtige Hinweise auf mögliche Funktionen des 66.3-kDaProteins gefunden werden (vgl. auch Kap. 4.4).

\subsubsection{Prozessierung des 66.3-kDa-Proteins}

Durch Immunpräzipitation nach metabolischer Markierung konnte die Prozessierung des 66.3-kDa-Proteins in HT1080-66 und in 3T3-Zellen verfolgt werden (vgl. Abb. 3-17, Abb. 3-18). Durch die N-terminale Sequenzierung (Edmann-Abbau) wurden die N-terminalen Aminosäuren aller Fragmente und durch die Western-Blot-Analyse mit dem $\alpha$-His-Antikörper die C-terminalen Aminosäuren für die Fragmente mit 75-, 40- und 15 kDa bestimmt (vgl. Abb. 3-5). Die Analyse dieser Ergebnisse spricht für folgenden Ablauf einer Prozessierung des 66.3kDa-Proteins in HT1080-66. Bei der Translation und Translokation des Proteins ins Lumen des ER wird das 46 Aminosäuren lange Signalpeptid von der Prä-Proform des Proteins abgespalten und es entsteht die 75-kDa-Proform. Diese Proform wird in ein N-terminales 28-kDa-Fragment und ein C-terminales 40-kDa-Fragment prozessiert. Durch weitere Proteolyse aus dem C-terminalen 40-kDa-Fragment wird das C-terminale 15-kDa-Fragment prozessiert (vgl. Abb. $3-6)$.

Unsere Ergebnisse stehen denen von Jensen et al. (2007) gegenüber, die mit einem Peptidantikörper, der gegen den C-Terminus des homologen Proteins in der Ratte gerichtet ist (Accession-No. AAM23313), ein C-terminales 27-kDa-Fragment in stabil exprimierenden HeLaZellen und in M6P-aufgereinigten Proteinen aus murinem Hirngewebe nachweisen. Jensen et al. (2007) schlagen für das 66.3-kDa-Protein daher eine Prozessierung von der 76-kDa-Proform zu einem C-terminalen 40-kDa-Fragment vor, aus dem wiederum in einem proteolytischen Schritt ein C-terminales 27-kDa-Fragment entsteht. Weder das N-terminale 27-kDa-Fragment noch das C-terminale 15-kDa-Fragment des murinen Proteins wurde von Jensen et al. beschrieben. Für das humane homologe Protein, p76, beschreiben die Autoren eine Prozessierung der Vorläuferform (80 kDa) in ein N-terminales 32-kDa-Fragment und ein C-terminales 45/50-kDa- 
Fragment (Jensen et al. 2007). Es wird kein Äquivalent zu dem murinen 15-kDa-Fragment beschrieben. Für das murine 66.3-kDa-Protein kann die von Jensen et al. (2007) vorgeschlagene Prozessierung durch die hier vorliegenden Ergebnisse widerlegt werden. Zum einen wurde das 28-kDa-Fragment durch die von Kollmann et al. (2005) durchgeführte Massenspektrometrie als N-terminales Ende der Vorläuferform definiert (vgl. Kap. 1.5.2 und Tab. 6-1) und zum anderen wurde es durch die N-terminale Sequenzierung des rekombinant entstandenen Proteins identifiziert (vgl. Abb. 3-5). In Deglykosylierungsversuchen konnte zudem gezeigt werden, dass die drei putativen Glykosylierungsstellen des murine 28-kDa-Fragment genutzt werden (vgl. Abb. 3-13). Ein C-terminales Fragment mit drei N-Glykosylierungsstellen ist anhand der Aminosäuresequenz nicht abzuleiten. Das kleinste C-terminal-gelegene Fragment mit drei besetzten N-Glykosylierungsstellen wäre ein Fragment von AS 235 bis AS 521 und einer errechneten Größe von 36 kDa. Ein Fragment dieser Größe konnte weder von Jensen et al. noch in dieser Arbeit nachgewiesen werden.

Die Aufreinigung der einzelnen endogenen 66.3-kDa-Protein-Fragmente aus den murinen Geweben und deren massenspektrometrische Analyse bzw. N-terminale Sequenzierung könnte in weiterführenden Arbeiten diese Ergebnisse bestätigen.

\subsubsection{Posttranslationale Modifikation des 66.3-kDa-Proteins}

Das 66.3-kDa-Protein wurde hinsichtlich seiner Glykosylierung und der Bildung von intraund intermolekularen Disulfidbrücken untersucht. Im Western Blot von HT1080-66Homogenaten konnte ein annähernd identisches Bandenmuster der 66.3-kDa-Protein-Fragmente unter reduzierenden und nicht-reduzierenden Bedingungen gezeigt werden (vgl. Abb. 3-12). Dies spricht dafür, dass einzelne Fragmente des Proteins nicht über Disulfidbrücken verbunden sind. Die limitierte Deglykosylierung mit PNGase-F zeigte, dass alle fünf putativen N-Glykosylierungsstellen (Position 93, 115, 236, 441, 520 der Aminosäuresequenz) in HT108066-Zellen genutzt werden (vgl. Abb. 3-13, Abb. 3-14).

In einer massenspektrometrischen Analyse zur Identifizierung von M6P-Markierungen an lysosomalen und potentiell lysosomalen Proteinen wurde gezeigt, dass das humane p76 fünf Endo-H-sensible N-Glykane besitzt (Sleat et al. 2006a). Endo- $\beta-N-A c e t y l g l u k o s a m i n i d a s e-H$ (Endo-H) hydrolysiert bevorzugt N-Glykane mit Mannose-reichen Oligosaccharid-Seitenketten (Tarentino et al. 1974). Diese können wegen eines M6P-Restes nicht zu komplexen Oligosacchariden synthetisiert werden (Varki und Kornfeld S 1980, 1983). Im Vergleich zu anderen lysosomalen Proteinen besitzt p76 damit überdurchschnittlich viele Mannose-reiche Oligosaccharid-Seitenketten und potentielle M6P-Markierungen. Dies könnte zu einer 
besonderen Spezifität der Bindung am MPR beitragen und zu einer erhöhten Effizienz beim Transport in das Lysosom führen.

\subsection{Funktionelle Analyse des 66.3-kDa-Proteins}

Die Funktion des murinen 66.3-kDa-Proteins ist gänzlich unbekannt. Wie in Kap. 4.1 beschrieben, wurde unter den homologen Proteinen lediglich für p67 in D. dictyostelium eine Phospholipase-B-Aktivität beschrieben. Die Arbeitsgruppe etabliert derzeit einen in-vivo-Assay zur Überprüfung dieser Aktivität des 66.3-kDa-Proteins in der Maus. Bislang konnte jedoch keine Phospholipase-B-Aktivität nachgewiesen werden (Lübke, 2008). Parallel dazu wurde ein Knock-out-Maus-Modell konzipiert (Lübke, 2008) mit dem u.a. eine Phospholipase-B-Aktivität in-vivo untersucht werden soll. Jensen et al. (2007) konnten in Phospholipase-B-Aktivitätsassays für das p76 ebenfalls keine Aktivität nachweisen.

In der vorliegenden Arbeit sollten durch RNAi des 66.3-kDa-Proteins Hinweise auf seine Funktion erlangt werden. Zum anderen sollten über Affinitätschromatographie mit immobilisiertem 66.3-kD-Protein mögliche Interaktionspartner identifiziert und eine Interaktion dieser Proteine durch in-vitro-Co-Immunpräzipitation und Yeast-Two-Hybrid bestätigt werden.

Die $R N A i$ eines Proteins auf zellulärer Ebene ist eine Methode, um die Auswirkungen einer selektiv induzierten Proteindefizienz auf den Stoffwechsel einer Zelle zu untersuchen (Elbashir et al. 2001; Fire et al. 1998; Tuschl 2001). In dieser Arbeit wurde eine stabile Transfektion der $R N A i$-Sequenz in 3T3-Zellen gewählt. In Western-Blot-Analysen konnte für das 66.3-kDaProtein und die Serincarboxypepdidase-1 (als Kontrolle) eine Suppression der ProteinExpression von maximal $50 \%$ nachgewiesen werden (Ergebnisse nicht gezeigt). Ursächlich für die geringe Suppression ist höchstwahrscheinlich die Wahl der short-interference-RNA (siRNA). Es existieren noch keine sicheren Vorhersagen für die Effizienz von siRNA (Campbell und Choy 2004). Um an Zellen Versuche zum Stoffwechsel durchführen zu können, wird eine Suppression von unter $10 \%$ angestrebt und häufig erreicht. Da die Knock-out-Maus zeitnah zur Verfügung steht, wurde von weiteren $R N A i$-Versuchen in dieser Arbeit abgesehen.

\subsubsection{Identifizierung von Bindungspartnern}

Zur Identifizierung von Bindungspartnern des 66.3-kDa-Proteins wurde eine Fraktion hoch angereicherter lysosomaler Proteine mit immobilisiertem 66.3-kDa-Protein in saurem $\mathrm{pH}$ inkubiert und potentielle Bindungspartner mit schrittweise steigenden Salzkonzentrationen eluiert. Die eluierten Proteine wurden massenspektrometrisch analysiert (vgl. Abb. 3-19, Abb. 3-20 und Tab. 3-3). Unter den identifizierten Proteinen waren für den experimentellen Ansatz 
typische Kontaminanten, wie humanes Keratin oder bovines Serum-Albumin, die wahrscheinlich aus der Vorinkubation mit einer BSA-Säule resultierten. Vier Proteine aus der Maus wurden identifiziert: die drei zytoplasmatischen Proteine, Partitioningdefective protein $\underline{3}$ homolog isoform 1 (Par3), Glial fibrillary acidic protein (GFAP) und OuterDense-Fiber-21 (Odf21) und das lysosomale Protein Cathepsin D. Für Par3 wurden bislang verschiedene Funktionen beschrieben. So ist es in C. elegans für die asymmetrische Zellteilung während der Embryogenese essentiell (Kemphues et al. 1988). Eine jüngere Arbeit beschreibt Par3 als Teil eines Multienzymkomplexes, der die Entwicklung von Cilien in Säugerzellen steuert (Sfakianos et al. 2007). Das GFAP ist ein Intermediärfilament-Protein und an der Bewegung und Struktur von Gliazellen, insbesondere den Astrozyten, beteiligt und wird bei der Astrogliose überexprimiert (Eng LF et al. 2000). Die Funktion von Odf21 ist bislang nicht bekannt.

Aufgrund ihres extra-lysosomalen Vorkommens und der Detektion in jeweils nur einem der beiden affinitätschromatographischen Versuche (V1 oder V2) wurde eine Interaktion dieser murinen Proteine mit dem 66.3-kDa-Protein als unwahrscheinlich angesehen. Lediglich Cathepsin D konnte in allen drei Versuchen (V1-V3) reproduzierbar detektiert werden. Cathepsin D ist zudem ein lysosomales Protein, so dass ein erster Hinweis auf eine Proteininteraktion des 66.3-kDa-Proteins mit Cathepsin D erbracht wurde.

Cathepsin D ist ein in Eukaryoten konserviertes, ubiquitär vorkommendes Protein und katalysiert die hydrolytische Spaltung von Peptidbindungen. Cathepsin D ist eine Endopeptidase und wird aufgrund von zwei katalytisch aktiven Aspartatresten im aktiven Zentrum zu den Aspartatpeptidasen (A1-Familie) gezählt. Das aktive Zentrum von Cathepsin D besitzt eine hohe Affinität zu hydrophoben Aminosäuresequenzen aus fünf Aminosäuren (Conner 2002). Das pHOptimum von Cathepsin D liegt bei 3,5 (Bond und Butler 1987). Das N-acylierte Pentapeptid Pepstatin A bindet mit hoher Affinität im aktiven Zentrum von Cathepsin D und inhibiert dessen Funktion (Morishima et al. 1970). Procathepsin D (53 kDa) wird lysosomal teils durch Cysteinpeptidasen und teils autoproteolytisch über eine Zwischenstufe (47 kDa) zu nichtkovalent verknüpftem, enzymatisch aktivem Cathepsin D (31 kDa und $15 \mathrm{kDa}$ ) aktiviert (Gieselmann et al. 1983). Neben seiner Funktion als Endopeptidase beim allgemeinen lysosomalen Proteinabbau spielt Cathepsin D eine wichtige Rolle bei der Apoptose. Auf der einen Seite ist Cathepsin D ein Mediator der durch TNF- $\alpha$, FAS/APO1 und Interferon- $\gamma$ induzierten Apoptose und kann bei entsprechender Überexpression in Hela-Zellen zum früheren Zelltod führen (Deiss et al. 1996). Auf der anderen Seite aber führt die Defizient von Cathepsin D in Photorezeptorzellen von Cathepsin-D-Knock-out-Mäusen zur frühzeitigen 
Apoptose (Koike et al. 2003). Zudem wurde Cathepsin D eingehend zu seiner Rolle bei der Proliferation (Glondu et al. 2002), Angiogenese (Berchem et al. 2002) und Metastasierung (Garcia et al. 1990) des Mammakarzinoms untersucht.

Cathepsin-D-Knock-out-Mäuse entwickeln sich bis zur zweiten Lebenswoche normal. Nach 14 Tagen ist eine Atrophie der Mukosa des Ileums festzustellen, die sich zu einer fulminanten nekrotisierenden Enteritis mit vermehrten Thromboembolien entwickelt. Zudem kommt es zu einem nekrotisierenden Abbau von Milz und Thymus und einem Verlust von T- und B-Zellen in lymphatischem Gewebe. Die Mäuse sterben mit 26 \pm 1 Tagen an den Auswirkungen dieser Symptome (Saftig et al. 1995). Cathepsin D scheint damit eine wichtige Rolle bei der Umwandlung der neonatalen zur adulten Schleimhaut zu spielen. Die proteolytische Aktivität von den Fibroblasten Cathepsin-D-defizienter Mäuse war nicht eingeschränkt, was darauf schließen lässt, dass die Endopeptidaseaktivität von Cathepsin D von anderen Proteinen übernommen werden kann (Saftig et al. 1995).

Es besteht die Möglichkeit, dass Cathepsin D als Aspartatpeptidase eine Rolle bei der Prozessierung des 66.3-kDa-Proteins spielt. Aus diesem Grund wurde versucht, aufgereinigtes 66.3-kDa-Protein mit aktiviertem Cathepsin D zu prozessieren, bzw. die Prozessierung in MEF und in Cathepsin-D-defizienten MEF durch Immunpräzipitation $\mathrm{zu}$ vergleichen und die subzelluläre Verteilung des 66.3-kDa-Proteins in der Immunfluoreszenz zu untersuchen (vgl. Abb. 3-23 und Abb. 3-24). Da bei der in-vitro-Prozessierung des 66.3-kDa-Proteins keine Prozessierung durch Cathepsin D detektiert werden konnte und auch die subzelluläre Verteilung in Kontroll-MEF und in Cathepsin-D-defizienten MEF identisch war, kann davon ausgegangen werden, dass Cathepsin D keine essentielle Rolle bei der Prozessierung des 66.3-kDa-Proteins einnimmt. Bei der metabolischen Markierung konnte eine leicht verzögerte Prozessierungskinetik des 66.3-kDa-Proteins in Cathepsin-D-defizienten MEF festgestellt werden (vgl. Abb. 3-23).

Um die Protein-Protein-Interaktion zwischen Cathepsin D und dem 66.3-kDa-Protein mit einer zweiten, unabhängigen Methode zu bestätigen, wurden Co-Immunpräzipitationen in HT1080-66 mit dem 66-Antiserum durchgeführt. Bei der Detektion von Cathepsin D mit dem Cat-D-Antiserum (Kaninchen) wurden die Cathepsin-D-Fragmente (31, 47- und $53 \mathrm{kDa}$ ) von den überstrahlenden Signalen der leichten $(\sim 25 \mathrm{kDa})$ und schweren $(\sim 50 \mathrm{kDa})$ Ketten der Immunglobuline des Immunpräzipitationsantikörpers (66-Antiserum) überlagert. Alternativ zur Co-Immunopräzipitation wurde Pepstatin A als bekannter Bindungspartner von Cathespin D (s.o.) immobilisiert und mit einer Fraktion 50-fach angereicherter lysosomaler Proteine (F2, 
subzelluläre Fraktionierung) inkubiert. Allerdings konnte das 66.3-kDa-Protein nicht als Komplex mit Cathepsin D über Pepstatin A co-präzipitiert werden (Ergebnisse nicht gezeigt).

Mit der $\mathrm{Y} 2 \mathrm{H}$-Methode wurde die potentielle Proteininteraktion zwischen dem Cathepsin D und dem 66.3-kDa-Protein bzw. Fragmenten des 66.3-kDa-Proteins untersucht. Die ProteinProtein-Interaktion bei $Y 2 H$-Versuchen finden bei etwa neutralen pH-Bedingungen im Zellkern der Hefen statt, da dort die entsprechenden Transkriptionsfaktoren reassembliert werden und an die DNA binden können. Trotz dieses für lysosomale Proteine unphysiologischen pH-Wertes wurden bereits erfolgreich lysosomale Protein-Protein Interaktionen mit $Y 2 H$ nachgewiesen (Liu et al. 2006a; Liu et al. 2006b; Ye et al. 2005). Die cDNA der einzelnen Fragmente des 66.3-kDaProteins (Prä-Proform, Proform, 40-, 30-, 15-kDa und ein Mittelfragment) sowie die cDNA von Cathepsin D wurden in das entsprechende $Y 2 H$-Vektorensystem kloniert.

Im $Y 2 H$ konnte ein weiterer Hinweis einer schwachen Interaktion zwischen Cathepsin D und dem 28-kDa- und 15-kDa-Fragment des 66.3-kDa-Proteins geführt werden, jedoch nicht mit der Proform des 66.3-kDa-Proteins (vgl. Abb. 3-21). Dies kann einerseits darin begründet sein, dass unter den gegebenen Bedingungen nur diese Fragmente und nicht die Proform reagieren. Andererseits könnten bei der Affinitätschromatographie nicht die Proform des 66.3-kDa-Proteins sondern auch die bei der Aufreinigung des rekombinanten Proteins co-aufgereinigten 28-kDaund 15-kDa-Fragmente (vgl. Abb. 3-3) das Cathepsin D gebunden haben. In weiteren $Y 2 H-$ Versuchen muss die Interaktion der beiden Fragmente genauer untersucht werden. Dazu gehören einerseits weitere Negativkontrollen mit den interagierenden Fragmenten und dem komplementären, leeren bait- oder prey-Vektor und andererseits weitere Interaktionen mit Teilen der interagierenden Fragmente, um die Bindungsstellen des 66.3-kDa-Proteins zu identifizieren. Zudem sollte über mindestens eine weitere Methode die Interaktion unter lysosomalen pHBedingungen verifiziert werden. Dies ist mit dem $Y 2 H$-Vektorensystem z.B. auch durch eine CoImmunpräzipitation nach einer in-vitro-Translation mit radioaktiver Markierung des Proteins möglich, bei der nicht die zuvor genannte Problematik der Detektion nach einfacher CoImmunopräzipitation bestünde. 


\subsection{Ausblick}

An die molekulare Charakterisierung des 66.3-kDa-Proteins wird sich nun eine intensive funktionelle Charakterisierung anschließen. In dieser Arbeit konnte bereits über eine affinitätschromatographische Interaktion Cathepsin D als möglicher Interaktionspartner identifiziert werden. Dieser Hinweis wurde zudem in den $Y 2 H$-Versuchen durch die Interaktion zwischen Cathepsin D und den 28-kDa- und 15-kDa-Fragmenten bestätigt. In weiteren Versuchen sollte die Interaktion unter physiologischen Bedingungen, d.h. bei lysosomalem pHWert bestätigt werden. Dies könnte z.B. durch eine Immunpräzipitation des Komplexes nach Behandlung mit einem membrangängigen Crosslinkers bzw. über die Immunopräzipitation aufgereinigter, rekombinanter Fragmente in vitro geschehen.

Das Knock-out-Maus-Modell befindet sich derzeit in einem Stadium, in dem in absehbarer Zeit die ersten funktionellen Untersuchungen an diesen Tieren und ihren Geweben durchführbar sind. So sind Wachstums- und Entwicklungsstudien ebenso wie die biochemischen und histologischen Analysen von Geweben, Zellen und Organellen geplant. Über diesen ,reversegenetic-approach“ soll die Funktion des 66.3-kDa-Proteins identifiziert werden. Sollte der Knock-out des Proteins einen pathologischen Phänotyp aufweisen, so sollten humane Erkrankungen unbekannter Ätiologie mit diesem Phänotyp in Verbindung gebracht werden. Für eine Reihe lysosomaler Enzyme wurden bereits Mausmodelle für LSDs etabliert, an denen der pathophysiologische Mechanismus und eine mögliche Therapie untersucht werden.

Ein weiterer Ansatz zur Analyse der Funktion könnte die Kristallisation des Proteins und die anschließende Strukturanalyse anhand von Röntgen-Beugungsmustern sein. Ein dreidimensionales Modell der Proteinstruktur könnte über Vergleiche mit Datenbanken Hinweise auf eine Funktion des Proteins oder einzelner Domänen ermöglichen.

Die gewebespezifische Expression des 66.3-kDa-Proteins ist für lysosomale Proteine ungewöhnlich. Daher wäre die genaue Analyse der einzelnen Fragmente aus Gehirn (50 kDa), Lunge $(34 \mathrm{kDa})$ und Milz $(24 \mathrm{kDa})$ von Interesse. Eine Aufreinigung der Fragmente aus murinem Gewebe und die N-terminale Sequenzierung würden Rückschlüsse auf ihre Lokalisation im Gesamtprotein zulassen. In diesem Zusammenhang wäre auch die Synthese von Peptidantikörpern bzw. monoklonalen Antikörpern für die selektive Detektion der einzelnen Fragmente (40 kDa, $28 \mathrm{kDa}$ und $15 \mathrm{kDa})$ vorzunehmen. 


\section{$5 \quad$ Zusammenfassung}

Im Mittelpunkt der Arbeit steht das murine 66.3-kDa-Protein, das erstmals von Kollmann et al. (2005) im Rahmen einer Proteomanalyse als putativ lysosomales Matrixprotein beschrieben wurde. Erste Hinweise auf eine lysosomale Lokalisation ergaben sich mit dem Nachweis der M6P-abhängigen Internalisierung einer C-terminal markierten Form des 66.3-kDa-Proteins in Kontrollfibroblasten und dessen Transport in Lysosomen (Kollmann et al. 2005).

In der vorliegenden Arbeit gelang es, das 66.3-kDa-Protein stabil in HT1080-Zellen zu exprimieren, es für analytische Zwecke aus dem Zellkulturmedium aufzureinigen und ein Antiserum gegen das 66.3-kDa-Protein herzustellen. Das endogene 66.3-kDa-Protein konnte sowohl in Lysosomen überexprimierender HT1080-Zellen als auch in einer Fraktion angereicherter lysosomaler Proteine den lysosomalen Matrixproteinen zugeordnet werden. Das 66.3-kDa-Protein wird in stabil-exprimierenden-HT1080-Zellen aus einer Proform von 75 kDain ein C-terminales 40-kDa-Fragment und ein N-terminales 28-kDa-Fragment prozessiert. Durch limitierte Proteolyse erfolgt vom C-terminalen 40-kDa-Fragment die Abtrennung eines C-terminalen 15-kDa-Fragmentes. Da das 28-kDa- und das 15-kDa-Fragment bei der subzellulären Fraktionierung in der lysosomalen Fraktion nachgewiesen werden konnten, handelt es sich wahrscheinlich um die aktiven Formen des Proteins. Es wurde gezeigt, dass die einzelnen Fragmente des Proteins nicht über Disulfidbrücken miteinander verbunden sind und dass alle fünf putativen N-Glykosylierungsstellen in HT1080-66 mit N-Glykanen besetzt sind. Im Northern Blot konnten drei Transkripte zwischen $2 \mathrm{~kb}$ und 4 kb Größe detektiert werden. Dabei variieren sowohl die Höhe der Transkripte in den untersuchten Geweben als auch die relativen Mengen der drei Transkripte untereinander im jeweiligen Gewebe. Zudem fallen auf Proteinebene bei der Western-Blot-Analyse verschiedener Mausgewebe unterschiedliche Größen gewebespezifischer Varianten des 66.3-kDa-Proteins und eine gewebespezifische Expressionshöhe auf. So wurden in Gehirn-, Herz- und Milzgewebe Fragmente bei entsprechend 50, 34 bzw. 24 kDa detektiert, während in Hoden-, Leber- und Nierengewebe nur sehr schwache oder keine Signale des 66.3-kDa-Proteins zu detektieren waren.

Bei der Affinitätschromatographie von hoch angereicherten lysosomalen Proteinen an immobilisiertem 66.3-kDa-Protein konnte Cathepsin D als ein möglicher Bindungspartner des 66.3-kDa-Proteins identifiziert werden. Dieses Ergebnis wurde durch eine Interaktion zwischen Cathepsin D und dem 28-kDa- bzw. 15-kDa-Fragment des 66.3-kDa-Proteins in $Y 2 H$-Analysen bestätigt. Eine Prozessierung des 66.3-kDa-Proteins durch Cathepsin D konnte ausgeschlossen 
werden. Über das parallel zu dieser Arbeit generierte Knock-out-Maus-Modell werden in Kürze erste Ergebnisse von Wachstums- und Entwicklungsstudien sowie biochemische und histologische Analysen von Geweben, Zellen und Organellen verwertbar sein, die bei der funktionellen Analyse des 66.3-kDa-Proteins helfen können. 


\section{Anhang}




\subsection{Ergebnis der Proteomanalyse von Kollmann et al. (2005)}

Tab. 6-1: Ergebnis Proteomanalyse

\begin{tabular}{|c|c|c|c|c|c|}
\hline Proteins & $\begin{array}{l}\text { gi } \\
\text { number }\end{array}$ & $\begin{array}{c}\text { Theore- } \\
\text { tical } \\
M_{r} \\
\left(\times \mathbf{1 0}^{3}\right) \\
\end{array}$ & $\begin{array}{l}\text { 2D-GE number } \\
\text { of spots (spot \#) }\end{array}$ & $\begin{array}{l}\text { MudPIT: number } \\
\text { of unique peptides } \\
\text { (length of peptides } \\
\text { in amino acids) }\end{array}$ & $\begin{array}{c}\text { Sequence } \\
\text { coverage } \\
\text { in } \\
\text { MudPIT } \\
\end{array}$ \\
\hline \multicolumn{6}{|l|}{$\begin{array}{l}\text { Known lysosomal } \\
\text { matrix proteins: }\end{array}$} \\
\hline $\begin{array}{l}\alpha-D \text {-mannosidase- } \\
\text { acidic }\end{array}$ & 1914843 & 112 & $4(1,2,29,30)$ & $4(9,13,14,14)$ & $5 \%$ \\
\hline$\alpha$-L-fucosidase & 12832063 & 52 & $1(140)$ & --- & --- \\
\hline$\alpha$-glucosidase & 20913867 & 106 & $4(37 \rightarrow 40)$ & $3(11,12,13)$ & $3 \%$ \\
\hline $\begin{array}{l}\alpha-\mathrm{N} \text {-acetyl- } \\
\text { galactosaminidase }\end{array}$ & 3327016 & 47 & $\begin{array}{c}\mathbf{5} \\
(13,116,117,124,19 \\
4)\end{array}$ & $4(9,10,11,17)$ & $11 \%$ \\
\hline \multirow{2}{*}{$\begin{array}{l}\alpha-\mathrm{N} \text {-acetylgluco- } \\
\text { saminidase } \\
\text { acid ceramidase }\end{array}$} & 3329361 & 83 & $4(48 \rightarrow 51)$ & $7(8,8,8,11,13,13,13)$ & $10 \%$ \\
\hline & 9790019 & 45 & --- & $5(10,11,11,14,17)$ & $16 \%$ \\
\hline \multirow{2}{*}{$\begin{array}{l}\text { acid lipase I, } \\
\text { lysosomal } \\
\text { arylsulfatase A }\end{array}$} & 11496259 & 46 & --- & $2(10,11)$ & $5 \%$ \\
\hline & 1703420 & 54 & $1(198)$ & $6(6,6,8,9,11,16)$ & $11 \%$ \\
\hline arylsulfatase B & 33302601 & 43 & $8(6,10,58 \rightarrow 62,87)$ & $3(7,11,13)$ & $8 \%$ \\
\hline$\beta$-galactosidase & 192185 & 73 & $\begin{array}{c}12 \\
(5,41 \rightarrow 47,106,150,1 \\
59,171)\end{array}$ & $2(12,13)$ & $4 \%$ \\
\hline$\beta$-glucuronidase & 309257 & 74 & $9(7,25 \rightarrow 28,63 \rightarrow 66)$ & $4(6,11,13,15)$ & $7 \%$ \\
\hline \multirow[t]{2}{*}{$\begin{array}{l}\beta \text {-hexosaminidase } \\
\text { alpha }\end{array}$} & 232255 & 61 & $\begin{array}{c}34 \\
(11,12,71 \rightarrow 83,88 \rightarrow 9 \\
1,106 \rightarrow 113,130,154\end{array}$ & $3(7,8,13)$ & $5 \%$ \\
\hline & & & $\begin{array}{c}174,195,196,198,19 \\
9)\end{array}$ & & \\
\hline \multirow{2}{*}{$\begin{array}{l}\beta \text {-hexosaminidase } \\
\text { beta } \\
\beta \text {-mannosidase }\end{array}$} & 1346280 & 61 & $10(92 \rightarrow 99,151,193)$ & $4(8,10,10,16)$ & $8 \%$ \\
\hline & 13310141 & 101 & $6(3,32 \rightarrow 36)$ & $1(12)$ & $2 \%$ \\
\hline cathepsin B & 6681079 & 37 & $4(14,152,195197)$ & $5(8,10,11,13,14)$ & $17 \%$ \\
\hline $\begin{array}{l}\text { cathepsin C I } \\
\text { DPP-I }\end{array}$ & 31560607 & 52 & $10(131 \rightarrow 140)$ & $\begin{array}{c}10 \\
(6,7,7,8,8,10,12,12,14 \\
14)\end{array}$ & $21 \%$ \\
\hline cathepsin D & 115718 & 45 & $10(141 \rightarrow 149,151)$ & $5(9,10,10,10,18)$ & $14 \%$ \\
\hline cathepsin F & 4826565 & 52 & -- & $1(15)$ & $3 \%$ \\
\hline cathepsin L & 200501 & 38 & $\begin{array}{c}\mathbf{6} \\
(168 \rightarrow 170,172,183 \\
186)\end{array}$ & $3(10,16,16)$ & $13 \%$ \\
\hline cathepsin Z & 11066226 & 34 & $\begin{array}{c}9 \\
(15,16,18 \rightarrow 20,155 \rightarrow \\
158)\end{array}$ & $5(9,10,11,12,17)$ & $19 \%$ \\
\hline \multirow{5}{*}{$\begin{array}{l}\text { ceroid-lipofusc. } \\
\text { neur. prot. } 5 \\
\text { deoxyribo } \\
\text { nuclease II } \\
\text { dipeptidyl } \\
\text { peptidase II } \\
\text { galactocerebro- } \\
\text { sidase } \\
\text { legumain }\end{array}$} & 20881345 & 39 & $1(141)$ & --- & --- \\
\hline & 6753654 & 39 & $2(160,161)$ & $1(9)$ & $3 \%$ \\
\hline & 13626390 & 56 & $7(8,100 \rightarrow 105)$ & $3(10,12,14)$ & $7 \%$ \\
\hline & 2459856 & 76 & -- & $1(16)$ & $2 \%$ \\
\hline & 7242187 & 49 & $3(84 \rightarrow 86)$ & $1(12)$ & $3 \%$ \\
\hline $\begin{array}{l}\mathrm{N} \text {-acetyl- } \\
\text { glucosamine-6- }\end{array}$ & 29789239 & 61 & $7(4,52 \rightarrow 57)$ & $\begin{array}{c}13 \\
(6,7,8,9,9,1012,12,12,1\end{array}$ & $27 \%$ \\
\hline
\end{tabular}




\begin{tabular}{|c|c|c|c|c|c|}
\hline Proteins & $\begin{array}{l}\text { gi } \\
\text { number }\end{array}$ & $\begin{array}{c}\text { Theore- } \\
\text { tical } \\
M_{r} \\
\left(\times \mathbf{1 0}^{3}\right) \\
\end{array}$ & $\begin{array}{l}\text { 2D-GE number } \\
\text { of spots (spot \#) }\end{array}$ & $\begin{array}{l}\text { MudPIT: number } \\
\text { of unique peptides } \\
\text { (length of peptides } \\
\text { in amino acids) }\end{array}$ & $\begin{array}{l}\text { Sequence } \\
\text { coverage } \\
\text { in } \\
\text { MudPIT } \\
\end{array}$ \\
\hline sulfatase & & & & $3,3,13,16,17)$ & \\
\hline neuraminidase 1 & 24496770 & 45 & $2(115,123)$ & --- & --- \\
\hline \multirow{2}{*}{$\begin{array}{l}\text { Niemann Pick } \\
\text { type C2 prot. } \\
\text { prosaposin }\end{array}$} & 12963667 & 16 & --- & $4(7,11,12,16)$ & $31 \%$ \\
\hline & 1381582 & 61 & --- & $\begin{array}{c}12 \\
(7,9,10,10,10,11,11,11 \\
11,12,14,15)\end{array}$ & $24 \%$ \\
\hline $\begin{array}{l}\text { protective protein } \\
\text { for } \beta \text {-galacto- } \\
\text { sidase }\end{array}$ & 6679437 & 54 & $\begin{array}{c}19(14,111 \rightarrow 114,122 \\
, 125 \rightarrow 129,152,153, \\
173 \rightarrow 175,189 \rightarrow 191\end{array}$ & $5(7,8,11,13,18)$ & $12 \%$ \\
\hline ribonuclease 6 & 12858578 & 30 & $1(176)$ & --- & --- \\
\hline $\begin{array}{l}\text { tripeptidyl } \\
\text { peptidase I }\end{array}$ & 12644085 & 61 & $1(77)$ & -- & --- \\
\hline $\begin{array}{l}\text { cellular repressor } \\
\text { of E1A-stimulated } \\
\text { genes (CREG) }\end{array}$ & 6753520 & 25 & $4(23,24,184,185)$ & --- & --- \\
\hline $\begin{array}{l}\text { secreted } \\
\alpha \text {-mannosidase } \\
\text { class 2B (M2B2) }\end{array}$ & 6678792 & 116 & $4(1,2,29,30)$ & $3(11,12,13)$ & $4 \%$ \\
\hline \multicolumn{6}{|l|}{$\begin{array}{l}\text { Putative } \\
\text { lysosomal matrix } \\
\text { proteins: }\end{array}$} \\
\hline $\begin{array}{l}\text { mammalian } \\
\text { ependymin related } \\
\text { protein } 2 \text { (MERP-2) }\end{array}$ & 13562142 & 26 & $4(21,22,174,175)$ & $3(11,11,18)$ & $18 \%$ \\
\hline $\begin{array}{l}\text { retinoid-inducible } \\
\text { serine carboxy- } \\
\text { peptidase (RISC) }\end{array}$ & 12852682 & 51 & $4(118 \rightarrow 121)$ & $6(7,7,9,10,13,15)$ & $14 \%$ \\
\hline $\begin{array}{l}\text { hypothetical } \\
66.3-k D a \text { protein }\end{array}$ & 12004583 & 66 & $\begin{array}{c}17 \\
(9,67 \rightarrow 70,162 \rightarrow 167 \\
177 \rightarrow 181,200\end{array}$ & $6(7,8,9,12,12,13)$ & $11 \%$ \\
\hline $\begin{array}{l}\text { progranulin/ } \\
\text { epithelin }\end{array}$ & 26384542 & 65 & -- & $5(7,10,13,13,14)$ & $10 \%$ \\
\hline \multicolumn{6}{|l|}{$\begin{array}{l}\text { Non-lysosomal } \\
\text { contaminants }\end{array}$} \\
\hline dynamin 2 & 6681207 & 98 & $1(192)$ & --- & --- \\
\hline $\begin{array}{l}\text { unnamed protein } \\
\text { product }\end{array}$ & 26354020 & 20 & --- & $2(7,15)$ & $12 \%$ \\
\hline $\begin{array}{l}\text { similar to RIKEN } \\
\text { cDNA } 9030227 G 01\end{array}$ & 38081771 & 62 & --- & $1(8)$ & $2 \%$ \\
\hline $\begin{array}{l}\text { keratin complex } 2 \text {, } \\
\text { gene } 17\end{array}$ & 38077188 & 121 & --- & $2(12,12)$ & $2 \%$ \\
\hline
\end{tabular}

Die Tabelle aus Kollmann et al. (2005, S. 3972) zeigt alle in der Proteomanalyse identifizierten Proteine. 


\subsection{Klonierung des 66.3-kDa-Proteins in HT1080}

\subsubsection{Primer}

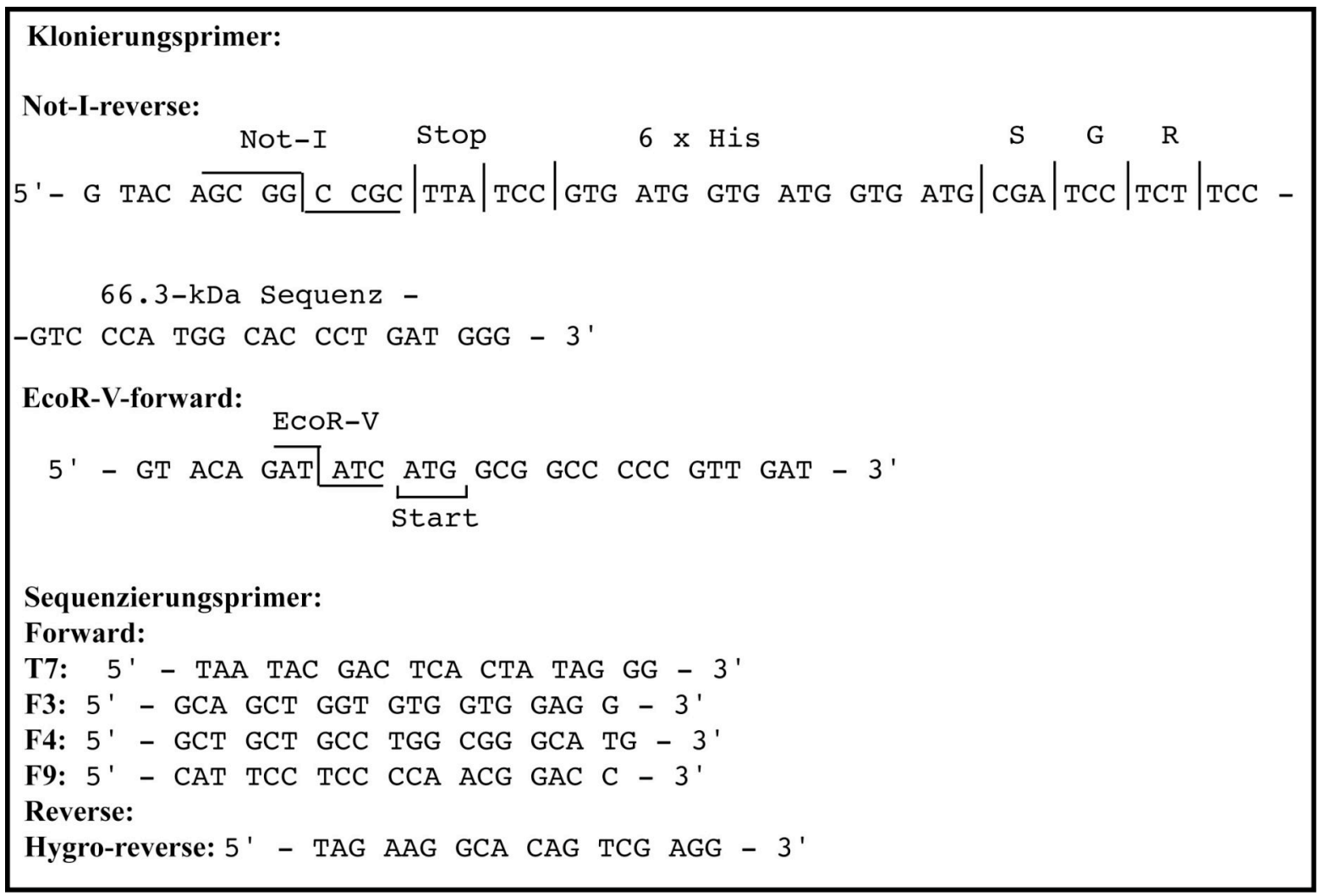

Abb. 6-1: Klonierungsprimer

Primer für die Klonierung des 66.3-kDa-Protein in den pcDNA-3.1-Hygro Vektor

\subsubsection{Vektor}
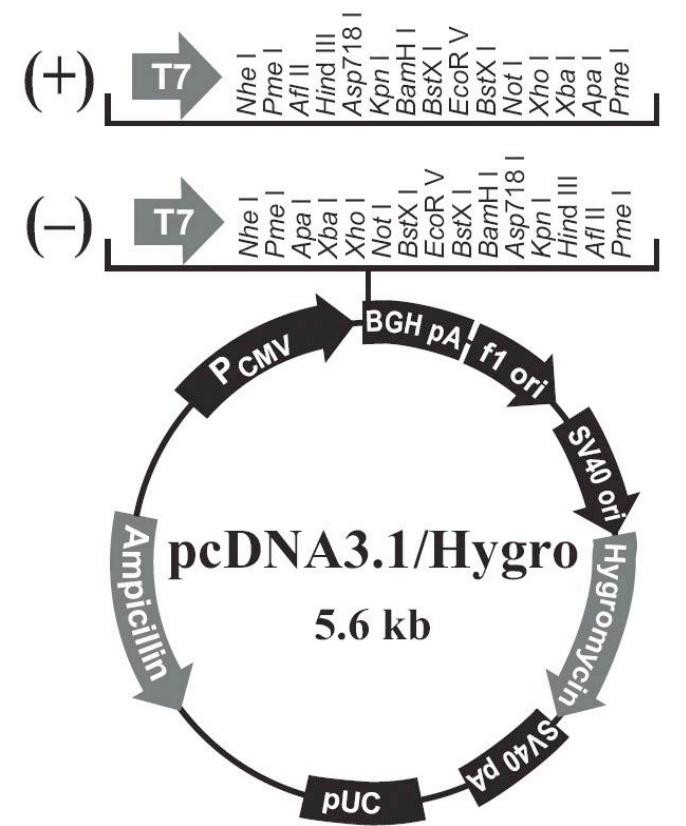

Abb. 6-2: $\quad$ pcDNA3.1/HYGRO-Vektor

(Invitrogen, Karlsruhe) Transfektionsvektor für 66.3-kDaProtein-Sequenz in HT1080-Zellen. 


\subsection{Yeast-two-Hybrid}

\subsubsection{Vektorkarten}

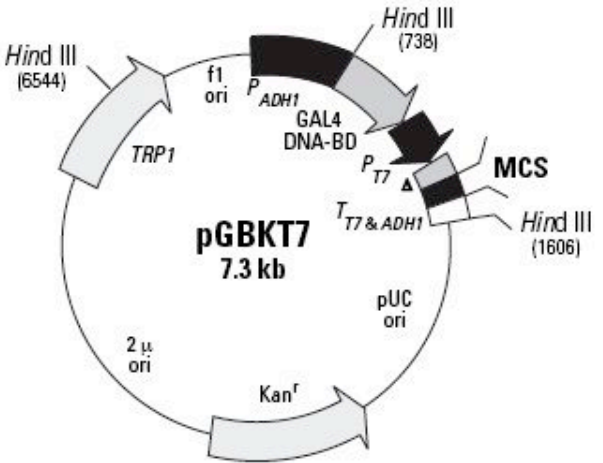

$\Delta$ c-Myc epitope tag

MATCHMAKER 5' DNA-BD Vector
1155 Insert Screening Amplimer

TCA TCG GAA GAG AGT AGT AAC AAA GGT CAA AGA CAG TTG ACT GTA TCG CCG GAA TTT

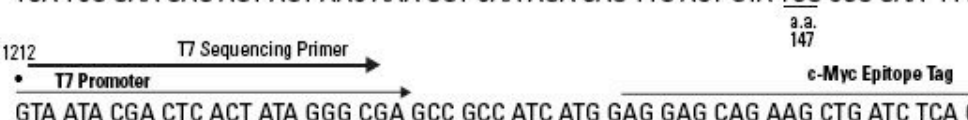

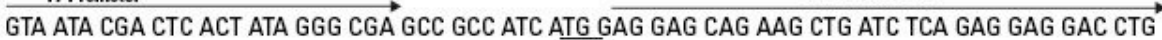
START

1281

CAT ATg GCC ATg GAg GCC GAA TTC CCG Ggg ATC CGT CGA CCT GCA GCG GCC GCA TAACTAGCATAACCCC

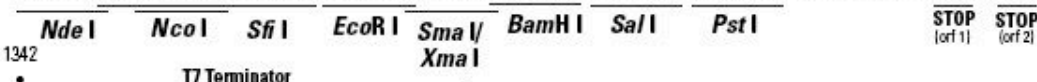

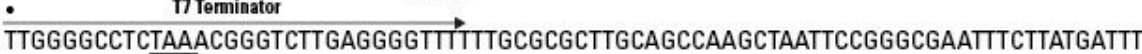
STOP

1430

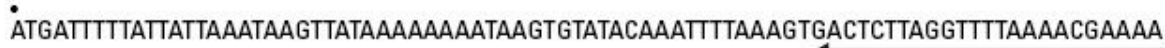

$\stackrel{\text { 3' DNA-BD Sequencing Primer }}{\longleftarrow}$

MATCHMAKER 3' DNA-BD Vector Insert Screening Amplimer

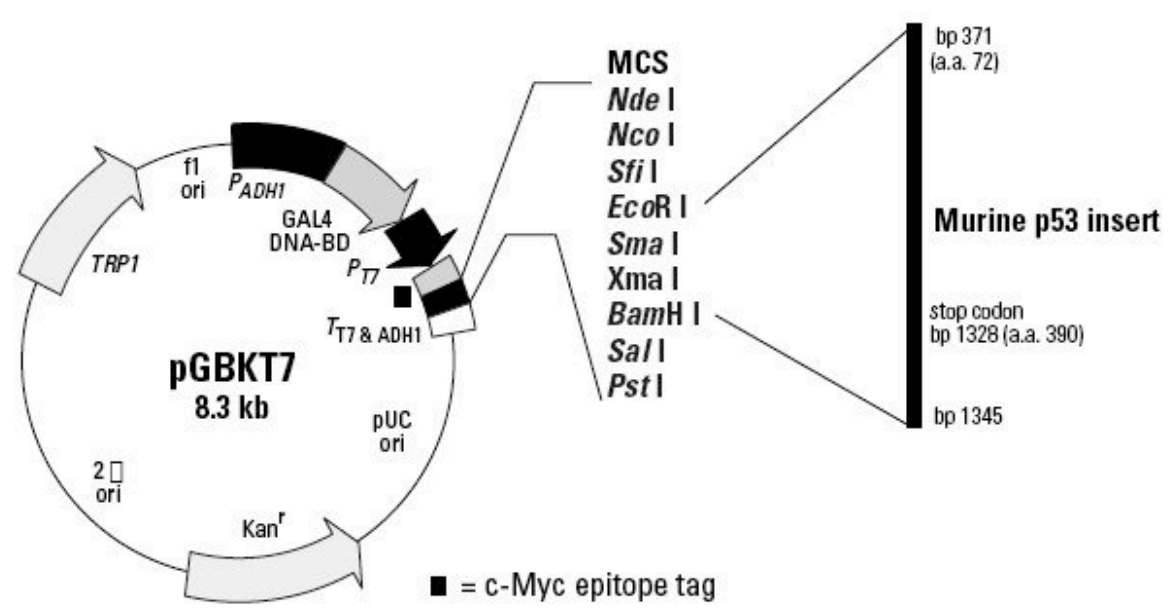

Abb. 6-3: pGBKT7-

Vektor

(Clontech, Palo Alto, USA)

Abb. 6-4: pGBKT7p53-Vektor

(Clontech, Palo Alto, USA) 


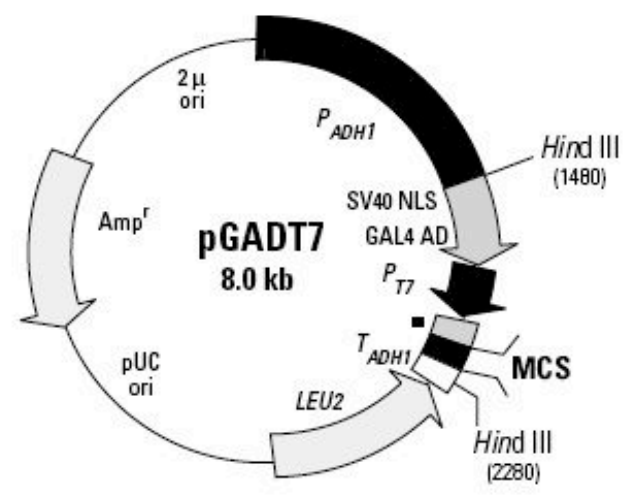

Abb. 6-5: pGADT7-Vektor

(Clontech, Palo Alto, USA)

- HA epitope tag
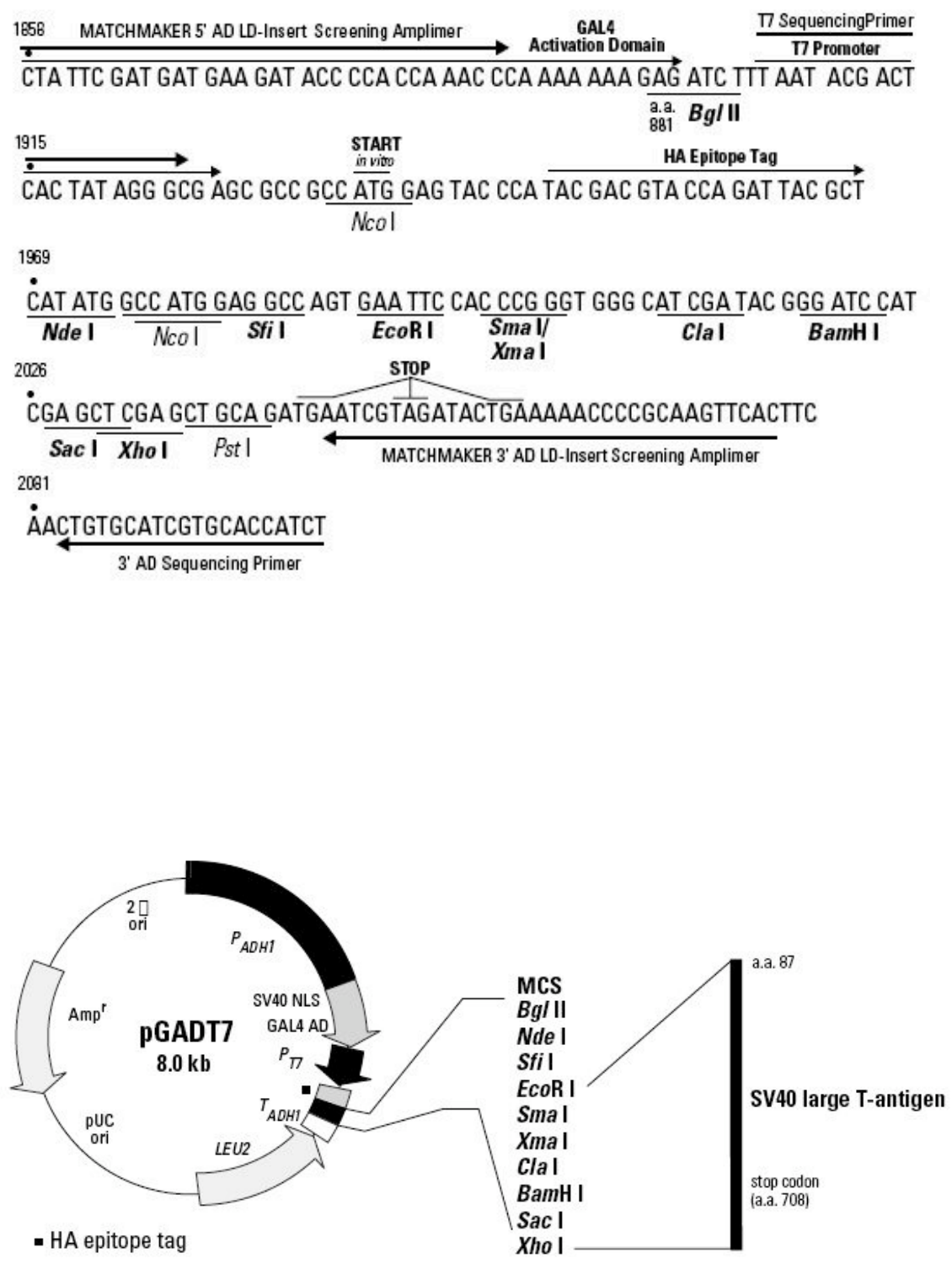

Abb. 6-6: pGADT7-SV40large-T antigen-Vektor

(Clontech, Palo Alto, USA) 


\subsubsection{Yeast-two-Hybrid-Klonierung}

Tab.6-2: Primertabelle

Primer Name

\begin{tabular}{|c|c|c|}
\hline & Primer Name & Primersequenz (5' nach 3') \\
\hline \multicolumn{3}{|l|}{$\begin{array}{l}\text { Klonierungs- } \\
\text { primer }\end{array}$} \\
\hline \multirow{7}{*}{$\begin{array}{l}\text { 66.3-kDa- } \\
\text { 66Protein }\end{array}$} & A: 66-EcoR1-Met1-F & GAATTC ATGATGGCGGCCCCCGTGGATGG \\
\hline & B: 66-EcoR1-Leu47-F & GAATTC CTCCCTACCCTGGGGCCCGGC \\
\hline & C: 66-EcoR1-Cys249-F & GAATTC TGCTCTGCCCTCATCAAGCTGC \\
\hline & D: 66-EcoR1-Ser514-F & GAATTC TCTGACCTCAACCCCGCCAATG \\
\hline & E: 66-BamH1-Asp594-R & GGATCC TCAGTCCCATGGCACCCTGATG \\
\hline & F: 66-BamH1-Arg513-R & GGATCC TCA GCGGGCAGAGATGGCATTCTC \\
\hline & G: 66-BamH1-Ser248-R & GGATCC TCA TGAACCGGAGCCCAGGGAAG \\
\hline \multirow[t]{2}{*}{ Cathepsin D } & H: mCatD-Nde1-Met1-F & CATATG ATGAAGACTCCCGGCGTCTTG \\
\hline & $\mathrm{J}:$ mCatD-SAL1-STOP-R & GTCGAC TTAGAGTACGACAGCATTGGC \\
\hline \multicolumn{3}{|l|}{$\begin{array}{l}\text { Sequenzie- } \\
\text { rungsprimer }\end{array}$} \\
\hline \multirow{3}{*}{$\begin{array}{l}66.3-\mathrm{kDa}- \\
\text { Protein }\end{array}$} & E: 66BamH1-Asp594-R & GGATCC TCAGTCCCATGGCACCCTGATG \\
\hline & F: 66-BamH1-Arg513-R & GGATCC TCA GCGGGCAGAGATGGCATTCTC \\
\hline & G: 66-BamH1-Ser248-R & GGATCC TCA TGAACCGGAGCCCAGGGAAG \\
\hline \multicolumn{3}{|l|}{ Cathepsin D } \\
\hline \multicolumn{3}{|l|}{$\begin{array}{l}66.3-\mathrm{kDa}- \\
\text { Protein und } \\
\text { Cathepsin D }\end{array}$} \\
\hline & $\mathrm{K}$ : T7-Sequenzing-Primer & TAATACGACTCACTATAGGGC \\
\hline & L: pGADT-3’R & pGADT-3'R AD-Sequenzing Primer (Matchmaker) \\
\hline & M: pGBKT-3'R & pGBKT-3'R AD-Sequenzing Primer (Matchmaker) \\
\hline
\end{tabular}

Primersequenz (5' nach 3') 


\subsubsection{Sequenzvergleich des 66.3-kDa-Proteins mit homologen Proteinen}

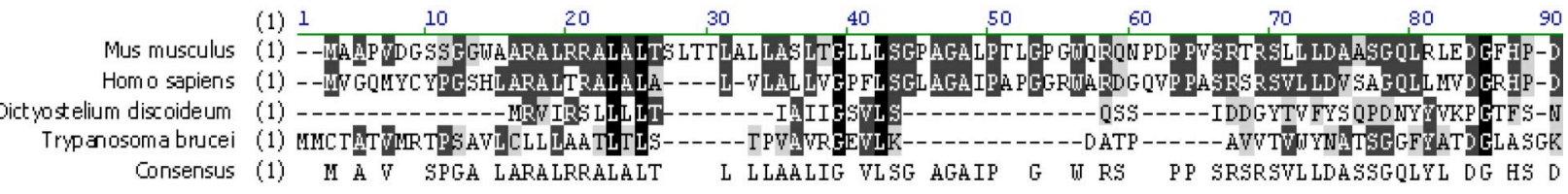

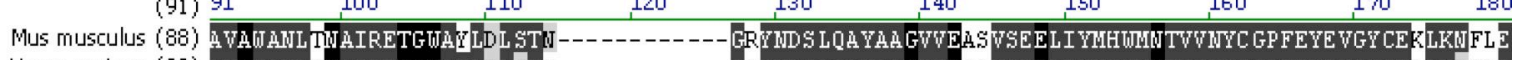

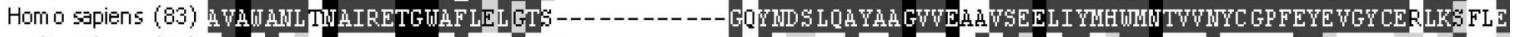

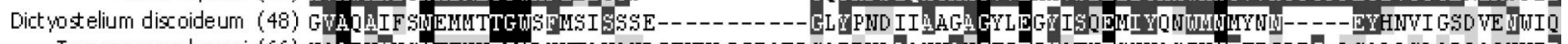

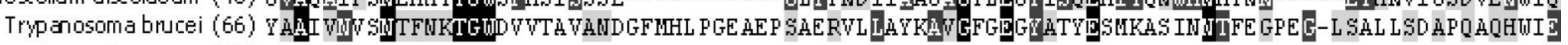

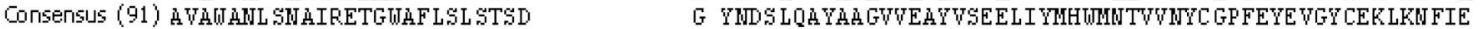

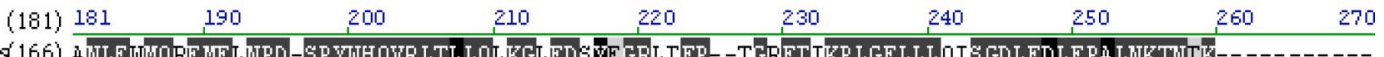

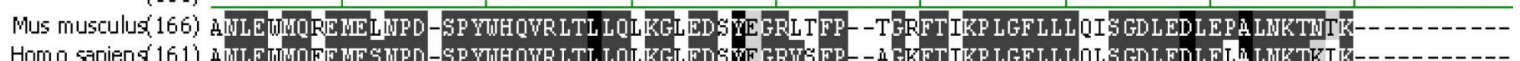

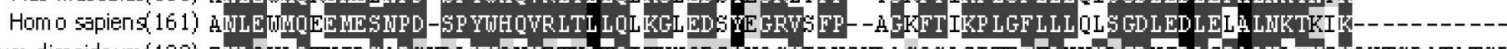

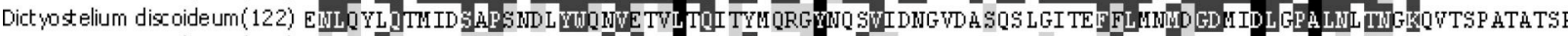

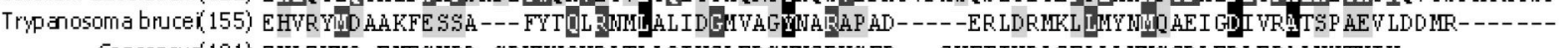

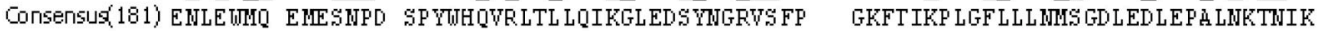

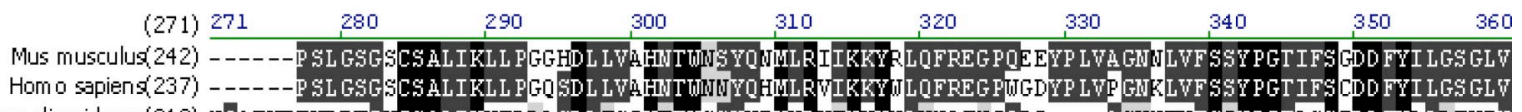

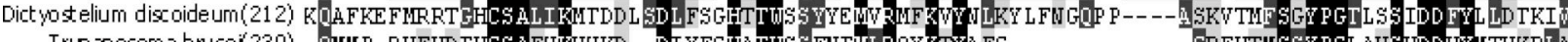

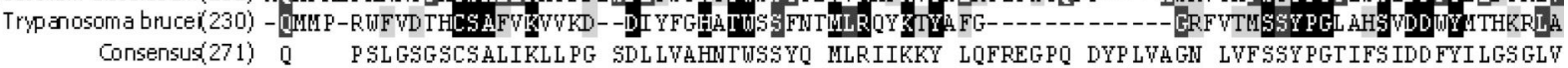

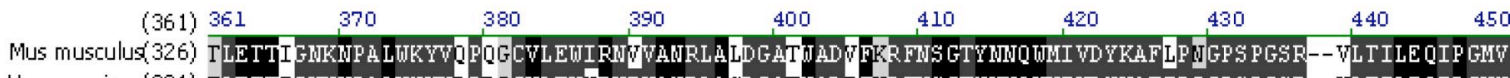

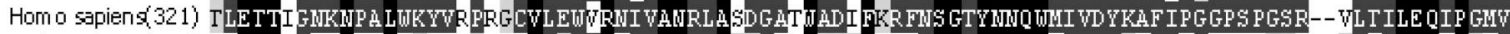

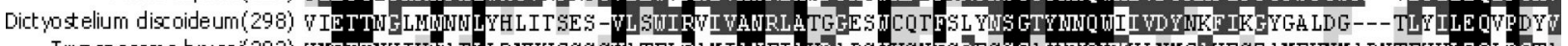

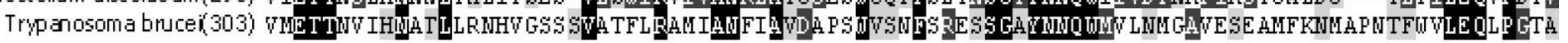

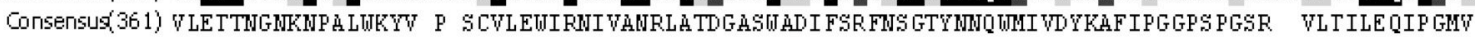
(451) 451
$460 \quad 470 \quad 480$
$490 \quad 500$
$510 \quad 520 \quad 530$
540

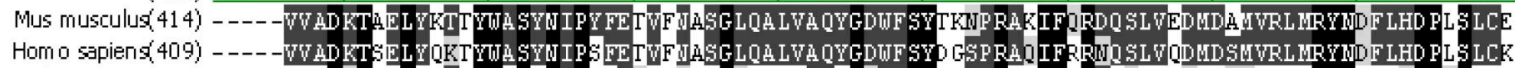



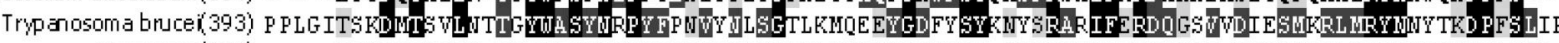

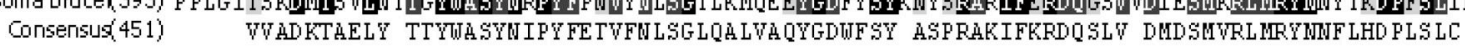

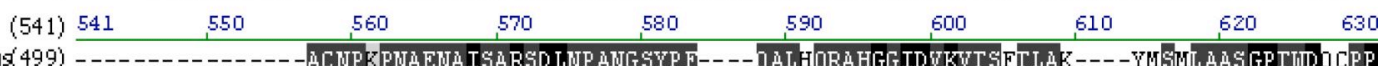



Hom o spien (494) -------

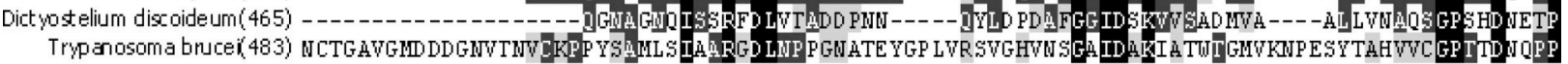

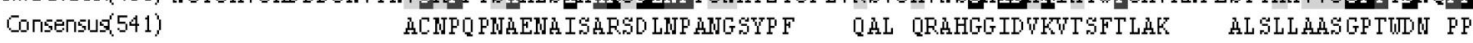

(631) 631

650

660

680

690

700

719

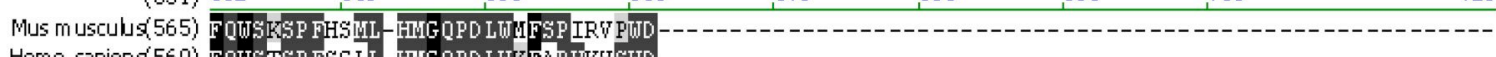

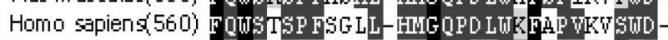

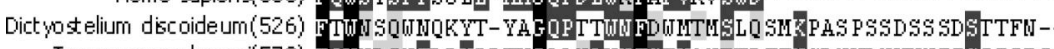

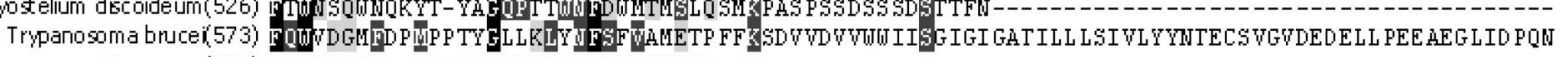
ConsensUS 631) FOTSSSPF ML HMGQPDLTWFSP TKMSTD $\mathrm{K}$

\section{Abb. 6-7: $\quad$ Alignment von homologen Proteinen des 66.3-kDa-Protein}

Zwischen Aminosäure 410 und 417 befindet sich die konservierte Phospholipase-B-Sequenz und in H. sapiens und M. musculus die zusätzliche Lipasesequenz $G x S x G$ zwischen Aminosäure 430 und 435. Schwarz: identische Aminosäuren; Dunkelgrau: identische Aminosäuren bei mehr als $50 \%$ Übereinstimmung; Hellgrau: Aminosäuren mit ähnlichen Eingenschaften. Die Abbildung wurde mit dem Programm „VectorNTI Advance V.10“ (Invitrogen) mit der „Clustal-W“-Methode (Thompson et al. 1994) erstellt. 


\section{$7 \quad$ Literaturverzeichnis}

Ahlberg J, Marzella L, Glaumann H (1982): Uptake and degradation of proteins by isolated rat liver lysosomes. Suggestion of a microautophagic pathway of proteolysis. Lab Invest $\underline{47}$, 523-532.

Alexander DL, Schwartz KJ, Balber AE, Bangs JD (2002): Developmentally regulated trafficking of the lysosomal membrane protein p67 in Trypanosoma brucei. J Cell Sci $\underline{115}, 3253-3263$.

Arstila AU, Trump BF (1968): Studies on cellular autophagocytosis. The formation of autophagic vacuoles in the liver after glucagon administration. Am J Pathol 53, 687-733.

Baehner F, Kampmann C, Whybra C, Miebach E, Wiethoff CM, Beck M (2003): Enzyme replacement therapy in heterozygous females with Fabry disease: results of a phase IIIB study. J Inherit Metab Dis $\underline{26}, 617-627$.

Baron R, Neff L, Louvard D, Courtoy PJ (1985): Cell-mediated extracellular acidification and bone resorption: evidence for a low $\mathrm{pH}$ in resorbing lacunae and localization of a $100-\mathrm{kD}$ lysosomal membrane protein at the osteoclast ruffled border. J Cell Biol 101, 2210-2222.

Barton NW, Brady RO, Dambrosia JM, Di Bisceglie AM, Doppelt SH, Hill SC, Mankin HJ, Murray GJ, Parker RI, Argoff CE, et al. (1991): Replacement therapy for inherited enzyme deficiency--macrophage-targeted glucocerebrosidase for Gaucher's disease. N Engl J Med 324, 1464-1470.

Berchem G, Glondu M, Gleizes M, Brouillet JP, Vignon F, Garcia M, Liaudet-Coopman E (2002): Cathepsin-D affects multiple tumor progression steps in vivo: proliferation, angiogenesis and apoptosis. Oncogene 21, 5951-5955.

Berkovic SF, Carpenter S, Andermann F, Andermann E Wolfe LS (1988): Kufs' disease: a critical reappraisal. Brain 111 ( Pt 1), 27-62.

BioRad Activated Immunoaffinity Supports Affi-Gel 10. BioRad, Hercules 2000. 
Bond JS, Butler PE (1987): Intracellular proteases. Annu Rev Biochem $\underline{56}$, 252-253.

Brady RO, Murray GJ, Moore, DF Schiffmann R (2001): Enzyme replacement therapy in Fabry disease. J Inherit Metab Dis 24 Suppl 2, 18-24; discussion 11-12.

Bresciani R, von Figura K (1996): Dephosphorylation of the mannose-6-phosphate recognition marker is localized in later compartments of the endocytic route. Identification of purple acid phosphatase (uteroferrin) as the candidate phosphatase. Eur J Biochem 238, 669674.

Brickman MJ, Balber AE (1994): Transport of a lysosomal membrane glycoprotein from the Golgi to endosomes and lysosomes via the cell surface in African trypanosomes. J Cell Sci 107 ( Pt 11), 3191-3200.

Brix K, Linke M, Tepel C, Herzog V (2001): Cysteine proteinases mediate extracellular prohormone processing in the thyroid. Biol Chem $\underline{382}, 717-725$.

Byrd JC, MacDonald RG (2000): Mechanisms for high affinity mannose 6-phosphate ligand binding to the insulin-like growth factor II/mannose 6-phosphate receptor. J Biol Chem $\underline{275}, 18638-18646$.

Byrd JC, Park JH, Schaffer BS, Garmroudi F, MacDonald RG (2000): Dimerization of the insulin-like growth factor II/mannose 6-phosphate receptor. J Biol Chem $\underline{275}$, 1864718656.

Campbell TN, Choy FY (2004): Knockdown of chimeric glucocerebrosidase by green fluorescent protein-directed small interfering RNA. Genet Mol Res $\underline{3}$, 282-287.

Cheng SH, Smith AE (2003): Gene therapy progress and prospects: gene therapy of lysosomal storage disorders. Gene Ther $\underline{10}, 1275-1281$.

Clontech Matchmaker GAL4 Two-Hybrid System 3 \& Libraries User Manual. Clontech, Palo Alto 1999.

Clontech Yeast Protocols Handbook. Clontech, Palo Alto 2001.

Conner GE: Cathepsin D. In: Handbook of Proteolytic Enzymes. hrsg. v. Barrett AJ, Rawlings ND, Woessner JF, Academic press, New York 2002, 746-751. 
Conzelmann E, Sandhoff K (1983): Partial enzyme deficiencies: residual activities and the development of neurological disorders. Dev Neurosci $\underline{6}, 58-71$.

Cuervo AM, Dice JF (1996): A receptor for the selective uptake and degradation of proteins by lysosomes. Science 273, 501-503.

Cuervo AM, Dice JF (1998): Lysosomes, a meeting point of proteins, chaperones, and proteases. J Mol Med 76, 6-12.

Cuervo AM, Dice JF (2000): Unique properties of LAMP2a compared to other LAMP2 isoforms. J Cell Sci 113 Pt 24, 4441-4450.

Cuppoletti J, Aures-Fischer D, Sachs G (1987): The lysosomal H+ pump: 8-azido-ATP inhibition and the role of chloride in $\mathrm{H}+$ transport. Biochim Biophys Acta $\underline{899}, 276-284$.

Dahms NM, Lobel P, Breitmeyer J, Chirgwin JM, Kornfeld S (1987): 46 kd mannose 6phosphate receptor: cloning, expression, and homology to the $215 \mathrm{kd}$ mannose 6phosphate receptor. Cell 50, 181-192.

Dahms NM, Lobel P, Kornfeld S (1989): Mannose 6-phosphate receptors and lysosomal enzyme targeting. J Biol Chem 264, 12115-12118.

Danon MJ, Oh SJ, DiMauro S, Manaligod JR, Eastwood A, Naidu S, Schliselfeld LH (1981): Lysosomal glycogen storage disease with normal acid maltase. Neurology $\underline{31}, 51-57$.

D'Azzo A, Hoogeveen A, Reuser AJ, Robinson D, Galjaard H (1982): Molecular defect in combined beta-galactosidase and neuraminidase deficiency in man. Proc Natl Acad Sci USA $\underline{79}, 4535-4539$.

de Duve C (1963): The lysosome. Sci Am 208, 64-72.

de Duve C (1983): Lysosomes revisited. Eur J Biochem 137, 391-397.

de Duve C, Pressman B, Gianetto R, Wattiaux R Appelmans F (1955): Tissue fraction studies. 6. Intracellular distribution patterns of enzymes in rat liver tissue. Biochem J 604-617. 
Deiss LP, Galinka H, Berissi H, Cohen O, Kimchi A (1996): Cathepsin D protease mediates programmed cell death induced by interferon-gamma, Fas/APO-1 and TNF-alpha. EMBO J 15, 3861-3870.

Deuschl F, Kollmann K, von Figura K, Lubke T (2006): Molecular characterization of the hypothetical 66.3-kDa protein in mouse: lysosomal targeting, glycosylation, processing and tissue distribution. FEBS Lett $\underline{580}$, 5747-5752.

Elbashir SM, Harborth J, Lendeckel W, Yalcin A, Weber K, Tuschl T (2001): Duplexes of 21nucleotide RNAs mediate RNA interference in cultured mammalian cells. Nature $\underline{411}$, 494-498.

Eng CM, Guffon N, Wilcox WR, Germain DP, Lee P, Waldek S, Caplan L, Linthorst GE, Desnick RJ (2001): Safety and efficacy of recombinant human alpha-galactosidase A-replacement therapy in Fabry's disease. N Engl J Med 345, 9-16.

Eng LF, Ghirnikar RS, Lee YL (2000): Glial fibrillary acidic protein: GFAP-thirty-one years (1969-2000). Neurochem Res $\underline{25}$, 1439-1451.

Eskelinen EL, Illert AL, Tanaka Y, Schwarzmann G, Blanz J, Von Figura K, Saftig P (2002): Role of LAMP-2 in lysosome biogenesis and autophagy. Mol Biol Cell 13, 3355-3368.

Fields S, Song O (1989): A novel genetic system to detect protein-protein interactions. Nature $\underline{340}, 245-246$.

Fire A, Xu S, Montgomery MK, Kostas SA, Driver SE, Mello CC (1998): Potent and specific genetic interference by double-stranded RNA in Caenorhabditis elegans. Nature $\underline{391}$, 806-811.

Futerman AH, van Meer G (2004): The cell biology of lysosomal storage disorders. Nat Rev Mol Cell Biol $\underline{5}, 554-565$.

Gahl WA, Bashan N, Tietze F, Bernardini I, Schulman JD (1982): Cystine transport is defective in isolated leukocyte lysosomes from patients with cystinosis. Science 217, 1263-1265.

Galjart NJ, Gillemans N, Meijer D, d'Azzo A (1990): Mouse "protective protein". cDNA cloning, sequence comparison, and expression. J Biol Chem 265, 4678-4684. 
Garcia M, Derocq D, Pujol P, Rochefort H (1990): Overexpression of transfected cathepsin D in transformed cells increases their malignant phenotype and metastatic potency. Oncogene 5, 1809-1814.

Geuze HJ (1998): The role of endosomes and lysosomes in MHC class II functioning. Immunol Today $\underline{19}, 282-287$.

Gieselmann V (1995): Lysosomal storage diseases. Biochim Biophys Acta 1270, 103-136

Gieselmann V, Pohlmann R, Hasilik A, Von Figura K (1983): Biosynthesis and transport of cathepsin D in cultured human fibroblasts. J Cell Biol 97, 1-5.

Glondu M, Liaudet-Coopman E, Derocq D, Platet N, Rochefort H, Garcia M (2002): Downregulation of cathepsin-D expression by antisense gene transfer inhibits tumor growth and experimental lung metastasis of human breast cancer cells. Oncogene 21, 5127-5134.

Goldstein JL, Brown MS, Anderson RG, Russell DW, Schneider WJ (1985): Receptor-mediated endocytosis: concepts emerging from the LDL receptor system. Annu Rev Cell Biol 1, 139.

Gough NR, Fambrough DM (1997): Different steady state subcellular distributions of the three splice variants of lysosome-associated membrane protein LAMP-2 are determined largely by the COOH-terminal amino acid residue. J Cell Biol 137, 1161-1169.

Hajioff D, Enever Y, Quiney R, Zuckerman J, Mackermot K, Mehta A (2003): Hearing loss in Fabry disease: the effect of agalsidase alfa replacement therapy. J Inherit Metab Dis $\underline{26}$, 787-794.

Harmatz P, Giugliani R, Schwartz I, Guffon N, Teles EL, Miranda MC, Wraith JE, Beck M, Arash L, Scarpa M, et al. (2006): Enzyme replacement therapy for mucopolysaccharidosis VI: a phase 3, randomized, double-blind, placebo-controlled, multinational study of recombinant human $\mathrm{N}$-acetylgalactosamine 4-sulfatase (recombinant human arylsulfatase B or rhASB) and follow-on, open-label extension study. J Pediatr 148, 533-539.

Hasilik A (1992): The early and late processing of lysosomal enzymes: proteolysis and compartmentation. Experientia 48, 130-151. 
Hasilik A, Neufeld EF (1980): Biosynthesis of lysosomal enzymes in fibroblasts. Synthesis as precursors of higher molecular weight. J Biol Chem $\underline{255}$, 4937-4945.

Heukeshoven J, Dernick R (1988): Improved silver staining procedure for fast staining in PhastSystem Development Unit. I. Staining of sodium dodecyl sulfate gels. Electrophoresis $\underline{9}, 28-32$.

Hickman S, Neufeld EF (1972): A hypothesis for I-cell disease: defective hydrolases that do not enter lysosomes. Biochem Biophys Res Commun $\underline{49}$, 992-999.

Hille-Rehfeld A (1995): Mannose 6-phosphate receptors in sorting and transport of lysosomal enzymes. Biochim Biophys Acta 1241, 177-194.

Hoogeveen AT, Verheijen FW, Galjaard H (1983): The relation between human lysosomal betagalactosidase and its protective protein. J Biol Chem 258, 12143-12146.

Hopwood JJ, Bunge S, Morris CP, Wilson PJ, Steglich C, Beck M, Schwinger E, Gal A (1993): Molecular basis of mucopolysaccharidosis type II: mutations in the iduronate-2sulphatase gene. Hum Mutat $\underline{2}, 435-442$.

Horowitz M, Pasmanik-Chor M, Borochowitz Z, Falik-Zaccai T, Heldmann K, Carmi R, Parvari R, Beit-Or H, Goldman B, Peleg L, et al. (1998): Prevalence of glucocerebrosidase mutations in the Israeli Ashkenazi Jewish population. Hum Mutat 12, 240-244.

Invitrogen Lipofectamine 2000 Transfection Reagent Users Manual. Invitrogen, Karlsruhe 2006.

Itoh K, Takiyama N, Kase R, Kondoh K, Sano A, Oshima A, Sakuraba H, Suzuki Y (1993): Purification and characterization of human lysosomal protective protein expressed in stably transformed Chinese hamster ovary cells. J Biol Chem 268, 1180-1186.

Jensen AG, Chemali M, Chapel A, Kieffer-Jaquinod S, Jadot M, Garin J, Journet A (2007): Biochemical characterization and lysosomal localization of the mannose-6-phosphate protein p76 (hypothetical protein LOC196463). Biochem J 402, 449-458.

Jentsch TJ, Stein V, Weinreich F, Zdebik AA (2002): Molecular structure and physiological function of chloride channels. Physiol Rev $\underline{82}, 503-568$. 
Jeyakumar M, Butters TD, Cortina-Borja M, Hunnam V, Proia RL, Perry VH, Dwek RA, Platt FM (1999): Delayed symptom onset and increased life expectancy in Sandhoff disease mice treated with N-butyldeoxynojirimycin. Proc Natl Acad Sci U S A 96, 6388-6393.

Kakkis ED, Muenzer J, Tiller GE, Waber L, Belmont J, Passage M, Izykowski B, Phillips J, Doroshow R, Walot I, et al. (2001): Enzyme-replacement therapy in mucopolysaccharidosis I. N Engl J Med $\underline{344}$, 182-188.

Kelley RJ, Brickman MJ, Balber AE (1995): Processing and transport of a lysosomal membrane glycoprotein is developmentally regulated in African trypanosomes. Mol Biochem Parasitol 74, 167-178.

Kelley RJ, Alexander DL, Cowan C, Balber AE, Bangs JD (1999): Molecular cloning of p67, a lysosomal membrane glycoprotein from Trypanosoma brucei. Mol Biochem Parasitol $\underline{98}$, $17-28$.

Kemphues KJ, Priess JR, Morton DG, Cheng NS (1988): Identification of genes required for cytoplasmic localization in early C. elegans embryos. Cell $\underline{52}, 311-320$.

Koike M, Shibata M, Ohsawa Y, Nakanishi H, Koga T, Kametaka S, Waguri S, Momoi T, Kominami E, Peters C, et al. (2003): Involvement of two different cell death pathways in retinal atrophy of cathepsin D-deficient mice. Mol Cell Neurosci 22, 146-161.

Kollmann K, Mutenda KE, Balleininger M, Eckermann E, von Figura K, Schmidt B, Lubke T (2005): Identification of novel lysosomal matrix proteins by proteome analysis. Proteomics $\underline{5}, 3966-3978$.

Konecki DS, Foetisch K, Zimmer KP, Schlotter M, Lichter-Konecki U (1995): An alternatively spliced form of the human lysosome-associated membrane protein-2 gene is expressed in a tissue-specific manner. Biochem Biophys Res Commun 215, 757-767.

Kornfeld R, Kornfeld S (1985): Assembly of asparagine-linked oligosaccharides. Annu Rev Biochem 54, 631-664.

Kornfeld S (1992): Structure and function of the mannose 6-phosphate/insulinlike growth factor II receptors. Annu Rev Biochem 1ㅗ, 307-330.

Kornfeld S, Mellman I (1989): The biogenesis of lysosomes. Annu Rev Cell Biol $\underline{5}$, 483-525. 
Kyte J, Doolittle RF (1982): A simple method for displaying the hydropathic character of a protein. J Mol Biol 157, 105-132.

Laemmli UK (1970): Cleavage of structural proteins during the assembly of the head of bacteriophage T4. Nature $\underline{227}, 680-685$.

Leighton F, Poole B, Beaufay H, Baudhuin P, Coffey JW, Fowler S, De Duve C (1968): The large-scale separation of peroxisomes, mitochondria, and lysosomes from the livers of rats injected with triton WR-1339. Improved isolation procedures, automated analysis, biochemical and morphological properties of fractions. J Cell Biol 37, 482-513.

Lemansky P, Gieselmann V, Hasilik A, Von Figura K (1985): Synthesis and transport of lysosomal acid phosphatase in normal and I-cell fibroblasts. J Biol Chem 260, 90239030.

Lester RL, Smith AL (1961): Studies on the electron transport system. 28. The mode of reduction of tetrazolium salts by beef heart mitochondria; role of coenzyme Q and other lipids. Biochim Biophys Acta 47, 475-496.

Li H, Kolluri SK, Gu J, Dawson MI, Cao X, Hobbs PD, Lin B, Chen G, Lu J, Lin F, et al. (2000): Cytochrome c release and apoptosis induced by mitochondrial targeting of nuclear orphan receptor TR3. Science $\underline{289}, 1159-1164$.

Lichter-Konecki U, Moter SE, Krawisz BR, Schlotter M, Hipke C, Konecki DS (1999): Expression patterns of murine lysosome-associated membrane protein 2 (LAMP-2) transcripts during morphogenesis. Differentiation $\underline{65}, 43-58$.

Liu J, Guo Q, Chen B, Yu Y, Lu H, Li YY (2006a): Cathepsin B and its interacting proteins, bikunin and TSRC1, correlate with TNF-induced apoptosis of ovarian cancer cells OV90. FEBS Lett $\underline{580}, 245-250$.

Liu J, Liu NS, Yuan HY, Guo Q, Lu H, Li YY (2006b): Human homologue of SETA binding protein 1 interacts with cathepsin B and participates in TNF-Induced apoptosis in ovarian cancer cells. Mol Cell Biochem 292, 189-195. 
Löffler G, Petrides PE: Biochemie und Pathobiochemie. 7. Auflage; Springer-Verlag, Berlin 2003, 606 .

Lowry OH, Rosebrough NJ, Farr AL, Randall RJ (1951): Protein measurement with the Folin phenol reagent. J Biol Chem 193, 265-275.

Lübke T, Göttingen: Abbildung für diese Arbeit bereitgestellt, November 2006.

Lübke T, Göttingen: mündliche Mitteilung, Januar 2008.

Luedtke CC, Andonian S, Igdoura S, Hermo L (2000): Cathepsin A is expressed in a cell- and region-specific manner in the testis and epididymis and is not regulated by testicular or pituitary factors. J Histochem Cytochem $\underline{48}$, 1131-1146.

Masson C, Cisse I, Simon V, Insalaco P, Audran M (2004): Fabry disease: a review. Joint Bone Spine 71, 381-383.

Matsuda J, Suzuki O, Oshima A, Yamamoto Y, Noguchi A, Takimoto K, Itoh M, Matsuzaki Y, Yasuda Y, Ogawa S, et al. (2003): Chemical chaperone therapy for brain pathology in G(M1)-gangliosidosis. Proc Natl Acad Sci U S A $\underline{100}$, 15912-15917.

Meikle PJ, Hopwood JJ, Clague AE, Carey WF (1999): Prevalence of lysosomal storage disorders. JAMA 281, 249-254.

Mignani R, Cagnoli L (2004): Enzyme replacement therapy in Fabry's disease: recent advances and clinical applications. J Nephrol $\underline{17}$, 354-363.

Morgan CP, Insall R, Haynes L, Cockcroft S (2004): Identification of phospholipase B from Dictyostelium discoideum reveals a new lipase family present in mammals, flies and nematodes, but not yeast. Biochem J $\underline{382}$, 441-449.

Morishima H, Takita T, Aoyagi T, Takeuchi T, Umezawa H (1970): The structure of pepstatin. J Antibiot (Tokyo) 23, 263-265.

Morreau H, Galjart NJ, Willemsen R, Gillemans N, Zhou XY, d'Azzo A (1992): Human lysosomal protective protein. Glycosylation, intracellular transport, and association with beta-galactosidase in the endoplasmic reticulum. J Biol Chem 267, 17949-17956. 
Mullis K, Faloona F, Scharf S, Saiki R, Horn G, Erlich H (1986): Specific enzymatic amplification of DNA in vitro: the polymerase chain reaction. Cold Spring Harb Symp Quant Biol 51 Pt 1, 263-273.

Myerowitz R (1997): Tay-Sachs disease-causing mutations and neutral polymorphisms in the Hex A gene. Hum Mutat $\underline{9}$, 195-208.

Naureckiene S, Sleat DE, Lackland H, Fensom A, Vanier MT, Wattiaux R, Jadot M, Lobel P (2000): Identification of HE1 as the second gene of Niemann-Pick C disease. Science 290, 2298-2301.

Neufeld EF, Muenzer J: The Mucopolysaccharidoses. In: The Metabolic and Molecular Bases of Inherited Disease, hrsg. v. Scriver CR, Beaudet AL, Sly WS, Valle D, Childs B, Kinzler KW, Vogelstein B, $8^{\text {th }}$ Edition, Vol. 3, McGraw-Hill, New York 2001, 3421-3452.

Neuhoff V, Arold N, Taube D, Ehrhardt W (1988): Improved staining of proteins in polyacrylamide gels including isoelectric focusing gels with clear background at nanogram sensitivity using Coomassie Brilliant Blue G-250 and R-250. Electrophoresis $\underline{9}, 255-262$.

Nishimura A, Morita M, Nishimura Y, Sugino Y (1990): A rapid and highly efficient method for preparation of competent Escherichia coli cells. Nucleic Acids Res $\underline{18}, 6169$.

Nishino I, Fu J, Tanji K, Yamada T, Shimojo S, Koori T, Mora M, Riggs JE, Oh SJ, Koga Y, et al. (2000): Primary LAMP-2 deficiency causes X-linked vacuolar cardiomyopathy and myopathy (Danon disease). Nature $\underline{406}, 906-910$.

Ohashi T, Watabe K, Uehara K, Sly WS, Vogler C, Eto Y (1997): Adenovirus-mediated gene transfer and expression of human beta-glucuronidase gene in the liver, spleen, and central nervous system in mucopolysaccharidosis type VII mice. Proc Natl Acad Sci U S A $\underline{94}$, 1287-1292.

Ohkuma S, Poole B (1978): Fluorescence probe measurement of the intralysosomal pH in living cells and the perturbation of $\mathrm{pH}$ by various agents. Proc Natl Acad Sci U S A $\underline{75}, 3327-$ 3331. 
Perez SE, Steller H (1996): Molecular and genetic analyses of lama, an evolutionarily conserved gene expressed in the precursors of the Drosophila first optic ganglion. Mech Dev $\underline{59}, 11$ 27.

Peterson GL (1979): Review of the Folin phenol protein quantitation method of Lowry, Rosebrough, Farr and Randall. Anal Biochem 100, 201-220.

Platt FM, Neises GR, Reinkensmeier G, Townsend MJ, Perry VH, Proia RL, Winchester B, Dwek RA Butters TD (1997): Prevention of lysosomal storage in Tay-Sachs mice treated with N-butyldeoxynojirimycin. Science 276 , 428-431.

Pohlmann R, Waheed A, Hasilik A, von Figura K (1982): Synthesis of phosphorylated recognition marker in lysosomal enzymes is located in the cis part of Golgi apparatus. $\mathrm{J}$ Biol Chem 257, 5323-5325.

Poorthuis BJ, Wevers RA, Kleijer WJ, Groener JE, de Jong JG, van Weely S, Niezen-Koning KE, van Diggelen OP (1999): The frequency of lysosomal storage diseases in The Netherlands. Hum Genet 105, 151-156.

Preusser-Kunze A, Mariappan M, Schmidt B, Gande SL, Mutenda K, Wenzel D, von Figura K, Dierks T (2005): Molecular characterization of the human Calpha-formylglycinegenerating enzyme. J Biol Chem 280, 14900-14910.

Qiagen Miniprep Handbook. Qiagen, Hilden 2003.

Qiagen Plasmid Purification Handbook, Qiagen, Hilden 2003.

Qiagen QIAquick® Spin Handbook. Qiagen, Hilden 2002.

Qiagen RNeasy® Mini Handbook. Qiagen, Hilden 1999.

Roces DP, Lullmann-Rauch R, Peng J, Balducci C, Andersson C, Tollersrud O, Fogh J, Orlacchio A, Beccari T, Saftig P, et al. (2004): Efficacy of enzyme replacement therapy in alpha-mannosidosis mice: a preclinical animal study. Hum Mol Genet $\underline{13}$, 1979-1988.

Roche PNGase F Produktbeschreibung. Version 4, Roche, Mannheim 2003. 
Rome LH, Hill DF (1986): Lysosomal degradation of glycoproteins and glycosaminoglycans. Efflux and recycling of sulphate and N-acetylhexosamines. Biochem J 235, 707-713.

Saftig P, Hetman M, Schmahl W, Weber K, Heine L, Mossmann H, Koster A, Hess B, Evers M, von Figura K, et al. (1995): Mice deficient for the lysosomal proteinase cathepsin D exhibit progressive atrophy of the intestinal mucosa and profound destruction of lymphoid cells. Embo J 14, 3599-3608.

Saftig P, Hunziker E, Everts V, Jones S, Boyde A, Wehmeyer O, Suter A, von Figura K (2000): Functions of cathepsin $\mathrm{K}$ in bone resorption. Lessons from cathepsin $\mathrm{K}$ deficient mice. Adv Exp Med Biol 477, 293-303.

Saitou N, Nei M (1987): The neighbor-joining method: a new method for reconstructing phylogenetic trees. Mol Biol Evol $\underline{4}, 406-425$.

Sambrook J, Maniatis T, Fritsch EF: Molecular cloning: a laboratory manual. Cold Spring Harbor Laboratory, Cold Spring Harbor, N.Y. 1989.

Sfakianos J, Togawa A, Maday S, Hull M, Pypaert M, Cantley L, Toomre D, Mellman I (2007): Par3 functions in the biogenesis of the primary cilium in polarized epithelial cells. J Cell Biol 179, 1133-1140.

Sleat DE, Donnelly RJ, Lackland H, Liu CG, Sohar I, Pullarkat RK, Lobel P (1997): Association of mutations in a lysosomal protein with classical late-infantile neuronal ceroid lipofuscinosis. Science 277, 1802-1805.

Sleat DE, Zheng H, Qian M, Lobel P (2006a): Identification of sites of mannose 6phosphorylation on lysosomal proteins. Mol Cell Proteomics $\underline{5}, 686-701$.

Sleat DE, Wang Y, Sohar I, Lackland H, Li Y, Li H, Zheng H, Lobel P (2006b): Identification and validation of mannose 6-phosphate glycoproteins in human plasma reveal a wide range of lysosomal and non-lysosomal proteins. Mol Cell Proteomics 5, 1942-1956.

Stein M, Zijderhand-Bleekemolen JE, Geuze H, Hasilik A, von Figura K (1987): Mr 46,000 mannose 6-phosphate specific receptor: its role in targeting of lysosomal enzymes. EMBO J $\underline{6}, 2677-2681$. 
Storch S, Braulke T: Transport of Lysosomal Enzymes. In: Lysosomes. hrsg. v. Saftig P, Landes Bioscience/Eurekah.com Springer Science+Business Media, Inc, Georgetown, Tex. New York, N.Y. 2005, 18.

Sun-Wada GH, Wada Y, Futai M (2003): Lysosome and lysosome-related organelles responsible for specialized functions in higher organisms, with special emphasis on vacuolar-type proton ATPase. Cell Struct Funct $\underline{28}$, 455-463.

Suzuki Y, Oshima A, Namba E: Beta-Galactosidase Deficiency (Beta-Galactosidosis): $\mathrm{G}_{\mathrm{M} 1}$ Gangliosidosis and Morquio B Disease. In: The Metabolic and Molecular Bases of Inherited Disease, hrsg. v. Scriver CR, Beaudet AL, Sly WS, Valle D, Childs B, Kinzler KW, Vogelstein B, $8^{\text {th }}$ Edition, Vol. 3, McGraw-Hill, New York 2001, 3775-3809.

Tarentino AL, Plummer TH, Jr. Maley F (1974): The release of intact oligosaccharides from specific glycoproteins by endo-beta-N-acetylglucosaminidase H. J Biol Chem $\underline{249}$, 818824.

The QIAexpressionist - Handbook for high-level expression and purification of 6xHis-tagged proteins. Qiagen, Hilden 2003.

Thompson JD, Higgins DG, Gibson TJ (1994): CLUSTAL W: improving the sensitivity of progressive multiple sequence alignment through sequence weighting, position-specific gap penalties and weight matrix choice. Nucleic Acids Res 22, 4673-4680.

Tiede S, Storch S, Lubke T, Henrissat B, Bargal R, Raas-Rothschild A, Braulke T (2005): Mucolipidosis II is caused by mutations in GNPTA encoding the alpha/beta GlcNAc-1phosphotransferase. Nat Med 11, 1109-1112.

Tollersrud OK, Berg T: Lysosomal Storage Disorders. In: Lysosomes. hrsg. v. Saftig P, Landes Bioscience/Eurekah.com Springer Science+Business Media, Inc, Georgetown, Tex. New York, N.Y. 2005,60-74.

Tuschl T (2001): RNA interference and small interfering RNAs. Chembiochem 2 , 239-245.

Van den Hout JM, Reuser AJ, de Klerk JB, Arts WF, Smeitink JA, Van der Ploeg AT (2001): Enzyme therapy for pompe disease with recombinant human alpha-glucosidase from rabbit milk. J Inherit Metab Dis 24, 266-274. 
van der Spoel A, Bonten E, d'Azzo A (1998): Transport of human lysosomal neuraminidase to mature lysosomes requires protective protein/cathepsin A. EMBO J 17, 1588-1597.

Varki A, Kornfeld S (1980): Structural studies of phosphorylated high mannose-type oligosaccharides. J Biol Chem $\underline{255}$, 10847-10858.

Varki A, Kornfeld S (1983): The spectrum of anionic oligosaccharides released by endo-beta-Nacetylglucosaminidase $\mathrm{H}$ from glycoproteins. Structural studies and interactions with the phosphomannosyl receptor. J Biol Chem $\underline{258}$, 2808-2818.

Vellodi A (2005): Lysosomal storage disorders. Br J Haematol 128, 413-431.

von Figura K, Hasilik A (1986): Lysosomal enzymes and their receptors. Annu Rev Biochem 55, 167-193.

Waite M (1985): Approaches to the study of mammalian cellular phospholipases. J Lipid Res $\underline{26}$, 1379-1388.

Wall DA, Grange DK, Goulding P, Daines M, Luisiri A, Kotagal S (1998): Bone marrow transplantation for the treatment of alpha-mannosidosis. J Pediatr 133, 282-285.

Wattiaux R, Wibo M, Baudhuin P (1963): [Effect of the injection of Triton WR 1339 on the hepatic lysosomes of the rat.]. Arch Int Physiol Biochim 71, 140-142.

Weber K, Osborn M (1969): The reliability of molecular weight determinations by dodecyl sulfate-polyacrylamide gel electrophoresis. J Biol Chem 244, 4406-4412.

Weinreb NJ, Charrow J, Andersson HC, Kaplan P, Kolodny EH, Mistry P, Pastores G, Rosenbloom BE, Scott CR, Wappner RS, et al. (2002): Effectiveness of enzyme replacement therapy in 1028 patients with type 1 Gaucher disease after 2 to 5 years of treatment: a report from the Gaucher Registry. Am J Med 113, 112-119.

Whittington R, Goa KL (1992): Alglucerase. A review of its therapeutic use in Gaucher's disease. Drugs $\underline{44}, 72-93$. 
Winkel LP, Kamphoven JH, van den Hout HJ, Severijnen LA, van Doorn PA, Reuser AJ, van der Ploeg AT (2003): Morphological changes in muscle tissue of patients with infantile Pompe's disease receiving enzyme replacement therapy. Muscle Nerve 27, 743-751.

Wraith JE, Clarke LA, Beck M, Kolodny EH, Pastores GM, Muenzer J, Rapoport DM, Berger KI, Swiedler SJ, Kakkis ED, et al. (2004): Enzyme replacement therapy for mucopolysaccharidosis I: a randomized, double-blinded, placebo-controlled, multinational study of recombinant human alpha-L-iduronidase (laronidase). J Pediatr 144, 581-588.

Ye XX, Lu H, Yu Y, Ding N, Zhang NL, Huo KK, Wan DF, Li YY, Gu JR (2005): P5644 interacts with phosphatidylinositol-4-phosphate adaptor protein-1 associated protein-1. Mol Cell Biochem 271, 151-158.

York SJ, Arneson LS, Gregory WT, Dahms NM, Kornfeld S (1999): The rate of internalization of the mannose 6-phosphate/insulin-like growth factor II receptor is enhanced by multivalent ligand binding. J Biol Chem $\underline{274}$, 1164-1171.

Zhou D, Li P, Lin Y, Lott JM, Hislop AD, Canaday DH, Brutkiewicz RR, Blum JS (2005): LAMP-2a facilitates MHC class II presentation of cytoplasmic antigens. Immunity 22 , 571-581. 
Veröffentlichungen aus dieser Arbeit:

Publikation:

Deuschl F, Kollmann K, von Figura K, Lubke T (2006): Molecular characterization of the hypothetical 66.3-kDa-Protein in mouse: lysosomal targeting, glycosylation, processing and tissue distribution. FEBS Lett 580, 5747-5752.

Posterpräsentation:

Deuschl F, Kollmann K, von Figura K, Lubke T: Molecular characterization of the hypothetical 66.3-kDa protein in mouse, European Study Group on Lysosomal Diseases, 27.-30.9.2007, 16th ESGLD Workshop, Perugia, Italien. 


\section{Danksagung}

Herrn JProf. Dr. Torben Lübke danke ich für die Vergabe des Themas, für seine ständige Diskussionsbereitschaft, für das große persönliche Engagement bei der Betreuung meiner Arbeit und das anregende Arbeitsklima in seiner Arbeitsgruppe.

Bei Herrn Prof. Dr. Kurt von Figura möchte ich mich für die konstruktiven Diskussionen bedanken.

Frau Dr. Katrin Kollmann, Frau Ellen Eckermann-Felkl, Frau Martina Balleininger und Herrn Markus Damme danke ich für die ständige Diskussions- und Hilfsbereitschaft und für die vielen schönen und lustigen gemeinsamen Stunden im Labor.

Besonderer Dank gilt Katrin.

Bei Herrn Dr. Bernhard Schmidt, Nicole Eiselt und Klaus Neifert möchte ich mich ganz herzlich für die Durchführung der massenspektrometrischen Untersuchungen und der Proteinsequenzierung bedanken.

Herrn Dipl. Biologe Peter Braun danke ich für die Mithilfe bei den Yeast-two-Hybrid Versuchen.

Jenny, Jutta, Tanja, Karthik, Mals, Olaf und Peter danke ich für die fachliche Hilfe und das freundschaftliche Arbeitsklima, das mir mein Arbeiten am Institut so leicht gemacht hat.

Frau Diederich, Frau Engelmann, Frau Eplinius und allen anderen Mitarbeitern der Biochemie II danke ich für das angenehme Arbeitsklima und die freundliche Unterstützung.

Katrin, Markus und Katie danke ich herzlichst für das Korrekturlesen dieser Arbeit.

Der DFG danke ich für das großzügige Reisestipendium, das es mir ermöglichte mein Poster auf dem ESGLD in Perugia vorzustellen.

Ich danke meinen lieben Eltern, meinem lieben Bruder und meiner lieben Katie für die bedingungslose Unterstützung meiner Pläne und Ziele. Meinen Eltern danke ich zudem für ihre Großzügigkeit während meiner gesamten Studienzeit.

Meinen lieben Freunden Christian, Florian, Hinnerk, Lena, Norina, Peter, Sebastian, Sebastian, Sven, Vera und Wolfgang danke ich für ihre Freundschaft und die aktive Anteilnahme an meiner Arbeit. 


\section{Lebenslauf}

Am 23.6.1980 wurde ich als erstes Kind meiner Eltern Edelgard Deuschl-Jendrejewski und Günther Deuschl in Dachau/München geboren. Im Jahr 1982 zog meine Familie nach Freiburg im Breisgau. Die Grundschule schloss ich 1991 an der „Deutschen Schule Washington“ gegen Ende eines achtmonatigen Auslandsaufenthaltes meiner Familie in Washington D.C., USA, ab. Ich war Schüler der altsprachlichen Gymnasien "Kolleg St. Sebastian” in Stegen/Freiburg im Breisgau, und ab 1995 der „Kieler Gelehrtenschule“ in Kiel, wo ich meine Schulausbildung im Jahre 2000 mit dem Abitur abschloss. Anschließend leistete ich meinen Zivildienst an der Körperbehindertenschule des „Bildungszentrums Mettenhof“ in Kiel. Im Oktober 2001 begann ich das Studium der Humanmedizin an der Georg-August-Universität zu Göttingen, das ich voraussichtlich im Herbst 2008 mit der 2. Ärztlichen Prüfung abschließen werde. Von Januar 2005 bis Juni 2006 war ich als studentische Hilfskraft in der Abteilung Biochemie II der Georg-August-Universität zu Göttingen in der Arbeitsgruppe von JProf. Dr. Torben Lübke und Professor Dr. Kurt von Figura angestellt und begann ab Januar 2006 die experimentelle Arbeit meiner vorliegenden Dissertation mit dem Thema „Molekulare Charakterisierung des murinen 66.3-kDa-Proteins“ in der Arbeitsgruppe von JProf. Dr. Torben Lübke. 